\title{
Novel factors and mechanisms in control of CD36- mediated cardiac fatty acid transport
}

Citation for published version (APA):

Angin, Y. (2013). Novel factors and mechanisms in control of CD36-mediated cardiac fatty acid transport. [Doctoral Thesis, Maastricht University]. Uitgeverij BOXPress. https://doi.org/10.26481/dis.20131204ya

Document status and date:

Published: 01/01/2013

DOI:

10.26481/dis.20131204ya

Document Version:

Publisher's PDF, also known as Version of record

\section{Please check the document version of this publication:}

- A submitted manuscript is the version of the article upon submission and before peer-review. There can be important differences between the submitted version and the official published version of record.

People interested in the research are advised to contact the author for the final version of the publication, or visit the DOI to the publisher's website.

- The final author version and the galley proof are versions of the publication after peer review.

- The final published version features the final layout of the paper including the volume, issue and page numbers.

Link to publication

\footnotetext{
General rights rights.

- You may freely distribute the URL identifying the publication in the public portal. please follow below link for the End User Agreement:

www.umlib.nl/taverne-license

Take down policy

If you believe that this document breaches copyright please contact us at:

repository@maastrichtuniversity.nl

providing details and we will investigate your claim.
}

Copyright and moral rights for the publications made accessible in the public portal are retained by the authors and/or other copyright owners and it is a condition of accessing publications that users recognise and abide by the legal requirements associated with these

- Users may download and print one copy of any publication from the public portal for the purpose of private study or research.

- You may not further distribute the material or use it for any profit-making activity or commercial gain

If the publication is distributed under the terms of Article $25 \mathrm{fa}$ of the Dutch Copyright Act, indicated by the "Taverne" license above, 
Novel factors and mechanisms in control of CD36-mediated cardiac fatty acid transport 
The studies presented in this thesis were performed at the Department of Molecular Genetics, within CARIM, School for Cardiovascular Diseases, Maastricht University, the Netherlands.

Cover design by Jean Scheijen

Layout by Yeliz Angin

Thesis Universiteit Maastricht

ISBN: 978-90-8891-756-1

Copyright Yeliz Angın, Maastricht 2013

Printed by: Proefschriftmaken.nl || Uitgeverij BOXPress 


\title{
Novel factors and mechanisms in control of CD36-mediated cardiac fatty acid transport
}

\author{
Proefschrift
}

ter verkrijging van de graad van doctor aan de Universiteit Maastricht, op gezag van de Rector Magnificus, Prof. Dr. L.L.G. Soete, volgens het besluit van het college van decanen, in het openbaar te verdedigen op woensdag 4 december 2013 om 16:00 uur

door

\section{Yeliz Angın}

Geboren te Ankara, Turkije, op 8 mei 1983 


\section{Promotor:}

Prof. dr. Jan F.C. Glatz

\section{Co-promotores:}

Dr. Joost J.F.P. Luiken

Dr. Dietbert Neumann

\section{Beoordelingscommissie:}

Prof. dr. Ellen E. Blaak (voorzitter)

Dr. Debby P.Y. Koonen (Universitair Medisch Centrum Groningen)

Prof. dr. ir. Ko A.P. Willems van Dijk (Leiden Universitair Medisch Centrum)

Prof. dr. Casper G. Schalkwijk

Dr. Paul G.A. Volders

Financial support by the Dutch Heart Foundation for the publication of this thesis is gratefully acknowledged. 


\section{Contents}

Chapter 1 General Introduction

Chapter 2 CD36 inhibition prevents lipid accumulation and contractile dysfunction in rat Cardiomyocytes

Chapter 3 Omega-3 fatty acids prevent insulin resistance in

cardiomyocytes as induced by high insulin exposure

Chapter 4 Calcium signaling recruits substrate transporters GLUT4 and CD36 to the sarcolemma without increasing substrate uptake

Chapter 5 Involvement of zinc in fatty acid transport function of CD36:

A novel link to type 2 diabetes

Chapter 6 General Discussion

Summary

Samenvatting

Ozet

Curriculum vitae 

Chapter 1

General Introduction 
The heart functions as a result of alternating contractions and relaxations. This uninterrupted mechanical activity of the heart to pump blood through the circulation requires the continuous availability of metabolic energy. In addition, the heart responds to many hormonal, electrical and metabolic changes by adjusting the rate and intensity of contractions. For this the heart may switch between energy substrates.

Cardiomyocytes are the contractile unit of (striated) cardiac muscle and contain many mitochondria to produce the ample energy required for both mechanical and electrical activity and for functioning of ion channels and transmembrane pumps and transporter proteins. The heart can utilize a variety of substrates including (long-chain) fatty acids (LCFAs), carbohydrates, amino acids, ketones, and lactate to derive its continuous energy needs. Of the substrates utilized, under normal physiological conditions the oxidation of LCFAs (60-70\%) and of carbohydrates (30-40\%) contribute predominantly to daily energy needs [1]. Entry of carbohydrates and LCFAs into heart is facilitated via tissue specific protein structured transporters. Glucose is carried across the plasma membrane by glucose transporters (GLUTs). LCFAs can be either carried by membrane fattyacid transporters like FATP or CD36, or otherwise passively diffuse across the membrane [2]. Regulation of substrate uptake occurs by reversible translocation of GLUT4 and CD36 from intracellular storage compartments to the cell surface in response to several physiological stimuli (e.g., insulin, contractions) [2]. The flexibility of the heart to switch between different substrates ensures continuous ATP production to maintain its functions in various situations, for instance during the transition from rest to exercise or in order to adapt to changes in substrate availability. However, deterioration in the ability of heart to switch between various substrates upon different physiological and pathophysiological conditions (stress, enhanced work load) contributes to the development and/or progression of cardiac dysfunction [1,3]. Disturbances in cardiac substrate metabolism are usually associated with contractile and left ventricular dysfunction although the sequence of the triggering is not known [2]. Therefore, research aimed at understanding the regulation and molecular etiology of protein transporter mediated cardiac substrate utilization in the heart constitutes a pivotal field of investigation and may yield new therapeutic approaches for the diseased heart.

This thesis describes new insights into the regulation of cardiac substrate uptake in normal and diseased states including the underlying molecular mechanisms. In particular, these studies emphasize the importance of cardiac substrate transporters and their regulation for maintaining cardiac energy homeostasis, especially in the context of type 2 diabetes. Below the reader is provided with a short overview of the basics of cardiac substrate metabolism and specific aspects underlying the studies performed in this thesis. 


\section{Cardiac physiology at a glance}

The heart has four compartments called chambers. The upper two chambers are the atria and the lower two chambers are the ventricles. Atria receive blood coming from all over the body and deliver it into ventricles. Diastole and systole are the terms to explain relaxation and contraction of ventricles in cardiac muscle, respectively. Ventricles, after having blood from atrium during the diastole, pump it away from the heart into the arteries during systole. In each systole the right ventricle pumps low-oxygen blood into the pulmonary artery and the left ventricle pumps oxygen-rich blood into the aorta. Rhythmically occurring contractions and relaxations are initiated and coordinated by nerves called Sinoatrial Node (SN) in atrium and flowingly by the Atrioventricular Node in ventricles [4].
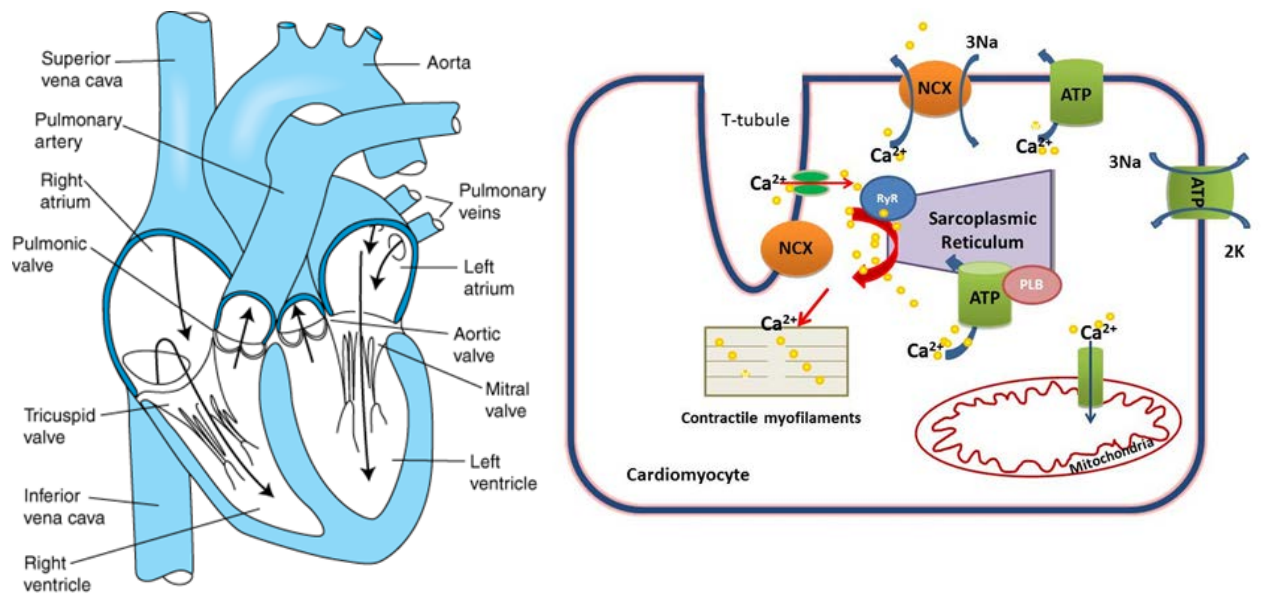

Source: Mohrman DE, Heller LJ,

Cardiovascular Physiology, $7^{\text {th }}$ edition

Fig. 1 Heart chambers and excitation contraction coupling. The figure on the left represents the heart chambers. The right atrium receives oxygen and nutrient poor blood coming from the entire body while the left atrium collects oxygen and nutrient rich blood coming from the lungs. During diastole, the ventricles are filled with the blood received from the atria, and pump it out of the heart during systole. The figure on the right (adapted from Bers DM, 2002) represents the events in excitation-contraction coupling. Contraction of a cardiac muscle starts with the depolarization of the cell membrane which leads to activation of voltage dependent channels. $\mathrm{Ca}^{2+}$ entry via depolarization-activated channels trigger an increased amount of $\mathrm{Ca}^{2+}$ release from the intracellular $\mathrm{Ca}^{2+}$ store, i.e., sarcoplasmic reticulum (SR). $\mathrm{Ca}^{2+}$ initiates contraction and then is removed by the common functions of $\mathrm{SR} \mathrm{Ca}^{2+}$-ATPase, Na/ $\mathrm{Ca}^{2+}$ exchanger, sarcolemmal $\mathrm{Ca}^{2+}$-ATPase and mitochondrial $\mathrm{Ca}^{2+}$ uniporter during the relaxation phase of contraction. Ion movements are indicated at the contraction phase (red arrows) and at the relaxation phase (blue arrows). ATP, sarcolemmal or sarcoplasmic reticulum $\mathrm{Ca}^{2+}$-ATPase; NCX, Sodium-calcium exchanger; PLB, phospholamban.

The excitation-contraction coupling is a process involving conversion of electrical excitation of cardiomyocytes into contraction of the entire heart. Excitation (depolarization of action potential) of cardiac muscle initiates a series of events that is accompanied by a rise in intracellular calcium $\left(\mathrm{Ca}^{2+}\right)$ [5]. During the action potential, $\mathrm{Ca}^{2+}$ enters the cell through voltage dependent $\mathrm{Ca}^{2+}$ channels 
(mainly L-type $\mathrm{Ca}^{2+}$ channels) triggering a major amount of $\mathrm{Ca}^{2+}$ release from the sarcoplasmic reticulum $\left(\mathrm{Ca}^{2+}\right.$ induced $\mathrm{Ca}^{2+}$ release). Elevated intracellular $\mathrm{Ca}^{2+}$ concentrations $\left(\left[\mathrm{Ca}^{2+}\right]_{\mathrm{i}}\right)$ initiate contraction by binding of $\mathrm{Ca}^{2+}$ to the myofilament protein troponin $\mathrm{C}$. At the relaxation phase of contraction intracellular $\mathrm{Ca}^{2+}$ has to be removed which will then lead to disassociation of $\mathrm{Ca}^{2+}$ from troponin. Subsequent removal of $\mathrm{Ca}^{2+}$ is mediated by common activity of sarcolemmal $\mathrm{Na}^{+} /$ $\mathrm{Ca}^{2+}$ exchangers, sarcoplasmic reticulum (SR) $\mathrm{Ca}^{2+}$-ATPase, sarcolemmal $\mathrm{Ca}^{2+}$ ATPase, and mitochondrial $\mathrm{Ca}^{2+}$ uniporter [5] (Fig. 1).

\section{Cardiac energy production}

The amount of ATP stored in the heart is not that large $(\sim 5 \mu \mathrm{mol} / \mathrm{g}$ wet weight $)$ and is just sufficient to maintain heart functions for a couple of seconds. Therefore, ATP synthesis and hydrolyzation rates are considerably high to maintain this ATP concentration in the heart [1]. Under non-ischemic conditions, the heart produces its ATP mainly ( 95\%) via oxidative phosphorylation of substrates primarily from glucose and LCFAs. In case of acute increases of energy needs, the heart uses additional pathways for ATP synthesis like glycolysis, phosphotransferase reactions catalyzed by creatine and adenylate kinases $[1,6]$. Oxidative phosphorylation takes place in the inner membrane of mitochondria where the electron transport chain is located. Acetyl-CoA is the fuel of citric acid cycle (Krebs cycle) and is generated by $\beta$-oxidation of LCFA (60-90\%) and of pyruvate (10$40 \%$ ) in healthy heart [7].

\section{Cardiac substrate transporters and substrate metabolism}

Glucose and LCFAs are predominantly carried across the plasma membrane by protein substrate transporters. Besides being present at the plasma membrane, substrate transporters are stored in endosomal compartments from where vesicles containing substrate transporters (e.g. GLUT4 and/or CD36) are formed to transport these proteins to the plasma membrane [8].

Because of its hydrophilic properties, glucose is unable to diffuse through the lipid bilayer of a cell membrane and needs to be transported. Glucose transporters (GLUT)-1 and -4 are highly expressed in the heart. GLUT4 is an insulin responsive transporter expressed in the adult heart while GLUT1 is insulin independent glucose transporter responsible for basal glucose uptake and expression of it is also predominant in fetal heart $[9,10]$. There are other transporters expressed in the heart which have only recently been identified, like GLUT-3, -8, -10, and -12 [11, 12]. However, functions and contributions of these transporters to cardiac substrate uptake are yet to be completely elucidated. Because of their hydrophobic nature, LCFAs can cross the plasma membrane by passive diffusion. It has been shown in the heart and in other tissues like skeletal muscle and adipocytes that besides passive diffusion, LCFA uptake is facilitated by protein transporters at the plasma membrane. Facilitated transport gains importance in either high energy needing process (enhanced contraction) or after 
a meal upon a stimulus (elevated plasma insulin levels). Plasma membrane associated fatty acid binding protein $\left(\mathrm{FABP}_{\mathrm{pm}}\right)$ located on the outer membrane, and transmembrane proteins like fatty acid translocase/CD36 and fatty acid transport protein (FATPs 1-6) are putative transporters for LCFA. Of these LCFA transporters, only CD36 contributes to the major amount of inducible LCFA transport [7]. CD36 deficient humans are known to have low rates of cardiac fatty acid uptake which emphasizes the function of CD36 in the regulation of cardiac fatty acid metabolism in vivo $[13,14]$. These LCFA transporter proteins can compensate to some extent for each other. For instance, it was shown that FATP1 expression is increased in CD36 null mice which prevented a drop in basal LCFA uptake [15]. The molecular mechanism of how CD36 and other LCFA transporters facilitate LFCA transport is not well defined. Suggested mechanisms involve either binding of CD36 to LCFA at the cell surface and facilitating the LCFA entry through the sarcolemma alone, or cooperation with $\mathrm{FABP}_{\mathrm{pm}}$ [16]. It was also suggested that CD36 might serve as recruiter for LCFA on the plasma membrane by tethering and providing them to FATP1 and FATP6 for the transportation into the cell [7] (Fig. 2).

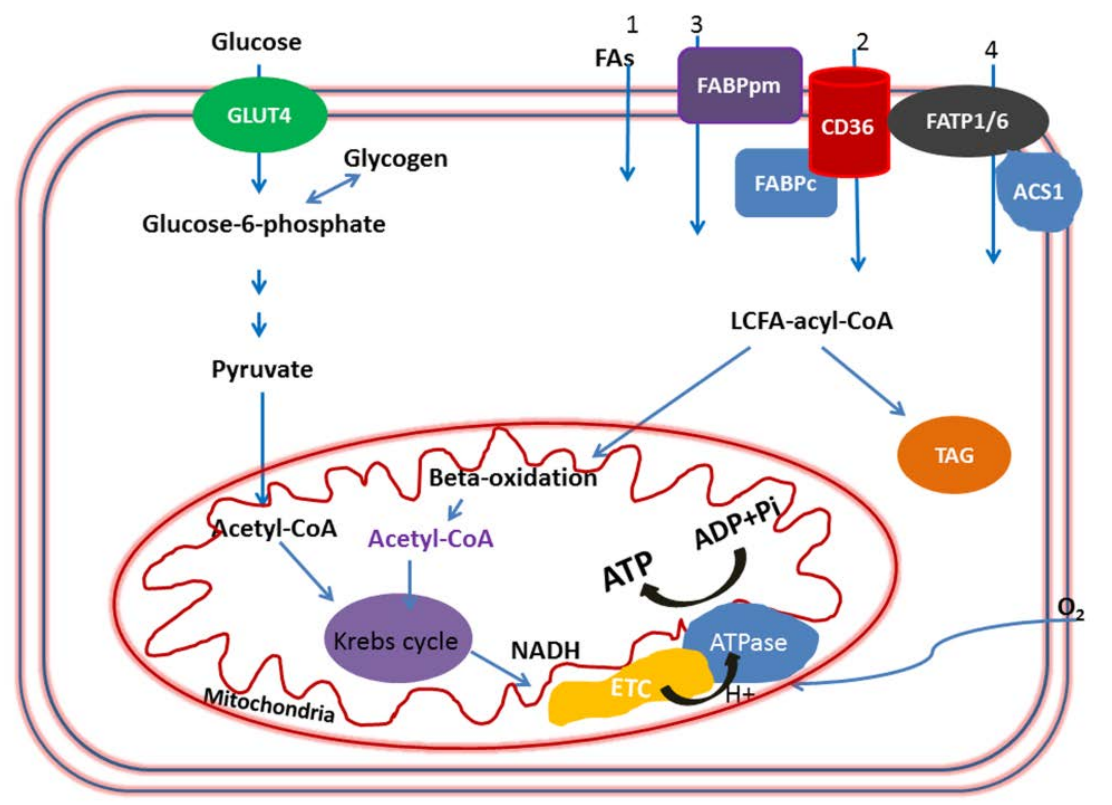

Fig. 2 Facilitated substrate transport and cellular fate of glucose and LCFAs. Glucose is taken up into cardiomyocytes by glucose transporter 4 (GLUT4). After cellular uptake, glucose is phosphorylated and converted into glucose-6-phosphate and thereby trapped in the cell. The glycolysis end product pyruvate is transported into mitochondria and converted into acetyl-Co A, the fuel of the citric acid cycle. Long-chain fatty acids (LCFAs) can either diffuse across the lipid bilayer (1) or are transported by protein transporters (2-4). Concomitant esterification of LCFAs to acyl-CoA esters occurs by acyl-CoA synthetase (ACSL) function of FAT1 or of ACSL1. Fatty acyl-CoA is either directed for TAG formation in the cytosol or for $\beta$-oxidation in the mitochondria. ETC, electron-transport chain; TAG, triacylglycerol.

Transporter-mediated substrate uptake is an important process not only because it is a mechanism to respond quickly to variations in energy requirements, but also it constitutes a control point for the regulation of substrate influx rate and 
subsequent cellular utilization processes [7]. In the healthy heart the amounts of both LCFA and glucose taken up into cardiomyocytes are exquisitely coupled to their subsequent metabolism. After taken up into a cell, glucose is converted into glucose- 6 phosphate by an enzyme called hexokinase to maintain a low intracellular glucose concentration, and hence a steep glucose gradient between outside and inside the cell. Phosphorylated glucose (glucose-6-phosphate) either undergoes glycolysis for production of pyruvate or is synthesized into glycogen. Pyruvate can either be converted into lactate in the cytoplasm or transported into mitochondria for complete oxidation through formation of acetyl-CoA entering the citric acid cycle for ATP production [17].

After their cellular uptake, LCFA either bind to cytoplasmic FABP $\left(\mathrm{FABP}_{\mathrm{c}}\right)$ for transport through the soluble cytoplasm or are directly converted into acylcoenzyme A (acyl-CoA) and thereby simultaneously activated and trapped in the cell. Being different from other LCFA transporters, FATP1 has long-chain acyl coenzyme A (acyl-CoA) synthetase (ACSL) activity which facilitates internalization of LCFAs via rapid esterification [7]. The fate of LCFA whether to undergo $\beta$ oxidation for energy production or being stored into triacylglycerols is already determined by the type of acyl-CoA synthetase isoenzymes $[18,19]$. There are 5 types ACSL isoenzymes (ACSL1,-3,-4,-5,-6) each showing a distinct tissue distribution. ACSL1 contributes to the majority of cardiac acyl-CoA formation. Whole body ACSL1 knockout mice showed 90\% decreased total ACSL activity and palmitate oxidation concomitant with an increased glucose and pyruvate oxidation. These data suggest that ACSL1 is responsible for the synthesis of acylCoA which will be utilized in $\beta$-oxidation in the heart [19].

\section{Signaling pathways involved in transporter mediated substrate uptake}

The amount of glucose and LCFA taken up into the cardiomyocyte is controlled by several mechanisms including expression levels and recycling rate of GLUTs and LCFA transporters to the plasma membrane $[9,20]$. Intracellular and membrane distributions of GLUT4 and CD36 are changed by different stimuli. Both an increased rate of contractions and insulin trigger the translocation of endosomal recycling vesicles carrying GLUT4 and CD36 to the plasma membrane [8, 21, 22]. Vesicular transport plays an important role in recycling of vesicles containing GLUT4 and CD36 between the plasma membrane and endosomal stores. An Akt substrate of $160 \mathrm{kDa}$ (AS160), which has Rab GTPase activity, is the common mediator for translocation of GLUT4 and CD36 containing vesicles to the plasma membrane in response to insulin or contraction [23-25]. Below the insulin and contraction mediated substrate uptake processes are discussed in more detail.

\section{Insulin signaling}

Insulin has many metabolic functions like stimulating cell growth, cell proliferation, protein synthesis, and gene transcription. Glucose homeostasis in the blood circulation is regulated by insulin and glucagon actions. In the fasting state, 
blood glucose levels are maintained by glycogenolysis or gluconeogenesis in the liver that is elicited upon secretion of glucagon from pancreatic $\alpha$-cells. After a meal, insulin secreted from the Langerhans islets of the pancreas initiates clearance of substrates from the blood circulation into cells of insulin responsive tissues such as skeletal muscle, adipose tissue and liver. Following the binding of insulin to extracellular $\alpha$-subunit of its receptor located on the cell surfaces a series of signaling events is initiated. Insulin binding to the insulin receptor (IR) results in auto-phosphorylation and activation of intrinsic tyrosine kinase activity of the transmembrane $\beta$-subunit [26]. Activated IR phosphorylates and activates a series of insulin receptor substrate (IRS) proteins. Activation of IRS leads to activation of two main signaling pathways: the mitogen-activated protein kinase (MAPK) pathway which is involved in the execution of insulin's cell growth and proliferation actions, and the phosphatidylinositol 3-kinase pathway (PI3K). PI3K is a heterodimeric protein consisting of a catalytic (p110) and a regulatory subunit (p58). After being recruited and activated through binding of p58 to IR and IRS, PI3K catalyses the phosphorylation of phosphoinositides to phosphatidylinositol3,-4,-5-tri-phosphate (PIP3). Increases in PIP3 activate phosphoinositededependent kinase 1 (PDK1) and serine-threonine dependent protein kinase $\mathrm{B}$ (PKB/Akt) [17]. Activation of PKB/Akt initiates activation of a series of vesicular transport proteins which are involved in GLUT4 translocation. One of those is Rab GTPase-activating protein which has recently been shown as a player in GLUT4 translocation via insulin signalling pathway [27].

Insulin also induces LCFA uptake and CD36 translocation in a similar manner to GLUT4 translocation as it also involves activation of the PI3K pathway [28]. Importantly, the metabolic action of insulin is different for glucose and LCFA that is taken up into cells. While insulin increases glucose utilization inside cardiomyocytes, FAs are directed for storage [29] (Fig. 3).

\section{Contraction signaling}

It has been shown in both skeletal and cardiac muscle that enhanced contractions activate the energy sensor AMP-dependent protein kinase (AMPK) [2]. AMPK is a serine/threonine protein kinase which is sensitive to the AMP/ATP and ADP/ATP ratios [30, 31]. Any cellular process causing an increase in AMP/ATP levels or in ADP/ATP levels leads to AMPK activation. AMP acts as allosteric regulator of AMPK activation [31]. AMP (or ADP) binding to the regulatory $\gamma$-subunit of AMPK, makes AMPK conformationally accessible for phosphorylation by an upstream AMPK kinases at the Thr172 residue within the catalytic $\alpha$-subunit [30, 31]. AMPK stimulates catabolic pathways for increased energy production through enhanced oxidation of substrates and simultaneously downregulates anabolic pathways to slow down energy consumption caused by biosynthesis and storage of substrates. So far 3 kinases have been pointed as having AMPK kinase activity. These are tumor suppressor gene LKB1 [32-34], $\mathrm{Ca}^{2+}$-calmodulin dependent protein kinase kinase $\alpha$ and $\beta$ (CaMKK- $\alpha /$ CaMKK- $\beta$ ) [35], and TGF $\beta$ activated kinase-1 (TAK1) $[36,37]$. The muscle specific isoform CaMKK- $\beta$ is activated upon a rise in intracellular $\mathrm{Ca}^{2+}$ concentrations whereas LKB1 is constitutively active [38]. However, LKB1 can only activate AMPK in conditions with increased AMP levels. 
There are contradictory findings in the literature regarding the regulation of AMPK by upstream kinases in contraction-stimulated substrate uptake. So far only LKB1 has been shown as an upstream kinase of AMPK in contraction mediated substrate uptake in the heart [39]. It was shown that oligomycin induced LCFA and glucose uptake was completely abolished in cardiomyocytes from AMPK- $\alpha 2$ and LKB1 deficient mice [39]. In LKB1 deficient skeletal muscle cells contraction induced AMPK activation and glucose uptake was completely abolished [40]. However findings regarding the activation of AMPK via CaMKKs in contraction mediated substrate uptake are restricted to studies in skeletal muscle and these findings are contradictory. CaMKK- $\beta$ has been appointed as upstream kinases of AMPK in the regulation of substrate metabolism (especially for glucose uptake) in contracting skeletal muscle [41-44]. On the other hand, it was also suggested that contraction-mediated glucose uptake in skeletal muscle involves separate activation of both AMPK and calcium signaling $[41,45,46]$ since contractions also leads to a rise in $\left[\mathrm{Ca}^{2+}\right]_{i}$. Overall it is not well defined whether CaMKK- $\beta / \mathrm{CaMKs}$ contribute to contraction mediated substrate uptake alone or through activation of AMPK in the heart. Both CaMKs and CaMKKs have been shown to exhibit autonomous activity independent of intracellular $\left[\mathrm{Ca}^{2+}\right]_{\mathrm{i}}$ which might be important for the activation of these kinases in heart where $\left[\mathrm{Ca}^{2+}\right]_{\mathrm{i}}$ is finely regulated.

Both pharmacological and genetic approaches have been used to study AMPK and its downstream signaling involved in skeletal and cardiac substrate metabolism. Pharmacological AMPK activators include AICAR and oligomycin. AMPK has two catalytic isoforms; AMPK $\alpha 1$ and $\alpha 2$ out of which AMPK 2 is suggested to be responsible for basal and AICAR induced glucose uptake. Whereas contraction induced glucose uptake was not affected in either knockout models suggesting that one isoform substitutes for another upon enhanced contraction [47]. Activation of AMPK leads to both GLUT4 and CD36 translocation to the plasma membrane and concomitantly to an increased glucose and LCFA uptake into cardiomyocytes $[15,39,48-50]$. AMPK dependent LCFA uptake into cardiomyocytes involves CD36 [15]. It has been shown in CD36 null mice that oligomycin-induced LCFA uptake was $80 \%$ diminished compared to CD36 positive mouse cardiomyocytes [15]. However, the exact molecular mechanism by which AMPK leads to transporter translocation is not known. There are findings supporting the involvement of AS160 (Rab GTPase-activating protein) [51, 52].

Contraction signaling also activates protein kinase-D1 (PKD1) independent from AMPK [53]. Activation of PKD1 was shown to lead to translocation of GLUT4, but not of CD36, to the plasma membrane and to concomitantly increase glucose uptake, but not LCFA uptake. Activation of PKD1 will occur upon binding to the tumor suppressor death-activated protein kinase (DAPK) in response to increased reactive oxygen species (ROS) production (ROS-DAPK-PKD-1 pathway) [54] (Fig. $3)$. 


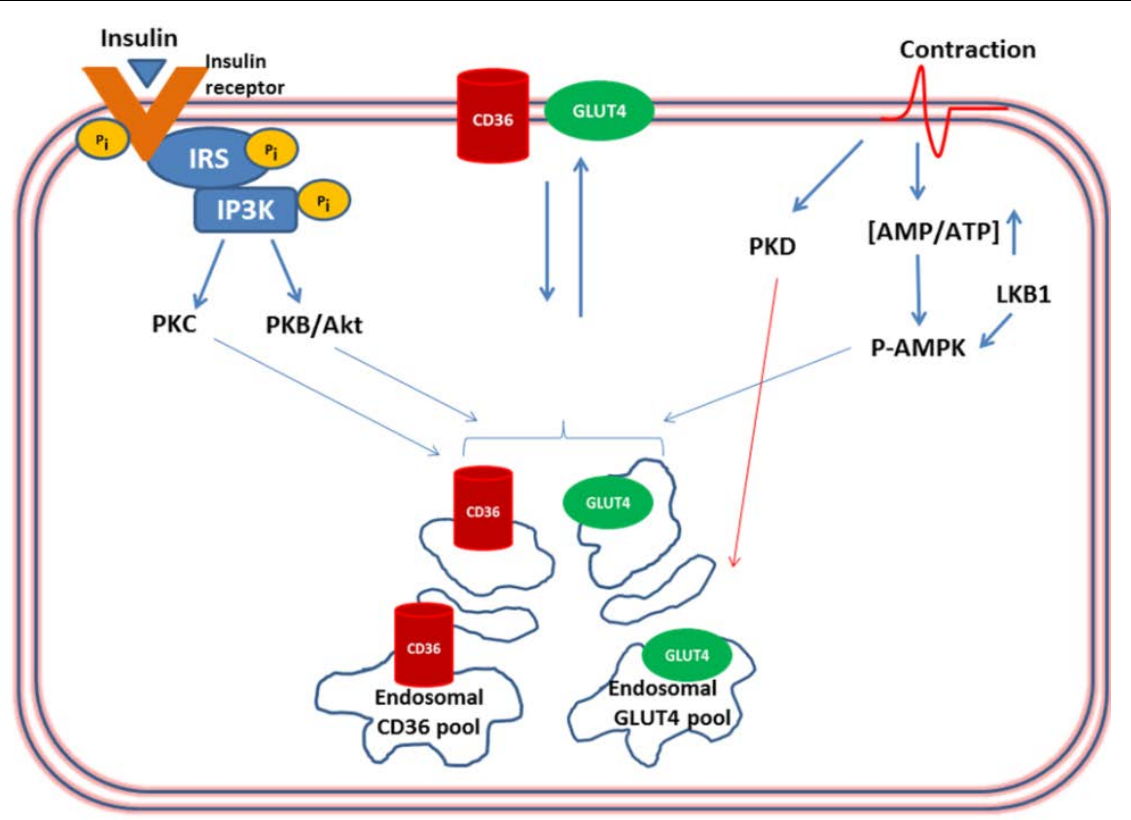

Fig. 3 Insulin and contraction mediated cardiac substrate metabolism. Insulin binding to its receptor activates downstream targets which result in vesicular translocation of GLUT4 and CD36 to sarcolemma via activation of AS160 dependent manner and subsequent increases in glucose and LCFA uptake into cells. Similarly contractions activate both PKD and AMPK. Activation of PKD results in only increased translocation of GLUT4 to sarcolemma and increased glucose uptake levels while AMPK activation triggers both GLUT4 and CD36 translocation to sarcolemma and subsequent increases in substrate uptake. AMPK dependent substrate uptake process also involves AS160 as insulin pathway; however PKD downstream targets involved in cardiac substrate uptake have not been identified yet.

\section{Cardiac substrate metabolism in the diabetic heart}

Type 2 diabetes mellitus (T2DM) is a world-wide chronic condition which is associated with numerous pathophysiological conditions like insulin resistance, hyperinsulinemia, hyperglycemia, oxidative stress, inflammation, dyslipidemia [55]. In the long term any of these conditions might trigger and contribute into a functional disorder of cardiac muscle which is known as diabetic cardiomyopathy [56]. Diabetic cardiomyopathy progresses as independent from other cardiovascular disease like hypertension and coronary artery disease. Diabetic cardiomyopathy is characterized in the early stages by diastolic dysfunction and ventricular hypertrophy and in later stages by systolic dysfunction [57-59].

Short term metabolic alterations upon various conditions (substrate and oxygen availability, increased metabolic end products (like diacylglycerol, ceramides), hormones, energy status, cellular stress) are compensated and balanced via switches in between the metabolic signaling pathways as implicated by the Randle cycle [60]. However, long term metabolic alterations contribute to cardiovascular dysfunction. Growing evidence suggests that especially cardiac insulin resistance and impaired metabolic flexibility largely contribute to the development of diabetic cardiomyopathy [56]. For instance, in the type 2 diabetes 
the lack of proper insulin action impairs glucose uptake and utilization while leading to high circulating levels of LCFAs through elevated lipolysis levels in adipose tissue [61]. Under these conditions the heart adapts to the utilization of LCFA [62]. This substrate switch is accompanied with many maladaptive changes related to increased LCFA utilization like increased oxygen use [63, 64], elevated ROS production $[63,65,66]$, increased TAG stores and accumulation of lipid metabolites $[67,68]$. All these changes might contribute to development of diabetic cardiomyopathy $[69,70]$. Increased fatty acid metabolites result in the activation of PKC- $\theta$ which in turn leads to increased IRS-1/Ser307 phosphorylation and concomitantly decreased phosphorylation and activation of IRS- 1 mediated PI3K activity [71]. As results insulin sensitivity on glucose transport is decreased. Another explanation of inhibited glucose signalling is through inhibition of glycolytic enzymes via fatty acid oxidation end products. For instance, 6phosphofructo-1-kinase (PFK) and pyruvate dehydrogenase (PDH) are inhibited via accumulation of citrate and acetyl-CoA, respectively which eventually inhibit glucose transport [56].

Cardiac substrate transporters contribute to the metabolic alterations listed above during progression to cardiomyopathy. Decreased translocation of GLUT4, increased overexpression of fatty acid transporter proteins CD36 and $\mathrm{FABP}_{\mathrm{pm}}$, and the permanent translocation of CD36 to the plasma membrane upon high levels of circulating fatty acids go along with impaired insulin actions [72, 73].

CD36 as a drug target for the treatment of lipid induced insulin resistance is valuable tool as well as to prevent progression into associated disease. As a proofof-principle, it has been already shown that inhibition of CD36 mediated fatty acid transport by using its cell-impermeable inhibitor sulfo- $N$-succimidyl-oleate (SSO) reduced LCFA uptake rate, TAG accumulation and the levels of un-esterified LCFA in obese Zucker rats [72].

\section{Aim of the thesis}

Modulation of cardiac substrate metabolism is one of the major therapeutic approaches to prevent progression of heart failure. This thesis aims to provide new insights in our understanding of cardiac substrate metabolism and related diseases by investigating the molecular mechanism and the regulation of cardiac substrate uptake in the healthy and diabetic heart.

As explained above, diabetic cardiomyopathy is associated with increased cellular uptake of LCFA leading to accumulation TAG and fatty acid metabolites. This thesis aims to investigate the regulation of protein transporter mediated cardiac substrate uptake in the context of type 2 diabetes. More specifically, the research addresses the alterations in the functions of CD36 and GLUT4 in an in vitro cell culture model of insulin resistance where primary adult rat cardiomyocytes were maintained during the 48 hours in the absence or presence of either high insulin or high palmitate containing culture mediums. 
Another topic addressed in this thesis is the role of both calcium $\left(\mathrm{Ca}^{2+}\right)$ and zinc $\left(\mathrm{Zn}^{2+}\right)$ ions and related signaling pathways in cardiac substrate metabolism. Both $\mathrm{Ca}^{+}$and $\mathrm{Zn}^{2+}$ ions are crucially important for the conduct of physiological functions. $\mathrm{Zn}^{2+}$ deficiency is associated with the development of diabetes and related complications. At the same time $\mathrm{Zn}^{2+}$ has many described physiological roles in the cardiovascular system. However, there are hardly any findings establishing the molecular mechanisms which associate $\mathrm{Zn}^{2+}$ deficiency with diabetes and related cardiovascular disease. Therefore we wanted to investigate the effect of $\mathrm{Zn}^{2+}$ deficiency on cardiac substrate metabolism in both freshly isolated and cultured primary rat cardiomyocytes.

$\mathrm{Ca}^{2+}$ is a major regulator of contraction and also plays major role in the activation of $\mathrm{Ca}^{2+} /$ calmodulin dependent protein kinases (CaMKs). The role of $\mathrm{Ca}^{2+}$ and CaMKKs/CaMKs in the substrate uptake process has not yet been investigated in the heart. Previously, studies on $\mathrm{Ca}^{2+}$ and the CaMKK/CaMK system were restricted to skeletal muscle. This research topic was also relevant because in some cell systems and in skeletal muscle it has been shown that CaMKKs are upstream kinases of the energy sensor AMPK. Therefore, we aimed to investigate the effect of increased $\left[\mathrm{Ca}^{2+}\right]_{\mathrm{i}}$ and activated CaMKKs/CaMKs on cardiac substrate transporters and contraction dependent substrate uptake processes in the heart. We used pharmacological approaches to activate both $\mathrm{Ca}^{2+}$-signaling and contraction signaling (AMPK) separately since it is known that in skeletal muscle contraction will activate both signaling pathways.

Lastly we studied the effects of polyunsaturated fatty acids (PUFAs), EPA (C20:5n-3) and DHA (C22:6n-3), on cardiac substrate metabolism in an in vitro insulin resistance model of primary rat cardiomyocytes. PUFAs, EPA and DHA (C22:6n-3), have been shown to improve insulin sensitivity in insulin-sensitive tissues. Although the exact mechanisms have not been revealed yet, one of the mechanisms is through incorporation of PUFAs into cellular membranes, thereby effecting membrane fluidity and phospholipid composition [74]. However, the direct effect of n-3 PUFAs on insulin signaling in the myocardium has not been examined.

We used freshly isolated cardiomyocytes to perform the studies represented in this thesis. Adult primary cardiomyocytes isolated from mouse and rat constitute a suitable model to study cardiac substrate metabolism [75]. Mostly pharmacological approaches were applied to either activate or inhibit certain signaling pathways by metal-ion chelating and kinase inhibition using wellestablished compounds. Detailed information regarding the action mechanisms of used pharmacological compounds in this thesis are shown in the Table1. 


\begin{tabular}{|c|c|c|c|}
\hline $\begin{array}{l}\text { Abbreviation / full } \\
\text { name }\end{array}$ & Action mechanisms & $\begin{array}{l}\text { Effects in cardimyocytes or } \\
\text { in (*)other tissue/cell type }\end{array}$ & $\begin{array}{l}\text { Related } \\
\text { literature }\end{array}$ \\
\hline Oligomycin & $\begin{array}{l}\text { Inhibits } \mathrm{F}_{0} \text { part of } \mathrm{H}^{+}-\mathrm{ATP} \\
\text { synthase which located in } \\
\text { electron-transport chain in } \\
\text { the mitochondria. }\end{array}$ & $\begin{array}{l}\text { Leads ATP depletion and } \\
\text { thereby activation of AMPK. } \\
\text { AMPK activation leads } \\
\text { translocation of GLUT4 and } \\
\text { CD36 to sarcolemma and } \\
\text { increased substrate uptake }\end{array}$ & $\begin{array}{l}{[48]} \\
{[15,76]}\end{array}$ \\
\hline $\begin{array}{l}\text { AICAR / 5- } \\
\text { aminoimidazole-4- } \\
\text { carboxamine-1- } \beta \text { - D- } \\
\text { ribofuranoside }\end{array}$ & $\begin{array}{l}\text { After taken into cell by } \\
\text { adenosine transporters, it is } \\
\text { subsequently } \\
\text { phosphorylated to ZMP (5- } \\
\text { aminoimidazole-4- } \\
\text { carboxamide-1- } \beta \text {-d- } \\
\text { furanosyl 5- } \\
\text { monophosphate) within the } \\
\text { cell, which mimics AMP } \\
\text { action in AMPK signaling } \\
\text { [77]. }\end{array}$ & $\begin{array}{l}\text { AICAR-induced AMPK } \\
\text { activation increases LCFA } \\
\text { uptake as well as } \\
\text { sarcolemmal fatty-acid } \\
\text { transporter (CD36) content } \\
\text { AICAR induced AMPK } \\
\text { activation does not lead to } \\
\text { increases in glucose uptake } \\
\text { since AICAR does not activate } \\
\text { PKD }\end{array}$ & $\begin{array}{l}{[48,76,78,} \\
79]\end{array}$ \\
\hline $\begin{array}{l}\text { Compound C / 6-[4-(2- } \\
\text { piperidin-1-yl-ethoxy)- } \\
\text { phenyl)] 3-pyridin-4- } \\
\text { yl-pyrazolo[1,5-a] } \\
\text { pyrimidine }\end{array}$ & $\begin{array}{l}\text { Cell permeable, selective } \\
\text { ATP-competitive inhibitor } \\
\text { of AMPK [80] }\end{array}$ & $\begin{array}{l}\text { Inhibits AMPK mediated } \\
\text { processes }\end{array}$ & $\begin{array}{l}{[81]^{*}} \\
\text { example } \\
\text { from } \\
\text { skeletal } \\
\text { muscle }\end{array}$ \\
\hline $\begin{array}{l}\text { Ara } A \text { / adenine 9- } \beta \text { - } \\
\text { Darabino-furanoside }\end{array}$ & $\begin{array}{l}\text { competitive inhibitor of } \\
\text { AMPK [82] }\end{array}$ & $\begin{array}{l}\text { Inhibits AMPK mediated } \\
\text { processes }\end{array}$ & $\begin{array}{l}{[82]^{*}} \\
\text { example } \\
\text { from } \\
\text { skeletal } \\
\text { muscle } \\
\end{array}$ \\
\hline A23187 & $\mathrm{Ca}^{2+}$ ionophore & $\begin{array}{l}\text { Increases cytoplasmic } \\
\text { calcium and thereby leads } \\
\text { activation of calcium- } \\
\text { activated protein kinases and } \\
\text { calcium handling proteins }\end{array}$ & [83] \\
\hline Thapsigargin & $\begin{array}{l}\text { Inhibits sarcoplasmic } \\
\text { reticulum } \mathrm{Ca}^{2+} \text {-ATPase [84] }\end{array}$ & $\begin{array}{l}\text { Increases cytoplasmic } \\
\text { calcium and thereby leads } \\
\text { activation of calcium- } \\
\text { activated protein kinases and } \\
\text { calcium handling proteins }\end{array}$ & {$\left[85,86^{*}\right]$} \\
\hline ST0-609 & $\begin{array}{l}\text { Selective inhibitor of } \\
\text { CaMKKs [35] }\end{array}$ & $\begin{array}{l}\text { Inhibits CaMKK- } \beta \text { action in } \\
\text { cardiomyocytes }\end{array}$ & {$[87,88]$} \\
\hline KN93 & $\begin{array}{l}\text { Specific inhibitor of CaMKII; } \\
\text { displays inhibitory effects } \\
\text { on CaMKII phosphorylation } \\
\text { as competitor to calmodulin } \\
\text { [89] }\end{array}$ & $\begin{array}{l}\text { Inhibits CaMKII dependent } \\
\text { processes } \\
\text { Inhibits L-type Ca }{ }^{2+} \text { (Cav1.2 } \\
\text { and Cav1.3) channel currents }\end{array}$ & {$[90]^{*}$} \\
\hline $\begin{array}{l}\text { TPEN / tetrakis-[2- } \\
\text { pyridylmethyl]- } \\
\text { ethyene-diamine }\end{array}$ & $\begin{array}{l}\text { TPEN is a heavy metal } \\
\text { chelator with low affinities } \\
\text { for } \mathrm{Ca}^{2+} \text { and } \mathrm{Mg}^{2+} \text { and very } \\
\text { high affinities for } \mathrm{Zn}^{2+} \text { and } \\
\mathrm{Fe}^{2+},\left(2.6 \times 10^{-6}, 2.4 \times 10^{-15}\right) \\
{[91]}\end{array}$ & Chelates $\mathrm{Zn}^{2+}$ & [92] \\
\hline 1,10-o-Phenanthroline & $\mathrm{Zn}^{2+}$ chelator [93] & Chelates metal ions & {$[94]^{*}$} \\
\hline
\end{tabular}




\section{Outline of the thesis}

Chapter 2 introduces an in vitro cell culture model to study cardiac substrate transporters in the regulation of cardiac substrate uptake under the conditions inducing insulin resistance. Primary rat cardiomyocytes were maintained during 48 hours in the absence or presence of either high levels of palmitic acid or insulin containing culture medium. This chapter puts forward CD36 as a key molecule to target fatty acid induced insulin resistance and contractile dysfunction by mediating exceeded LCFA influx into cardiomyocytes of primary cell culture model of adult rats. Chapter 3 investigates the effect of a rise in $\left[\mathrm{Ca}^{2+}\right]_{\mathrm{i}}$ and activated CaMKKs/CaMKs on GLUT4 and CD36 transporters and transporter mediated substrate uptake. In this study, differences in the molecular mechanism of contraction-mediated substrate uptake between cardiac and skeletal muscles are shown. Chapter 4 reports the beneficial effects of fish oils EPA and DHA on insulin signaling in an insulin resistance model of primary rat cardiomyocytes. Chapter 5 reveals the molecular mechanisms of impaired insulin signaling upon $\mathrm{Zn}^{2+}$ deficiency in both cultured and freshly isolated rat primary cardiomyocytes. In chapter 6, the main results presented in this thesis are summarized and discussed in relation to the latest insights from the literature. 


\section{References}

1. Stanley WC, Recchia FA, Lopaschuk GD. Myocardial substrate metabolism in the normal and failing heart. Physiol Rev. 2005;85:1093-129.

2. Schwenk RW, Luiken JJ, Bonen A, Glatz JF. Regulation of sarcolemmal glucose and fatty acid transporters in cardiac disease. Cardiovascular research. 2008;79:249-58.

3. Turer AT, Malloy CR, Newgard CB, Podgoreanu MV. Energetics and metabolism in the failing heart: important but poorly understood. Current opinion in clinical nutrition and metabolic care. 2010;13:458-65.

4. David E. Mohrman, Heller LJ. Cardiovascular Physiology. July 16, 2010 ed.

5. Bers DM. Cardiac excitation-contraction coupling. Nature. 2002;415:198-205.

6. Ingwall JS. Energy metabolism in heart failure and remodelling. Cardiovascular research. 2009;81:412-9.

7. Glatz JF, Luiken JJ, Bonen A. Membrane fatty acid transporters as regulators of lipid metabolism: implications for metabolic disease. Physiol Rev. 2010;90:367-417.

8. Steinbusch LK, Schwenk RW, Ouwens DM, Diamant M, Glatz JF, Luiken JJ. Subcellular trafficking of the substrate transporters GLUT4 and CD36 in cardiomyocytes. Cellular and molecular life sciences : CMLS. 2011;68:2525-38.

9. Kraegen EW, Sowden JA, Halstead MB, Clark PW, Rodnick KJ, Chisholm DJ, et al. Glucose transporters and in vivo glucose uptake in skeletal and cardiac muscle: fasting, insulin stimulation and immunoisolation studies of GLUT1 and GLUT4. The Biochemical journal. 1993;295 ( Pt 1):287-93.

10. Abel ED. Glucose transport in the heart. Front Biosci. 2004;9:201-15.

11. Waller AP, George M, Kalyanasundaram A, Kang C, Periasamy M, Hu K, et al. GLUT12 functions as a basal and insulin-independent glucose transporter in the heart. Biochimica et biophysica acta. 2013;1832:121-7.

12. Aerni-Flessner L, Abi-Jaoude M, Koenig A, Payne M, Hruz PW. GLUT4, GLUT1, and GLUT8 are the dominant GLUT transcripts expressed in the murine left ventricle. Cardiovascular diabetology. 2012;11:63.

13. Yuasa-Kawase M, Masuda D, Yamashita T, Kawase R, Nakaoka H, Inagaki M, et al. Patients with CD36 deficiency are associated with enhanced atherosclerotic cardiovascular diseases. J Atheroscler Thromb. 2012;19:263-75.

14. Fukuchi K, Nozaki S, Yoshizumi T, Hasegawa S, Uehara T, Nakagawa T, et al. Enhanced myocardial glucose use in patients with a deficiency in long-chain fatty acid transport (CD36 deficiency). J Nucl Med. 1999;40:239-43.

15. Habets DD, Coumans WA, Voshol PJ, den Boer MA, Febbraio M, Bonen A, et al. AMPK-mediated increase in myocardial long-chain fatty acid uptake critically depends on sarcolemmal CD36. Biochem Biophys Res Commun. 2007;355:204-10.

16. Chabowski A, Gorski J, Luiken JJ, Glatz JF, Bonen A. Evidence for concerted action of FAT/CD36 and FABPpm to increase fatty acid transport across the plasma membrane. Prostaglandins, leukotrienes, and essential fatty acids. 2007;77:345-53.

17. Bertrand L, Horman S, Beauloye $\mathrm{C}$, Vanoverschelde JL. Insulin signalling in the heart. Cardiovascular research. 2008;79:238-48.

18. Coleman RA, Lewin TM, Van Horn CG, Gonzalez-Baro MR. Do long-chain acyl-CoA synthetases regulate fatty acid entry into synthetic versus degradative pathways? J Nutr. 2002;132:2123-6.

19. Ellis JM, Mentock SM, Depetrillo MA, Koves TR, Sen S, Watkins SM, et al. Mouse cardiac acyl coenzyme a synthetase 1 deficiency impairs Fatty Acid oxidation and induces cardiac hypertrophy. Molecular and cellular biology. 2011;31:1252-62.

20. Luiken JJ, Coort SL, Koonen DP, van der Horst DJ, Bonen A, Zorzano A, et al. Regulation of cardiac long-chain fatty acid and glucose uptake by translocation of substrate transporters. Pflugers Arch. 2004;448:1-15.

21. Luiken JJ, Koonen DP, Willems J, Zorzano A, Becker C, Fischer Y, et al. Insulin stimulates long-chain fatty acid utilization by rat cardiac myocytes through cellular redistribution of FAT/CD36. Diabetes. 2002;51:3113-9.

22. Luiken JJ, Coort SL, Koonen DP, Van der Horst DJ, Bonen A, Zorzano A, et al. Regulation of cardiac long-chain fatty acid and glucose uptake by translocation of substrate transporters. Pflügers Arch. 2004;448:1-15. 
23. Samovski D, Su X, Xu Y, Abumrad NA, Stahl PD. Insulin and AMPK regulate FA translocase/CD36 plasma membrane recruitment in cardiomyocytes via Rab GAP AS160 and Rab8a Rab GTPase. J Lipid Res. 2012;53:709-17.

24. Peck GR, Chavez JA, Roach WG, Budnik BA, Lane WS, Karlsson HK, et al. Insulin-stimulated phosphorylation of the Rab GTPase-activating protein TBC1D1 regulates GLUT4 translocation. The Journal of biological chemistry. 2009;284:30016-23.

25. Webster I, Friedrich SO, Lochner A, Huisamen B. AMP kinase activation and glut4 translocation in isolated cardiomyocytes. Cardiovasc J Afr. 2010;21:72-8.

26. Gammeltoft S, Van Obberghen E. Protein kinase activity of the insulin receptor. The Biochemical journal. 1986;235:1-11.

27. Sano H, Kane S, Sano E, Miinea CP, Asara JM, Lane WS, et al. Insulin-stimulated phosphorylation of a Rab GTPase-activating protein regulates GLUT4 translocation. The Journal of biological chemistry. 2003;278:14599-602.

28. van Oort MM, van Doorn JM, Bonen A, Glatz JF, van der Horst DJ, Rodenburg KW, et al. Insulininduced translocation of CD36 to the plasma membrane is reversible and shows similarity to that of GLUT4. Biochim Biophys Acta. 2008;1781:61-71.

29. Dyck DJ, Steinberg G, Bonen A. Insulin increases FA uptake and esterification but reduces lipid utilization in isolated contracting muscle. American journal of physiology Endocrinology and metabolism. 2001;281:E600-7.

30. Shirwany NA, Zou MH. AMPK in cardiovascular health and disease. Acta Pharmacol Sin. 2010;31:1075-84.

31. Hardie DG, Ross FA, Hawley SA. AMPK: a nutrient and energy sensor that maintains energy homeostasis. Nature reviews Molecular cell biology. 2012;13:251-62.

32. Shaw RJ, Kosmatka M, Bardeesy N, Hurley RL, Witters LA, DePinho RA, et al. The tumor suppressor LKB1 kinase directly activates AMP-activated kinase and regulates apoptosis in response to energy stress. Proceedings of the National Academy of Sciences of the United States of America. 2004;101:3329-35.

33. Hawley SA, Boudeau J, Reid JL, Mustard KJ, Udd L, Makela TP, et al. Complexes between the LKB1 tumor suppressor, STRAD alpha/beta and M025 alpha/beta are upstream kinases in the AMPactivated protein kinase cascade. J Biol. 2003;2:28.

34. Hong SP, Leiper FC, Woods A, Carling D, Carlson M. Activation of yeast Snf1 and mammalian AMPactivated protein kinase by upstream kinases. Proceedings of the National Academy of Sciences of the United States of America. 2003;100:8839-43.

35. Hawley SA, Pan DA, Mustard KJ, Ross L, Bain J, Edelman AM, et al. Calmodulin-dependent protein kinase kinase-beta is an alternative upstream kinase for AMP-activated protein kinase. Cell Metab. 2005;2:9-19.

36. Momcilovic M, Hong SP, Carlson M. Mammalian TAK1 activates Snf1 protein kinase in yeast and phosphorylates AMP-activated protein kinase in vitro. J Biol Chem. 2006;281:25336-43.

37. Sato S, Sanjo H, Takeda K, Ninomiya-Tsuji J, Yamamoto M, Kawai T, et al. Essential function for the kinase TAK1 in innate and adaptive immune responses. Nat Immunol. 2005;6:1087-95.

38. Sakamoto K, Goransson O, Hardie DG, Alessi DR. Activity of LKB1 and AMPK-related kinases in skeletal muscle: effects of contraction, phenformin, and AICAR. Am J Physiol Endocrinol Metab. 2004;287:E310-7.

39. Habets DD, Coumans WA, El Hasnaoui M, Zarrinpashneh E, Bertrand L, Viollet B, et al. Crucial role for LKB1 to AMPKalpha2 axis in the regulation of CD36-mediated long-chain fatty acid uptake into cardiomyocytes. Biochim Biophys Acta. 2009;1791:212-9.

40. Sakamoto K, McCarthy A, Smith D, Green KA, Grahame Hardie D, Ashworth A, et al. Deficiency of LKB1 in skeletal muscle prevents AMPK activation and glucose uptake during contraction. EMBO J. 2005;24:1810-20.

41. Witczak CA, Fujii N, Hirshman MF, Goodyear LJ. Ca2+/calmodulin-dependent protein kinase kinase-alpha regulates skeletal muscle glucose uptake independent of AMP-activated protein kinase and Akt activation. Diabetes. 2007;56:1403-9.

42. Abbott MJ, Edelman AM, Turcotte LP. CaMKK is an upstream signal of AMP-activated protein kinase in regulation of substrate metabolism in contracting skeletal muscle. Am J Physiol Regul Integr Comp Physiol. 2009;297:R1724-32.

43. Jensen TE, Rose AJ, Jorgensen SB, Brandt N, Schjerling P, Wojtaszewski JF, et al. Possible CaMKKdependent regulation of AMPK phosphorylation and glucose uptake at the onset of mild tetanic skeletal muscle contraction. Am J Physiol Endocrinol Metab. 2007;292:E1308-17. 
44. Jensen TE, Rose AJ, Hellsten Y, Wojtaszewski JF, Richter EA. Caffeine-induced Ca(2+) release increases AMPK-dependent glucose uptake in rodent soleus muscle. American journal of physiology Endocrinology and metabolism. 2007;293:E286-92.

45. Wright DC, Hucker KA, Holloszy JO, Han DH. Ca2+ and AMPK both mediate stimulation of glucose transport by muscle contractions. Diabetes. 2004;53:330-5.

46. Youn JH, Gulve EA, Holloszy JO. Calcium stimulates glucose transport in skeletal muscle by a pathway independent of contraction. Am J Physiol. 1991;260:C555-61.

47. Jorgensen SB, Viollet B, Andreelli F, Frosig C, Birk JB, Schjerling P, et al. Knockout of the alpha2 but not alpha1 5'-AMP-activated protein kinase isoform abolishes 5-aminoimidazole-4-carboxamide1-beta-4-ribofuranosidebut not contraction-induced glucose uptake in skeletal muscle. J Biol Chem. 2004;279:1070-9.

48. Luiken JJ, Coort SL, Willems J, Coumans WA, Bonen A, van der Vusse GJ, et al. Contraction-induced fatty acid translocase/CD36 translocation in rat cardiac myocytes is mediated through AMPactivated protein kinase signaling. Diabetes. 2003;52:1627-34.

49. Abbott MJ, Bogachus LD, Turcotte LP. AMPKalpha2 deficiency uncovers time dependency in the regulation of contraction-induced palmitate and glucose uptake in mouse muscle. J Appl Physiol. 2011;111:125-34.

50. Fujii N, Jessen N, Goodyear LJ. AMP-activated protein kinase and the regulation of glucose transport. American journal of physiology Endocrinology and metabolism. 2006;291:E867-77.

51. Kramer HF, Witczak CA, Taylor EB, Fujii N, Hirshman MF, Goodyear LJ. AS160 regulates insulinand contraction-stimulated glucose uptake in mouse skeletal muscle. The Journal of biological chemistry. 2006;281:31478-85.

52. Kramer HF, Witczak CA, Fujii N, Jessen N, Taylor EB, Arnolds DE, et al. Distinct signals regulate AS160 phosphorylation in response to insulin, AICAR, and contraction in mouse skeletal muscle. Diabetes. 2006;55:2067-76.

53. Luiken JJ, Vertommen D, Coort SL, Habets DD, El Hasnaoui M, Pelsers MM, et al. Identification of protein kinase D as a novel contraction-activated kinase linked to GLUT4-mediated glucose uptake, independent of AMPK. Cell Signal. 2008;20:543-56.

54. Dirkx E, Schwenk RW, Coumans WA, Hoebers N, Angin Y, Viollet B, et al. Protein kinase D1 is essential for contraction-induced glucose uptake but is not involved in fatty acid uptake into cardiomyocytes. J Biol Chem. 2012;287:5871-81.

55. Olokoba AB, Obateru OA, Olokoba LB. Type 2 diabetes mellitus: a review of current trends. Oman Med J. 2012;27:269-73.

56. Mandavia CH, Aroor AR, Demarco VG, Sowers JR. Molecular and metabolic mechanisms of cardiac dysfunction in diabetes. Life sciences. 2013;92:601-8.

57. Miki T, Yuda S, Kouzu H, Miura T. Diabetic cardiomyopathy: pathophysiology and clinical features. Heart Fail Rev. 2013;18:149-66.

58. Liu JE, Palmieri V, Roman MJ, Bella JN, Fabsitz R, Howard BV, et al. The impact of diabetes on left ventricular filling pattern in normotensive and hypertensive adults: the Strong Heart Study. J Am Coll Cardiol. 2001;37:1943-9.

59. Schannwell CM, Schneppenheim M, Perings S, Plehn G, Strauer BE. Left ventricular diastolic dysfunction as an early manifestation of diabetic cardiomyopathy. Cardiology. 2002;98:33-9.

60. Hue L, Taegtmeyer $\mathrm{H}$. The Randle cycle revisited: a new head for an old hat. Am J Physiol Endocrinol Metab. 2009;297:E578-91.

61. Jocken JW, Goossens GH, Boon H, Mason RR, Essers Y, Havekes B, et al. Insulin-mediated suppression of lipolysis in adipose tissue and skeletal muscle of obese type 2 diabetic men and men with normal glucose tolerance. Diabetologia. 2013.

62. An D, Rodrigues B. Role of changes in cardiac metabolism in development of diabetic cardiomyopathy. American journal of physiology Heart and circulatory physiology. 2006;291:H1489-506.

63. Boudina S, Sena S, Theobald H, Sheng X, Wright JJ, Hu XX, et al. Mitochondrial energetics in the heart in obesity-related diabetes: direct evidence for increased uncoupled respiration and activation of uncoupling proteins. Diabetes. 2007;56:2457-66.

64. How OJ, Aasum E, Severson DL, Chan WY, Essop MF, Larsen TS. Increased myocardial oxygen consumption reduces cardiac efficiency in diabetic mice. Diabetes. 2006;55:466-73.

65. Inoguchi T, Li P, Umeda F, Yu HY, Kakimoto M, Imamura M, et al. High glucose level and free fatty acid stimulate reactive oxygen species production through protein kinase $\mathrm{C}$--dependent activation of NAD(P)H oxidase in cultured vascular cells. Diabetes. 2000;49:1939-45. 
66. Ye G, Metreveli NS, Ren J, Epstein PN. Metallothionein prevents diabetes-induced deficits in cardiomyocytes by inhibiting reactive oxygen species production. Diabetes. 2003;52:777-83.

67. Szczepaniak LS, Dobbins RL, Metzger GJ, Sartoni-D'Ambrosia G, Arbique D, Vongpatanasin W, et al. Myocardial triglycerides and systolic function in humans: in vivo evaluation by localized proton spectroscopy and cardiac imaging. Magn Reson Med. 2003;49:417-23.

68. Sharma S, Adrogue JV, Golfman L, Uray I, Lemm J, Youker K, et al. Intramyocardial lipid accumulation in the failing human heart resembles the lipotoxic rat heart. FASEB journal : official publication of the Federation of American Societies for Experimental Biology. 2004;18:1692-700.

69. Lopaschuk GD, Ussher JR, Folmes CD, Jaswal JS, Stanley WC. Myocardial fatty acid metabolism in health and disease. Physiological reviews. 2010;90:207-58.

70. Boudina S, Abel ED. Diabetic cardiomyopathy revisited. Circulation. 2007;115:3213-23.

71. Yu C, Chen Y, Cline GW, Zhang D, Zong H, Wang Y, et al. Mechanism by which fatty acids inhibit insulin activation of insulin receptor substrate-1 (IRS-1)-associated phosphatidylinositol 3-kinase activity in muscle. The Journal of biological chemistry. 2002;277:50230-6.

72. Coort SL, Hasselbaink DM, Koonen DP, Willems J, Coumans WA, Chabowski A, et al. Enhanced sarcolemmal FAT/CD36 content and triacylglycerol storage in cardiac myocytes from obese zucker rats. Diabetes. 2004;53:1655-63.

73. Garvey WT, Hardin D, Juhaszova M, Dominguez JH. Effects of diabetes on myocardial glucose transport system in rats: implications for diabetic cardiomyopathy. The American journal of physiology. 1993;264:H837-44.

74. Lorente-Cebrian S, Costa AG, Navas-Carretero S, Zabala M, Martinez JA, Moreno-Aliaga MJ. Role of omega-3 fatty acids in obesity, metabolic syndrome, and cardiovascular diseases: a review of the evidence. Journal of physiology and biochemistry. 2013.

75. Kammermeier H, Rose H. Are isolated cardiomyocytes a suitable experimental model in all lines of investigation in basic cardiology? Basic Res Cardiol. 1988;83:343-9.

76. Chabowski A, Momken I, Coort SL, Calles-Escandon J, Tandon NN, Glatz JF, et al. Prolonged AMPK activation increases the expression of fatty acid transporters in cardiac myocytes and perfused hearts. Molecular and cellular biochemistry. 2006;288:201-12.

77. Merrill GF, Kurth EJ, Hardie DG, Winder WW. AICA riboside increases AMP-activated protein kinase, fatty acid oxidation, and glucose uptake in rat muscle. The American journal of physiology. 1997;273:E1107-12.

78. Wong AK, Howie J, Petrie JR, Lang CC. AMP-activated protein kinase pathway: a potential therapeutic target in cardiometabolic disease. Clin Sci (Lond). 2009;116:607-20.

79. Chabowski A, Coort SL, Calles-Escandon J, Tandon NN, Glatz JF, Luiken JJ, et al. The subcellular compartmentation of fatty acid transporters is regulated differently by insulin and by AICAR. FEBS Lett. 2005;579:2428-32.

80. Zhou G, Myers R, Li Y, Chen Y, Shen X, Fenyk-Melody J, et al. Role of AMP-activated protein kinase in mechanism of metformin action. The Journal of clinical investigation. 2001;108:1167-74.

81. Canto C, Gerhart-Hines Z, Feige JN, Lagouge M, Noriega L, Milne JC, et al. AMPK regulates energy expenditure by modulating NAD+ metabolism and SIRT1 activity. Nature. 2009;458:1056-60.

82. Musi N, Hayashi T, Fujii N, Hirshman MF, Witters LA, Goodyear LJ. AMP-activated protein kinase activity and glucose uptake in rat skeletal muscle. American journal of physiology Endocrinology and metabolism. 2001;280:E677-84.

83. Przygodzki T, Sokal A, Bryszewska M. Calcium ionophore A23187 action on cardiac myocytes is accompanied by enhanced production of reactive oxygen species. Biochimica et biophysica acta. 2005;1740:481-8.

84. Lytton J, Westlin M, Hanley MR. Thapsigargin inhibits the sarcoplasmic or endoplasmic reticulum Ca-ATPase family of calcium pumps. The Journal of biological chemistry. 1991;266:17067-71.

85. Prasad AM, Inesi G. Effects of thapsigargin and phenylephrine on calcineurin and protein kinase C signaling functions in cardiac myocytes. American journal of physiology Cell physiology. 2009;296:C992-C1002.

86. Ma Y, Yang F, Wang Y, Du Z, Liu D, Guo H, et al. CaMKK $\beta$ is involved in AMP-activated protein kinase activation by baicalin in LKB1 deficient cell lines. Plos One. 2012;7(10):e47900.

87. Yan H, Zhang DX, Shi X, Zhang Q, Huang YS. Activation of the prolyl-hydroxylase oxygen-sensing signal cascade leads to AMPK activation in cardiomyocytes. J Cell Mol Med. 2012;16:2049-59.

88. Li L, Zhang H, Li T, Zhang B. Involvement of adenosine monophosphate-activated protein kinase in morphine-induced cardioprotection. J Surg Res. 2011;169:179-87.

89. Tokumitsu H, Chijiwa T, Hagiwara M, Mizutani A, Terasawa M, Hidaka H. KN-62, 1-[N,O-bis(5isoquinolinesulfonyl)-N-methyl-L-tyrosyl]-4-phenylpiperazi ne, a specific inhibitor of Ca2+/calmodulin-dependent protein kinase II. J Biol Chem. 1990;265(8):4315-20. 
90. Gao L, Blair LA, Marshall J. CaMKII-independent effects of KN93 and its inactive analog KN92: reversible inhibition of L-type calcium channels. Biochemical and biophysical research communications. 2006;345:1606-10.

91. Shumaker DK, Vann LR, Goldberg MW, Allen TD, Wilson KL. TPEN, a Zn2+/Fe2+ chelator with low affinity for $\mathrm{Ca} 2+$, inhibits lamin assembly, destabilizes nuclear architecture and may independently protect nuclei from apoptosis in vitro. Cell Calcium. 1998;23:151-64.

92. Turan B. Zinc-induced changes in ionic currents of cardiomyocytes. Biol Trace Elem Res. 2003;94:49-60.

93. Kiss Z. The zinc chelator 1,10-phenanthroline enhances the stimulatory effects of protein kinase $\mathrm{C}$ activators and staurosporine, but not sphingosine and H2O2, on phospholipase D activity in NIH 3T3 fibroblasts. The Biochemical journal. 1994;298 ( Pt 1):93-8.

94. Vanden Hoek TL, Shao Z, Li C, Zak R, Schumacker PT, Becker LB. Reperfusion injury on cardiac myocytes after simulated ischemia. The American journal of physiology. 1996;270:H1334-41. 


\section{Chapter 2}

\section{CD36 inhibition prevents lipid accumulation and contractile dysfunction in rat cardiomyocytes}

Yeliz Angin*1, Laura K.M. Steinbusch*1, Peter J. Simons ${ }^{\dagger}$, Sabrina Greulich, Nicole T.H. Hoebers*, Kim Douma*, Marc A.M.J. van Zandvoort*, Will A. Coumans*, Wino Wijnen*, Michaela Diamant§, D. Margriet Ouwens", Jan F.C. Glatz*, Joost J.F.P. Luiken*

*CARIM, Maastricht University, Universiteitssingel 50, P.O. Box 616, 6200 MD Maastricht, the Netherlands,

†Bioceros BV, Yalelaan 46, 3584 CM Utrecht, the Netherlands,

‡German Diabetes Center, Auf'm Hennekamp 65, 40225 Düsseldorf, Germany §Diabetes Center, VUmc, Postbus 7057, 1007 MB Amsterdam, the Netherlands

1 These authors equally contributed to the manuscript.

Biochem J. (2012) 448(1):43-53 


\begin{abstract}
An increased cardiac fatty acid supply and increased sarcolemmal presence of the long-chain fatty acid transporter CD36 are associated with and contribute to impaired cardiac insulin sensitivity and function. We aimed at preventing the development of insulin resistance and contractile dysfunction in cardiomyocytes by blocking CD36-mediated palmitate uptake. Insulin resistance and contractile dysfunction were induced in primary cardiomyocytes by $48 \mathrm{~h}$ incubation in media containing either $100 \mathrm{nM}$ insulin (high insulin; HI) or $200 \mu \mathrm{M}$ palmitate (high palmitate; HP). Under both culturing conditions, insulin-stimulated glucose uptake and Akt-phosphorylation were abrogated or markedly reduced. Furthermore, cardiomyocytes cultured in each medium displayed elevated sarcolemmal CD36 content, increased basal palmitate uptake, lipid accumulation and decreased sarcomere shortening. Immunochemical CD36 inhibition enhanced basal glucose uptake and prevented elevated basal palmitate uptake, triacylglycerol accumulation, and contractile dysfunction in cardiomyocytes cultured in either medium. Additionally, CD36 inhibition prevented loss of insulin signaling in cells cultured in HP, but not in HI medium. In conclusion, CD36 inhibition prevents lipid accumulation and lipid-induced contractile dysfunction in cardiomyocytes, but likely independently of effects on insulin signaling. Nonetheless, pharmacological CD36 inhibition may be considered as a treatment strategy to counteract impaired functioning of the lipid-loaded heart.
\end{abstract}




\section{Introduction}

Increased cardiac lipid content has been associated with pathophysiological conditions like cardiac insulin resistance and contractile dysfunction which may lead to the development of diabetic cardiomyopathy [1-3]. Cardiac lipid accumulation occurs as a result of elevated long-chain fatty acid (LCFA) supply [4] and/or increased uptake of LCFA [5-7]. Excessive entry of LCFA into cardiomyocytes provides increased substrates for mitochondrial LCFA oxidation. When the flux of incoming LCFA exceeds the mitochondrial $\beta$-oxidation capacity, LCFA will increasingly be stored as triacylglycerols and converted into bio-active metabolites such as diacylglycerols. Notably, there is a strong correlation between triacylglycerol storage and insulin resistance $[8,9]$. Moreover, diacylglycerols have been regarded to be causal to the development of insulin resistance through activation of PKC-mediated Ser/Thr phosphorylation of the insulin receptor substrate, thereby impairing downstream insulin signaling [10].

Glucose and LCFA are the major energy substrates for the heart. Cardiac substrate uptake is dependent on plasma glucose and LCFA concentrations, as well as the sarcolemmal presence of glucose and LCFA transporters [7, 11]. The main glucose transporter (GLUT) in the heart is GLUT4, whereas LCFA uptake is largely mediated by CD36 [12]. Also other LCFA transporters have been found to be present in the heart such as members of the family of fatty acid transporter proteins (FATPs), but these proteins have a minor role in bulk uptake of LCFA into the heart [7]. Insulin is a major physiological stimulator of cardiac glucose and fatty acid uptake. Insulin-stimulated glucose uptake is due to GLUT4 translocation from intracellular compartments to the sarcolemma via a vesicle-mediated process [12-14]. A similar vesicle-mediated process is also responsible for CD36 translocation from intracellular compartments to the sarcolemma, which entirely accounts for insulin-stimulated LCFA uptake [12]. Accordingly, in cardiomyocytes from CD36 knockout mice, insulin-induced CD36 translocation is completely abolished [15].

The expression of CD36 in the heart is not changed in rodent models of insulin resistance. However, this transporter has been shown to permanently relocate from intracellular stores to the sarcolemma. This CD36 relocation will cause chronically elevated LCFA uptake into the heart, followed by myocellular lipid accumulation, and consequently insulin resistance [7, 16, 17]. Ultimately, permanent sarcolemmal CD36 relocation may lead to cardiac dysfunction [16]. Accordingly, ablation of CD36 has been shown to preserve cardiac function in Western diet-fed mice [18], and also in mice suffering from PPAR $\alpha$ overexpressioninduced lipotoxicity [19]. Taken together, CD36 and its increased abundance at the sarcolemma play a key role in the development of high-fat diet-induced cardiac dysfunction.

CD36 is a multifactorial protein and has different functions in different cell types. Several endogenous CD36-ligands (LCFA, thrombospondin-1, oxidized lowdensity lipoproteins) with different binding regions on the extracellular domain of CD36 are known [20-22]. In addition, synthetic CD36-specific binding molecules 
(sulfo-N-succinimydyl oleate (SSO), hexarelin, EP80317) and antibodies have been introduced [23, 24]. Sulfo-N-succinimidyl esters of LCFA have proven to block initial LCFA uptake into heart and muscle [25]. However, they are not useful in long-term experiments because of their chemical instability [24]. In search for other CD36 ligands that interfere with the fatty acid transport function of CD36, we tested whether hexarelin, EP80317 and anti-CD36 monoclonal antibodies (mAb) would inhibit short-term LCFA uptake into cardiomyocytes prior to testing their protective potential against the detrimental effects of cardiomyocytic lipid overload.

To test the putative preventive effect of CD36 ligands on cardiomyocyte lipid accumulation, insulin resistance and contractile dysfunction, we first needed to establish suitable culturing conditions in which cardiomyocytes develop excessive lipid storage and loss of insulin signaling and contractile function. For this, we chronically exposed rat primary cardiomyocytes to two different media. One medium contained a high concentration of insulin (HI), because insulin is known to induce CD36 translocation to the sarcolemma and thereby increase LCFA uptake and lipid accumulation. Besides, it is known that chronic insulin-treatment induces loss of insulin signaling in cardiomyocytes [26]. A second medium contained a high concentration of palmitate (HP), which is known to reduce contractile function [27]. As a result, cardiomyocytes were cultured in a HI or a HP containing medium with/without a CD36-blocking compound. Then, we evaluated the cultured cardiomyocytes on surface CD36 presence, glucose and LCFA uptake, insulin signaling, myocellular lipid content and contractile function. We describe here that inhibition of CD36-mediated LCFA uptake by a CD36-blocking compound prevents lipid accumulation and loss of sarcomere shortening in these cultured cardiomyocytes.

\section{Materials and Methods}

\section{$\underline{\text { Materials }}$}

2-Deoxy-D-[1-3 $\mathrm{H}]$ glucose and $\left[1-{ }^{14} \mathrm{C}\right]$ palmitic acid were obtained from GE Healthcare (Little Chalfont, UK). Laminin and insulin were purchased from Sigma (Saint Louis, USA). Bovine serum albumin (BSA) (fraction V), dependent on the application, was derived from MP Biomedicals (Irvine, USA) (for cardiomyocyte isolation and incubation purposes), or from Sigma (other purposes). Collagenase type II was from Worthington (Freehold, USA). SSO was synthesized in our laboratory [28], EP80317 was from Bio-Connect (special production by Peptides International, Kentucky, USA). Hexarelin was a gift from Prof. Dr. Heemskerk (CARIM, Maastricht, NL). The anti-CD36 monoclonal antibody (mAb) clone 63 (anti-CD36-cl63; also known as clone CRF D2717) was from BD Biosciences (Franklin Lakes, NJ, USA), and kindly provided by Bioceros BV, (Utrecht, NL). The anti-CD36 mAb clone 10E10 (anti-CD36-cl10E10) was produced by Bioceros BV. 


\section{Experimental animals}

Male Lewis rats, 200-250 gram, were purchased from Charles River laboratories and used for cardiomyocyte isolation. All animals were fed ad libitum and kept under normal $12 \mathrm{~h} / 12 \mathrm{~h}$ dark-light cycles. All procedures were approved by the Experimental Animal Committee of Maastricht University, NL.

\section{Cardiomyocyte isolation and culturing}

Cardiomyocyte isolations were performed as described previously [29] with the only difference being the sterile conditions that were taken into account for subsequent culturing. After isolation of cardiomyocytes, 200,000 cells/well were routinely seeded in laminin coated 6-well plates $(9.6 \mathrm{~cm} 2)$, unless otherwise specified. After $90 \mathrm{~min}$ adhesion in modified Krebs-Ringer medium [30] supplemented with $0.45 \%$ BSA, the adhesion medium was replaced with control medium (based on M199 supplemented with $5 \mathrm{mM}$ creatine monohydrate, $3.2 \mathrm{mM}$ carnitine hydrochloride, $3.1 \mathrm{mM}$ taurine, $100 \mathrm{U} / \mathrm{ml}$ penicillin and streptomycin, 20 $\mu \mathrm{M}$ palmitate (palmitate:BSA 0.3:1) HI medium (control medium supplemented with $100 \mathrm{nM}$ insulin) or HP medium (control medium with more palmitate; 200 $\mu \mathrm{M}$, palmitate:BSA 3:1). Cells were cultured for $48 \mathrm{~h}$ and in case of measurements of short-term insulin effects cardiomyocytes were washed with modified KrebsRinger supplemented with $0.45 \% \mathrm{BSA}$ and $1 \mathrm{mM} \mathrm{CaCl}_{2}$ (medium A) and left untreated for 30 minutes (explained in detail in Results section).

\section{Measurement of substrate uptake}

We measured uptake of 2-Deoxy-D-[1-3 H]glucose and $\left[{ }^{-14} \mathrm{C}\right]$ palmitic acid (in complex with BSA) into freshly isolated cardiomyocytes [30] as well as into cardiomyocytes in culture [13], as previously described. With respect to freshly isolated cardiomyocytes, cells were pre-incubated with anti-CD36-specific binding molecules (500 $\mu \mathrm{M}$ SSO, $100 \mu \mathrm{M}$ EP80317, $20 \mu \mathrm{M}$ hexarelin, $0.83 \mu \mathrm{g} / \mathrm{ml}$ anti-CD36cl63, $1.7 \mu \mathrm{g} / \mathrm{ml}$ anti-CD36-cl10E10) at $37^{\circ} \mathrm{C}$ while shaking for $20 \mathrm{~min}$, and subsequently incubated without/with oligomycin $(5 \mu \mathrm{M})$ for an additional $20 \mathrm{~min}$. Then, a mixture of 2-Deoxy-D-[1-3 H]glucose and [1-14C]palmitic acid was added the last $5 \mathrm{~min}$ of incubation and radioactivity was measured in scintillation fluid (Opti-Fluor) Perkin Elmer, Waltham, USA.

With respect to two days-cultured cardiomyocytes, a mixture of 2-Deoxy-D$\left[1-{ }^{3} \mathrm{H}\right]$ glucose and $\left[1-{ }^{14} \mathrm{C}\right]$ palmitic acid was added for $10 \mathrm{~min}$ directly following a $15 \mathrm{~min}$ incubation period with/without insulin $(100 \mathrm{nM})$. Then, cells were washed with Stop medium (modified Krebs Ringer buffer, $1 \mathrm{mM} \mathrm{CaCl}, 0.2 \mathrm{mM}$ phloretin) on ice, lysed in sample buffer (40\% glycerol, $0.25 \mathrm{M}$ Tris, $1 \mathrm{M}$ DTT) and radioactivity was measured in scintillation fluid (Opti-Fluor, Perkin Elmer, Waltham, USA). 


\section{Detection of phosphorylation of enzymes within the insulin signaling network}

Following a 15 min treatment with/without insulin (100 nM), cells were lysed in sample buffer (40\% glycerol, $0.25 \mathrm{M}$ Tris, $1 \mathrm{M}$ DTT, bromo-phenol-blue) and used for protein detection by SDS-polyacrylamide gel electrophoresis $(20 \mu \mathrm{g}$ protein per lane), followed by Western blotting, as previously described [31]. Antibodies against phospho-Ser473-Akt, Akt, phospho-Ser9-GSK3 $\beta$ and GSK3 $\beta$ were purchased from Cell Signalling Technologies (Danvers, MA), phospho-Thr642AS160 from Upstate (Millipore) (Billerica, MA), CD36 from GenTex Inc. (San Antonio, TX, USA), GLUT4 and GAPDH from Abcam (Cambridge, USA) and caveolin3 from BD Transduction laboratories (Franklin Lakes, USA). The anti-CD36 monoclonal antibody MO25 was a gift from Dr. N.N. Tandon, Thrombosis Research Laboratory, Otsuka Maryland Medicinal Laboratories Rockville, Maryland., and was used only for Western blotting. Western blot images were analyzed with a Molecular Imager (ChemiDoc XRS, BioRad) and quantified with Quantity One® (BioRad).

\section{Measurement of sarcomere shortening and $\mathrm{Ca}^{2+-}$ fluxes}

For measurement of sarcomere shortening and $\mathrm{Ca}^{2+}$-fluxes, cells were cultured on $35 \mathrm{~mm}$ high dishes with elastic surface from Ibidi GmBH (München,Germany). After two days of culturing, cells were preloaded with Fura-2 AM (Merck chemicals (Darmstadt, Germany) for 25 min at room temperature, washed twice with control medium 199 and then incubated for $20 \mathrm{~min}$ with medium 199. Subsequently, contractile function and $\mathrm{Ca}^{2+}$-transients were analyzed in cells showing an intact rod-shaped morphology and sarcomere length $>1.6 \mu \mathrm{m}$ as described previously [32]. Before measurement was started, cells were electrically pre-stimulated for 5 min with $1 \mathrm{~Hz}$ to reach a steady-state level for sarcomere shortening and Fura-2 fluorescence. Then, cells were paced with bipolar pulses of $5 \mathrm{~ms}$ duration at $1 \mathrm{~Hz}$. The cytosolic $\mathrm{Ca}^{2+}$ concentration was monitored as a ratio of the fluorescence emission peaks at 340 and $380 \mathrm{~nm}$. In each experimental condition, data files were recorded of 10 consecutive beats for at least eight different cells. Sarcomere shortening and $\mathrm{Ca}^{2+}$-transients were measured with a fluorescence system from IonOptix (Dublin, Ireland) and calculated using IonWizard (IonOptix).

\section{Myocellular triacylglycerol and diacylglycerol contents}

For measurement of intramyocellular lipid content, cardiomyocytes were cultured in $55 \mathrm{~cm}^{2}$ glass petridishes with $1 \times 10^{6}$ cell density. Intramyocellular lipids were determined after 2 days of culturing as described previously [33]. In short, samples containing $400 \mu \mathrm{g}$ of protein were used for intracellular lipid extraction in methanol/chloroform, and an internal standard and water were added. Afterwards thin-layer chromatography was used to separate lipids. Bands were resolved with a hexane/diethylether/propanol (87:10:3) resolving solution. Triacylglycerol and diacylglycerol bands were detected with a Molecular Imager (ChemiDoc XRS, BioRad) and analyzed with Quantity One® (BioRad). 


\section{Sarcolemmal presence of CD36}

Following a 15 min treatment with/without insulin $(100 \mathrm{nM})$, cells were incubated for $10 \mathrm{~min}$ with $2 \mu \mathrm{g} / \mathrm{ml}$ anti-CD36-cl63, which is known to cross-react with rat CD36, and FITC labeled rabbit-anti-mouse IgA secondary antibodies (1:500; Rockland, USA). Cardiomyocytes were washed with adhesion medium and then the viable cardiomyocytes were imaged using the Leica SP5 imaging platform in twophoton mode (Leica Microsystems, Wetzlar, Germany) with the emission filters optimized for FITC-detection. Images were processed with ImageJ. Cardiomyocytes were kept at $37^{\circ} \mathrm{C}$ during incubation and imaging.

\section{$\underline{\text { Statistics }}$}

Differences among the data obtained from five to eight experiments are presented as means \pm S.E.M. Statistical difference between groups of observations was evaluated by unpaired Student's t-test, one-Way ANOVA or 2-Way ANOVA, depending on the groups compared. $\mathrm{P}$ values equal to or less than 0.05 are considered as significant.

\section{Results}

Anti-CD36 mAb clone 63 (anti-CD36-cl63) treatment inhibits LCFA uptake in freshly isolated cardiomyocytes

Our first aim was to select a CD36 ligand that would inhibit LCFA uptake into cardiomyocyte cultures. Therefore we tested the ability of hexarelin $(100 \mu \mathrm{m})$, EP80317 $(20 \mu \mathrm{m})$ and two distinct anti-CD36 antibodies, i.e., anti-CD36-cl63 (0.83 $\mu \mathrm{g} / \mathrm{ml})$ and anti-CD36-cl10E10 $(1.7 \mu \mathrm{g} / \mathrm{ml})$, to block short-term LCFA uptake into cardiomyocytes under basal conditions to find out that only the anti-CD36-cl63 was effective (Fig. 1A). In addition, the specific CD36 inhibitor SSO modestly inhibited basal LCFA uptake, as described previously [23]. Expectedly, the putative LCFA uptake-blocking effects of the selected CD36 ligands can be best appreciated under conditions in which CD36 has a large contribution to the LCFA uptake rate in cardiomyocytes. Therefore, we also tested the ability of these CD36 ligands to inhibit LCFA uptake into cardiomyocytes treated with the F1F0-ATPase inhibitor oligomycin, because oligomycin treatment is known to enhance the contribution of CD36 to total LCFA uptake into rat cardiomyocytes from about $50 \%$ to $>80 \%$ [28]. In concordance with the effects under basal condition, only SSO and anti-CD36cl63 significantly inhibited LCFA uptake under oligomycin stimulation (Fig. 1A).

We then tested lower and higher concentrations of the used CD36 ligands on LCFA uptake in cardiomyocytes. In case of EP80317 and hexarelin, higher concentrations impaired cell viability (data not shown). In case of anti-CD36cl10E10 (data not shown) and anti-CD36-cl63 (Fig. 1B), no further inhibitory effect was observed at higher concentrations, whereas lower anti-CD36-cl63 concentrations did not significantly inhibit LCFA uptake. In contrast to LCFA uptake, both SSO and anti-CD36-cl63 did not inhibit basal or oligomycinstimulated glucose uptake (Figs. $1 \mathrm{~A}$ and $\mathrm{B}$ ), thereby providing evidence that their inhibitory effects on cardiac substrate uptake are selective for LCFA uptake. 
Because SSO is unsuited as a long-term blocker of LCFA uptake [24], we selected anti-CD36-cl63 $(0.83 \mu \mathrm{g} / \mathrm{ml})$ to chronically inhibit palmitate uptake into primary cardiomyocyte cultures.

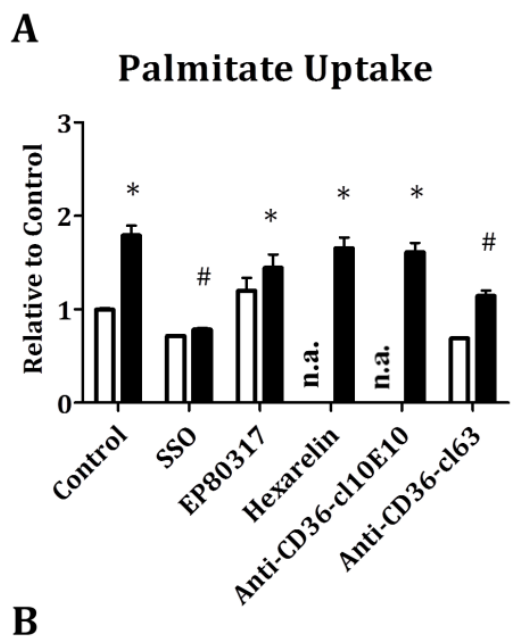

Palmitate Uptake

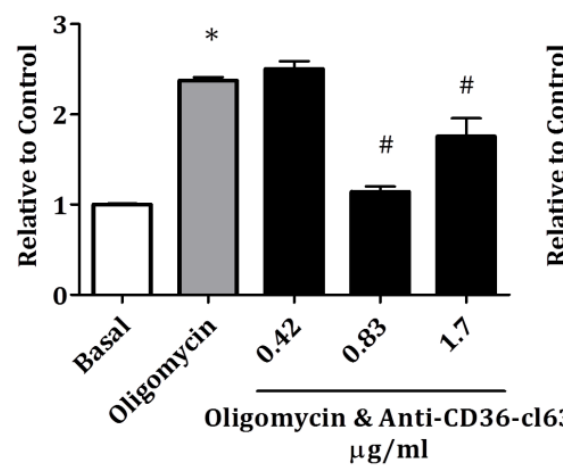

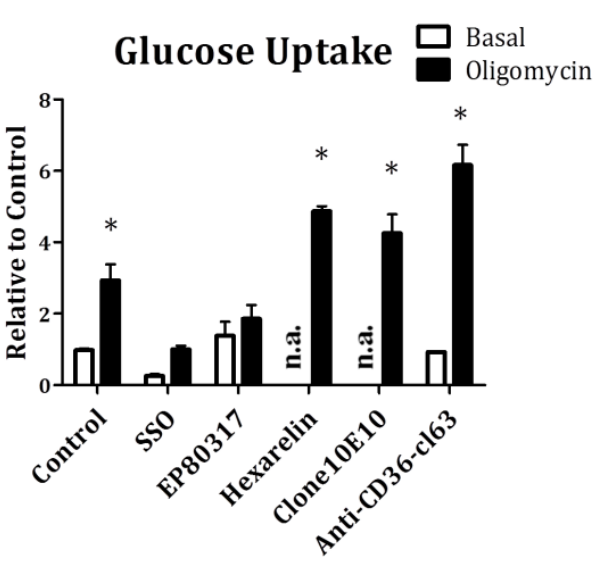

Glucose Uptake

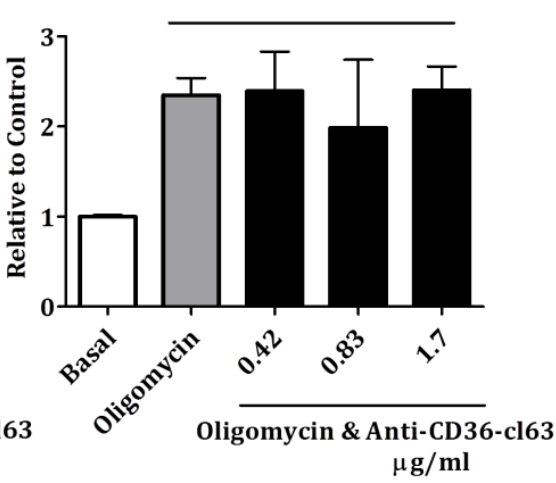

Fig. 1 Effects of selected CD36 ligands on basal and oligomycin-stimulated glucose and LCFA uptake into cardiomyocytes. (A) Cardiomyocytes were pre-incubated with CD36 ligands for $20 \mathrm{~min}$. (blank, $0.5 \mathrm{mM}$ SSO, $100 \mu \mathrm{M}$ EP80317, 20 $\mu \mathrm{M}$ hexarelin, $0.83 \mu \mathrm{g} / \mathrm{ml}$ anti-CD36-cl63 and $1.7 \mu \mathrm{g} / \mathrm{ml}$ antiCD36-cl10E10). Next, oligomycin $(5 \mu \mathrm{M})$ was added for $20 \mathrm{~min}$, followed by (5 min) measurement of uptake of [3H]glucose and [14C]palmitate $(n=5)$. (B) Cardiomyocytes were incubated for 20 min with different concentrations of anti-CD36-cl63 prior to oligomycin stimulation and measurement of substrate uptake $(\mathrm{n}=3)$. Values are displayed as mean +/- S.E.M. n.a.: not analysed; * vs. basal; \# vs. oligomycin $(\mathrm{p}<0.05)$

\section{Short-term insulin effect on substrate disappears after 30 minutes}

To assay insulin-stimulated glucose and LCFA uptake, we treated cardiomyocytes with insulin for 15 min prior to substrate uptake measurements. However, in case of culturing cardiomyocytes in HI medium for two days, chronic and short-term insulin effects might be present at the same time. To fully appreciate the chronic 
effects of insulin on Akt phosphorylation and substrate uptake, short-term effect of insulin must have completely faded out. Therefore, we determined the disappearance time of short-term insulin effects on glucose and, for comparison, on LCFA uptake into basally cultured cardiomyocytes. Cardiomyocytes were stimulated with insulin (100 $\mathrm{nM})$ for $15 \mathrm{~min}$ and directly assayed for substrate uptake or, the stimulus medium containing insulin was washed away and substrate uptake was measured at several time-points (Fig. 2). Firstly, insulin significantly increased both glucose and palmitate uptake rates (Fig. 2). Secondly, glucose uptake returned to basal level after $15 \mathrm{~min}$ and palmitate uptake returned to basal level after $30 \mathrm{~min}$. Therefore, in the following experiments cells were washed after 48 hours of culturing. Then, control medium was added to all wells, and we waited for 30 min before starting insulin-sensitivity measurements.

Palmitate Uptake

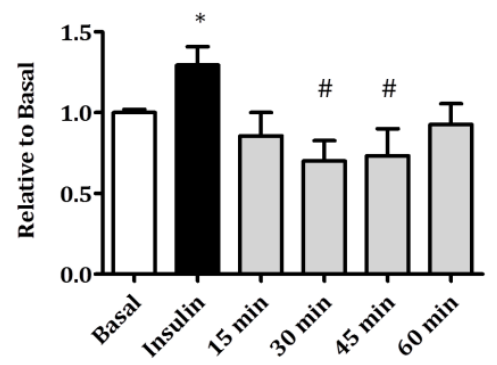

Glucose Uptake

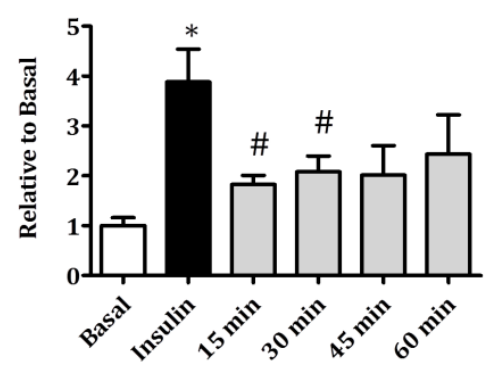

Fig. 2 Disappearance of acute insulin effects on glucose and palmitate uptake into cardiomyocytes. $90 \mathrm{~min}$ after seeding, cardiomyocytes were stimulated with insulin for 15 minutes, and uptake of 2-Deoxy-D-[1-3 H]glucose and [1-14C]palmitic acid was measured directly hereafter, or at indicated time points after insulin removal. Values are displayed as mean +/- S.E.M (n=5). * vs. basal, \# vs. insulin $(\mathrm{p}<0.05)$

Establishment of lipid loaded and insulin resistant cardiomyocytes with decreased contractile activity

Cardiomyocytes were exposed to HI or HP containing medium to induce myocellular insulin resistance. One of the initial steps in acquisition of myocellular insulin resistance is the permanent relocation of CD36 to the sarcolemma [34]. Sarcolemmal CD36 presence was measured in viable cells by two-photon microscopy. First, it was confirmed that this method could be successfully applied in our experimental setting, because short-term $(15 \mathrm{~min})$ insulin treatment of basally cultured cardiomyocytes promoted the well-recognized increase in CD36 presence at the sarcolemma (Fig. 3A), which is due to translocation from intracellular stores [34]. Additionally, HI and HP media enhanced sarcolemmal CD36 presence (Fig. 3B). However, total (i.e., sum of intracellular and sarcolemmal) CD36 protein expression was not altered after culturing of cardiomyocytes in HI or HP media (Fig. 3C), implicating that upon either of the insulin resistance-inducing conditions CD36 is permanently relocated from intracellular stores to the sarcolemma. Additionally, both insulin resistanceinducing media did not alter myocellular GLUT4 expression (Fig. 3C). 
A

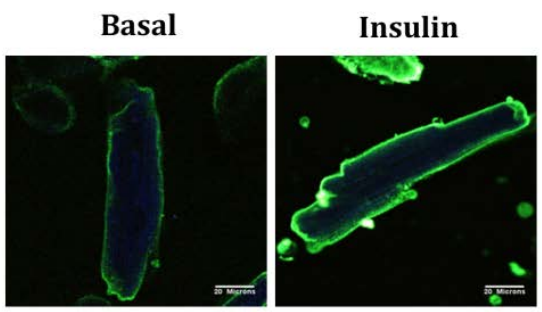

B

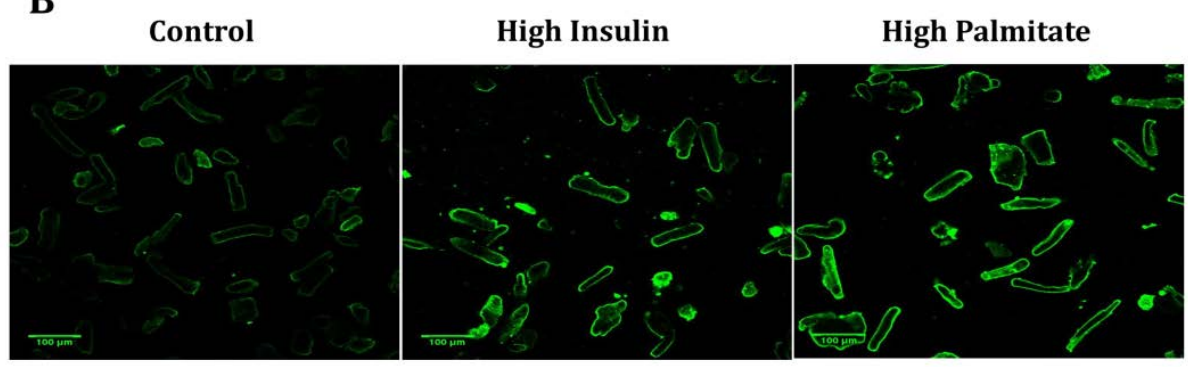

C

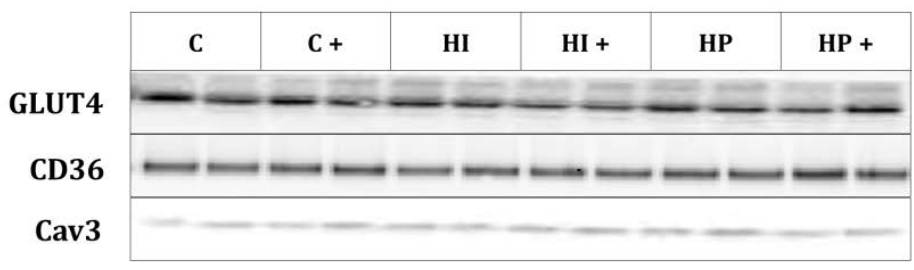

Fig. 3 Effects of culturing under insulin resistance-inducing conditions on cell surface content and total expression levels of CD36 in cardiomyocytes. (A) For verification of the suitability of 2 photon microscopy to visualize changes in cell surface localization of CD36, cells were short-term (15 min) treated with $100 \mathrm{nM}$ insulin to positively confirm the well-described insulin-induced CD36 translocation event. CD36 was detected upon FITC labeling. Representative images are shown $(n=3)$. (B) Cardiomyocytes were cultured in control medium, or in media containing high insulin or high palmitate concentrations for 48 hours, and then used for microscopic detection of CD36. $n=3$. (C) Protein expression of GLUT4 and CD36, and caveolin3 (Cav3; loading control) was measured in cell lysates from cardiomyocytes cultured in control medium (C), high insulin (HI) or high palmitate (HP) media without or with (C+, HI+. HP+) $0.83 \mu \mathrm{g} / \mathrm{ml}$ anti-CD36-cl63. Representative blots are shown (n=3)

Basally cultured cardiomyocytes displayed a 3.8-fold increase in glucose uptake and a 1.5 -fold increase in palmitate uptake upon insulin treatment. Cardiomyocytes cultured in either HI or HP medium showed no change in basal glucose uptake (Fig. 4). In contrast, these cardiomyocytes exhibited elevated basal LCFA uptake (amounting to 1.4-fold and 1.6-fold, respectively) compared to basally cultured cells. In addition, cardiomyocytes cultured in either HI or HP media displayed a loss of insulin-stimulated glucose and LCFA uptake (Fig. 4).

For evaluation of insulin signaling, phosphorylation of Akt and its two direct substrates AS160 and GSK3 $\beta$ were assessed. In basally cultured cardiomyocytes, short-term insulin addition increased Akt-Ser473 phosphorylation, AS160 phosphorylation and GSK3 $\beta$-Ser9 phosphorylation by 4.4- 


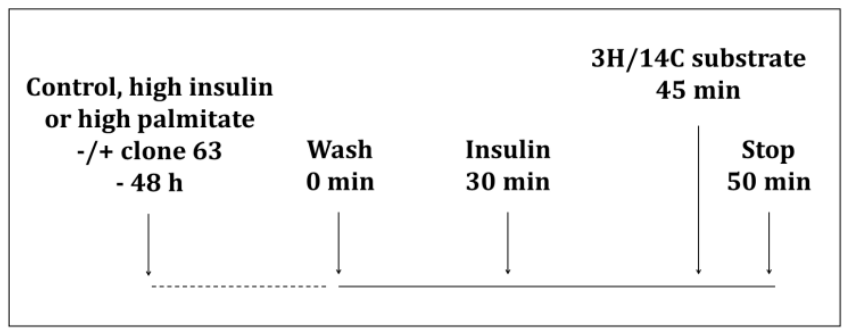

Glucose Uptake

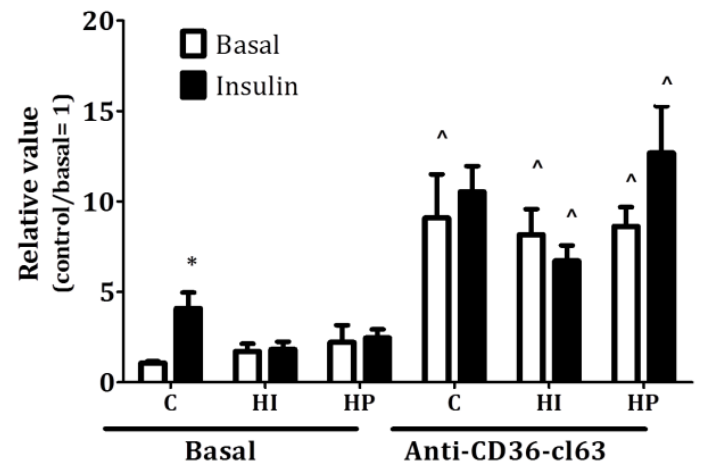

Palmitate Uptake

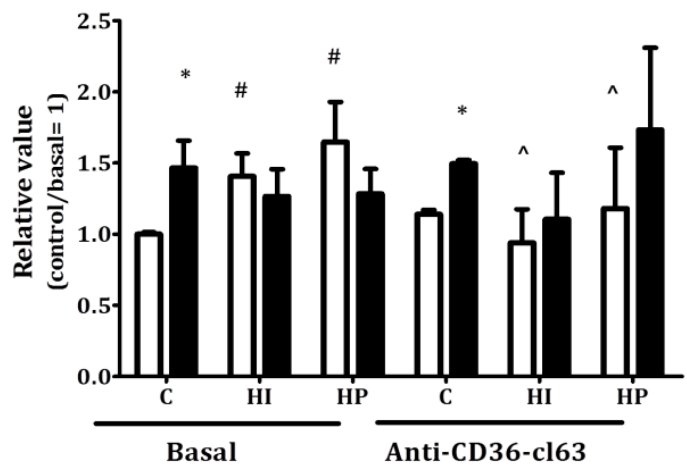

Fig. 4 Effect of antiCD36-cl63 on substrate uptake into cardiomyocytes cultured under insulin resistance -inducing conditions. Cardiomyocytes were cultured in control medium (C), or in media containing high insulin (HI) or high palmitate (HP) concentrations in the absence or presence of $0.83 \mu \mathrm{g} / \mathrm{ml}$ anti-CD36cl63. Upon 2 days culturing, cells were allowed to recover for 30 min prior to short-term (15 min) insulin (100 nM) addition and subsequent measurement of uptake of [3H] glucose and [14C] palmitate. Values are displayed as mean +/S.E.M $\quad(n=5) . \quad * \quad$ insulin effect, \# medium effect, $\wedge$ anti-CD36 effect $(p<0.05)$

fold, 3.8-fold and 2.5-fold, respectively (Fig. 5B). Insulin-stimulated signaling was completely lost in cardiomyocytes cultured in HI medium, and largely reduced in cardiomyocytes cultured in HP medium. In this latter instance, only a residual 3.1fold insulin-stimulation of Akt-Ser473 phosphorylation was observed, while induction of GSK3 $\beta$ and AS160 was completely abrogated (Fig. 5B). These decreases in insulin signaling were not accompanied by changes in total expression of Akt nor of downstream substrates (supplemental Fig. 1).

With respect to myocellular lipid accumulation, cardiomyocytes cultured in HI or HP medium displayed increased triacylglycerol content (1.6-fold, and 2.3- 
A

\begin{tabular}{|c|c|c|c|c|c|c|c|c|c|c|c|}
\hline \multicolumn{4}{|c|}{ Control } & \multicolumn{4}{|c|}{ High Insulin } & \multicolumn{4}{|c|}{ High Palmitate } \\
\hline \multicolumn{2}{|c|}{ - } & \multicolumn{2}{|c|}{$\begin{array}{c}\text { Anti-CD36- } \\
\text { cl63 }\end{array}$} & \multicolumn{2}{|c|}{ - } & \multicolumn{2}{|c|}{$\begin{array}{l}\text { Anti-CD36- } \\
\text { cl63 }\end{array}$} & \multicolumn{2}{|c|}{ - } & \multicolumn{2}{|c|}{$\begin{array}{l}\text { Anti-CD36- } \\
\text { cl63 }\end{array}$} \\
\hline C & Ins & C & Ins & $\mathrm{C}$ & Ins & C & Ins & C & Ins & C & Ins \\
\hline- & & -1 & & & & & & & & & -- \\
\hline
\end{tabular}

pAS160

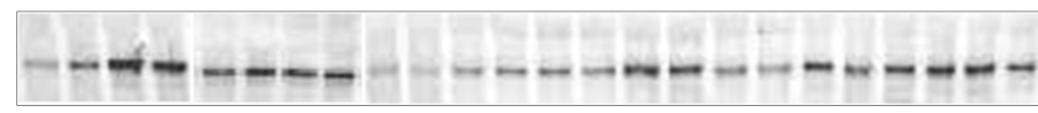

pGSK3B

cav3
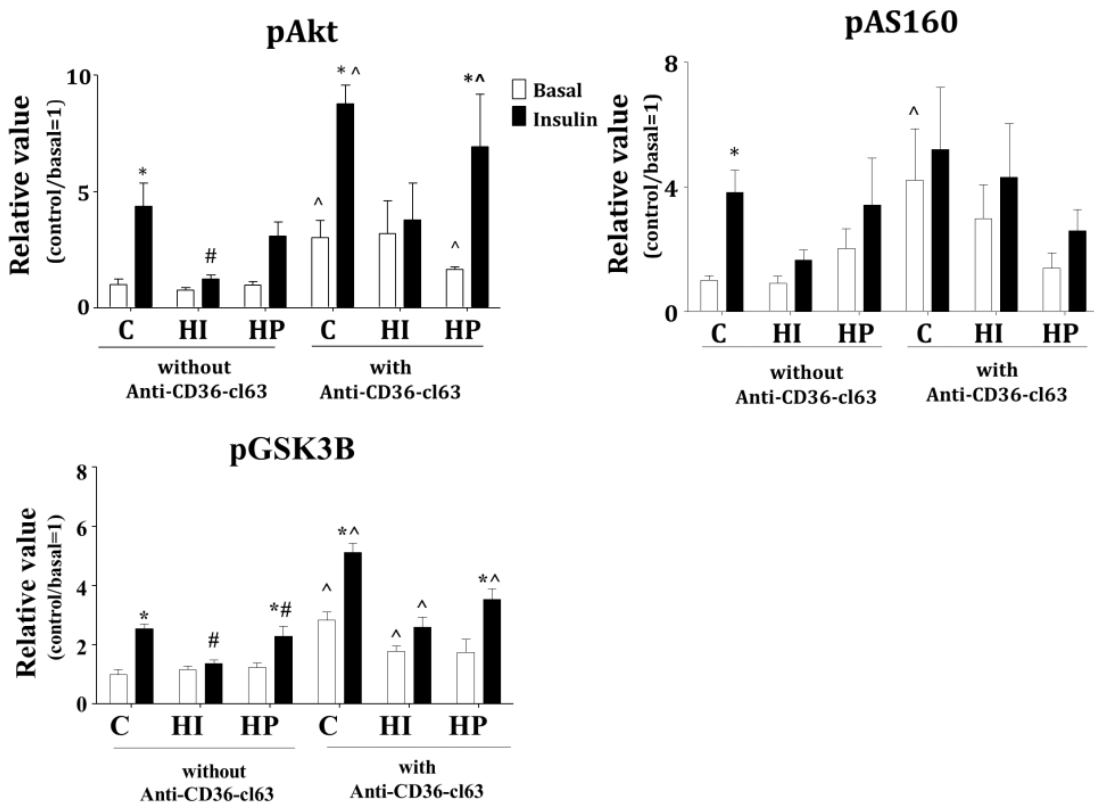

Fig. 5 Effect of anti-CD36-cl63 on insulin signaling in cardiomyocytes cultured under insulin resistance-inducing conditions. Cardiomyocytes were cultured in control medium (C), or in media containing high insulin (HI) or high palmitate (HP) concentrations in the absence or presence of 0.83 $\mu \mathrm{g} / \mathrm{ml}$ anti-CD36-cl63. Upon 2 days culturing, cells were allowed to recover for 30 min prior to shortterm (15 min) insulin (100 $\mathrm{nM}$ ) addition and subsequent Western blotting of phosphorylation of Akt (pAkt), AS160 (pAS160) and GSK3 $\beta$ (pGSK3 $\beta$ ). Representative blots are shown in (A) Quantification of the signals is shown in (B) Values are displayed as mean +/- S.E.M $(n=5) . *$ insulin effect, \# medium effect, ^ anti-CD36 effect $(\mathrm{p}<0.05)$ 
fold, respectively) compared to basally cultured cardiomyocytes (Fig. 6), but we did not observe changes in diacylglycerol stores (Fig. 6).

To investigate whether exposure to HI or HP media leads to physiological dysfunction of cardiomyocytes, we analyzed the kinetics and amplitude of the contraction, shortening and re-lengthening rates, as well as peak sarcomere shortening. Compared to basally cultured cardiomyocytes, peak sarcomere shortening decreased by $38 \%$ and $62 \%$ during culturing in HI and HP media, respectively (Fig. 7A). Departure velocity and return velocity of contraction were also reduced by culturing in HI and HP media (departure velocity: $-45 \%$ and $62 \%$, respectively, return velocity: $-65 \%$ and $-70 \%$, respectively). Intracellular $\mathrm{Ca}^{2+}$ fluxes (velocity of $\mathrm{Ca}^{2+}$ increases and decreases, and peak Fura-2 fluorescence signal) were unchanged in cardiomyocytes cultured in either medium (Fig. 7B).

Thus, cardiomyocytes cultured in HI or HP media displayed elevations in sarcolemmal CD36 presence, basal LCFA uptake and myocellular triacylglycerol content. In addition, cardiomyocytes cultured in either medium showed loss of insulin-stimulated substrate uptake, insulin signaling and sarcomere shortening, and hence, displayed hallmark features of lipid-induced insulin resistance and contractile dysfunction.

\section{Effects of anti-CD36-cl63 treatment on prevention of lipid accumulation and} development of insulin resistance

Anti-CD36-cl63 was used to evaluate the effects of a blockade of CD36-mediated LCFA uptake on prevention of the development of insulin resistance and contractile dysfunction in cardiomyocytes cultured in HI or HP media. Anti-CD36cl63 was added at the start of the 2 days culturing of cardiomyocytes under basal or insulin resistance-inducing conditions, and was removed by washing the cardiomyocytes prior to the measurements of short-term glucose and palmitate uptake. The lack of an effect of anti-CD36-cl63 on basal and insulin-stimulated palmitate uptake into basally cultured cardiomyocytes (Fig. 4) indicates that this antibody has effectively been washed away (as shown with two-photon microscopy, see supplemental Fig. 2), and suggests that there has been no compensatory upregulation of CD36 (in agreement with Fig. 1C) or of other LCFA transporters. Furthermore, treatment with anti-CD36-cl36 increased basal glucose uptake into cardiomyocytes by 4.0 to 8.0 -fold under all three culturing conditions, and short-term insulin treatment did not further stimulate glucose uptake (Fig. 4). Notably, treatment with anti-CD36-cl63 prevented the increase in basal LCFA uptake in cardiomyocytes cultured in HI or HP media. On the other hand, insulinstimulated LCFA uptake was not restored by treatment with anti-CD36-cl63.

When investigating insulin-signaling we observed that treatment with antiCD36-cl63 increased basal Akt-Ser473 phosphorylation in all three culturing conditions (C: 3.0-fold; HI: 3.2-fold; HP: 1.7-fold) (Fig. 5A-B). Treatment with antiCD36-cl63 did not alter insulin-stimulated Akt phosphorylation in basally cultured cardiomyocytes, and did not prevent loss of insulin-stimulated Akt phosphorylation in cardiomyocytes cultured in HI medium. However, treatment 
with anti-CD36-cl63 was successful in preventing loss of insulin-stimulated Akt phosphorylation in cardiomyocytes cultured in HP medium. Overall, changes in Akt-Ser473 phosphorylation were largely reflected by changes in GSK3 $\beta$-Ser9 phosphorylation, and to a lesser extent by changes in AS160 phosphorylation.

With respect to intramyocellular lipid accumulation, treatment with antiCD36-cl63 robustly reduced triacylglycerol content in cardiomyocytes cultured in control medium, and completely prevented the increase in triacylglycerol storage upon culturing in HI or HP media (Fig. 6). There was no effect of treatment with anti-CD36-cl63 on myocellular diacylglycerol content (Fig. 6).

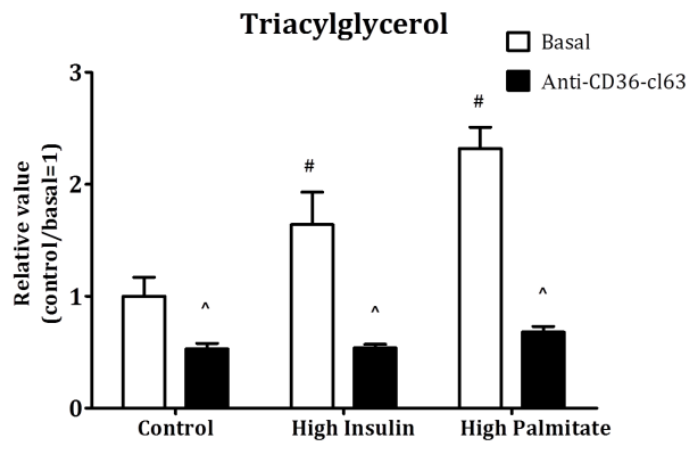

Diacylglycerol

Fig. 6 Effect of anti-CD36-cl63 on lipid accumulation in cardiomyocytes cultured under insulin resistanceinducing conditions. Cardiomyocytes were cultured in control medium (C) or in media containing high insulin (HI) or high palmitate (HP) concentrations in the absence or presence of $0.83 \mu \mathrm{g} / \mathrm{ml}$ antiCD36-cl63. After 2 days culturing, cardiomyocytes were lysed, and used for measurement of triacylglycerol and diacylglycerol content via HPTLC. Values are displayed as mean +/- S.E.M $(\mathrm{n}=5)$. \# medium effect, $\wedge$ anti-CD36 effect $(\mathrm{p}<0.05)$

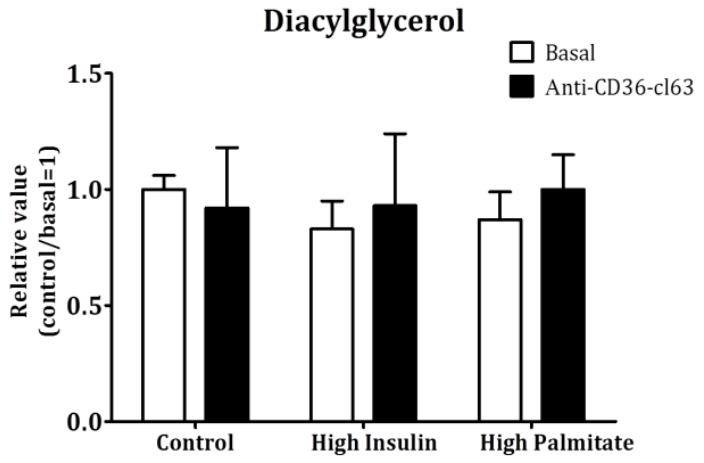

With respect to parameters of contractile function, treatment with the antiCD36-cl63 had no effect on sarcomere shortening or intracellular Ca2+ oscillations in basally cultured cardiomyocytes. Treatment of primary cardiomyocytes with anti-CD36-cl63 totally or largely prevented the decrease in peak sarcomere shortening in HI or HP cultured cardiomyocytes, respectively (Fig 7). Additionally, shortening and relengthening rates were partially retained upon treatment of $\mathrm{HI}-$ cultured cardiomyocytes with anti-CD36-cl63. In contrast, intracellular $\mathrm{Ca}^{2+}$ oscillations were not altered by treatment anti-CD36-cl63 (Fig. 7). 
A

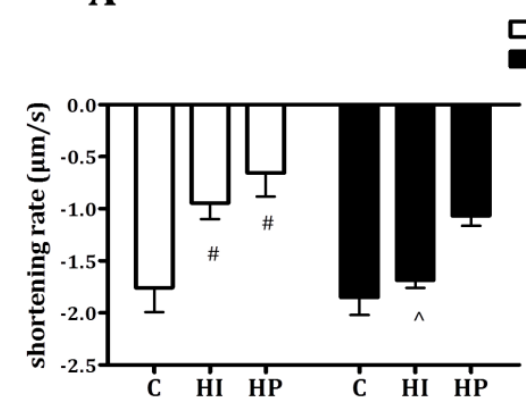

Basal

Anti-CD36-cl63
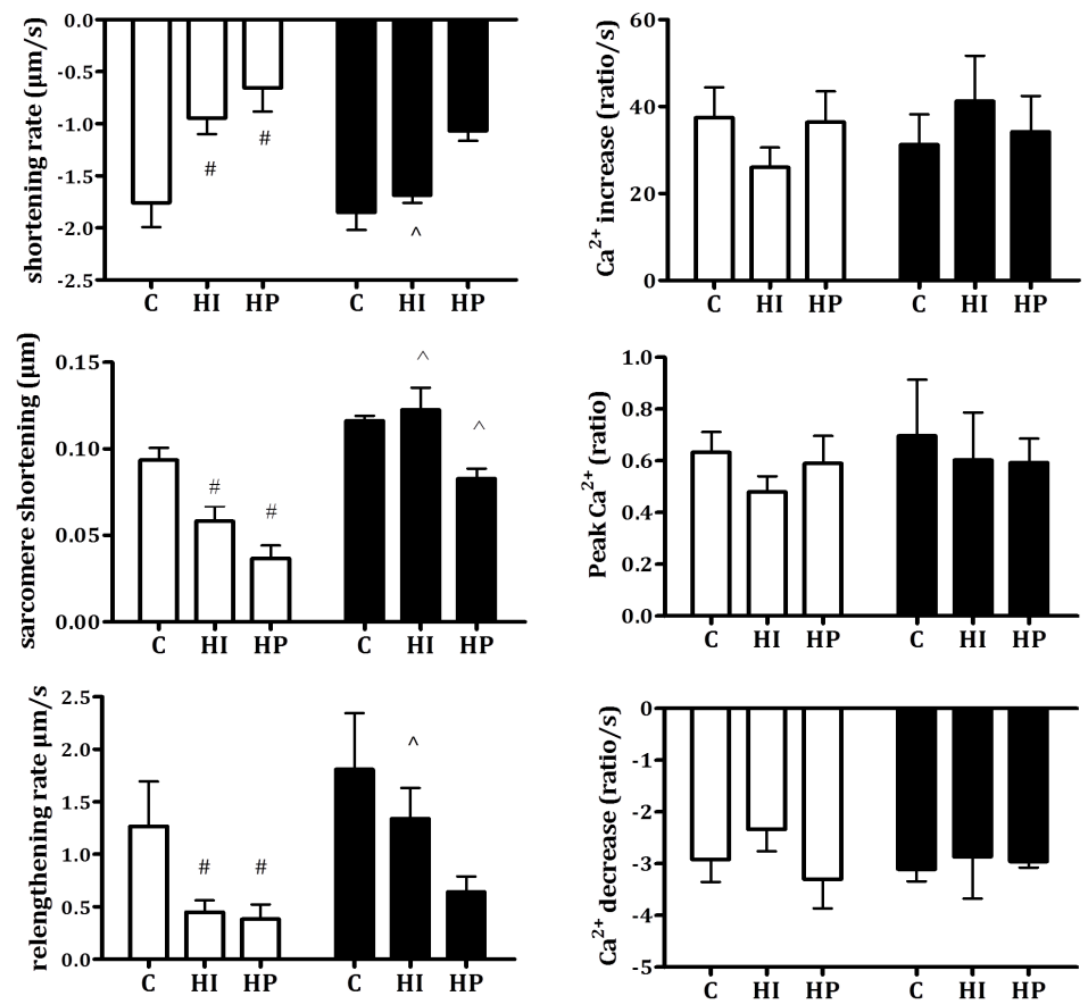

Fig. 7 Effect of anti-CD36-cl63 on contractile functions of cardiomyocytes cultured under insulin resistance-inducing conditions. Cardiomyocytes were cultured in control medium (C) or in media containing high insulin (HI) or high palmitate (HP) concentrations in the absence or presence of 0.83 $\mu \mathrm{g} / \mathrm{ml}$ anti-CD36-cl63. After 2 days culturing, cardiomyocytes were used for analysis of parameters; (A) sarcomere shortening and (B) $\mathrm{Ca}^{2+}$-fluxes The following parameters are displayed: (A) departure velocity of contraction; peak sarcomere shortening; return velocity of contraction; (B) velocity of cytosolic $\mathrm{Ca} 2+$ increases, peak Fura-2 fluorescence signal, and velocity of cytosolic $\mathrm{Ca}^{2+}$ decreases. Values are displayed as mean +/- S.E.M of at least 10 independent experiments. \# medium effect, ${ }^{\wedge}$ antiCD36 effect $(\mathrm{p}<0.05)$

We also tested the effects of anti-CD36-cl10E10, which detects CD36 on Western blot (supplemental Fig. 3) but which failed to block short-term LCFA uptake (Fig. 1A), on glucose uptake and contractile function in cardiomyocytes cultured in basal, HI and HP media. In contrast to anti-CD36-cl63, anti-CD36cl10E10 did not increase basal glucose uptake under all three culturing conditions or restore peak sarcomere shortening in HI-cultured cardiomyocytes (supplemental Fig. 3). Hence, the beneficial effects of anti-CD36-cl63 cardiomyocytes exposed to lipotoxic conditions are likely not due to simply binding to CD36, but rather due to a blockade of the transport function of CD36. 
In summary, treatment of cardiomyocytes cultured in HI or HP medium with anti-CD36-cl63 prevented lipid accumulation and lipid-induced contractile dysfunction. However, treatment with anti-CD36-cl63 only protected insulin signaling in cardiomyocytes cultured in HP medium, and not when cultured in HI medium.

\section{Discussion}

Here we described the preventive action of a pharmacological blockade of LCFA uptake in the development of insulin resistance and contractile dysfunction in cardiomyocytes. Although there are many studies reporting on the ability of lipids to decrease insulin signaling and to alter substrate utilization in cellular systems including cardiomyocytes, none of these studies have proposed to restore the maladaptive changes by blocking protein-mediated cellular LCFA uptake. In the present study, we investigated the suitability of CD36 as a target to restore insulin sensitivity and contractile parameters in cultures of cardiomyocytes exposed to insulin resistance-inducing conditions. Firstly, a variety of structurally unrelated compounds reported to inhibit CD36 function, were screened for their ability to inhibit LCFA uptake into primary cardiomyocytes. Secondly, we established that cardiomyocytes cultured in HI or HP containing medium displayed key features of lipid-induced insulin resistance [34]. Finally, we demonstrated that inhibition of CD36-mediated LCFA uptake was able to prevent lipid accumulation and contractile dysfunction in cardiomyocytes cultured under insulin resistanceinducing conditions.

Anti-CD36 mAb clone 63 (anti-CD36-cl63) potently inhibits LCFA uptake into primary cardiomyocytes

Sulfo-N-succinimydyl oleate (SSO) is the most widely established inhibitor of CD36-mediated LCFA uptake, but its use in long-term incubations is not feasible because of its relatively short half-life in aqueous solutions [24]. Nonetheless, the use of SSO in short-term LCFA uptake studies confirmed that maximally stimulated LCFA uptake in these primary cardiomyocytes is largely CD36-dependent. The CD36-specific thrombospondin-binding peptide inhibitors hexarelin and EP80317 did not affect LCFA uptake demonstrating that the thrombospondin-binding domain of CD36 is not involved in LCFA transport or does not overlap with the LCFA-binding pocket of CD36 [35, 36]. Hence, both peptides are likely to be unsuited for protection against myocellular lipid-overload. The use of CD36specific mAbs proved to be more promising in terms of blocking LCFA uptake. Specifically, anti-CD36 mAb (clone 63) treatment inhibited maximally stimulated LCFA uptake by $>30 \%$ (Fig. 1). However, frequently used anti-CD36 mAbs, like clone M025 and clone OKM5 [37], did not appear to affect LCFA uptake. Whereas SSO inhibited LCFA uptake by $>70 \%$ [38] in heart giant sarcolemmal vesicles, both these latter anti-CD36 mAbs were without effect on LCFA uptake in these vesicles (Luiken \& Bonen, 1999, unpublished results). Taken together, the anti-CD36 mAb clone 63 is a valuable in vitro tool to test whether CD36-mediated LCFA uptake would be a target for offering protection to lipid-overloaded cardiomyocytes against the development of insulin resistance and contractile dysfunction. 


\section{Development of a cardiomyocyte model for lipid-induced insulin resistance}

Long-term incubation of cell lines or primary cell cultures with saturated LCFA species has been shown to induce insulin resistance at the level of decreased insulin signaling and/or decreased insulin-stimulated glucose uptake [39-41]. However, long-term effects on LCFA transport, transporters and storage have not been investigated yet. Chronic insulin stimulation has also been used to induce insulin resistance in cardiomyocyte cultures [26], but again, LCFA transport and transporters were not measured. In the present study, chronic insulin treatment as well as chronic palmitate treatment of cardiomyocyte cultures enhanced the presence of CD36 at the sarcolemma in concordance with elevated basal LCFA uptake and triacylglycerol accumulation. Simultaneously, insulin-stimulated phosphorylation of proteins in the insulin signaling cascade and insulin-stimulated glucose and LCFA uptake were lost or markedly reduced in chronic insulin or palmitate treated cardiomyocytes. These results indicate that both chronic conditions induce key features of insulin resistance in this in vitro cardiomyocyte model. Yet, there are some subtle differences in insulin-treated and palmitatetreated cardiomyocytes concerning these features of insulin resistance: lipid accumulation in palmitate-treated cells is 2-fold greater than in insulin-treated cells, while inhibition of insulin signaling is less extensive in palmitate-treated cells, and inhibition of insulin-stimulated substrate uptake is almost identical in both insulin- and palmitate-treated cardiomyocytes. This demonstrates that there is no linear relationship between lipid accumulation, impairment of insulin signaling and of insulin-stimulated glucose uptake. Another striking feature of the $\mathrm{HI}$ and HP cultured cells is that the increase in myocellular triacylglycerol storage is not accompanied by increased diacylglycerol levels. This is different from the concomitant increases in myocellular diacylglycerol and triacylglycerol contents in rodents fed with high fat diets for several weeks (e.g., see ref. [13]). Likely this is related to the much shorter (i.e., $48 \mathrm{~h}$ ) exposure of the cells to lipotoxic conditions, in which time the diacylglycerol and triacylglycerol stores might not have reached full equilibrium yet. However, importantly, given that the cells are insulin resistant, it can be deduced that diacylglycerols do not contribute to the acquisition of insulin resistance in these cultured cardiomyocytes.

With respect to cardiomyocyte contractility, culturing of cardiomyocytes in HI or HP containing media impaired contractile amplitude. This is in agreement with recent findings that exposure of freshly isolated adult mouse cardiomyocytes to palmitate rapidly reduced unloaded fractional cell shortening [27], and in line with the currently accepted notion that insulin resistance is causal to contractile dysfunction [42]. There is more controversy about the association of insulin resistance with disturbance of $\mathrm{Ca}^{2+}$ dynamics. In our experiments $\mathrm{Ca}^{2+}$ oscillations were unchanged in cultured cells with HI and HP containing media. This is in agreement with the lack of changes in kinetics and amplitude of $\mathrm{Ca}^{2+}$ transients in cardiomyocytes from mice fed a high fat diet [43]. However, cardiomyocytes from insulin resistant sucrose-fed mice and ob/ob mice displayed decreased $\mathrm{Ca}^{2+}$ oscillations $[44,45]$. Nonetheless, sarcomere shortening is considered as a better marker of mechanical output for evaluating cardiomyocyte function [46]. Interestingly, the alterations in contractile function were proportional to the 
amount of myocellular triacylglycerol accumulation, because high palmitatecultured cardiomyocytes showed greater dysfunction and greater triacylglycerol accumulation than in high-insulin cultured cells. This supports the concept that myocellular accumulation of lipids is causal to contractile dysfunction.

In conclusion, both $\mathrm{HI}$ and $\mathrm{HP}$ containing media provide suitable culturing conditions for inducing insulin resistance and contractile dysfunction in cardiomyocytes via myocellular lipid overload.

\section{Inhibition of CD36-mediated LCFA uptake prevents reduction of insulin sensitivity} and contractile function in lipid-overloaded cardiomyocytes

The main purpose of this study was to prevent the development of lipid-induced insulin resistance and contractile dysfunction by inhibition of CD36-mediated LCFA uptake.

First, we investigated the metabolic effects of inhibition of CD36-mediated LCFA uptake in basally cultured insulin sensitive cardiomyocytes. Treatment of basally cultured cardiomyocytes with anti-CD36-cl63 enhanced basal glucose uptake, and insulin did not further stimulate glucose uptake suggesting that insulin-stimulated glucose uptake contributes to increased basal glucose uptake in CD36-inhibited cardiomyocytes. This increased basal glucose uptake occurred in the absence of changes in GLUT4 expression, suggesting that a relocation of GLUT4 from intracellular insulin-responsive stores to the sarcolemma might explain this increase in basal glucose uptake. Furthermore, the anti-CD36-cl63-induced increase in basal glucose uptake is likely due to a blockade of the transport function of CD36 rather than just binding to CD36. Namely, another anti-CD36 antibody, anti-CD36-cl10E10, unable to block the LCFA transport function, does not increase glucose uptake. This shows that merely binding to CD36 is not sufficient for a change in substrate switch towards glucose. Interestingly, the increase in basal glucose uptake was accompanied by an increase in phosphorylation of both Akt and its direct target AS160. Phosphorylation of AS160 will inhibits its rab-GTPase activity, so that GLUT4 translocation-mediating rab proteins will be re-activated. Subsequently, GLUT4 will be liberated from retention within the intracellular stores. Remarkably, insulin-stimulated Akt phosphorylation was retained in basally cultured cardiomyocytes treated with anti-CD36-cl63, which is in contrast to the loss of insulin-stimulated glucose uptake. Perhaps in these cardiomyocytes, GLUT4 is already completely depleted from the intracellular storage compartments, including the insulin-responsive stores, so that extra phosphorylation of Akt and of AS160 upon insulin addition would be futile in this respect. Another explanation could come from a recent study in which it was shown that Akt is not the rate-limiting step of insulininduced glucose uptake [47]. However, insulin-stimulated glucose uptake in these anti-CD36-cl63 treated cardiomyocytes was not further increased by additional stimulation of AMP-activated kinase (AMPK) signaling, whereas AMPK and insulin stimulation act synergistically in basally treated cardiomyocytes (supplemental Fig. 4). This observation provides further evidence for this notion of depletion of intracellular GLUT4 storage upon a chronic CD36 blockade. 
How anti-CD36-cl63 could trigger basal Akt phosphorylation in cardiomyocytes is a matter of speculation. Perhaps, a pharmacological blockade of CD36 transport function prevents accumulation of LCFA metabolites that would inhibit kinases upstream of Akt or Akt itself. For instance, ceramides are known to directly inhibit Akt [48], and preventing their accumulation would therefore increase basal Akt phosphorylation. This would also assume that ceramide pools would more rapidly follow the changes in influx in LCFA than the diacylglycerols. Further research is needed to elucidate the molecular mechanisms behind increased basal Akt phosphorylation in anti-CD36-cl63 treated cardiomyocytes.

Treatment of cardiomyocytes cultured under both insulin resistanceinducing conditions with the anti-CD36 mAb-cl63 enhanced basal Akt/GSK3 $\beta$ phosphorylation and basal glucose uptake similarly to basally cultured cardiomyocytes treated with the anti-CD36 mAb-cl63. More importantly, however, this treatment prevented myocellular lipid accumulation and loss of contractile function. Remarkably, treatment with the anti-CD36-cl63 prevented the loss of insulin stimulated Akt/GSK3 $\beta$ phosphorylation in cardiomyocytes cultured in HP medium but was not able to retain insulin signaling in cardiomyocytes cultured in HI medium. We have no explanation for these selective preventive effects of the anti-CD36 mAb-cl63 on insulin signaling and insulin-stimulated glucose uptake in one model of insulin resistant cardiomyocytes and not in the other. However, we may only conclude that the prevention of myocellular lipid accumulation can be connected to preservation of contractile function in the absence of preservation of insulin signaling. Possibly, the prevention of myocellular lipid accumulation might directly explain the anti-CD36 mAb-mediated preservation of contractile function. Namely, increased depositioning of lipid droplets in between the contractile fibers could directly inhibit contraction mechanics, which is then prevented by blocking CD36-mediated LCFA uptake. Alternatively, the prevention of myocellular lipid accumulation would prevent the activation of lipid-activated transcription factors that would otherwise induce an unfavourable switch in the expression pattern of isoforms of contractile proteins. However, we cannot exclude the possibility that the protective effects of the anti-CD36 mAb are not related to inhibition of LCFA uptake. For instance, binding of the anti-CD36 mAb-cl63 to CD36 might induce intracellular signaling (e.g., Akt activation) that would directly or indirectly preserve contractile function of cardiomyocytes. Nonetheless, the finding that the anti-CD36 mAb prevents the reduction in contractile function in cardiomyocytes cultured under both insulin resistance-inducing conditions provides powerful evidence that CD36 offers a suitable target to prevent the onset of cardiomyocyte dysfunction under these adverse conditions.

\section{Conclusions}

On top of the previous findings in CD36-knockout mice that CD36-mediated LCFA uptake plays a key role in the development of lipid-induced insulin resistance and cardiac dysfunction $[17,18]$, the present findings illustrate that a pharmacological blockade of CD36 is a treatment strategy to counteract lipid accumulation and to protect against loss of cardiac function. Specifically, the blockade of CD36mediated LCFA uptake caused a substrate switch towards glucose and prevented 
lipid accumulation and decreases in contractile function in two in vitro models of lipid-induced cardiac insulin resistance. Increased cardiac glucose uptake is known to be involved in the development of cardiomyocyte hypertrophy, suggesting that proper titration of anti-CD36 treatment is necessary to avoid a total shift of cardiomyocyte metabolism towards glucose utilization.

CD36 is known to have a number of different functions in different mammalian cell types. Therefore, a pharmacological CD36 inhibitor that would interfere with all these functions would be unfavourable. However, a hypothetical agent that would selectively block the sarcolemmal LCFA transport function of CD36 would not have these adverse side effects, and would therefore be optimally suited to improve cardiac lipid overload and contractile dysfunction in vivo. In this respect, it has been speculated that the LCFA binding pocket in the extracellular domain of CD36 is mainly not overlapping with the docking sites of thrombospondin and oxLDL [35]. Therefore, the LCFA binding pocket might be the subject of a novel drug design strategy to specifically block the CD36 transport function.

\section{Acknowledgements}

This work was supported by the Dutch Diabetes Research Foundation (Grant: 2006.00.044), the EU European Cooperation in the field of Scientific and Technical Research (COST) Action BM0602 (Adipose tissue: A key target for prevention of the metabolic syndrome), and CTMM, the Center for Translational Molecular Medicine, project PREDICCt (grant 01C-104), and supported by the Netherlands Heart Foundation, Dutch Diabetes Research Foundation, and Dutch Kidney Foundation.

Y.A. and L.K.M.S. designed and performed the experiments, analyzed the data and wrote the manuscript. P.J.S. and M.A.M.J.Z. reviewed manuscript. S.G., N.H., W.A.C and K.D. performed experiments. D.M.O., M.D. and J.F.C.G. edited the manuscript. J.J.F.P.L. designed the experiments and edited the manuscript. The authors would like to thank Lei Ding, Jurriaan Hodzelmans and Pascal Vroemen for their technical assistance. 


\section{References}

1. Rodrigues B, Cam MC, McNeill JH. Metabolic disturbances in diabetic cardiomyopathy. Mol Cell Biochem. 1998;180:53-7.

2. Stanley WC, Lopaschuk GD, McCormack JG. Regulation of energy substrate metabolism in the diabetic heart. Cardiovasc Res. 1997;34:25-33.

3. Carley AN, Severson DL. Fatty acid metabolism is enhanced in type 2 diabetic hearts. Biochim Biophys Acta. 2005;1734:112-26.

4. Menard SL, Croteau E, Sarrhini O, Gelinas R, Brassard P, Ouellet R, et al. Abnormal in vivo myocardial energy substrate uptake in diet-induced type 2 diabetic cardiomyopathy in rats. Am J Physiol Endocrinol Metab. 2010;298:E1049-57.

5. Tomita T, Wilson L, Chiga M. Idiopathic dilated cardiomyopathy--an evidence of abnormal lipid accumulation accumulation in myocardium. Am J Cardiovasc Pathol. 1990;3:81-5.

6. Chavez JA, Knotts TA, Wang LP, Li G, Dobrowsky RT, Florant GL, et al. A role for ceramide, but not diacylglycerol, in the antagonism of insulin signal transduction by saturated fatty acids. J Biol Chem. 2003;278:10297-303.

7. Glatz JFC, Luiken JJFP, Bonen A. Membrane fatty acid transporters as regulators of lipid metabolism: implications for metabolic disease. Physiol Rev. 2010;90:367-417.

8. Bonen A, Parolin ML, Steinberg GR, Calles-Escandon J, Tandon NN, Glatz JF, et al. Triacylglycerol accumulation in human obesity and type 2 diabetes is associated with increased rates of skeletal muscle fatty acid transport and increased sarcolemmal FAT/CD36. Faseb J. 2004;18:1144-6.

9. Holloway GP, Benton CR, Mullen KL, Yoshida Y, Snook LA, Han XX, et al. In obese rat muscle transport of palmitate is increased and is channeled to triacylglycerol storage despite an increase in mitochondrial palmitate oxidation. Am J Physiol Endocrinol Metab. 2009;296:E738-47.

10. Savage DB, Petersen KF, Shulman GI. Disordered lipid metabolism and the pathogenesis of insulin resistance. Physiol Rev. 2007;87:507-20.

11. Lopaschuk GD, Ussher JR, Folmes CD, Jaswal JS, Stanley WC. Myocardial fatty acid metabolism in health and disease. Physiol Rev. 2010;90:207-58.

12. Steinbusch LK, Schwenk RW, Ouwens DM, Diamant M, Glatz JF, Luiken JJ. Subcellular trafficking of the substrate transporters GLUT4 and CD36 in cardiomyocytes. Cell Mol Life Sci. 2011.

13. Schwenk RW, Dirkx E, Coumans WA, Bonen A, Klip A, Glatz JF, et al. Requirement for distinct vesicle-associated membrane proteins in insulin- and AMP-activated protein kinase (AMPK)induced translocation of GLUT4 and CD36 in cultured cardiomyocytes. Diabetologia. 2010;53:2209-19.

14. Martin S, Slot JW, James DE. GLUT4 trafficking in insulin-sensitive cells. A morphological review. Cell Biochem Biophys. 1999;30:89-113.

15. Habets DDJ. Regulation of cardiac long-chain fatty acid and glucose utilization: studies from genetically manipulated mice. Maastricht: Maastricht University; 2008.

16. Coort SL, Luiken JJ, van der Vusse GJ, Bonen A, Glatz JF. Increased FAT (fatty acid translocase)/CD36-mediated long-chain fatty acid uptake in cardiac myocytes from obese Zucker rats. Biochem Soc Trans. 2004;32:83-5.

17. Ouwens DM, Diamant M, Fodor M, Habets DD, Pelsers MM, El Hasnaoui M, et al. Cardiac contractile dysfunction in insulin-resistant rats fed a high-fat diet is associated with elevated CD36-mediated fatty acid uptake and esterification. Diabetologia. 2007;50:1938-48.

18. Steinbusch LK, Luiken JJ, Vlasblom R, Chabowski A, Hoebers NT, Coumans WA, et al. Absence of fatty acid transporter CD36 protects against Western-type diet-related cardiac dysfunction following pressure overload in mice. Am J Physiol Endocrinol Metab. 2011.

19. Yang J, Sambandam N, Han X, Gross RW, Courtois M, Kovacs A, et al. CD36 deficiency rescues lipotoxic cardiomyopathy. Circ Res. 2007;100:1208-17.

20. Collot-Teixeira S, Martin J, McDermott-Roe C, Poston R, McGregor JL. CD36 and macrophages in atherosclerosis. Cardiovasc Res. 2007;75:468-77.

21. Kennedy DJ, Kuchibhotla S, Westfall KM, Silverstein RL, Morton RE, Febbraio M. A CD36dependent pathway enhances macrophage and adipose tissue inflammation and impairs insulin signalling. Cardiovasc Res. 2011;89:604-13.

22. Sun B, Boyanovsky BB, Connelly MA, Shridas P, van der Westhuyzen DR, Webb NR. Distinct mechanisms for OxLDL uptake and cellular trafficking by class B scavenger receptors CD36 and SR-BI. J Lipid Res. 2007;48:2560-70. 
23. Pettersson I, Muccioli G, Granata R, Deghenghi R, Ghigo E, Ohlsson C, et al. Natural (ghrelin) and synthetic (hexarelin) GH secretagogues stimulate H9c2 cardiomyocyte cell proliferation. J Endocrinol. 2002;175:201-9.

24. Coort SL, Willems J, Coumans WA, van der Vusse GJ, Bonen A, Glatz JF, et al. Sulfo-N-succinimidyl esters of long chain fatty acids specifically inhibit fatty acid translocase (FAT/CD36)-mediated cellular fatty acid uptake. Mol Cell Biochem. 2002;239:213-9.

25. Kusaka Y, Tanaka T, Okamoto F, Terasaki F, Matsunaga Y, Miyazaki H, et al. Effect of sulfo-Nsuccinimidyl palmitate on the rat heart: myocardial long-chain fatty acid uptake and cardiac hypertrophy. Journal of molecular and cellular cardiology. 1995;27:1605-12.

26. Bertrand L, Ginion A, Beauloye C, Hebert AD, Guigas B, Hue L, et al. AMPK activation restores the stimulation of glucose uptake in an in vitro model of insulin-resistant cardiomyocytes via the activation of protein kinase B. Am J Physiol Heart Circ Physiol. 2006;291:H239-50.

27. Haim TE, Wang W, Flagg TP, Tones MA, Bahinski A, Numann RE, et al. Palmitate attenuates myocardial contractility through augmentation of repolarizing Kv currents. Journal of molecular and cellular cardiology. 2010;48:395-405.

28. Luiken JJ, Coort SL, Willems J, Coumans WA, Bonen A, van der Vusse GJ, et al. Contraction-induced fatty acid translocase/CD36 translocation in rat cardiac myocytes is mediated through AMPactivated protein kinase signaling. Diabetes. 2003;52:1627-34.

29. Steinbusch LK, Wijnen W, Schwenk RW, Coumans WA, Hoebers NT, Ouwens DM, et al. Differential regulation of cardiac glucose and fatty acid uptake by endosomal $\mathrm{pH}$ and actin filaments. Am J Physiol Cell Physiol. 2010;298:C1549-59.

30. Luiken JJ, van Nieuwenhoven FA, America G, van der Vusse GJ, Glatz JF. Uptake and metabolism of palmitate by isolated cardiac myocytes from adult rats: involvement of sarcolemmal proteins. J Lipid Res. 1997;38:745-58.

31. Bonen A, Luiken JJ, Arumugam Y, Glatz JF, Tandon NN. Acute regulation of fatty acid uptake involves the cellular redistribution of fatty acid translocase. J Biol Chem. 2000;275:14501-8.

32. Greulich S, De Wiza DH, Preilowksi S, Ding Z, Mueller H, Langin D, et al. Secretory products of guinea pig epicardial fat induce insulin resistance and impair primary adult rat cardiomyocyte function. J Cell Mol Med. 2011.

33. Alkhateeb H, Chabowski A, Glatz JF, Luiken JF, Bonen A. Two phases of palmitate-induced insulin resistance in skeletal muscle: impaired GLUT4 translocation is followed by a reduced GLUT4 intrinsic activity. Am J Physiol Endocrinol Metab. 2007;293:E783-93.

34. Coort SL, Bonen A, van der Vusse GJ, Glatz JF, Luiken JJ. Cardiac substrate uptake and metabolism in obesity and type-2 diabetes: role of sarcolemmal substrate transporters. Mol Cell Biochem. 2007;299:5-18.

35. Silverstein RL, Febbraio M. CD36, a scavenger receptor involved in immunity, metabolism, angiogenesis, and behavior. Sci Signal. 2009;2:re3.

36. Nergiz-Unal R, Rademakers T, Cosemans JM, Heemskerk JW. CD36 as a multiple-ligand signaling receptor in atherothrombosis. Cardiovasc Hematol Agents Med Chem. 2011;9:42-55.

37. Yamamoto N, Ikeda H, Tandon NN, Herman J, Tomiyama Y, Mitani T, et al. A platelet membrane glycoprotein (GP) deficiency in healthy blood donors: Naka- platelets lack detectable GPIV (CD36). Blood. 1990;76:1698-703.

38. Luiken JJ, Turcotte LP, Bonen A. Protein-mediated palmitate uptake and expression of fatty acid transport proteins in heart giant vesicles. J Lipid Res. 1999;40:1007-16.

39. Dimopoulos N, Watson M, Sakamoto K, Hundal HS. Differential effects of palmitate and palmitoleate on insulin action and glucose utilization in rat L6 skeletal muscle cells. Biochem J. 2006;399:473-81.

40. Pickersgill L, Litherland GJ, Greenberg AS, Walker M, Yeaman SJ. Key role for ceramides in mediating insulin resistance in human muscle cells. J Biol Chem. 2007;282:12583-9.

41. Ragheb R, Shanab GM, Medhat AM, Seoudi DM, Adeli K, Fantus IG. Free fatty acid-induced muscle insulin resistance and glucose uptake dysfunction: evidence for PKC activation and oxidative stress-activated signaling pathways. Biochem Biophys Res Commun. 2009;389:211-6.

42. Ren J, Porter JE, Wold LE, Aberle NS, Muralikrishnan D, Haselton JR. Depressed contractile function and adrenergic responsiveness of cardiac myocytes in an experimental model of Parkinson disease, the MPTP-treated mouse. Neurobiol Aging. 2004;25:131-8.

43. Howarth FC, Qureshi MA, Gbewonyo AJ, Tariq S, Adeghate E. The progressive effects of a fat enriched diet on ventricular myocyte contraction and intracellular Ca2+ in the C57BL/6J mouse. Mol Cell Biochem. 2005;273:87-95. 
44. Fauconnier J, Lanner JT, Zhang SJ, Tavi P, Bruton JD, Katz A, et al. Insulin and inositol 1,4,5trisphosphate trigger abnormal cytosolic $\mathrm{Ca} 2+$ transients and reveal mitochondrial $\mathrm{Ca} 2+$ handling defects in cardiomyocytes of ob/ob mice. Diabetes. 2005;54:2375-81.

45. Dong F, Fang CX, Yang X, Zhang X, Lopez FL, Ren J. Cardiac overexpression of catalase rescues cardiac contractile dysfunction induced by insulin resistance: Role of oxidative stress, protein carbonyl formation and insulin sensitivity. Diabetologia. 2006;49:1421-33.

46. McDonald KS. The interdependence of Ca2+ activation, sarcomere length, and power output in the heart. Pflugers Arch. 2011;462:61-7.

47. Ginion A, Auquier J, Benton CR, Mouton C, Vanoverschelde JL, Hue L, et al. Inhibition of the mTOR/p70S6K pathway is not involved in the insulin-sensitizing effect of AMPK on cardiac glucose uptake. Am J Physiol Heart Circ Physiol. 2011;301:H469-77.

48. Summers SA, Garza LA, Zhou H, Birnbaum MJ. Regulation of insulin-stimulated glucose transporter GLUT4 translocation and Akt kinase activity by ceramide. Mol Cell Biol. 1998;18:5457-64. 


\section{Supplemental data concerning chapter 2}
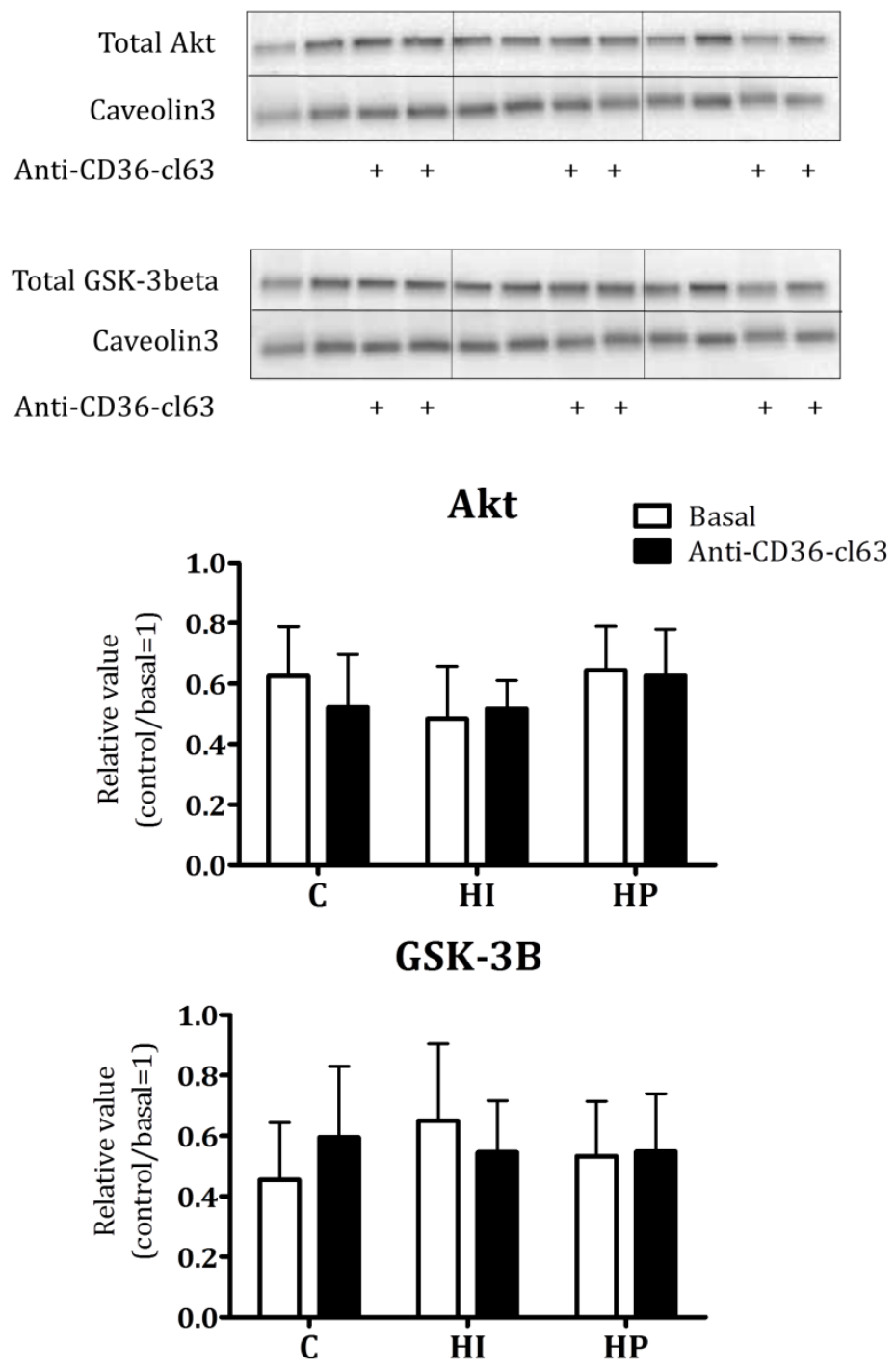

Supplemental Fig 1 Total expression of Akt and downstream targets in cardiomyocytes is not altered upon HI and HP treatment in the absence or presence of anti-CD36-cl63. Cardiomyocytes were cultured in control medium (C), or in media containing high insulin (HI) or high palmitate (HP) concentrations in the absence or presence of $0.83 \mu \mathrm{g} / \mathrm{ml}$ anti-CD36-cl63. Upon 2 days culturing, cells were allowed to recover for $30 \mathrm{~min}$ prior to short-term $(15 \mathrm{~min})$ insulin $(100 \mathrm{nM})$ addition and subsequent Western blot analysis of total Akt and GSK3 $\beta$ content. Hence, the changes in the phosphorylation states of these proteins (see Fig. 5) are not due to changes in total protein expression. 


$$
\text { LPI+IgA }
$$

after washing

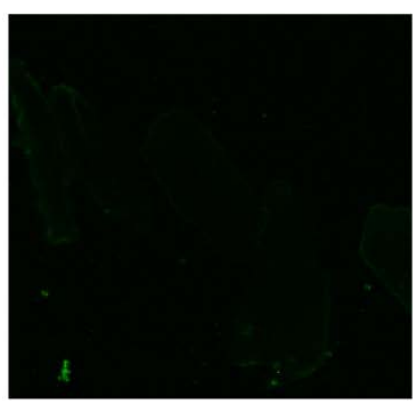

LPI+IgA

without washing

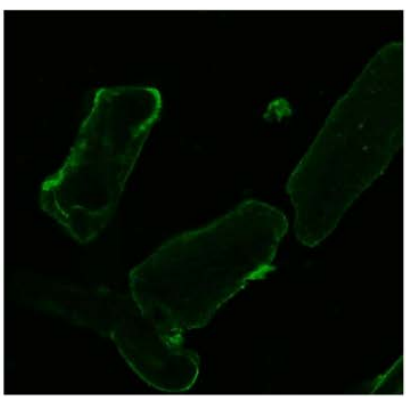

Supplemental Fig 2 The washing steps after 48 h culturing almost entirely remove anti-CD36-cl63 used to detect the cell surface localization of CD36. Cardiomyocytes were cultured in control medium for 48 hours in the presence of $0.83 \mu \mathrm{g} / \mathrm{ml}$ anti-CD36-cl63 (right panel) and subsequently washed as described in Materials and Methods (left panel), and then used for microscopic detection of anti-CD36cl63 using a FITC-labeled secondary antibody. $n=3$. It is of note that upon washing the fluorescent signal has almost completely disappeared, indicating that the washing procedure effectively removes antiCD36-cl63. 
A

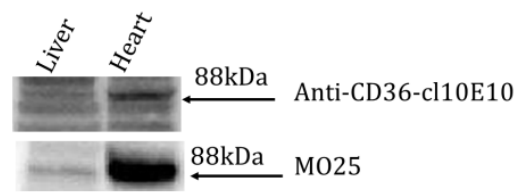

B

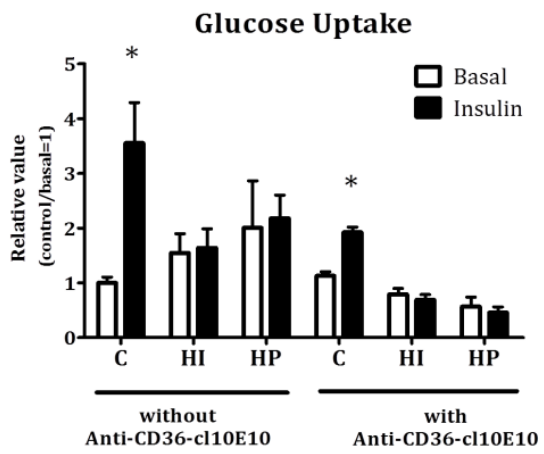

C Sarcomere Dynamics
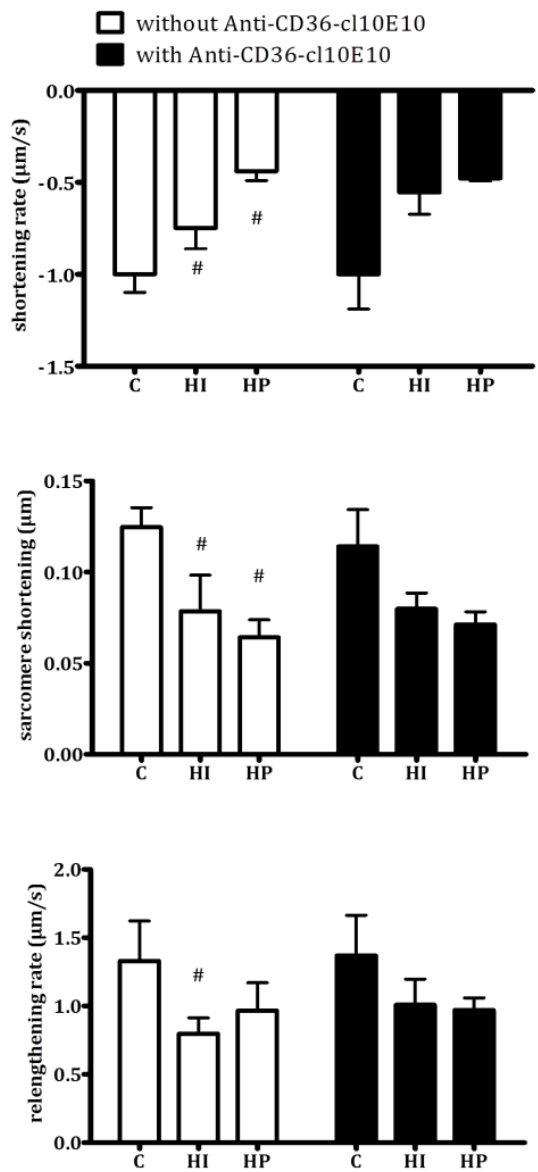

Supplemental Fig. 3 Binding to CD36 is not sufficient for anti-CD36 antibodies to prevent the maladaptive changes in cardiomyocytes upon exposure to lipotoxic conditions. A. Anti-CD36-cl10E10 detects CD36 on Western blot. CD36 protein expression was checked in the homogenates from liver (negative control) and heart tissue by Western blotting. The ability of anti-CD36-cl10E10 monoclonal antibody to detect CD36 was compared with the anti-CD36 monoclonal antibody MO25 routinely used for Western blotting. Cardiomyocytes were cultured in control medium (C), or in media containing high insulin (HI) or high palmitate (HP) concentrations in the absence (Basal) or presence of $1.7 \mu \mathrm{g} / \mathrm{ml}$ antiCD36-cl10E10. B. Upon 2 days culturing, cells were allowed to recover for $30 \mathrm{~min}$ prior to short-term $(15 \mathrm{~min})$ insulin $(100 \mathrm{nM})$ addition and subsequent measurement of 2-Deoxy-D-[1-3 H]glucose uptake. C. Upon 2 days culturing, cardiomyocytes were used for analysis of peak sarcomere shortening. Values are displayed as mean +/- S.E.M ( $\mathrm{n}=3) .{ }^{*}$ insulin effect, \# medium effect, ${ }^{\wedge}$ anti-CD36 effect $(\mathrm{p}<0.05)$. These data demonstrate that, in contrast to anti-CD36-cl63 (see Fig. 4 and 7), anti-CD36-cl10E10 does not induce the substrate switch to increased glucose uptake, and does not preserve contractile function in cardiomyocytes exposed to lipotoxic conditions. In conclusion, merely binding to CD36 is not sufficient for anti-CD36 antibodies to prevent or protect against lipid-induced contractile dysfunction. 


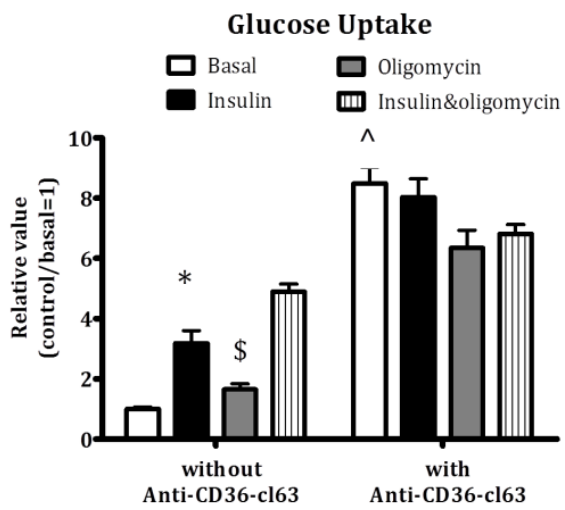

Supplemental Fig. 4 AMP-activated kinase (AMPK) stimulation does not increase glucose uptake in anti-CD36-cl63-treated cardiomyocytes. Cardiomyocytes were cultured in control medium in the absence or presence of $1.7 \mu \mathrm{g} / \mathrm{ml}$ anti-CD36-cl63. (A) Upon 2 days culturing, cells were allowed to recover for $30 \mathrm{~min}$ prior to short-term (15 min) addition of insulin (100 $\mathrm{nM})$ and/or the potent AMPK stimulator oligomycin $(5 \mu \mathrm{M})$, and subsequent measurement of 2-Deoxy-D$\left[1-{ }^{3} \mathrm{H}\right]$ glucose uptake. Values are displayed as mean +/- S.E.M ( $n=3)$. * insulin effect, \$ oligomycin effect, $\wedge$ anti-CD36 effect $(\mathrm{p}<0.05)$. These data demonstrate that short-term AMPK stimulation of anti-CD36cl63-treated cardiomyocytes, in contrast to basally cultured cardiomyocytes, either in the absence or presence of short-term insulin stimulation, does not stimulate glucose uptake. We suggest that anti-CD36-cl63-treatment leads to a maximal depletion of GLUT4 from the intracellular storage compartment, so that additional treatment of cardiomyocytes with GLUT4 translocation-inducing stimuli will be futile. 


\section{Chapter 3}

\section{Omega-3 fatty acids prevent insulin resistance in cardiomyocytes as induced by high insulin exposure}

\footnotetext{
Veronika Franekova ${ }^{1 *}$, Yeliz Angin ${ }^{2 *}$, Nicole Hoebers ${ }^{2}$, Dipanjan Chanda ${ }^{2}$, Peter Simons ${ }^{3}$, Jan F.C. Glatz ${ }^{2}$, Joost J.F.P. Luiken ${ }^{2}$, Terje Larsen ${ }^{1}$

${ }^{1}$ Cardiovascular Research Group, Department of Medical Biology, Health Sciences Faculty, University of Tromsø, Norway;

${ }^{2}$ Department of Molecular Genetics, Cardiovascular Research Institute Maastricht, Maastricht University, Maastricht, the Netherlands;

${ }^{3}$ Bioceros BV, Utrecht, the Netherlands

* These authors contributed equally to this study.

submitted
} 


\begin{abstract}
Insulin resistance is an important risk factor for the development of several cardiac pathologies, thus advocating strategies for restoring insulin sensitivity of the heart in these conditions. Polyunsaturated fatty acids (PUFAs), EPA (C20:5n-3) and DHA (C22:6n-3), have been shown to improve insulin sensitivity in insulinsensitive tissues, but the direct effect of these $\omega$-3 PUFAs on insulin signaling in the myocardium has not been examined. The aim of this study was therefore to examine the ability of EPA and DHA to prevent insulin resistance in isolated rat cardiomyocytes. Primary rat cardiomyocytes were made insulin resistant by $48 \mathrm{~h}$ incubation in high insulin (HI) medium. Parallel incubations were supplemented by $200 \mu \mathrm{M}$ EPA or DHA. Insulin sensitivity was assessed by subsequent measurements of cellular glucose and long-chain fatty acid uptake, as well as phosphorylation of proteins in the insulin signaling cascade. In addition, contractile function (sarcomere shortening of electrically stimulated cardiomyocytes) was recorded. Insulin resistant cardiomyocytes showed decreased glucose uptake, increased fatty acid uptake, and reduced phosphorylation of Akt/PKB, AS160 and GSK3 $\beta$. The abundance of the fatty acid transporter CD36 at the sarcolemma was also increased in insulin resistant cells, and cell shortening was significantly reduced. Addition of EPA or DHA to the HI medium prevented the induction of insulin resistance and also prevented the sarcolemmal abundance of CD36. Only cardiomyocytes incubated in the presence of EPA exhibited improvements in glucose and fatty acid uptake and cell shortening. We conclude that $\omega-3$ PUFAs protect metabolic and functional characteristics of cardiomyocytes subjected to insulin resistance-evoking conditions.
\end{abstract}




\section{Introduction}

An elevated supply of lipids in obesity and type 2 diabetes leads to alterations of myocardial substrate metabolism, manifested insulin resistance with reduced glucose utilization and increased long-chain fatty acid (LCFA) utilization [1-3]. Thus, isolated cardiomyocytes from various diabetic/obese rodent models show impaired insulin signaling, including reduced activation of Akt/PKB, reduced GLUT4 translocation from intracellular compartments to the sarcolemma, as well as impaired insulin-induced glucose uptake [4-6]. Several mechanisms have been proposed to lead to impaired insulin signaling in insulin sensitive tissues, including intracellular accumulation of LCFA and their derivatives (fatty acyl-CoA, diacylglycerol and ceramides). Glucose and LCFA are the major substrates for the heart, and GLUT4 and CD36 the major substrate transporters, which are regulated by reversible insulin-induced translocation [7]. Notably, increased LCFA supply to cardiomyocytes will evoke persistent relocation of CD36 from intracellular stores to the sarcolemma, followed by chronically elevated LCFA uptake and lipid accumulation, eventually resulting in insulin resistance [8, 9]. Aditionally, sustained hyperinsulinemia itself has also been shown to chronically stimulate CD36 translocation in cardiomyocytes and consequently, lead to lipid-induced insulin resistance in a very similar manner to Cardiomyocytes exposed too LCFA oversupply, as reported previously $[6,8]$. We also found that insulin resistant cardiomyocytes exhibited contractile dysfunction (reduced cell shortening) [9].

Numerous studies have shown that diets enriched in EPA and/or DHA improve whole-body insulin resistance in rodent models of obesity and diabetes $[13,14]$. Intake of $\omega-3$ fatty acids also improves defects in insulin signaling and prevents alterations in glucose homeostasis in humans, due to improved lipoprotein metabolism and reduction in LCFA accumulation in muscle and liver [15]. Of interest, several studies in rat and mouse models of pressure overloadinduced heart failure have reported that intake of EPA and DHA prevents LV remodeling and contractile dysfunction [10-12]. The heart is considered as an insulin responsive organ, and impairment of insulin-stimulated cardiac glucose uptake has been described in animal models of diabetes and obesity [16]. Whether EPA and DHA have the potential to directly improve insulin signaling in the heart is, however, not clear. It is also disputed whether activation of AMP-activated protein kinase (AMPK) is involved in the beneficial effects of these $\omega-3$ fatty acids. Namely, mice treated with diet containing $\omega$-3 PUFAs did not show any changes in the activity of myocardial AMPK [17]. Furthermore, no effect of $\omega$-3 PUFAs on AMPK activity could be detected in cultured hepatocytes [18]. On the other hand, it has been demonstrated that $\omega-3$ PUFAs enhance AMPK activity in the liver [19], intestine [20], adipose tissue [21], and in 3T3-L1 cells and primary adipocytes [22].

To test the putative preventive effect of EPA and DHA on myocardial insulin resistance, rat primary cardiomyocytes were made insulin resistant by long-term exposure to a medium containing high concentrations of insulin, as previously described [9]. In order to study the effect of EPA and DHA, these fatty acids were complexed to albumin and co-incubated with high insulin. After washing the cells, insulin sensitivity was evaluated based on glucose uptake and LCFA uptake, as well 
as phosphorylation of selected proteins in the insulin signaling cascade in response to acute insulin administration. In addition, the effect of EPA and DHA on the presence of fatty acid transport protein CD36 in the sarcolemma was examined by confocal microscopy. Finally, we also examined the effect of EPA and DHA on myocardial cell shortening.

\section{Materials and Methods}

\section{$\underline{\text { Materials }}$}

Medium M199 and Penicilin/streptomycin were purchased from Invitrogen (Carlsbad, CA, USA). Phloretin, laminin, creatine monohydrate, carnitine hydrochloride, taurine, EPA and DHA were purchased from Sigma Aldrich (St. Louis, MO, USA). Collagenase type II was from Worthington (Freehold, USA). Insulin was obtained from Sigma (bovine insulin) or Novo Nordisk (human insulin). Bovine serum albumin (BSA, essentially fatty acid free, fraction V) was derived from MP Biomedicals (Irvine, USA) or from Sigma Aldrich (St. Louis. MO, USA). Phloretin was from Fluka. 2-deoxy-D-[1-3 H]glucose and $\left[1-{ }^{14} \mathrm{C}\right]$ palmitic acid were obtained from GE Healthcare (Piscataway, NJ, USA).

\section{Experimental animals}

Male Lewis rats (200-250 g) were purchased from Charles River Laboratories and were used for isolation of cardiomyocytes. All animals were fed ad libitum. All procedures were approved by the Experimental Animal Committee of Maastricht University, Maastricht, the Netherlands.

\section{Cardiomyocyte isolation and culturing}

Isolation of adult rat cardiomyocytes (Lewis rats 200-250 g, 2-3 months of age) were performed by using a Langendorff perfusion system according to the procedure described previously [23] with the only difference being sterile conditions that were taken into account to enable subsequent culturing. A modified Krebs Henseleit bicarbonate medium (MKR) containing $1.17 \mathrm{M} \mathrm{NaCl}, 26$ $\mathrm{mM} \mathrm{KCl}, 12 \mathrm{mM} \mathrm{KH}_{2} \mathrm{PO}_{4}, 12 \mathrm{mM} \mathrm{MgSO}_{4} \bullet 7 \mathrm{H}_{2} \mathrm{O}, 100 \mathrm{mM} \mathrm{NaHCO}_{3}, 100 \mathrm{mM}$ HEPES with adjusted pH 7.55 was stored at a 10 -fold concentration. MKR medium was diluted 10 -fold and equilibrated with a $95 \% 02 / 5 \% \mathrm{CO}_{2}$ gas phase at $37^{\circ} \mathrm{C}$ for daily use to prepare buffers used during cardiomyocyte isolation and experiments with cardiomyocytes.

Cells were seeded on laminin-coated six-well plates $\left(9.6 \mathrm{~cm}^{2}\right)$ (substrate uptake and signaling measurements ) or on 35-mm high dishes (Ibidi GmBH, München, Germany) with an elastic surface (for sarcomere shortening and for the surface CD36 measurements) at a density of 100,000 cells $/ \mathrm{ml}$ in 10-times diluted MKR supplemented with $0.45 \%$ (w/v) BSA. After 90 min adhesion, the medium was replaced with control medium [medium M199 supplemented with creatine monohydrate $(5 \mathrm{mM})$, carnitine hydrochloride $(3.2 \mathrm{mM})$, taurine $(3.1 \mathrm{mM})$ penicillin (100 units $/ \mathrm{ml})$, streptomycin $(10 \mathrm{mg} / \mathrm{ml})$ and palmitic acid $(20 \mu \mathrm{M})]$, 56 
high insulin medium (HI; control medium supplemented with $100 \mathrm{nM}$ insulin) or $\omega-3$ PUFA medium (high insulin medium supplemented with $200 \mu \mathrm{M}$ EPA or DHA). Cardiomyocyte cultures were kept and maintained in $5 \% \mathrm{CO}_{2}$ at $37^{\circ} \mathrm{C}$ for $48 \mathrm{~h}$. Medium was refreshed after $24 \mathrm{~h}$ of seeding. Following $48 \mathrm{~h}$ of culturing, cells were washed and allowed to recover in medium A (10-times diluted MKR supplemented with $0.45 \%(\mathrm{w} / \mathrm{v}) \mathrm{BSA}$ and $1 \mathrm{mM} \mathrm{CaCl2}$ ) for $30 \mathrm{~min}$ prior to start $15 \mathrm{~min}$ incubation with or without insulin $(100 \mathrm{nM})$. Fatty acids were bound to BSA in a ratio LCFA/BSA = 6:1 (for palmitic acid) or LCFA/BSA $=4: 1$ (for EPA and DHA). BSA was used as fatty acid free control added to the control medium to avoid interference from vehicle.

\section{Measurement of substrate uptake}

The uptake of 2-Deoxy-D-[1-3H]glucose and [1-14C]palmitic acid (in complex with BSA) into cultured cardiomyocytes was measured. Following a 15 min treatment with/without insulin $(100 \mathrm{nM})$, a mixture of 2-Deoxy-D-[1- $\left.{ }^{3} \mathrm{H}\right]$ glucose $(8 \mathrm{Ci} / \mathrm{mM})$ and $\left[1-{ }^{14} \mathrm{C}\right]$ palmitic acid was added into the incubation medium for $10 \mathrm{~min}$. Thereafter, cells were washed twice with ice-cold Stop medium (10-times diluted MKR buffer supplemented with $1 \mathrm{mM} \mathrm{CaCl}_{2}$ and $0.2 \mathrm{mM}$ phloretin) on ice, and then lysed in sample buffer (40\% (v/v) glycerol, $0.25 \mathrm{M}$ Tris and $1 \mathrm{M}$ DTT) followed by assessment of radioactivity in scintillation fluid (Opti-Fluor; PerkinElmer, Waltham,USA).

\section{Detection of phosphorylation of enzymes within the insulin network}

Following a 25 min treatment with/without insulin $(100 \mathrm{nM})$ cultured cardiomyocytes were lysed in $1.3 \mathrm{X}$ sample buffer (40\% (v/v) glycerol, $0.25 \mathrm{M}$ Tris, $1 \mathrm{M}$ DTT and $1.5 \mathrm{mM}$ bromo-phenol-blue) and used for protein detection. Approximately $20 \mu \mathrm{g}$ per sample was used for SDS-polyacrylamide gel electrophoresis followed by Western blotting.

Primary antibodies specific to Akt, phospho-Ser473-Akt, phospho-Thr172AMPK $\alpha$, phospho-Ser9-GSK3 $\beta$ were purchased from Cell Signaling Technology (Danvers, MA), phospho-Ser79-ACC and phospho-Thr642-AS160 from Upstate Biotechnology (Millipore) (Billerica, MA), GLUT4 from Abcam (Cambridge, USA), caveolin 3 from BD Transduction Laboratories (Franklin Lakes, USA) were used. Anti-CD36 antibody M025 was a gift from Dr N.N. Tandon (Thrombosis Research Laboratory, Otsuka Maryland Medicinal Laboratories Rockville, MS, U.S.A.). Western blot images were analyzed with a molecular imager (ChemiDoc XRS, BioRad Laboratories) and quantified with Quantity One® (Bio-Rad Laboratories).

\section{Sarcolemmal presence of CD36}

Following $48 \mathrm{~h}$ of culturing, cells were washed twice with control medium, treated with primary antibody against CD36 (BD Biosciences) for $10 \mathrm{~min}$ at $37^{\circ} \mathrm{C}$ followed by incubation with FITC-labelled rabbit-anti-mouse IgA secondary antibodies (1:500 dilution; Rockland). The viable cardiomyocytes were imaged using the Leica SP5 imaging platform in confocal mode (Leica Microsystems) with the 
emission filters optimized for FITC detection. Images were processed with Image (NIH).

\section{Measurement of sarcomere shortening}

Following $48 \mathrm{~h}$ of culturing, cells were washed twice with control medium and subsequently analyzed for contractile function as previously described [24]. Before the start of the measurements, cells were electrically pre-stimulated for 5 min with $1 \mathrm{~Hz}$ to reach a steady-state level for sarcomere shortening. Then, cells were paced with bipolar pulses of $5 \mathrm{~ms}$ duration at $1 \mathrm{~Hz}$. Under each experimental condition, data files were recorded of ten consecutive beats for at least eight different cells. Sarcomere shortening was measured with IonOptix (Dublin, Ireland) and calculated using IonWizard (IonOptix).

\section{$\underline{\text { Statistics }}$}

All data are presented as means \pm S.E.M. Statistical analyses were performed by one-way or two-way ANOVA or Student's t-test by using GraphPad Prism Program (GraphPad Software Inc., San Diego, CA, USA). P 0.05 was considered as significant.

\section{Results}

\section{Effect of EPA and DHA on insulin-stimulated glucose uptake}

Insulin resistance was induced in cultured adult primary rat cardiomyocytes during $48 \mathrm{~h}$ of insulin (100 $\mathrm{nM}$ ) exposure (HI medium) as previously described [9, 25]. Cardiomyocyte insulin sensitivity was assessed by insulin-stimulated glucose uptake. Non-treated cardiomyocytes during $48 \mathrm{~h}$ of culturing in control medium responded to acute insulin stimulation $(100 \mathrm{nM})$ by a 3.3 -fold increase in glucose uptake, while glucose uptake was hardly affected in insulin resistant cells (Fig. 1A). Interestingly, basal glucose uptake was significantly elevated in insulin resistant cardiomyocytes upon EPA $(200 \mu \mathrm{M})$ exposure during $48 \mathrm{~h}$ of culturing in $\mathrm{HI}$ medium. Furthermore, exposure of EPA also prevented the loss of insulin sensitivity, which was completely abolished in cardiomyocytes cultured in $\mathrm{HI}$ medium during $48 \mathrm{~h}$ (Fig. 1A). Thus, there was no difference in insulin-induced increment in glucose uptake between control and EPA-treated cardiomyocytes. The effect of DHA on glucose uptake was tested in parallel experiments, and like EPA, DHA also caused an increase on basal glucose uptake in cardiomyocytes subjected to insulin resistance-evoking conditions. On the other hand, the response to acute stimulation with insulin was blunted in DHA-treated cardiomyocytes, as compared to control cardiomyocytes (Fig. 1A).

Fig. 1B shows that the observed improvements in glucose uptake upon exposing cardiomyocytes to EPA or DHA were not associated with alterations in the total level of the insulin-regulated glucose transporter GLUT4. 
A

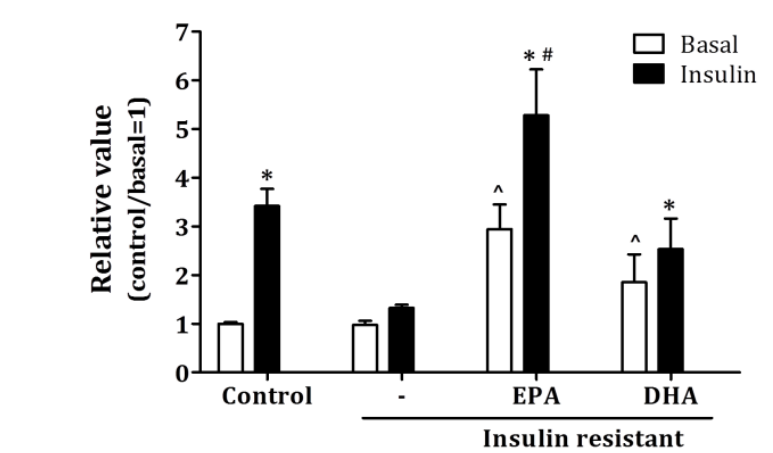

B

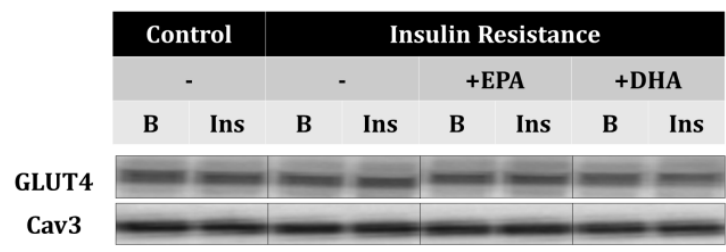

Fig. 1 Effect of $\omega-3$ PUFAs on glucose uptake and total expression level of GLUT4. Cardiomyocytes were preincubated for $48 \mathrm{~h}$ in control medium (C) or in medium supplied with $100 \mathrm{nM}$ insulin (high insulin, HI) in the absence or presence of $200 \mu \mathrm{M}$ EPA or DHA. Thereafter, cells were washed and allowed to recover for $30 \mathrm{~min}$ prior to short-term (25 min) incubation with or without insulin (100 nM). (A) Glucose uptake into cardiomyocytes was evaluated by the measurements of 2deoxy-D-[1-3 H]glucose which was added to medium for the last 10 minutes of short-term insulin incubations. Results are represented as mean values \pm SEM, $\quad(n=11$ and $n=4$ for incubations with EPA and DHA respectively). * $\mathrm{P}<0.05$ vs. control/basal value; $\wedge$ $P<0.05$ vs. basal value in the absence of $\omega-3$ PUFAs; \# P<0.05 vs. insulin-stimulated value in the absence of $\omega-3$ PUFAs in the insulin resistant group. (B) Western blot analysis of total GLUT4 in cardiomyocytes cultured in control or HI medium in the absence or presence of $\omega-3$ PUFAs during basal (B) and insulinstimulated conditions (Ins). Caveolin 3 (Cav3) was used as loading control.

\section{Effect of EPA and DHA on insulin signaling in cardiac myocytes}

A commonly used read-out of insulin resistance is decreased phosphorylation of enzymes in the canonical insulin signaling pathway. Insulin resistance was confirmed by markedly lower phosphorylation of Akt and two of its down-stream substrates, GSK3 $\beta$ and AS160, in response to acute (15 min) exposure to $100 \mathrm{nM}$ insulin, as compared that of control cells (Fig 2A). Thus, whereas insulin stimulation caused a 4.3-5.9 fold increase in phosphorylation state of control cells, we observed only a 1.5-2.2 fold increase in insulin resistant cells (Fig. 2 B-D). Addition of $\omega-3$ PUFA (EPA or DHA) to the culture medium during the $48 \mathrm{~h}$ incubation with insulin almost completely prevented the loss of insulin sensitivity of the cardiomyocytes, since the subsequent short-term insulin stimulation resulted in a similar increase in phosphorylation state of the three selected proteins as observed in control cells cultured with control medium (Fig. 2 A-D). We also observed that exposure of insulin resistant cardiomyocytes to EPA or DHA caused a slight increase in phosphorylation of all three proteins during baseline conditions (i.e. with no insulin) (Fig. 2 B-D). These changes in insulin signaling were not due to different loading or changes in total expression of Akt (data not shown). 

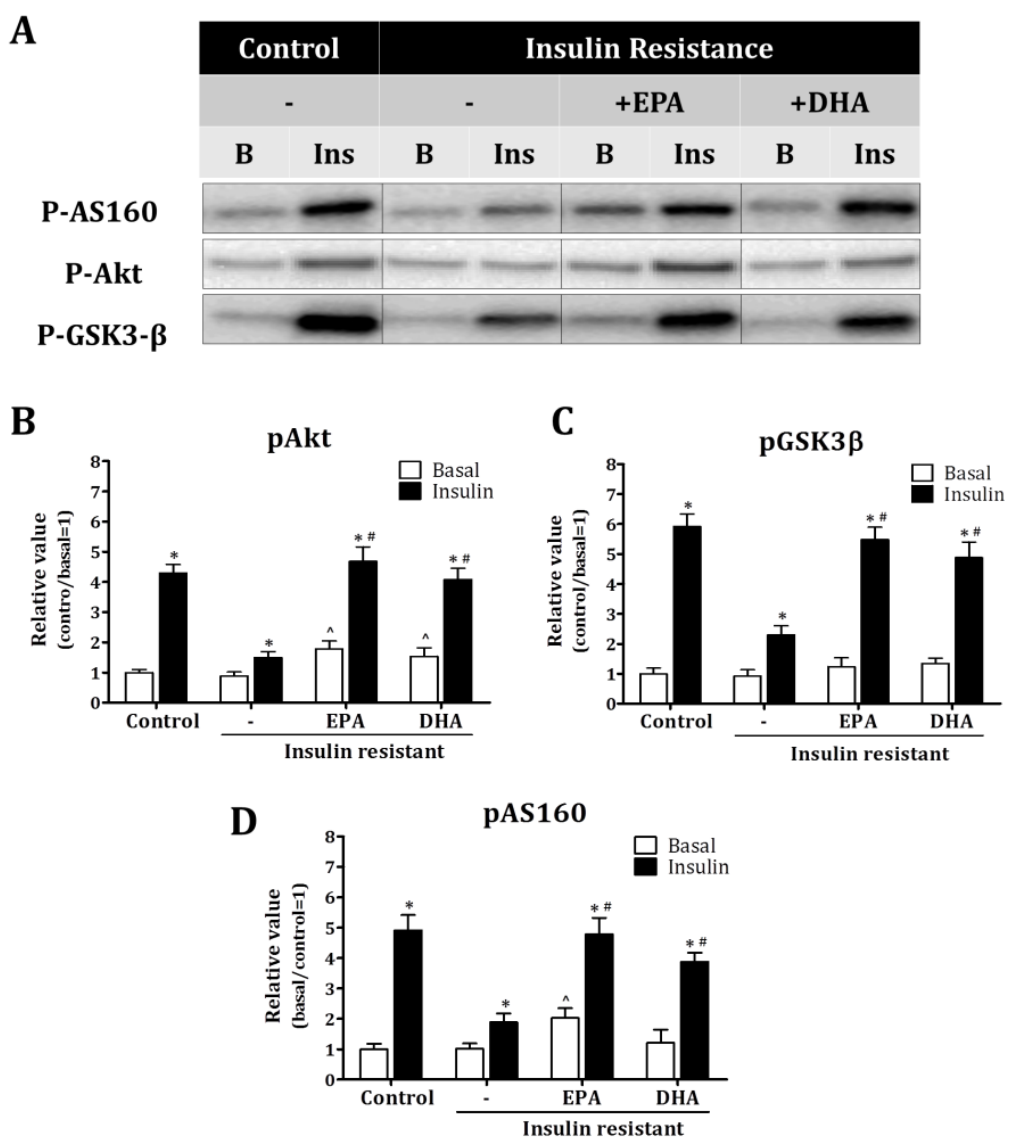

Fig. 2 Effect of $\boldsymbol{\omega}$-3 PUFAs on insulin signaling. Cardiomyocytes were pre-treated and stimulated with insulin as described in the legend of Fig. 1. (A) Western blot analysis of phosphorylated Akt/PKB (pAKT), GSK (pGSK3ß) and AS160 (pAS160) in cardiomyocytes cultured in control (C) or high insulin (HI) medium in the absence or presence of $\omega-3$ PUFAs during basal (B) and insulin-stimulated conditions (Ins). (B-D) Quantification of the signals from Western blot corrected for loading control. Results are represented as mean values \pm SEM $(n=10)$. ${ }^{*} \mathrm{P}<0.05$ vs. control/basal value; ${ }^{\wedge} P<0.05$ vs. basal value in the absence of $\omega-3$ PUFAs; \# P<0.05 vs. insulin-stimulated value in the absence of $\omega-3$ PUFAs in the insulin resistant group.

\section{Effect of EPA and DHA on insulin-stimulated fatty acid uptake}

Insulin led to a 1.4-fold stimulation of palmitate uptake in cardiomyocytes cultured with control medium (Fig. $3 \mathrm{~A}$ ), in agreement with previous studies $[9,26]$. This response was lost in cardiomyocytes cultured for $48 \mathrm{~h}$ under HI conditions, while co-incubation with EPA (but not DHA) recovered the insulin sensitivity. Furthermore, both EPA and DHA caused a marked ( $>2$-fold) stimulation of basal palmitate uptake in insulin resistant cardiomyocytes. The changes in palmitate uptake were not associated with changes in the expression of the total cellular content of the fatty acid transporter CD36 (Fig. 3B). We also examined the sarcolemmal abundance of CD36 by using immunofluorescence microscopy (Fig. 
3C). Cardiomyocytes cultured in HI medium exhibited a markedly elevated cell surface CD36 content in the absence of changes in total CD36 expression, in agreement with earlier observations [9]. Such persistent CD36 relocation is considered a hallmark event in the development of fatty acid induced insulin resistance. Persistent CD36 relocation was reversed in incubations with EPA and to some extent also with DHA, but not in incubations with palmitate. Co-incubation of EPA with anti-CD36 antibody abolished both basal and insulin stimulated palmitate uptake in cardiomyocytes which might suggest that EPA exerts its insulin sensitizing action after having been taken up across the cell membrane through CD36. We have shown earlier that anti-CD36 antibody (clone-63) blocks the fatty transport function of CD36 [9].

A

Palmitate Uptake

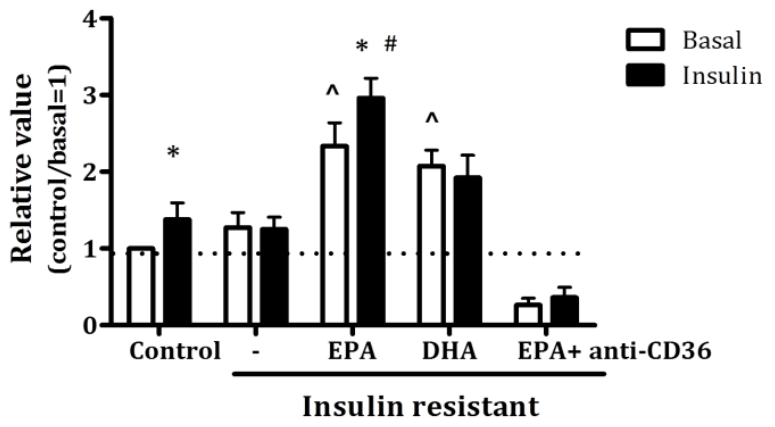

B

\begin{tabular}{|c|c|c|c|c|c|c|c|}
\hline \multicolumn{2}{|c|}{ Control } & \multicolumn{6}{|c|}{ Insulin Resistance } \\
\hline \multicolumn{2}{|c|}{ - } & \multicolumn{2}{|c|}{ - } & \multicolumn{2}{|c|}{ +EPA } & \multicolumn{2}{|c|}{ +DHA } \\
\hline B & Ins & B & Ins & B & Ins & B & Ins \\
\hline$m$ & $m$ & $=$ & 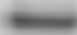 & $=$ & $=$ & $=$ & $=$ \\
\hline
\end{tabular}

C

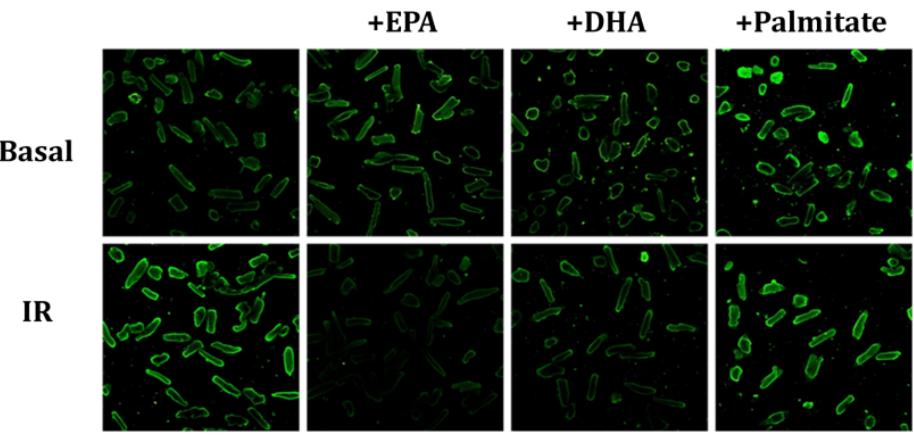

Fig. 3 Effect of $\omega$-3 PUFAs on palmitate uptake, total expression level and cell-surface content of CD36. Cardiomyocytes were pre-treated and stimulated with insulin as described in the legend of Fig. 1. (A) Palmitate uptake into cardiomyocytes was evaluated by the measurements of $\left[1-^{-14} \mathrm{C}\right]$ palmitic acid 
which was added to medium for the last 10 minutes of short-term insulin incubations. Also shown are the data from cardiomyocytes cultured in the presence of EPA co-incubated with anti-CD36 antibody. Results are represented as mean values \pm SEM, $(n=11$ and $n=4$ for incubations with EPA and DHA respectively). * $\mathrm{P}<0.05$ vs. control/basal value; ${ }^{\wedge} P<0.05$ vs. basal value in the absence of $\omega-3$ PUFAs; \# $\mathrm{P}<0.05$ vs. insulin-stimulated value in the absence of $\omega-3$ PUFAs in the insulin resistant group. (B) Western blot analysis of total CD36 in cardiomyocytes cultured in control or HI medium in the absence or presence of $\omega-3$ PUFAs during basal (B) and insulin-stimulated conditions (Ins). Caveolin 3 (Cav3) was used as loading control. Representative blots are shown. (C) Surface staining of CD36 in cardiomyocytes cultured in control or HI medium in the absence or presence of $200 \mu \mathrm{M}$ EPA, DHA or palmitate.

\section{Impact of EPA and DHA on cardiomyocyte contractility (shortening)}

It has been previously been shown that culturing of primary rat cardiomyocytes for $48 \mathrm{~h}$ in $\mathrm{HI}$ medium is associated with impaired peak sarcomere shortening (40\%; [9]). Here, we investigated the effect of EPA and DHA on sarcomere shortening of cardiomyocytes cultured for $48 \mathrm{~h}$ in HI medium. EPA improved peak sarcomere shortening by 1.6-fold (Fig. 4). Also DHA improved sarcomere shortening (1.5-fold), but this effect did not reach statistical significance $(\mathrm{P}>0.05$; Fig. 4). Hence, EPA, and perhaps DHA, have a beneficial effect on contractile functions of cardiomyocytes in conditions of impaired insulin signaling. Although the mechanisms of how $\omega-3$ PUFAs improve sarcomere shortening in insulin resistance cardiomyocytes are unknown, one of the possible explanations could be the incorporation of EPA into phospholipid membranes. Beneficial effects (like anti-arrhythmic actions, prevention of hypertrophy or reduction of myocardial infarct size) of $\omega$-3 PUFAs on cardiac functions have been shown earlier [27]. Dietary fats are known to determine fatty acid composition of cardiac cell membranes, similarly $\omega-3$ PUFAs especially DHA rich diets have been shown to attenuate cardiac functions through incorporation into phospholipid membranes [28-30]. For instance, $\omega$-3 PUFA incorporation into cardiac membranes made myocardium less susceptible to ischemic injury and aided post-ischemic recovery though reduced oxygen consumption [29].

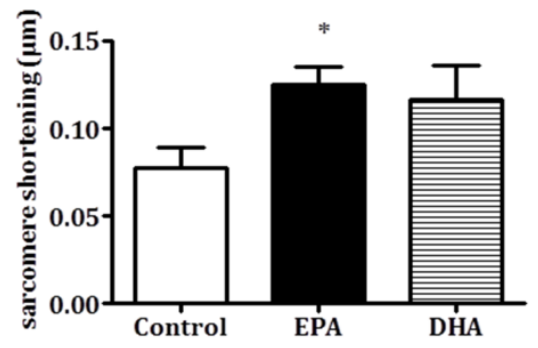

Fig. 4 Effect of $\omega-3$ PUFAs on peak sarcomere shortening. Cardiomyocytes were pre-incubated for $48 \mathrm{~h}$ in medium supplied with $100 \mathrm{nM}$ insulin (HI) in the absence or presence of $200 \mu \mathrm{M}$ EPA or DHA. Subsequently peak sarcomere shortening was recorded under $1 \mathrm{~Hz}$ and $5 \mathrm{~ms}$ of electrical pulsated cardiomyocytes. Results are represented as mean values \pm SEM, $(n=6) .{ }^{*} \mathrm{P}<0.05$ vs. value in the absence of $\omega$-3 PUFAs.

\section{Effect of EPA and DHA on AMPK signaling}

In order to investigate whether AMPK signaling is involved in the beneficial effects of the $\omega-3$ fatty acids on insulin sensitivity, substrate uptake and contractile function, activation of AMPK was assessed via phosphorylation at Thr172 within the catalytic $\alpha$-subunit, and via phosphorylation of its major subcellular target acetyl-CoA carboxylase (ACC). Culturing in HI medium, neither in the absence or 62 
presence of EPA or DHA had any effect on AMPK-Thr172 or ACC-Ser79 phosphorylation (Fig. 5). Hence, AMPK seems not involved in these beneficial actions of EPA and DHA.

Fig.5 Effect of $\omega-3$ PUFAs on AMPK signaling. Cardiomyocytes were pre-incubated for $48 \mathrm{~h}$ in medium supplied with $100 \mathrm{nM}$ insulin (HI) in the absence or presence of $200 \mu \mathrm{M}$ EPA or DHA. Thereafter cells were lysed, and used for Western detection of phosphorylated AMPK and ACC and for caveolin-3 (Cav3; loading control). Representative images are shown from $n=6$ observations.

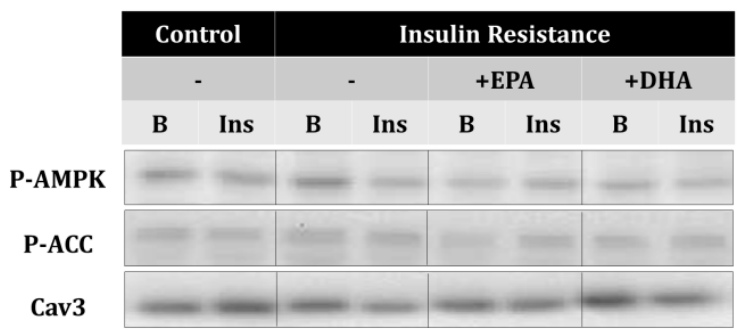

\section{Discussion}

Dysregulation of cardiac substrate metabolism in conditions of insulin resistance (obesity- and/or type 2 diabetes) eventually leads to functional deterioration of the heart. In the present study we investigated the effect of PUFAs on insulin signaling and substrate uptake in insulin resistant cardiomyocytes, which were generated by culturing the cells in HI medium. The main finding was that inclusion of $\omega-3$ poly-unsaturated fatty acids (PUFAs) in the HI medium counteracted the development of insulin resistance and improved insulin-stimulated glucose uptake. Apparently, the effect of EPA was stronger than that of DHA.

\section{Glucose uptake}

The presently observed ability of $\omega-3$ fatty acids to antagonize the development of insulin resistance in cardiomyocytes is in line with results which have been reported in several models in the past. Thus, improved insulin-stimulated glucose uptake was observed in skeletal muscle after treatment with EPA or DHA [31], as well as in adipocytes co-cultured with macrophages [32]. Also, EPA and DHA were found to be more effective than other unsaturated fatty acids (including oleic acid) in preventing insulin resistance in L6 skeletal muscle cells [33]. These authors speculated that the effect of EPA and DHA could be related to their PPAR $\alpha$ ligand activity or anti-inflammatory activity. Yet the beneficial effect of EPA was more potent than that of DHA, perhaps because it is a better PPAR $\alpha$ activator. Alternatively, EPA might have other, yet unknown, subcellular targets.

Insulin-stimulated glucose uptake in cardiac myocytes is mediated by translocation of the glucose transporter GLUT4 from intracellular compartments to the plasma membrane [34]. In accordance with previous studies [31, 35] we found that the preserved insulin sensitivity in cardiomyocytes co-incubated with EPA and DHA during HI conditions was not associated with changes in the total expression of cellular GLUT4. Because of experimental limitations, we were not able to measure GLUT4 translocation (surface GLUT4), but several reports have 
shown that the defect in GLUT4 translocation is associated with alterations of the insulin-induced activation of Akt/PKB signaling pathway [36, 37].

Insulin-stimulated glucose transport in the heart appears to be primarily mediated by the Akt/PKB signaling pathway [38]. Furthermore, the Rab GTPaseactivating protein AS160 is a substrate for Akt/PKB and serves as a link between insulin activation of Akt/PKB and the subsequent translocation of GLUT4 to the cell surface [39]. As expected, induction of insulin resistance in cardiomyocytes (in response to long-term HI exposure) was associated with reduced phosphorylation of both Akt/PKB and AS160. The presence of EPA and DHA in the incubation medium prevented, however, this response, and may therefore explain the finding of a preserved insulin sensitivity of the cardiomyocytes, as demonstrated by increased glucose uptake in response to acute insulin stimulation.

One should bear in mind that Akt/PKB is not the only kinase responsible for phosphorylation of AS160. For example, AMPK, independently of insulin, is also able to phosphorylate AS160 [40] and to stimulate glucose uptake in the heart [25, 41]. However, from previous studies in different mammalian tissues the impact of $\omega$-3 PUFAs on AMPK activity is not clear (see Introduction). Nonetheless, our present results indicate that EPA or DHA do not activate AMPK. Hence, other mechanisms must be responsible for preservation of insulin signaling and insulinstimulated glucose uptake by these $\omega-3$ PUFAs during culturing of cardiomyocytes under insulin resistance-inducing conditions.

The fact that EPA and DHA prevented the reduction in Akt/PKB activity (phosphorylation) during $\mathrm{HI}$ conditions could also explain the concomitant increased phosphorylation of GSK3, since GSK3 is a downstream target of Akt/PKB. Over the last two decades it has become apparent that GSK3 plays a key role in the regulation of many cell functions, including signaling by insulin, growth factors and nutrients [42]. Moreover, numerous studies have implicated GSK3 in the pathogenesis of insulin resistance and T2DM; increased GSK3 protein level was reported in human skeletal muscle [43], and increased activity of GSK3 was also reported in hearts from diabetic mice $[43,44]$. Therefore, the inhibition of GSK3 by EPA and DHA in the insulin resistant cardiomyocytes argues in favor of $\omega-3$ fatty acids as a therapeutic principle in insulin resistance and type 2 diabetes.

\section{Fatty acid uptake/CD36}

Redistribution of CD36 from intracellular stores to the plasma membrane and lipid accumulation are early changes occurring in the heart during diet-induced obesity and insulin resistance [9]. Thus, cardiomyocytes which were made insulin resistant by HI displayed elevated sarcolemmal CD36 content and increased basal palmitate uptake. The HI-induced increase in basal palmitate uptake was further increased in the presence of EPA and DHA but, surprisingly, this response was accompanied neither by changes in the total expression of CD36 nor by translocation of CD36 to the plasma membrane. On the contrary, inclusion of EPA and DHA significantly prevented the robust translocation of CD36 to the sarcolemma, which was otherwise seen in the insulin resistant cardiomyocytes. At 
a first glance, this observation seems paradoxical, but on the other hand it shows that exposure to EPA and DHA prevented one of the main processes involved in the development of insulin resistance, namely persistent CD36 relocation to the sarcolemma. The finding that insulin sensitivity, measured as acute insulinstimulated palmitate (and glucose) uptake was maintained in the presence of EPA supports this notion. Our results are also consistent with results by Madonna and colleagues [45], who observed a decreased plasma membrane content of CD36 after the treatment with EPA or DHA in human microvascular endothelial cells.

The fact that the EPA/DHA-induced elevation of basal palmitate uptake was not paralleled by elevated presence of CD36 at the sarcolemma indicates that EPA and DHA open alternative avenues for palmitate uptake, which by-pass the CD36 transporter. One possibility could be that the presence of EPA/DHA alters the fluidity of the sarcolemma by incorporation into the phospholipid by-layer, allowing for increased uptake of palmitate through passive diffusion [46]. Apparently, this was not the case, since blocking of CD36 during EPA exposure by specific anti-CD36 antibodies almost totally prevented the palmitate uptake (Fig. 3A). Perhaps, in addition to their prevention of CD36 permanent relocation to sarcolemma, both EPA and DHA alter the bilayer organization around CD36, thereby increasing the LCFA transport function of this membrane protein. The sum of these two opposing effects would then be an increase in basal LCFA uptake rate. However, an increase in basal palmitate uptake would be an undesired action, in the light of palmitate-induced insulin resistance via diacylglycerols and/or ceramides [47]. However, this could be counteracted by increased CD36-mediated EPA and DHA uptake into cardiomyocytes, allowing both $\omega-3$ fatty acids to reach intracellular targets, such as PPARs. Subsequently, PPAR $\alpha$ activation might increase mitochondrial $\beta$-oxidation of LCFA, thereby preventing/reversing the conversion of palmitate into diacylglycerols/ceramides.

\section{Concluding remarks}

In summary, the present study shows that EPA and DHA counteract the development of insulin resistance in isolated cardiomyocytes incubated under insulin resistance-evoking conditions by preserving the phosphorylation state of key proteins in the insulin signaling cascade. EPA and DHA also similarly prevent the persistent relocation of CD36 to the sarcolemma. EPA and DHA might exert these beneficial effects, not through one specific subcellular action, but rather through a combination of different actions, perhaps involving an increased fluidity of the sarcolemmal lipid bilayer, as well as activation of PPAR $\alpha$, but not involving AMPK. Interestingly, EPA more potently improved insulin stimulated glucose and LCFA uptake and contractile function. This suggests that EPA might have additional, yet unknown, subcellular targets in cardiomyocytes that are not shared by DHA treatment, which effects would contribute to EPA's superior beneficial actions. For instance, EPA, but not DHA, might activate VAMP2, a SNARE protein involved in the regulation of both insulin-stimulated glucose and LCFA uptake [48]. Finally, to our knowledge this is the first study extending the beneficial effects of $\omega-3$ fatty acids to preservation of contractile function of the heart at the cellular level and in the context of insulin resistance. 


\section{References}

1. Rodrigues B, Cam MC, McNeill JH. Metabolic disturbances in diabetic cardiomyopathy. Molecular and cellular biochemistry. 1998;180:53-7.

2. Aasum E, Hafstad AD, Severson DL, Larsen TS. Age-dependent changes in metabolism, contractile function, and ischemic sensitivity in hearts from db/db mice. Diabetes. 2003;52:434-41.

3. Abel ED, O'Shea KM, Ramasamy R. Insulin resistance: metabolic mechanisms and consequences in the heart. Arterioscler Thromb Vasc Biol. 2012;32:2068-76.

4. Desrois M, Sidell RJ, Gauguier D, King LM, Radda GK, Clarke K. Initial steps of insulin signaling and glucose transport are defective in the type 2 diabetic rat heart. Cardiovascular research. 2004;61:288-96.

5. Park SY, Cho YR, Kim HJ, Higashimori T, Danton C, Lee MK, et al. Unraveling the temporal pattern of diet-induced insulin resistance in individual organs and cardiac dysfunction in C57BL/6 mice. Diabetes. 2005;54:3530-40.

6. Ouwens DM, Boer C, Fodor M, de Galan P, Heine RJ, Maassen JA, et al. Cardiac dysfunction induced by high-fat diet is associated with altered myocardial insulin signalling in rats. Diabetologia. 2005;48:1229-37.

7. van Oort MM, van Doorn JM, Bonen A, Glatz JF, van der Horst DJ, Rodenburg KW, et al. Insulininduced translocation of CD36 to the plasma membrane is reversible and shows similarity to that of GLUT4. Biochim Biophys Acta. 2008;1781:61-71.

8. Ouwens DM, Diamant M, Fodor M, Habets DD, Pelsers MM, El Hasnaoui M, et al. Cardiac contractile dysfunction in insulin-resistant rats fed a high-fat diet is associated with elevated CD36-mediated fatty acid uptake and esterification. Diabetologia. 2007;50:1938-48.

9. Angin Y, Steinbusch LK, Simons PJ, Greulich S, Hoebers NT, Douma K, et al. CD36 inhibition prevents lipid accumulation and contractile dysfunction in rat cardiomyocytes. The Biochemical journal. 2012;448:43-53.

10. Storlien LH, Jenkins AB, Chisholm DJ, Pascoe WS, Khouri S, Kraegen EW. Influence of dietary fat composition on development of insulin resistance in rats. Relationship to muscle triglyceride and omega-3 fatty acids in muscle phospholipid. Diabetes. 1991;40:280-9.

11. Anderson BM, Ma DW. Are all n-3 polyunsaturated fatty acids created equal? Lipids Health Dis. 2009;8:33.

12. Stone NJ. Fish consumption, fish oil, lipids, and coronary heart disease. Circulation. 1996;94:233740 .

13. Duda MK, O'Shea KM, Stanley WC. omega-3 polyunsaturated fatty acid supplementation for the treatment of heart failure: mechanisms and clinical potential. Cardiovascular research. 2009;84:33-41.

14. O'Shea KM, Chess DJ, Khairallah RJ, Hecker PA, Lei B, Walsh K, et al. omega-3 Polyunsaturated fatty acids prevent pressure overload-induced ventricular dilation and decrease in mitochondrial enzymes despite no change in adiponectin. Lipids Health Dis. 2010;9:95.

15. Chen J, Shearer GC, Chen Q, Healy CL, Beyer AJ, Nareddy VB, et al. Omega-3 fatty acids prevent pressure overload-induced cardiac fibrosis through activation of cyclic GMP/protein kinase $G$ signaling in cardiac fibroblasts. Circulation. 2011;123:584-93.

16. Abel ED. Free fatty acid oxidation in insulin resistance and obesity. Heart Metab. 2010;48:5-10.

17. Dobrzyn A, Dobrzyn P, Miyazaki M, Ntambi JM. Polyunsaturated fatty acids do not activate AMPactivated protein kinase in mouse tissues. Biochemical and biophysical research communications. 2005;332:892-6.

18. Dentin R, Benhamed F, Pegorier JP, Foufelle F, Viollet B, Vaulont S, et al. Polyunsaturated fatty acids suppress glycolytic and lipogenic genes through the inhibition of ChREBP nuclear protein translocation. The Journal of clinical investigation. 2005;115:2843-54.

19. Suchankova G, Tekle M, Saha AK, Ruderman NB, Clarke SD, Gettys TW. Dietary polyunsaturated fatty acids enhance hepatic AMP-activated protein kinase activity in rats. Biochemical and biophysical research communications. 2005;326:851-8.

20. Gabler NK, Radcliffe JS, Spencer JD, Webel DM, Spurlock ME. Feeding long-chain n-3 polyunsaturated fatty acids during gestation increases intestinal glucose absorption potentially via the acute activation of AMPK. J Nutr Biochem. 2009;20:17-25.

21. Kopecky J, Rossmeisl M, Flachs P, Kuda O, Brauner P, Jilkova Z, et al. n-3 PUFA: bioavailability and modulation of adipose tissue function. The Proceedings of the Nutrition Society. 2009;68:361-9. 
22. Lorente-Cebrian S, Bustos M, Marti A, Martinez JA, Moreno-Aliaga MJ. Eicosapentaenoic acid stimulates AMP-activated protein kinase and increases visfatin secretion in cultured murine adipocytes. Clin Sci (Lond). 2009;117:243-9.

23. Luiken JJ, van Nieuwenhoven FA, America G, van der Vusse GJ, Glatz JF. Uptake and metabolism of palmitate by isolated cardiac myocytes from adult rats: involvement of sarcolemmal proteins. J Lipid Res. 1997;38:745-58.

24. Greulich S, de Wiza DH, Preilowski S, Ding Z, Mueller H, Langin D, et al. Secretory products of guinea pig epicardial fat induce insulin resistance and impair primary adult rat cardiomyocyte function. J Cell Mol Med. 2011;15:2399-410.

25. Bertrand L, Ginion A, Beauloye C, Hebert AD, Guigas B, Hue L, et al. AMPK activation restores the stimulation of glucose uptake in an in vitro model of insulin-resistant cardiomyocytes via the activation of protein kinase B. American journal of physiology Heart and circulatory physiology. 2006;291:H239-50.

26. Luiken JJ, Koonen DP, Willems J, Zorzano A, Becker C, Fischer Y, et al. Insulin stimulates long-chain fatty acid utilization by rat cardiac myocytes through cellular redistribution of FAT/CD36. Diabetes. 2002;51:3113-9.

27. Lorente-Cebrian S, Costa AG, Navas-Carretero S, Zabala M, Martinez JA, Moreno-Aliaga MJ. Role of omega-3 fatty acids in obesity, metabolic syndrome, and cardiovascular diseases: a review of the evidence. Journal of physiology and biochemistry. 2013.

28. Pepe S, McLennan PL. Dietary fish oil confers direct antiarrhythmic properties on the myocardium of rats. J Nutr. 1996;126:34-42.

29. Pepe S, McLennan PL. Cardiac membrane fatty acid composition modulates myocardial oxygen consumption and postischemic recovery of contractile function. Circulation. 2002;105:2303-8.

30. McLennan PL, Abeywardena MY, Dallimore JA, Raederstorff D. Dietary fish oil preserves cardiac function in the hypertrophied rat heart. Br J Nutr. 2012;108:645-54.

31. Aas V, Rokling-Andersen MH, Kase ET, Thoresen GH, Rustan AC. Eicosapentaenoic acid (20:5 n-3) increases fatty acid and glucose uptake in cultured human skeletal muscle cells. Journal of lipid research. 2006;47:366-74.

32. Oliver E, McGillicuddy FC, Harford KA, Reynolds CM, Phillips CM, Ferguson JF, et al. Docosahexaenoic acid attenuates macrophage-induced inflammation and improves insulin sensitivity in adipocytes-specific differential effects between LC n-3 PUFA. J Nutr Biochem. 2012;23:1192-200.

33. Sawada K, Kawabata K, Yamashita T, Kawasaki K, Yamamoto N, Ashida H. Ameliorative effects of polyunsaturated fatty acids against palmitic acid-induced insulin resistance in L6 skeletal muscle cells. Lipids Health Dis. 2012;11:36.

34. Fischer Y, Thomas J, Sevilla L, Munoz P, Becker C, Holman G, et al. Insulin-induced recruitment of glucose transporter 4 (GLUT4) and GLUT1 in isolated rat cardiac myocytes. Evidence of the existence of different intracellular GLUT4 vesicle populations. The Journal of biological chemistry. 1997;272:7085-92.

35. Le Foll C, Corporeau C, Le Guen V, Gouygou JP, Berge JP, Delarue J. Long-chain n-3 polyunsaturated fatty acids dissociate phosphorylation of Akt from phosphatidylinositol 3'-kinase activity in rats. American journal of physiology Endocrinology and metabolism. 2007;292:E1223-30.

36. Huisamen B. Protein kinase B in the diabetic heart. Molecular and cellular biochemistry. 2003;249:31-8.

37. Coort SL, Bonen A, van der Vusse GJ, Glatz JF, Luiken JJ. Cardiac substrate uptake and metabolism in obesity and type-2 diabetes: role of sarcolemmal substrate transporters. Molecular and cellular biochemistry. 2007;299:5-18.

38. Bertrand L, Horman S, Beauloye C, Vanoverschelde JL. Insulin signalling in the heart. Cardiovascular research. 2008;79:238-48.

39. Sano H, Kane S, Sano E, Miinea CP, Asara JM, Lane WS, et al. Insulin-stimulated phosphorylation of a Rab GTPase-activating protein regulates GLUT4 translocation. The Journal of biological chemistry. 2003;278:14599-602.

40. Kramer HF, Witczak CA, Fujii N, Jessen N, Taylor EB, Arnolds DE, et al. Distinct signals regulate AS160 phosphorylation in response to insulin, AICAR, and contraction in mouse skeletal muscle. Diabetes. 2006;55:2067-76.

41. Russell RR, 3rd, Bergeron R, Shulman GI, Young LH. Translocation of myocardial GLUT-4 and increased glucose uptake through activation of AMPK by AICAR. The American journal of physiology. 1999;277:H643-9.

42. Cohen P, Frame S. The renaissance of GSK3. Nature reviews Molecular cell biology. 2001;2:769-76. 
43. Nikoulina SE, Ciaraldi TP, Mudaliar S, Mohideen P, Carter L, Henry RR. Potential role of glycogen synthase kinase-3 in skeletal muscle insulin resistance of type 2 diabetes. Diabetes. 2000;49:26371.

44. Eldar-Finkelman H, Schreyer SA, Shinohara MM, LeBoeuf RC, Krebs EG. Increased glycogen synthase kinase-3 activity in diabetes- and obesity-prone C57BL/6J mice. Diabetes. 1999;48:16626.

45. Madonna R, Salerni S, Schiavone D, Glatz JF, Geng YJ, De Caterina R. Omega-3 fatty acids attenuate constitutive and insulin-induced CD36 expression through a suppression of PPAR alpha/gamma activity in microvascular endothelial cells. Thrombosis and haemostasis. 2011;106:500-10.

46. Hashimoto M, Hossain S, Yamasaki H, Yazawa K, Masumura S. Effects of eicosapentaenoic acid and docosahexaenoic acid on plasma membrane fluidity of aortic endothelial cells. Lipids. 1999;34:1297-304.

47. Samuel VT, Petersen KF, Shulman GI. Lipid-induced insulin resistance: unravelling the mechanism. Lancet. 2010;375:2267-77.

48. Schwenk RW, Dirkx E, Coumans WA, Bonen A, Klip A, Glatz JF, et al. Requirement for distinct vesicle-associated membrane proteins in insulin- and AMP-activated protein kinase (AMPK)induced translocation of GLUT4 and CD36 in cultured cardiomyocytes. Diabetologia. 2010;53:2209-19. 


\section{Chapter 4}

\section{Calcium signaling recruits substrate transporters GLUT4 and CD36 to the
sarcolemma without increasing substrate
uptake transporters GLUT4 and CD36 to the
sarcolemma without increasing substrate
uptake transporters GLUT4 and CD36 to the
sarcolemma without increasing substrate
uptake}

Yeliz Angin ${ }^{1}$, Robert W. Schwenk ${ }^{1}$, Reyhan Nergiz-Unal ${ }^{2}$, Nicole Hoebers ${ }^{1}$, Johan W. M. Heemskerk ${ }^{2}$, Will A. Coumans ${ }^{1}$, Marc A. M. J. van Zandvoort ${ }^{3}$, Arend Bonen ${ }^{4}$, Dietbert Neumann ${ }^{1}$, Jan F.C. Glatz ${ }^{1}$ and Joost J.F.P. Luiken ${ }^{1}$

\footnotetext{
${ }^{1}$ Department of Molecular Genetics, ${ }^{2}$ Department of Biochemistry, and

${ }^{3}$ Department of Molecular Cell Biology, School for Cardiovascular Diseases (CARIM), Maastricht University, Maastricht, the Netherlands ${ }^{4}$ Department of Human Health and Nutritional Sciences, University of Guelph, Guelph, Ontario, N1G 2W1, Canada
} 


\begin{abstract}
Activation of AMP-activated protein kinase (AMPK) in cardiomyocytes induces translocation of glucose transporter GLUT4 and long-chain fatty acid (LCFA) transporter CD36 from endosomal stores to the sarcolemma to enhance glucose and LCFA uptake, respectively. $\mathrm{Ca}^{2+} /$ calmodulin-activated kinase kinase- $\beta$ $($ CaMKK- $\beta$ ) is positioned directly upstream of AMPK. However, it is unknown whether acute increases in $\left[\mathrm{Ca}^{2+}\right]_{i}$ stimulate translocation of GLUT4 and CD36 and uptake of glucose and LCFA, and whether $\mathrm{Ca}^{2+}$ signaling converges with AMPK signaling to exert these actions. Therefore, we studied the interplay between $\mathrm{Ca}^{2+}$ and AMPK signaling in regulation of cardiomyocyte substrate uptake. Exposure of primary cardiomyocytes to inhibitors or activators of $\mathrm{Ca}^{2+}$ signaling did not affect AMPK-Thr172 phosphorylation nor basal and AMPK-mediated glucose and LCFA uptake. In contrast to their lack of an effect on substrate uptake, $\mathrm{Ca}^{2+}$ signaling activators induced GLUT4 and CD36 translocation. When cardiomyocytes were cotreated with activators of $\mathrm{Ca}^{2+}$ and AMPK signaling, $\mathrm{Ca}^{2+}$ signaling activators stimulated glucose and LCFA uptake on top of AMPK-mediated substrate uptake. $\mathrm{Ca}^{2+}$ signaling shows no involvement in AMPK-induced GLUT4/CD36 translocation and substrate uptake, but elicits transporter translocation via a separate pathway requiring $\mathrm{CaMKK} \beta / \mathrm{CaMKs}$. $\mathrm{Ca}^{2+}$-induced transporter translocation by itself appears ineffective to increase substrate uptake, but requires additional AMPK activation to effectuate transporter translocation into increased substrate uptake. $\mathrm{Ca}^{2+}$-induced transporter translocation might be crucial under excessive cardiac stress conditions that require supraphysiological energy demands. Alternatively, $\mathrm{Ca}^{2+}$ signaling might prepare the heart for substrate uptake during physiological contraction by inducing transporter translocation.
\end{abstract}




\section{Introduction}

Cardiac muscle meets its energy demands predominantly by uptake of glucose (20$30 \%$ ) and long-chain fatty acids (LCFA; 60-70\%) from the circulation. During the continuous contractile activity of the heart, glucose and LCFA are taken up into cardiomyocytes via protein-mediated transport involving glucose transporter-4 (GLUT4) and fatty acid translocase/CD36, respectively $[1,2]$. We and others have shown that enhanced cardiac contraction, e.g., as a result of increased sympathicus input, leads to the simultaneous translocation of GLUT4 and CD36 from endosomal compartments to the sarcolemma to increase substrate entry $[1,3,4]$.

With respect to the signaling mechanisms involved in contraction-induced GLUT4 and CD36 translocation in cardiomyocytes, there is solid evidence for the involvement of AMP-activated protein kinase (AMPK), especially the AMPK $\alpha 2$ isoform [4, 5]. Following a rise in subcellular AMP, the binding of AMP to AMPK makes this kinase conformationally accessible for phosphorylation by an AMPK kinase at Thr172, so that it will become activated. In cardiomyocytes from LKB1null mice, GLUT4 and CD36 translocation did not respond to contraction-like stimulation, disclosing LKB1 as the responsible upstream kinase of AMPK [5]. Activation of AMPK results in a series of signaling events, such as AS160 phosphorylation causing GLUT4 and CD36 translocation [6, 7] and a consequential increase in substrate uptake. Additionally, AMPK activation increases glucose and LCFA oxidation through phosphorylation of glycolytic enzymes and of acetyl-CoA carboxylase (ACC), respectively.

Besides regulating AMPK activity, the continuous contractions of the heart also regulate the reoccurring $\mathrm{Ca}^{2+}$ transients. A rise in the intracellular $\mathrm{Ca}^{2+}$ concentration $\left(\left[\mathrm{Ca}^{2+}\right]_{\mathrm{i}}\right)$ in each excitation-contraction coupling of the heart and also of skeletal muscle stimulates $\mathrm{Ca}^{2+}$-dependent signaling events, such as activation of $\mathrm{Ca}^{2+} /$ calmodulin-dependent kinases (CaMK/CaMKK) through binding of $\mathrm{Ca}^{2+}$ to its carrier protein calmodulin. The binding of the $\mathrm{Ca}^{2+} /$ calmodulin complex to the CaM domain of CaMKKs and of CaMKII releases the auto-inhibition and leads to further activation of these Ser/Thr protein kinases. Activated CaMKK phosphorylates and activates its downstream target CaMKI. There are two isoforms of CaMKK, of which only CaMKK- $\beta$ is highly expressed in the heart. Under normal physiological conditions, $\left[\mathrm{Ca}^{2+}\right]_{\mathrm{i}}$ in the heart is finely regulated and the activity of CaMKs is regulated by protein phosphatases in concert with $\left[\mathrm{Ca}^{2+}\right]_{i}[8-10]$. Despite that both CaMKK and CaMKII are activated in response to a cytoplasmic $\mathrm{Ca}^{2+}$ rise via a $\mathrm{Ca}^{2+} /$ calmodulin dependent manner, it has been shown in skeletal muscle that both kinases also have autonomous activity $[11,12]$. Additionally, it was reported that exercise leads to rapid activation and increased phosphorylation of CaMKII and its downstream targets [13]. However the degree of autonomous activity of both CaMKKs and CaMKs, the speed of their activation as well as the duration of their active states have not yet been reported for heart tissue.

Studies describing the role of $\mathrm{Ca}^{2+}$-signaling in skeletal muscle substrate uptake often have used caffeine to increase $\left[\mathrm{Ca}^{2+}\right]_{i}[14,15]$. Specifically, it has been shown that caffeine treatment induces CaMKK- $\beta$ and CaMKII phosphorylation, 
concomitantly with increased glucose uptake. This caffeine-induced glucose uptake was sensitive to pharmacological CaMKK $\beta$ and CaMKII inhibition [14]. Moreover, contraction-induced glucose uptake was, at least partly, inhibited by CaMKK- $\beta$ and CaMKII inhibitors, indicative for a role of both $\mathrm{Ca}^{2+}$ activated kinases in contraction-induced glucose uptake [14]. Contraction-induced LCFA uptake also appeared to be inhibited by CaMKK- $\beta$ inhibition in skeletal muscle [16], whereas CaMKII inhibition has not yet been studied in this respect.

In contrast to skeletal muscle, information is lacking about the roles of CaMKK- $\beta$ and CaMKII in contraction-induced substrate uptake in the heart, especially in relation to AMPK. A possible bridge between $\mathrm{Ca}^{2+}$ signaling and AMPK signaling might be provided by CaMKK- $\beta$, because it is one of the kinases known to have AMPK kinase activity in vitro and to activate AMPK in mammalian cells deficient in LKB1 $[17,18]$. Indeed, several studies in skeletal muscle indicate that CaMKK- $\beta$ and CaMKII stimulate muscle substrate uptake through AMPK activation. However, other data suggest that this $\mathrm{Ca}^{2+}$-induced signaling axis stimulates substrate uptake independently of AMPK $[14,16,19,20]$. Therefore, the aim of this study was to investigate the interrelation between AMPK, CaMKs and $\left[\mathrm{Ca}^{2+}\right]_{\mathrm{i}}$ in the regulation of transporter mediated substrate uptake into cardiomyocytes. In order to assess separately the effects of $\left[\mathrm{Ca}^{2+}\right]_{i}$ and of CaMKK- $\beta / \mathrm{CaMKs}$ on AMPK mediated substrate uptake, we used pharmacological agents to activate these signaling pathways individually and independent from contraction.

\section{Materials and Methods}

\section{$\underline{\text { Materials }}$}

2-Deoxy-D-[1-3H]glucose and [1-14C]palmitic acid were obtained from GE Healthcare (Piscataway, NJ, USA). Bovine serum albumin (BSA, fraction V, essentially fatty acid free), laminin, phloretin, DMSO, thapsigargin, A23187, STO609, and KN93, oligomycin, 5-amino-1- $\beta$-D-ribofuranosyl-imidazole-4carboxamide (AICAR), adenine $9-\beta$-D-arabinofuranoside (Ara-A) were obtained from Sigma Aldrich (St. Louis, MO, USA). Sulfo-NHS-LC-biotin and immobilized streptavidin were from Perbio Science (Etten-Leur, the Netherlands). Compound C was from Calbiochem (Radnor, Pennsylvania). Fluo-4 acetoxy-methylester and pluronic acid were from Invitrogen (F1420c1) (Bleiswijk, the Netherlands).

\section{$\underline{\text { Antibodies }}$}

Antibodies were purchased as indicated: phospho-ACC (Ser79) (\# 07-303) from Upstate (Billerica, MA, USA), phospho-AMPKa (Thr172) (\#2531) and phosphoCaMKII (Thr286) (\#3361) from Cell Signaling Technology (Beverly, MA, USA), phospho-CaMKI (sc-28438-R) from Santa Cruz Biotechnology (Santa Cruz, CA, USA), caveolin3 (\#610420) from BD Transduction Laboratories (Franklin Lakes, NJ, USA), anti-CD36 antibody (CRF D-2717) used in 2-photon microscopic images from BD Pharmingen (Franklin Lakes, NJ, USA), anti-GLUT4 (Ab 1346) used in Western Blotting from Chemicon International (Billerica, MA, USA). FITC-labeled rabbit anti-mouse IgA secondary antibody was from from Rockland 
Immunochemical Inc (Gilbertsville, PA, USA). The anti-CD36 antibody (\# M025) used in Western Blotting was a gift from dr. N. Tandon (Bethesda, USA).

\section{Isolation of primary rat cardiomyocytes}

Adult rat cardiomyocytes (Lewis rats 200-250 g, 2-3 months of age) were isolated by using a Langendorff perfusion system according to the procedure developed by Fischer et al [21] as has been described previously [22]. This method yields mainly ventricular myocytes. A modified Krebs Henseleit bicarbonate (MKR) medium was stored at a 10 -fold concentration, and contained $1.17 \mathrm{M} \mathrm{NaCl}, 26 \mathrm{mM} \mathrm{KCl}, 12 \mathrm{mM}$ $\mathrm{KH}_{2} \mathrm{PO}_{4}, 12 \mathrm{mM} \mathrm{MgSO}_{4}, 100 \mathrm{mM} \mathrm{NaHCO} 3,100 \mathrm{mM}$ HEPES. Upon 10 -fold dilution of the concentrated stock for daily use, the MKR medium was adjusted to $\mathrm{pH} 7.55$ and equilibrated with a $95 \% \mathrm{O}_{2} / 5 \% \mathrm{CO}_{2}$ gas phase at $37^{\circ} \mathrm{C}$.

\section{Experiments with freshly isolated cardiomyocytes}

To recover from the isolation procedure, cardiomyocytes were incubated for an additional $90 \mathrm{~min}$ in medium A (1x MKR medium supplemented with 2\% BSA, 2 $\mathrm{mM}$ D-glucose and $1 \mathrm{mM} \mathrm{CaCl} 2$ ) while rotating at room temperature $\left(24^{\circ} \mathrm{C}\right)$. For substrate uptake measurements, approximately 200,000 cells per condition and for signaling experiments approximately 100,000 cells per condition were used. During these experiments, cell suspensions were incubated with/without stimulators and/or inhibitors of $\mathrm{Ca}^{2+}$ and AMPK signaling in capped 20-ml glass vials. The vials were placed in a $37^{\circ} \mathrm{C}$ water bath under continuous shaking at 160 rpm.

Measurement of 2-deoxy-[1-3H]glucose and [1-14C]palmitate uptake rates into cardiomyocytes

To increase $\left[\mathrm{Ca}^{2+}\right]_{\mathrm{i}}$ and also activate CaMKs/CaMKKs, cardiomyocytes were exposed to $5 \mu \mathrm{M}$ A23187 or to $5 \mu \mathrm{M}$ thapsigargin for $20 \mathrm{~min}$. For AMPK activation, cardiomyocytes were either treated with oligomycin $(5 \mu \mathrm{M})$ or AICAR $(1.5 \mathrm{mM})$ during $20 \mathrm{~min}$, or were subjected to $4 \mathrm{~Hz}$ electric field stimulation during the last 7 min of a 20 min total incubation time. For inhibition of CaMKs, cardiomyocytes were pre-incubated with ST0-609 $(5 \mu \mathrm{M})$ or KN93 $(5 \mu \mathrm{M})$ for 20 min whereafter either CaMKs or AMPK activating stimuli were added for an additional $20 \mathrm{~min}$. Subsequently, substrate uptake was measured by addition of $0.5 \mathrm{ml}$ of a mixture of 2-deoxy-[1-3 H]glucose and $\left[1-{ }^{14} \mathrm{C}\right]$ palmitate/BSA complex, as described previously [22]. Five min after addition of the radiolabeled substrates, the uptake reaction was stopped by transferring the cell contents to $15-\mathrm{ml}$ Falcon tubes containing icecold MKR buffer with $0.1 \%$ BSA and $0.2 \mathrm{mM}$ phloretin (stop solution). Cells then were washed two-times for $2 \mathrm{~min}$ at $45 \mathrm{~g}$ in ice-cold stop solution, as previously described [22]. The radioactivity of the cell pellets was measured by scintillation counting. 


\section{Measurements of $\left[\mathrm{Ca}^{2+}\right]_{i}$}

Freshly isolated cardiomyocytes were plated in laminin-coated 12-well plates in medium A. Cardiomyocytes were allowed to attach to the bottom of each well during 90 min before loading with $5 \mu \mathrm{M}$ Fluo-4 acetoxymethyl ester (AM) and 2 $\mathrm{mg} / \mathrm{ml}$ pluronic F-127 for $30 \mathrm{~min}$. After a 15 min period to allow probe deesterification, the Fluo-4-loaded cells were washed 3 times with medium A. The washed cells in the 12 -well plate were subjected to $\mathrm{Ca}^{2+}$ measurements by pseudoratio fluorescence microscopic imaging, using a filter-wheel controlled Nikon Diaphot 200 microscope, equipped with a Hamamatsu EM-CCD digital camera and VitiTech (Sunderland, UK) image control software [23]. Recordings at $0.5 \mathrm{~Hz}$ from microscopic fields containing at least 15 cardiomyocytes were performed during addition of thapsigargin, A23187 or oligomycin (each at $5 \mu \mathrm{M}$ ) at the indicated time periods. Where indicated, cardiomyocytes were subjected to electric field stimulation at a frequency of $4 \mathrm{~Hz}$. Changes in Fluo- 4 fluorescence per region-ofinterest per image, representing a single cell, were converted to pseudo-ratio values $\mathrm{F}^{\prime}=\mathrm{F} / \mathrm{Fo}$; where $\mathrm{F}$ is the measured fluorescence value, Fo the average fluorescence level during $20 \mathrm{~s}$ under resting conditions, and F' the pseudo-ratio fluorescence level at any time. Calibration of $\mathrm{F}^{\prime}$ to nanomolar levels of $\left[\mathrm{Ca}^{2+}\right]_{\mathrm{i}}$ was made via the equation $\left[\mathrm{Ca}^{2+}\right]_{\mathrm{i}}=\mathrm{Kd} \mathrm{F}^{\prime} /\left(\mathrm{F}^{\prime} \max -\mathrm{F}^{\prime}\right)$. The maximal pseudo-ratio fluorescence level, F'max, was determined for each optical condition with calibrated solutions of free Fluo-4 [24].

\section{Surface detection of GLUT4 and CD36}

Three distinct methods were used to assess cellular surface presence of GLUT4 and CD36.

a) Biotinylation method: The biotinylation technique was used to separate plasma membrane proteins from subcellular proteins. After isolation, cardiomyocytes were plated on laminin coated $(10 \mu \mathrm{g} / \mathrm{ml}) 35-\mathrm{mm}$ culture plates. After $90 \mathrm{~min}$ attachment, cells were incubated with stimuli and subsequently biotinylated with the cell-impermeable reagent sulfo-NHS-LC-biotin in $1 \mathrm{x}$ MKR medium at a final concentration of $1 \mathrm{mg} / \mathrm{ml}$ for $45 \mathrm{~min}$ at $4^{\circ} \mathrm{C}$ as described previously [25]. Thereafter cells were treated with ice-cold glycine $(100 \mathrm{mM})$ in $1 \mathrm{x}$ MKR medium. After a brief wash with ice-cold 1x MKR medium, cells were scraped in $300 \mu$ lysis buffer (consisting of $50 \mathrm{mM}$ Tris-HCL, $150 \mathrm{mM} \mathrm{NaCl}, 1 \%(\mathrm{v} / \mathrm{v}$ ) Igepal CA-630 (or NP40), 5\% (w/v) sodium deoxycholate, 1\% (w/v) SDS, 4\% (v/v) complete protease inhibitor cocktail, 5\% PhosSTOP phosphatase inhibitor cocktail). The lysates were rotated for 1 hour at $4^{\circ} \mathrm{C}$ and centrifuged for $10 \mathrm{~min}$ at 13,000 x g at $4^{\circ} \mathrm{C} .30 \mu \mathrm{l}$ supernatant was used for detecting total protein samples with Western blotting, and $150 \mu \mathrm{l}$ supernatant incubated overnight with streptavidin beads. Samples then were centrifuged for $2 \mathrm{~min}$ at $13,000 \mathrm{x}$ g at $4^{\circ} \mathrm{C}$. Thereafter, beads were washed twice with lysis buffer. The biotinylated proteins were eluted by incubation of the streptavidin beads for $5 \mathrm{~min}$ at $95^{\circ} \mathrm{C}$ in sample buffer $(40 \%$ glycerol, 0.25 M Tris, 1 M DTT, bromo-phenol-blue). Samples were subjected to SDS polyacrylamide gel electrophoresis, followed by Western Blotting for the detection of GLUT4 and C36. 
b) Fractionation method: After recovery, cardiomyocytes were pre-treated for 20 min with kinase inhibitors STO-609 and KN93 and subsequently stimulated with the indicated agonist for $15 \mathrm{~min}$. Thereafter, cell suspensions were subjected to the fractionation procedure as previously described. GLUT4 and CD36 proteins were detected by Western blotting.

c) Two-photon microscopy: Following a 10 min pre-treatment with either A23187, thapsigargin or oligomycin, cells were labeled during $10 \mathrm{~min}$ with $2 \mu \mathrm{g} / \mathrm{ml}$ (diluted in medium A) anti-CD36 antibody. Subsequently, FITC-labeled rabbit anti-mouse IgA secondary antibody $\left(\mathrm{C}_{\text {end }}\right.$ 1:500) was added to the cells. Finally, cardiomyocytes were washed twice with medium A. Viable cardiomyocytes were imaged using Leica SP5 Multiphoton imaging platform (Leica Microsystems). The excitation wavelength of the $140 \mathrm{fs}$-pulsed laser was $800 \mathrm{~nm}$, while emission filters were optimized for FITC detection (500-560 nm). Laser power was kept as low as possible to avoid bleaching and photo-damage. Images were processed with Image software (JAVA-based imaging software from the National Institutes of Health). Cardiomyocytes were kept at $37^{\circ} \mathrm{C}$ during incubations and imaging.

\section{$\underline{\text { Statistics }}$}

Differences among the data obtained from five to eight experiments are presented as means \pm SEM. Statistical differences between groups of observations was evaluated by unpaired Student's t-test, one way-ANOVA and/or two-way ANOVA, depending on the groups compared by using statistical analysis software Prism 5 (GraphPad Software, Inc.). A P-value equal or less than 0.05 was considered statistically significant.

\section{Results}

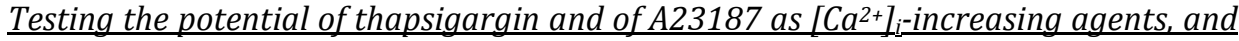
STO-609 and $\mathrm{KN} 93$ as $\mathrm{Ca}^{2+}$ signaling inhibitors in cardiomyocytes

Fluorescent $\mathrm{Ca}^{2+}$ indicators are suitable tools to study $\mathrm{Ca}^{2+}$ transients in primary adult cardiomyocytes [26]. In the present study, cardiomyocytes isolated from adult rats were adhered in 12-well plates and loaded with the $\mathrm{Ca}^{2+}$ probe Fluo-4 to measure single-cell $\mathrm{Ca}^{2+}$ transients by microscopic fluorescence imaging. We used two agents with different action mechanisms, i.e., the sarco/endoplasmic reticulum $\mathrm{Ca}^{2+}$-ATPase (SERCA) inhibitor thapsigargin and the $\mathrm{Ca}^{2+}$-ionophore $\mathrm{A} 23187$ to study the effects of increased $\left[\mathrm{Ca}^{2+}\right]$. Under resting conditions, in the absence of electric field stimulation, the majority of cells displayed incidental $\mathrm{Ca}^{2+}$ transients (Fig. 1A), which paralleled spontaneous contractions of the cells. In Fluo-4-loaded cells that were electrically stimulated at $4 \mathrm{~Hz}$ or treated with the ATP-synthase inhibitor oligomycin, the frequency of the $\mathrm{Ca}^{2+}$ transients noticeably increased from 5 to 14 and to 8 peaks per min, respectively. In either case, levels of $\left[\mathrm{Ca}^{2+}\right]_{\mathrm{i}}$ fully restored to basal levels in between each transient. Both conditions also raised the frequency of cardiomyocyte contractions. In contrast, stimulation of the cells with either thapsigargin or A23187 provoked marked and prolonged increases in $\left[\mathrm{Ca}^{2+}\right]_{\mathrm{i}}$ not restoring to baseline values within $5 \mathrm{~min}$. At these concentrations, 
A23178 and thapsigargin did not affect short-term cell survival, as the rod shaped appearance of the cardiomyocytes was not altered by these treatments (Fig. 1A).

A

Control

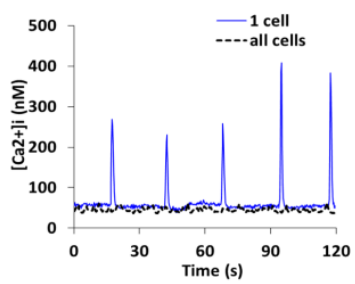

Thapsigargin
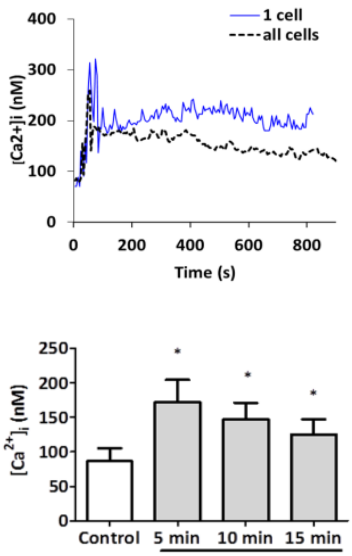

Thapsigargin

B Phospho-CaMKI

Phospho-CaMKII

Cav3

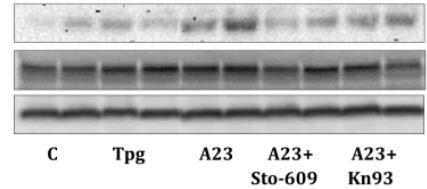

Phospho-CaMKI (Thr 177)
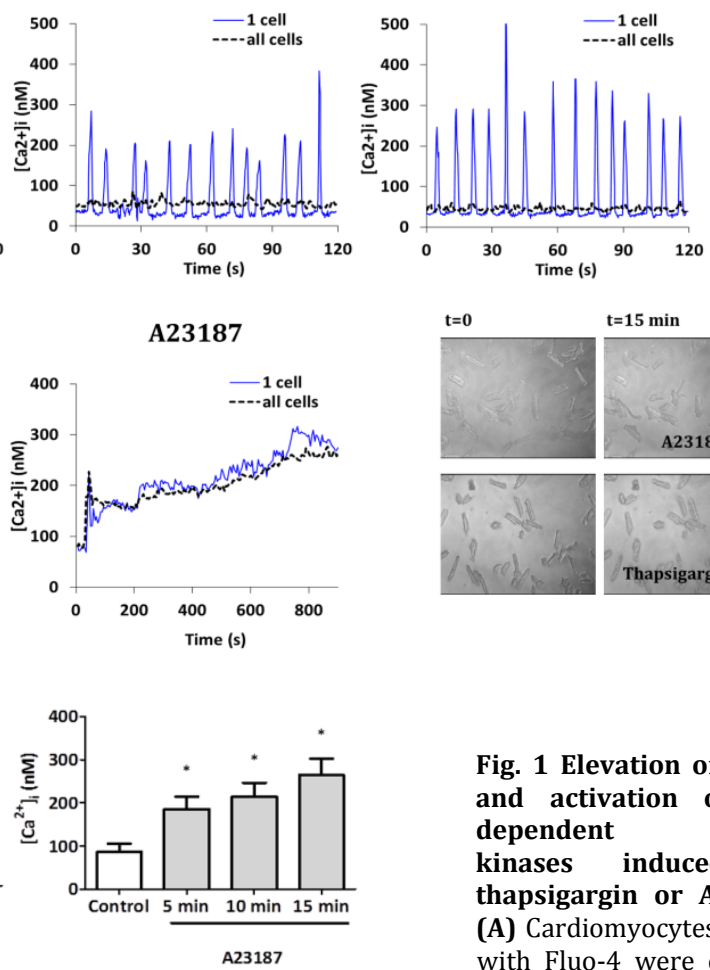

$\mathbf{t}=\mathbf{0}$

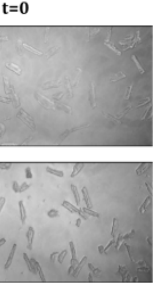

$\mathrm{t}=\mathbf{1 5}$ min

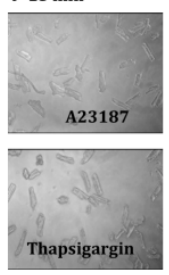

Fig. 1 Elevation of $\left[\mathrm{Ca}^{2+}\right]_{i}$ and activation of $\mathrm{Ca}^{2+}$ dependent protein kinases induced by thapsigargin or A23187. (A) Cardiomyocytes loaded with Fluo-4 were exposed to thapsigargin (Tpg, $5 \mu \mathrm{M}$ ) or A23187 (A23, $5 \mu \mathrm{M}$ ). Fluorescence changes in individual cells were recorded during $15 \mathrm{~min}$, whereas fluorescence changes in oligomycin $\mathrm{Cli}$, $5 \mu \mathrm{M}$ ) or in $4-\mathrm{Hz}$ electric field stimulation treated cells were recorded for 2 min. Traces are from representative cells, averaged traces are from 30-40 cells..

Cardiomyocytes were preincubated for $15 \mathrm{~min}$ in the absence (C) or presence of CaMKK inhibitor STO-609 $(5 \mu \mathrm{M})$ and CaMKII specific inhibitor KN93 $(5 \mu \mathrm{M})$ and then further treated with thapsigargin or A23187 for an additional $15 \mathrm{~min}$. (C) 
Cardiomyocytes were incubated for $15 \mathrm{~min}$ in the absence (C) or presence of oligomycin (Oli, $5 \mu \mathrm{M}$ ) or AICAR (1.5 mM). 4-Hz electric field stimulation was applied during the last $7 \mathrm{~min}$ of overall incubations. At the end of the incubations cells were lysed, and phosphorylation of CaMKI and of CaMKII were assessed by Western blotting. Caveolin-3 (Cav3) was used as a loading control. Values are displayed as mean \pm S.E.M ( $\mathrm{n}=5) .{ }^{*}$ vs. control, \# vs. A23187 $(\mathrm{P}<0.05)$.

Compatible with these differences in $\mathrm{Ca}^{2+}$ kinetics, thapsigargin and $\mathrm{A} 23187$ enhanced phosphorylation of CaMKI (by 1.6 and 2.2 fold, respectively) and of CaMKII (by 1.4 and 1.6 fold, respectively) (Fig. 1B). A23187-induced CaMKI phosphorylation was significantly inhibited by the CaMKK- $\beta$ inhibitor STO-609, but not by the CaMKII inhibitor KN93 (Fig. 1B). In contrast, A23187-induced CaMKII phosphorylation was significantly inhibited by KN93 but not by ST0-609 (Fig. 1B). We neither observed an increased phosphorylation of CaMKI nor of CaMKII upon $7 \mathrm{~min} 4 \mathrm{~Hz}$ stimulation (Fig. 1C), which is in contrast to findings in skeletal muscle [14, 15]. Additionally, treatment with oligomycin or AICAR treatment did not increase phosphorylation of either kinase (Fig. 1C).

We conclude that thapsigargin and A23187 can be used to increase $\left[\mathrm{Ca}^{2+}\right]_{\mathrm{i}}$ thereby activating both CaMKK- $\beta$ and CaMKII dependent signaling events in cardiomyocytes. Furthermore, $\mathrm{Ca}^{2+}$ signaling remains unchanged in response to oligomycin or AICAR indicating their specificity for AMPK activation in our cellular model. Also, the inhibitors STO-609 and KN93 block their intended target enzymes CaMKK $\beta$ and CaMKII, respectively.

\section{Effects of $\mathrm{Ca}^{2+}$ signaling on $A M P K$ activation and on AMPK-mediated substrate uptake}

We investigated the roles of CaMKK- $\beta$ and CaMKs in AMPK activation and in AMPK-mediated substrate uptake into cardiomyocytes. To activate AMPK in cardiomyocytes, we used both a pharmacological approach (oligomycin or AICAR) and a physiological approach (4-Hz electrostimulation). Each of these treatments induced AMPK-Thr172 phosphorylation (by 7.4-fold, 6.2-fold, and 2.9 -fold, respectively) and concomitantly phosphorylation of AMPK's major substrate ACC at Ser97 (by 10, 8, and 3-fold, respectively) (Fig. 2A), in agreement with our previous observations [4, 27]. Correspondingly, all three AMPK activators significantly enhanced palmitate uptake (by 1.7, 1.3, and 1.4 fold, respectively). Additionally, oligomycin and $4-\mathrm{Hz}$ electrostimulation enhanced glucose uptake (by 2.2 and 1.4 fold, respectively), whereas AICAR showed no effect (Fig. 2A). The inability of AICAR to induce glucose uptake is in agreement with our previous observations [5, 27, 28], and relates to the fact that next to AMPK activation, glucose uptake requires additional activation of protein kinase-D1 (PKD1). As a result, AICAR which in contrast to oligomycin or 4-Hz stimulation does not activate PKD1, can only be used to study AMPK-mediated LCFA uptake [28]. Pre-treatment of cardiomyocytes with ST0-609 or KN93 did not alter AMPK-Thr172 and ACCSer97 phosphorylation induced by all three AMPK-activating stimuli (Fig. 2A). Furthermore, pre-treatment with either of these inhibitors did not alter the effect of each of the three AMPK-activating stimuli on glucose nor palmitate uptake (Fig. 2B). 
In conclusion, $\mathrm{Ca}^{2+}$ signaling appears to be involved neither in AMPK activation nor in AMPK-mediated substrate uptake into cardiomyocytes.

A
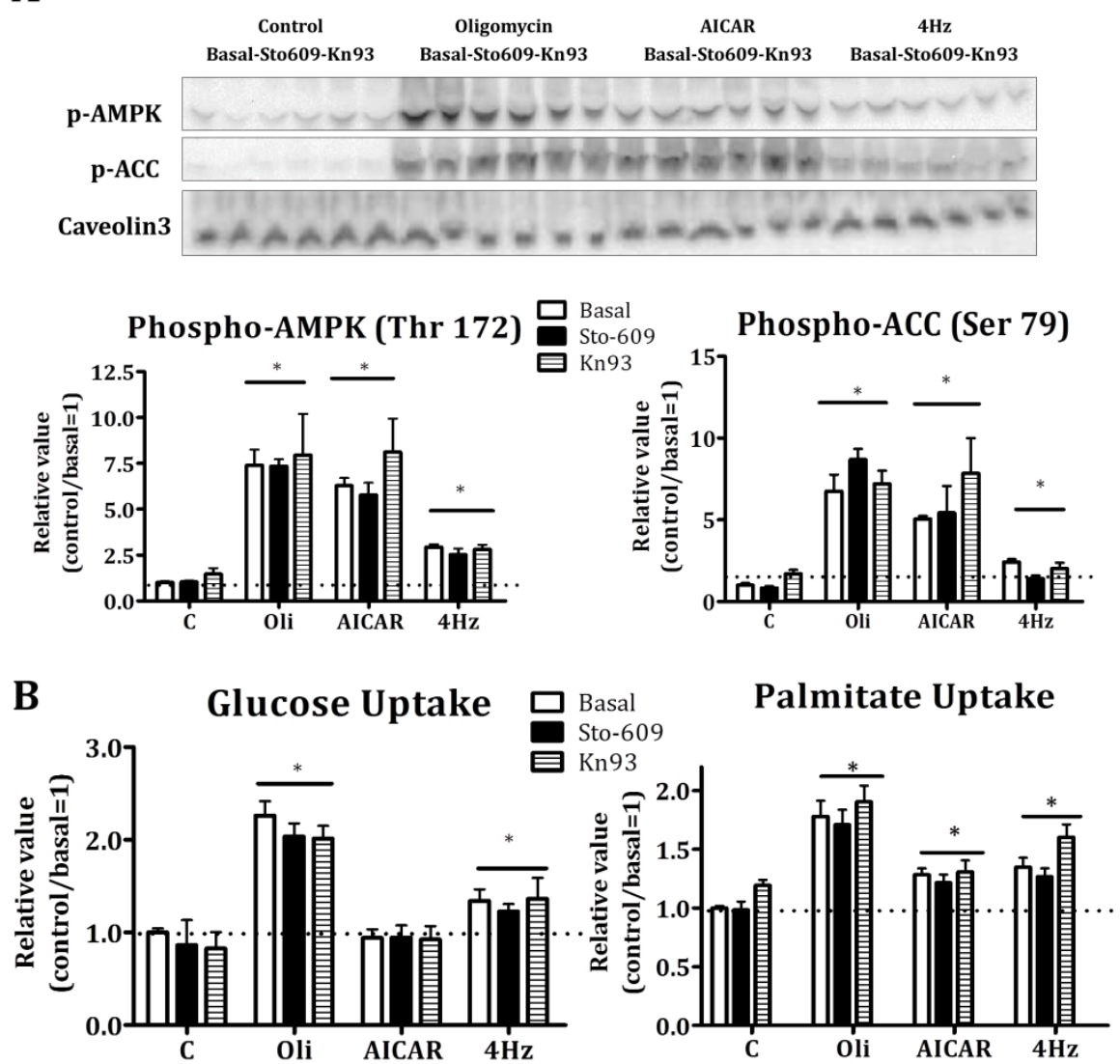

Fig. 2 Effects of ST0-609 and KN93 on AMPK activation and AMPK mediated substrate uptake into cardiomyocytes. Cardiomyocytes were pre-incubated for $15 \mathrm{~min}$ in the absence (C) or presence of ST0-609 or KN93, and subsequently subjected to AMPK activating stimuli: Oligomycin (Oli; $5 \mu$ M/15 $\mathrm{min}$ ), AICAR ( $5 \mathrm{mM} / 15 \mathrm{~min}$ ), electric field stimulation (4 Hz/7 min). (A) Cells were lysed, and activation of AMPK and ACC were assessed by Western blotting. (B) Uptake of 2-deoxy-[1-3 H]glucose and of [1${ }^{14} \mathrm{C}$ ]palmitate/BSA complex (5 $\mathrm{min}$ ) was determined as pelletable radioactivity. Values are displayed as mean \pm S.E.M $(n=5) .{ }^{*}$ vs. control $(\mathrm{P}<0.05)$.

\section{Effects of $\mathrm{Ca}^{2+}$ signaling on GLUT4 and CD36 translocation}

To investigate the effect of thapsigargin and of A23187 on GLUT4 and CD36 translocation, we used three independent methods to monitor transporter translocation: cell surface biotinylation, subcellular fractionation, and immunolabeling. Immunolabeling of cell surface protein, in contrast to the other methods, can only be employed for CD36 and not for GLUT4 detection, because suitable GLUT4 antibodies capable of recognizing the cell surface epitopes are lacking at present. In these experiments oligomycin, a well-established inducer 
of GLUT4 and CD36 translocation [4], was used as positive control to validate the suitability of each of these methods. First, cell surface biotinylation showed that oligomycin, as well as thapsigargin and A23187, enhanced sarcolemmal contents of GLUT4 (each by 1.3-fold) and CD36 (by 1.8, 2.1 and 1.9-fold, respectively) (Fig. 3A). This increase in cell surface content of both transporters occurred in the absence of changes in overall protein expression of GLUT4 and CD36 (Fig. 3A).

A

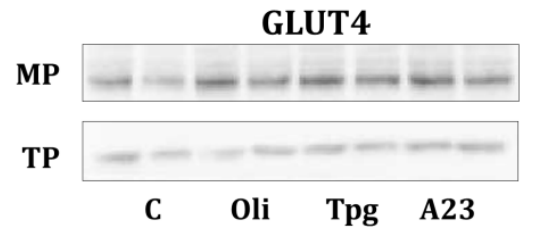

CD36

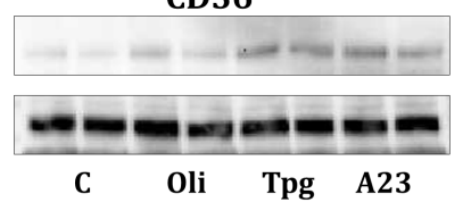

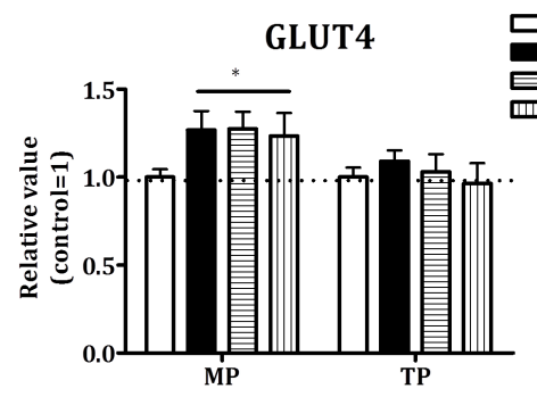

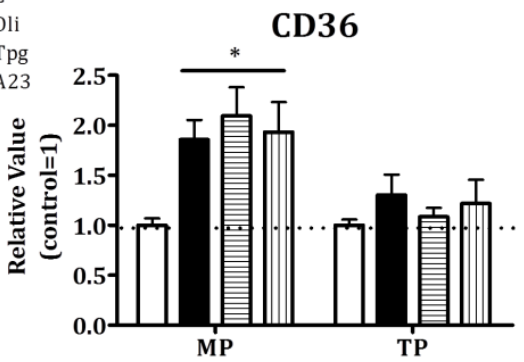

B

Plasma membrane

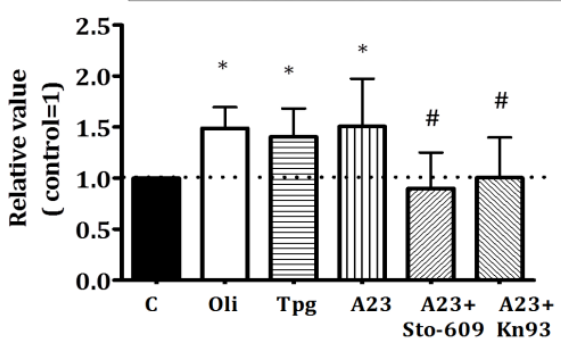

Low density microsomes
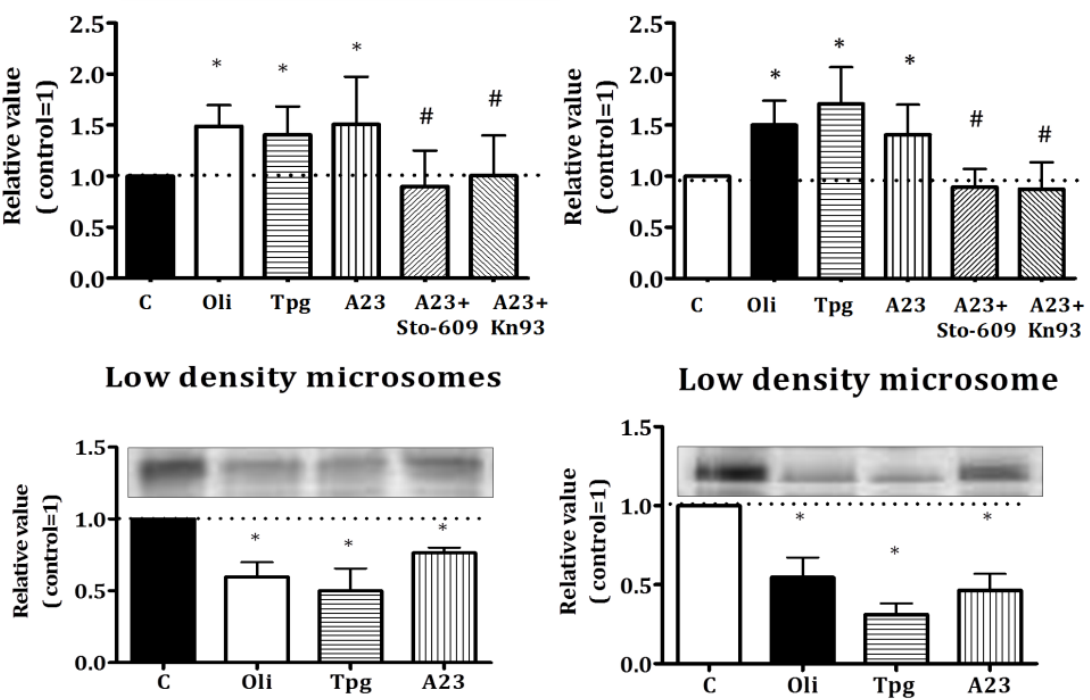

Low density microsome

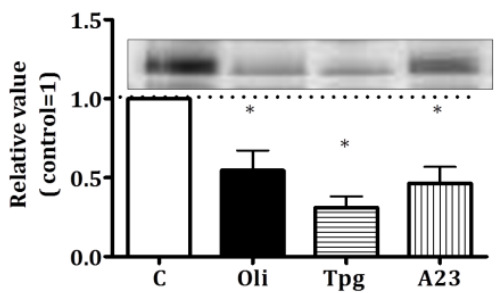




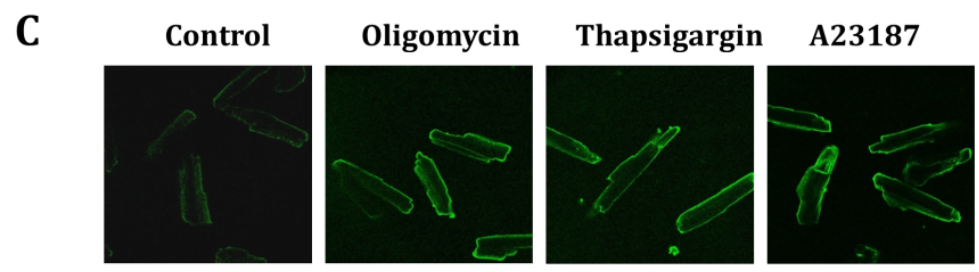

\section{Surface CD36}

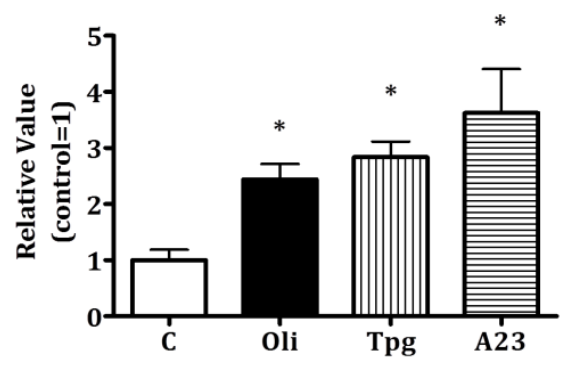

Fig. 3 Effects of $\left[\mathrm{Ca}^{2+}\right]_{\mathrm{i}}$-elevating agents on GLUT4 and CD36 translocation. (A, B) Cardiomyocytes were pre-incubated for $15 \mathrm{~min}$ in the absence (C) or presence of thapsigargin (Tpg; $5 \mu \mathrm{M}$ ), A23187 (A23; $5 \mu \mathrm{M}$ ), or oligomycin (Oli; $5 \mu \mathrm{M}$, positive control), and subsequently assessed on (A) sarcolemmal content of CD36 and GLUT4 using the biotinylation method, and on (B) plasma membrane and low density microsome content of CD36 and GLUT4 using the fractionation method. (C) Two-photon images of plasma membrane content of CD36 in primary cardiomyocytes subjected for 15 min to thapsigargin (Tpg), A23187 (A23), or oligomycin (Oli, positive control). Values are displayed as mean \pm S.E.M $(\mathrm{n}=5$ ). * vs. control , \# vs. A23187 ( $<<0.05)$.

Using subcellular fractionation, we also detected an increased sarcolemmal content of GLUT4 (by 1.5, 1.3, and 1.4-fold, respectively) and of CD36 (by 1.5, 1.7, and 1.4-fold, respectively) upon treatment with each of these stimuli (Fig. 3B). This method further demonstrated a concomitantly decreased content of GLUT4 (by $40 \%, 50 \%$, and 25\%, respectively) and of CD36 (by 50\%, 70\%, and 65\%, respectively) from the low density microsomal (LDM) fraction which represents intracellular membrane compartments (Fig. 3B).

Finally, immunodetection and microscopical visualization of CD36 in intact cardiomyocytes clearly demonstrated increased cell surface staining upon treatment with each stimulus (Fig. 3C).

In conclusion, just as oligomycin, the two applied $\mathrm{Ca}^{2+}$ raising agonists induce translocation of both GLUT4 and CD36 from intracellular membrane compartments to the sarcolemma.

\section{Effects of $\mathrm{Ca}^{2+}$ signaling on AMPK activation and substrate uptake}

Based on the observation that thapsigargin and or A23187 induce GLUT4 and CD36 translocation, we studied whether transporter membrane localization results in increased glucose and LCFA uptake rates, respectively. Whereas 
oligomycin markedly enhanced glucose and palmitate uptake into cardiomyocytes (Figs. 2B and 4A) and potently induced AMPK-Thr172 and ACC-Ser97 phosphorylation (Figs. 2A and 4B), thapsigargin and A23187 were without any effect on substrate uptake and phosphorylation of AMPK (Figs. 4A and 4B). Together, these findings indicate that AMPK activation is not involved in $\mathrm{Ca}^{2+}$ induced GLUT4 and CD36 translocation, and that $\mathrm{Ca}^{2+}$-induced translocation of both transporters as such is insufficient for increased glucose and/or LCFA uptake.

A

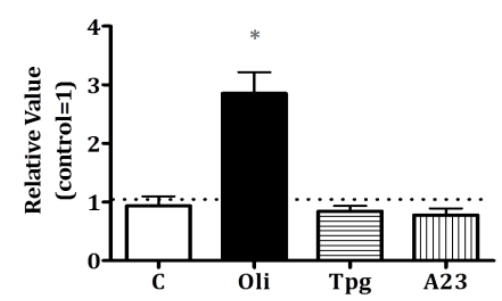

B

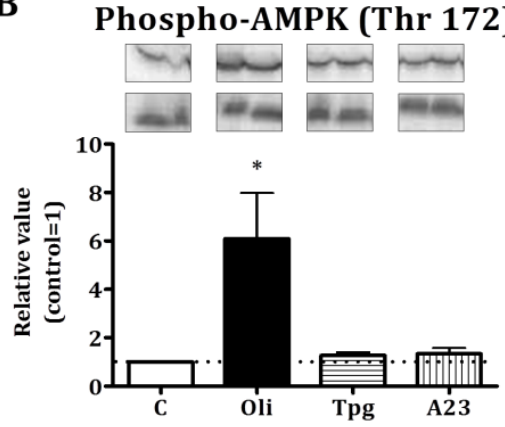

Palmitate Uptake

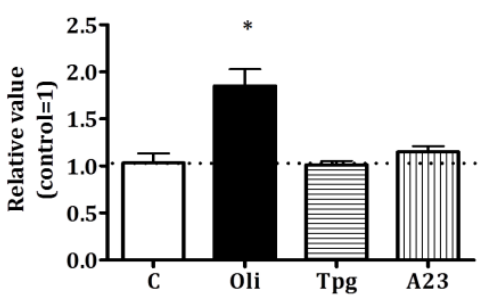

Phospho-ACC (Ser 79)

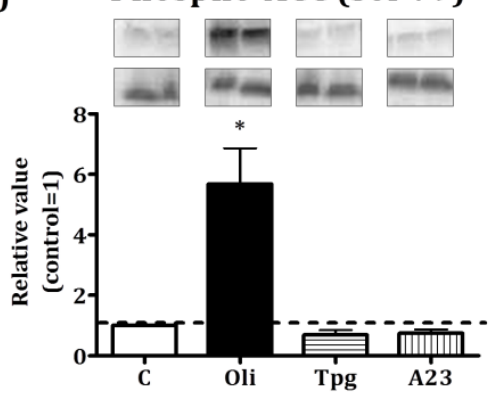

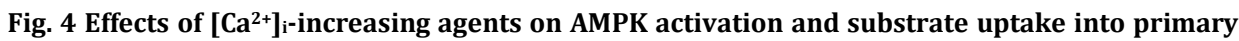
cardiomyocytes. Cardiomyocytes were incubated for $15 \mathrm{~min}$ in the absence (C) or presence of thapsigargin (Tpg; $5 \mu \mathrm{M})$, A23187 (A23; $5 \mu \mathrm{M})$, or oligomycin (Oli; $5 \mu \mathrm{M})$. (A) Uptake of 2-deoxy-[1$\left.{ }^{3} \mathrm{H}\right]$ glucose and of $\left[1^{-14} \mathrm{C}\right]$ palmitate $(5 \mathrm{~min})$ was determined as pelletable radioactivity. (B) Phosphorylation of AMPK and ACC was assessed by Western blotting. Values are displayed as mean \pm S.E.M ( $\mathrm{n}=5) .{ }^{*}$ vs. control $(\mathrm{P}<0.05)$.

\section{Combined effects of $\mathrm{Ca}^{2+}$ signaling and AMPK activation on substrate uptake}

Apparently, $\mathrm{Ca}^{2+}$-induced GLUT4 and CD36 translocation did not effectuate into increased uptake. However it is still possible, that co-activation of AMPK might be required to reveal a stimulatory action of $\mathrm{Ca}^{2+}$ raising agonists on glucose and LCFA uptake. For this purpose, we studied the effects of co-treatment of $\mathrm{Ca}^{2+}$ signaling activators with AMPK activators on glucose and palmitate uptake. In agreement with Fig. 4A, A23187 by itself did not alter glucose nor palmitate uptake, but it enhanced glucose uptake in the presence of oligomycin co-treatment (1.4-fold), and palmitate uptake in the presence of either oligomycin (1.2-fold) or AICAR (1.3-fold) co-treatment (Fig. 5A). In order to determine whether A23187stimulated substrate uptake was due to concomitant AMPK activation, and not to off-target actions of the used AMPK activators, we incubated the cardiomyocytes 
with established AMPK inhibitors, i.e., compound-C and adenine 9- $\beta$-Darabinofuranoside (Ara-A). As expected, each of these AMPK inhibitors inhibited AICAR-induced AMPK-Thr172 and ACC-Ser97 phosphorylation (Fig. 5B). While compound-C or Ara-A did not alter basal palmitate uptake, each agent completely inhibited AICAR-induced palmitate uptake (Fig. 5B). Furthermore, each agent completely inhibited A23187-stimulated palmitate uptake in the presence of AICAR co-treatment (Fig. 5B).

A
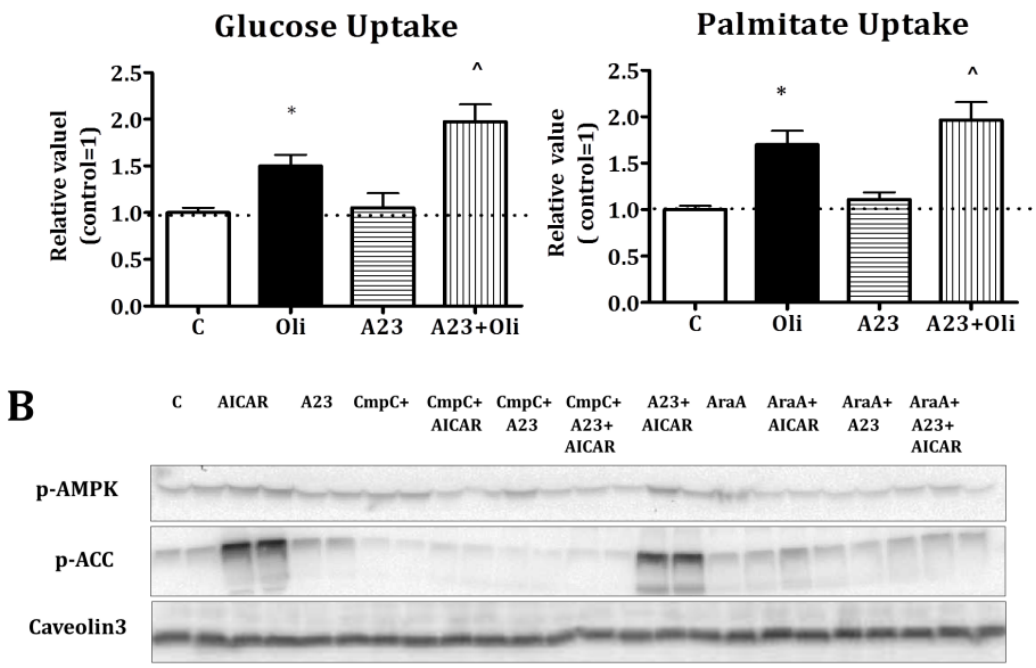

Palmitate Uptake

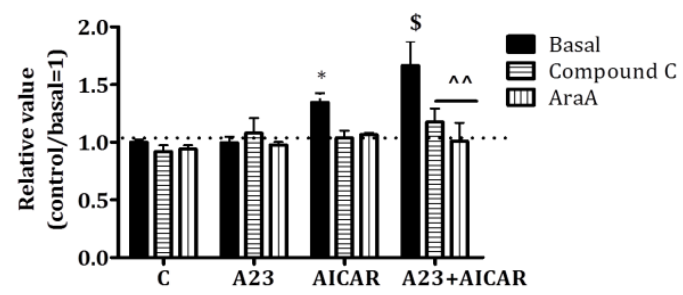

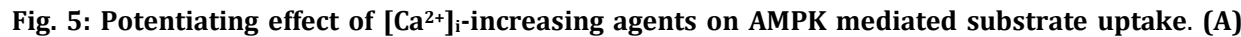
Cardiomyocytes were incubated for $15 \mathrm{~min}$ in the absence (C) or presence of oligomycin (Oli; $5 \mu \mathrm{M}$ ) and/or A23187 (A23; $5 \mu \mathrm{M}$ ) prior to assessment of the uptake of 2-deoxy-[1-3H]glucose and of [114C]palmitate (5 min). (B) Cardiomyocytes were incubated for $15 \mathrm{~min}$ in the absence (C) or presence of adenine 9- $\beta$-D-arabinofuranoside (AraA; $3 \mathrm{mM}$ ) or compound C $(50 \mu \mathrm{M})$ for $15 \mathrm{~min}$ prior to a $15 \mathrm{~min}$ incubation with A23187 and/or AICAR, and subsequent assessment of AMPK and ACC phosphorylation and of 2-deoxy-[1-3 H]glucose and $\left[1-{ }^{14} \mathrm{C}\right]$ palmitate uptake. Values are displayed as mean \pm S.E.M $(n=5)$. $*$ vs. control , ^ vs. oligomycin, \$ vs. AICAR, ${ }^{\wedge}$ vs. A23/AICAR $(\mathrm{P}<0.05)$.

In conclusion, the ability of A23187 to increase glucose and palmitate uptake into cardiomyocytes in the presence of AMPK activators indicates that $\mathrm{Ca}^{2+}$ induced transporter translocation requires AMPK co-activation for effectuating such translocation into enhanced substrate uptake. 


\section{Discussion}

The aim of this study was to investigate the interrelation between $\left[\mathrm{Ca}^{2+}\right]_{\mathrm{i}}, \mathrm{CaMKK}-$ $\beta / \mathrm{CaMKs}$, and AMPK in the regulation of transporter mediated substrate uptake into the heart. The major novel findings of this study are: (i) $\mathrm{Ca}^{2+}$ signaling is involved neither in AMPK activation nor in AMPK-mediated substrate uptake. (ii) Activation of $\mathrm{Ca}^{2+}$ signaling, similarly to AMPK signaling, stimulates translocation of GLUT4 and CD36 from endosomes to the sarcolemma. In contrast, (iii) activation of $\mathrm{Ca}^{2+}$ signaling does not stimulate glucose nor LCFA uptake, whereas AMPK signaling does. Finally, (iv) $\mathrm{Ca}^{2+}$-induced translocation of GLUT4 and/or CD36 can result in enhanced substrate uptake when accompanied with AMPK activation.

Together, these findings propose that $\mathrm{Ca}^{2+}$-induced transporter translocation may help to recruit an additional quantity of substrate transporters to the sarcolemma to have these available to respond rapidly to conditions that require supraphysiological energy demands.

(i) $\mathrm{Ca}^{2+}$ signaling is involved neither in $A M P K$ activation nor in AMPK-mediated substrate uptake

Several studies in mammalian non-muscle cells have shown that CaMKK $\beta$ overexpression can induce AMPK activation and AMPK-Thr172 phosphorylation [17-19]. Additionally, in skeletal muscle, the ability of STO-609 to inhibit AMPK activation upon caffeine treatment indicated that CaMKK $\beta$ is involved in $\mathrm{Ca}^{2+}$ induced AMPK activation $[16,19]$. However, in the present study using cardiomyocytes, the $\mathrm{Ca}^{2+}$ ionophore A23187 and the SERCA inhibitor thapsigargin, while increasing $\left[\mathrm{Ca}^{2+}\right]_{\mathrm{i}}$, did not alter AMPK activation. Moreover, STO-609 nor KN93 affected contraction-induced AMPK activation (4 Hz electric field stimulation), and also not AMPK activation by AICAR or oligomycin, thus excluding a role for CaMKK $\beta$ or CaMKII in the regulation of AMPK signaling in the heart. The inability of CaMKII to activate AMPK in cardiomyocytes is in agreement with previous work in skeletal muscle [14]. However, the lack of involvement of CaMKK $\beta$ in AMPK activation in cardiomyocytes is pointing towards differences in the regulation of AMPK between heart and skeletal muscle.

With respect to the regulation of substrate uptake, we observed that in cardiomyocytes AMPK-activating stimuli (including contraction) enhance GLUT4 and CD36 translocation, as well as glucose and LCFA uptake, in agreement with our previous studies $[5,29]$. The inability of ST0-609 or KN93 to inhibit AMPKmediated substrate uptake matches the inability of both inhibitors to affect AMPK signaling, and excludes the involvement of CaMKK $\beta$ or CaMKII herein. These findings are in line with our previous observations in cardiomyocytes from LKB1knockout mice, in which AMPK-mediated increases in glucose and LCFA uptake were entirely lost [5], and, therefore, provide further evidence that LKB1, and not CaMKK $\beta$, is the AMPK activating kinase involved in the contraction-induced regulation of cardiac substrate uptake. In contrast, in skeletal muscle contractioninduced substrate uptake is sensitive to ST0-609-mediated inhibition of CaMKK $\beta$ 
[16], illustrating that differences exist between heart and skeletal muscle in signaling cascades and substrate uptake during contraction.

\section{(ii) Activation of $\mathrm{Ca}^{2+}$ signaling stimulates translocation of GLUT4 and CD36}

Although the effect of $\left[\mathrm{Ca}^{2+}\right]_{\mathrm{i}}$-increasing stimuli on glucose transport in skeletal muscle has been a topic of several studies $[14,19,20]$, only few studies have shown GLUT4 translocation upon treatment with $\left[\mathrm{Ca}^{2+}\right]_{\mathrm{i}}$-increasing stimuli (e.g., [16]). More recently, the $\left[\mathrm{Ca}^{2+}\right]_{\mathrm{i}}$-increasing agent caffeine was reported to stimulate GLUT4 translocation in a ST0-609-sensitive manner, thereby implicating the involvement of CaMKK $\beta$ [16]. However, during caffeine stimulation not only CaMKK $\beta$ was activated, but also AMPK. Hence, during caffeine-induced GLUT4 translocation in skeletal muscle $\mathrm{Ca}^{2+}$ signaling cannot be separated from AMPK signaling. There are also evidences in skeletal muscle that $\mathrm{Ca}^{2+}$ is involved in insulin-stimulated GLUT4 translocation and docking of GLUT4 vesicles at and fusion with the sarcolemma [30,31].

To our knowledge no studies have shown that an elevation in $\left[\mathrm{Ca}^{2+}\right]_{\mathrm{i}}$ induces GLUT4 translocation in cardiomyocytes. We have used two independent methods to monitor GLUT4 translocation upon elevation of $\left[\mathrm{Ca}^{2+}\right]_{\mathrm{i}}$ by pharmacological agents (thapsigargin and A23187), i.e. surface biotinylation and cellular fractionation techniques. Both methods reveal that each of the $\mathrm{Ca}^{2+}$ signalinginducing agents induce GLUT4 translocation from intracellular stores to the cell surface in cardiomyocytes in the absence of AMPK activation. Therefore, our study is the first to show that intracellular $\mathrm{Ca}^{2+}$ increasing stimuli are able to induce GLUT4 translocation without concomitant AMPK activation.

Reports on a relation between $\mathrm{Ca}^{2+}$ signaling and CD36 translocation are limited to the observation that caffeine induces the translocation of CD36 simultaneously with GLUT4 translocation in skeletal muscle [16, 32]. We employed three independent methods, including antibody labeling in combination with twophoton microscopy, to study the effects of thapsigargin or of A23187 on CD36 translocation. Each of these methods clearly indicated enhanced CD36 translocation in response to activation of $\mathrm{Ca}^{2+}$ signaling. Furthermore, $\mathrm{Ca}^{2+}$ induced CD36 translocation appears to be regulated in a manner similar to $\mathrm{Ca}^{2+}$ induced GLUT4 translocation. Namely, both $\mathrm{Ca}^{2+}$-induced GLUT4 translocation and CD36 translocation are AMPK-independent, but are sensitive to inhibition by STO609 and KN93, which indicates the involvement of CaMKK- $\beta$ /CaMKs. The inability of $\mathrm{Ca}^{2+}$ signaling-inducing agents to induce AMPK activation in cardiomyocytes further suggests that $\mathrm{Ca}^{2+}$-induced transporter translocation proceeds independently from AMPK-mediated transporter translocation. Thus, cardiomyocytes appear to operate two separate pathways, i.e., AMPK and $\mathrm{Ca}^{2+} / \mathrm{CaMK}$ signaling, to initiate transporter translocation. 
(iii) Activation of $\mathrm{Ca}^{2+}$ signaling is not sufficient to stimulate glucose and LCFA uptake

In contrast to the parallel increases in AMPK-mediated substrate transporter translocation and AMPK-mediated substrate uptake, $\mathrm{Ca}^{2+}$-induced GLUT4 and CD36 translocation was not accompanied by increases in glucose and LCFA uptake. A likely explanation for these findings is that substrate transporter translocation is necessary but not sufficient for a given stimulus to increase substrate uptake. Hence, once arrived at the cell surface substrate transporters may need an additional activation step to become fully functional in substrate uptake. In case of AMPK signaling, this signaling route might then be involved in both substrate transporter translocation and cell surface activation of substrate transporters. In contrast, $\mathrm{Ca}^{2+}$ signaling appears to be involved only in the first step, the translocation, and ineffective in further cell surface activation. Evidence for such a two-step process in the stimulation of substrate transport has been previously reported in adipocytes as the inability of phosphatidylinositol-3,4,5-trisphosphate (PIP3) to stimulate glucose uptake into these cells despite a successful translocation of GLUT4 to the plasma membrane [33]. These latter findings indicate that PIP3 (the main product of insulin-stimulated phosphatidylinositol-3 kinase (PI3K) activation), is involved in insulin-stimulated GLUT4 translocation, but the GLUT4 activation step required for insulin-stimulated glucose uptake is mediated by another, perhaps PI3K-independent factor.

Similarly, in AMPK-mediated substrate uptake, the cell surface activation step would require different downstream mechanisms of AMPK compared to the translocation step. Specifically, whereas phosphorylation of AS160 (or its homologue TBC1D1) by AMPK is involved in the regulation of GLUT4 and CD36 translocation [7, 34], we do not necessarily expect AS160/TBC1D1 to be involved in cell surface transporter activation at the cell surface since the rabGTPase activity of both proteins is tightly connected to vesicular trafficking [35].

We can only speculate about the mechanism of AMPK-mediated transporter activation at the cell surface. This activation step might involve a signaling-induced phosphorylation of each of the transporters individually. However, evidence for phosphorylation of GLUT4 or of CD36 to regulate transport activity is scarce. For CD36, merely ectophosphorylation was reported [36], whereas for GLUT4, a study in adipocytes showed that GLUT4 phosphorylation is inversely correlated with glucose uptake in response to insulin stimulation [37]. Alternatively, both GLUT4 and CD36 might be activated in another, combined event. For instance, GLUT4 and CD36 may simultaneously translocate to sarcolemmal regions that are nonfunctional in substrate uptake and then laterally migrate through the sarcolemma to a subdomain that is functional in substrate uptake. Such sarcolemmal subdomains might include caveolae, which have been demonstrated to be necessary for LCFA uptake, at least in adipocytes [38]. 


\section{(iv) Combined activation of $\mathrm{Ca}^{2+}$ signaling and $\mathrm{AMPK}$ signaling synergistically} stimulates glucose and LCFA uptake in an AMPK-sensitive manner

One major observation in this study is that activation of $\mathrm{Ca}^{2+}$ signaling, by itself unsuccessful in stimulating glucose and LCFA uptake into cardiomyocytes, substantially stimulated cardiac substrate uptake upon co-activation of AMPK signaling. Hence, $\mathrm{Ca}^{2+}$ signaling is dependent on separate co-activation of AMPK signaling to stimulate cardiac substrate uptake (illustrated in Fig. 6). In view of the ability of $\mathrm{Ca}^{2+}$ signaling to induce both GLUT4 and CD36 to translocate to the sarcolemma, once arrived at the cell surface, both transporters might undergo subsequent activation by AMPK signaling. The observation that pharmacological AMPK inhibitors entirely block substrate uptake induced by combined activation of $\mathrm{Ca}^{2+}$ and AMPK signaling provides support that activation of $\mathrm{Ca}^{2+}$-recruited transporters is indeed due to AMPK, and not to an off-target effect of these stimuli.

Findings of this study point towards a gap in our knowledge on the role of $\mathrm{Ca}^{2+}$ and CaMKs on contraction stimulation of cardiac substrate uptake. Our findings revealed that upon an exaggerated rise in $\left[\mathrm{Ca}^{2+}\right]_{\mathrm{i}}$ by pharmacological agents, activation of CaMKs will induce both GLUT4 and CD36 translocation. However, contraction stimulation did not activate $\mathrm{Ca}^{2+}$ signaling, at least not within the observation time (several minutes). Perhaps, $\mathrm{Ca}^{2+}$-induced/CaMK-mediated transporter translocation might gain importance during pathological $\mathrm{Ca}^{2+}$ overload conditions [39], as mimicked by thapsigargin or A23187 treatment. Under such pathological conditions AMPK activity would not be expected to be impaired, and thus amply sufficient to mediate cell surface transporter activation. Then, $\mathrm{Ca}^{2+}$ induced transporter translocation can be effectuated into increased substrate uptake. Together, the present findings point towards the hypothetical presence of separate GLUT4/CD36-containing subcompartments within the endosomes specifically responsive to a rise in $\left[\mathrm{Ca}^{2+}\right]_{\mathrm{i}}$, next to the AMPK-responsive storage compartments for these transporters. The recruitment of transporters from these $\mathrm{Ca}^{2+}$-responsive storage compartments might be restricted to emergency situations (like hypoxia, fight/flight response) in order to meet the excessive metabolic demands of the heart in such condition.

Yet, the basal activity of CaMKs in the heart or the changes in activation of CaMKs on a msec time scale are not yet known. Similar to $\mathrm{Ca}^{2+}$ oscillations that activate CaMKs signaling, also AMPK activation status might fluctuate on the msec time scale. Expectedly there would be some delay to the CaMK signaling, because the increased energy demand (that is sensed by AMPK through changes in adenine nucleotide levels) evolves from the $\mathrm{Ca}^{2+}$-induced cardiomyocyte contraction. Thus, we could speculate about $\mathrm{Ca}^{2+} / \mathrm{CaMK}$ signaling preparing the cardiomyocyte for substrate uptake during contraction by inducing transporter translocation, which in case of actual energy requirement is finalized by AMPK into substrate uptake to refill cellular energy. At present, it is not possible for us to determine CaMK and AMPK signaling changes occurring at such rapid pace. In conclusion, we cannot exclude a possible msec action of CaMKs on transporter translocation under normal physiological conditions. 
Finally, identification of the proteins functioning downstream of CaMKs in $\mathrm{Ca}^{2+}$-induced translocation of GLUT4 and CD36 might provide novel targets to influence cardiac substrate uptake.

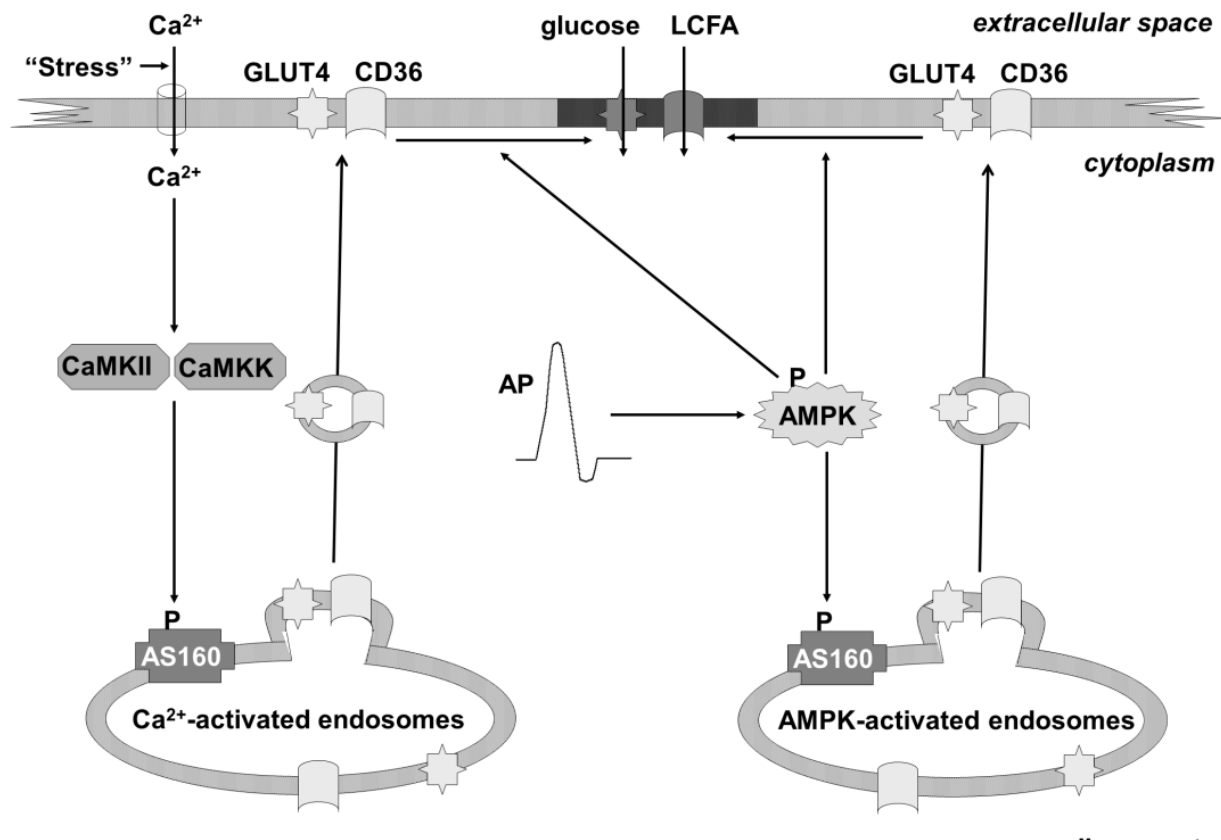

Fig. 6: Putative mechanism of the synergistic effect of $\mathrm{Ca}^{2+}$ and AMPK signaling on cardiac glucose and fatty acid uptake. Contraction as induced by an action potential (AP) leads to activation of AMPK. Both contraction-induced AMPK activation and a supraphysiological influx of $\mathrm{Ca}^{2+}$ into cardiomyocytes (e.g., induced by A23187) trigger translocation of GLUT4 and CD36 from separate AMPK-responsive and $\mathrm{Ca}^{2+}$ signaling-responsive endosomal subcompartments to the sarcolemma. AS160 is known to be involved in contraction-induced GLUT4/CD36 translocation [7]. Additionally, AS160 might be involved in $\mathrm{Ca}^{2+}$-induced transporter translocation, as CaMKII has been proposed to activate AS160 in muscle cells [40]. Hence, phosphorylation of AS160 by both signaling pathways will relieve GLUT4 and CD36 from their endosomal retention. Both transporters arrive at the sarcolemma in an inactive state (depicted by a light-gray fill colour). Then, both transporters need an activation step (possibly lateral movement through the bilayer towards a specific membrane domain, depicted as black with white spickels) to become functional in substrate uptake (depicted by a dark-gray fill colour). This latter step is dependent on AMPK activation. Hence, whereas AMPK-recruited transporters do not require additional signaling pathways to effectuate translocation into enhanced substrate uptake,

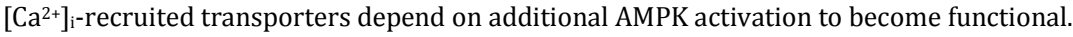

\section{Acknowledgements}

This work was performed within the framework of CTMM, the Center for Translational Molecular Medicine, project PREDICCt (grant no. 01C-104), and supported by the Netherlands Heart Foundation, Dutch Diabetes Research Foundation, and the Dutch Kidney Foundation. D.N. is the recipient of a VIDIInnovational Research Grant from the Netherlands Organization of Scientific Research (NWO-ALW Grant 864.10.007). 


\section{References}

1. Glatz JF, Luiken JJ, Bonen A. Membrane fatty acid transporters as regulators of lipid metabolism: implications for metabolic disease. Physiol Rev. 2010;90:367-417.

2. Luiken JJ, Coort SL, Koonen DP, van der Horst DJ, Bonen A, Zorzano A, et al. Regulation of cardiac long-chain fatty acid and glucose uptake by translocation of substrate transporters. Pflugers Arch. 2004;448:1-15.

3. Chabowski A, Coort SL, Calles-Escandon J, Tandon NN, Glatz JF, Luiken JJ, et al. The subcellular compartmentation of fatty acid transporters is regulated differently by insulin and by AICAR. FEBS Lett. 2005;579:2428-32.

4. Luiken JJ, Coort SL, Willems J, Coumans WA, Bonen A, van der Vusse GJ, et al. Contraction-induced fatty acid translocase/CD36 translocation in rat cardiac myocytes is mediated through AMPactivated protein kinase signaling. Diabetes. 2003;52:1627-34.

5. Habets DD, Coumans WA, El Hasnaoui M, Zarrinpashneh E, Bertrand L, Viollet B, et al. Crucial role for LKB1 to AMPKalpha2 axis in the regulation of CD36-mediated long-chain fatty acid uptake into cardiomyocytes. Biochim Biophys Acta. 2009;1791:212-9.

6. Schwenk RW, Dirkx E, Coumans WA, Bonen A, Klip A, Glatz JF, et al. Requirement for distinct vesicle-associated membrane proteins in insulin- and AMP-activated protein kinase (AMPK)induced translocation of GLUT4 and CD36 in cultured cardiomyocytes. Diabetologia. 2010;53:2209-19.

7. Samovski D, Su X, Xu Y, Abumrad NA, Stahl PD. Insulin and AMPK regulate FA translocase/CD36 plasma membrane recruitment in cardiomyocytes via Rab GAP AS160 and Rab8a Rab GTPase. J Lipid Res. 2012;53:709-17.

8. Bers DM, Guo T. Calcium signaling in cardiac ventricular myocytes. Ann N Y Acad Sci. 2005;1047:86-98.

9. Chiba H, Schneider NS, Matsuoka S, Noma A. A simulation study on the activation of cardiac CaMKII delta-isoform and its regulation by phosphatases. Biophys J. 2008;95:2139-49.

10. Anderson ME. Calmodulin kinase signaling in heart: an intriguing candidate target for therapy of myocardial dysfunction and arrhythmias. Pharmacol Ther. 2005;106:39-55.

11. Rose AJ, Kiens B, Richter EA. Ca2+-calmodulin-dependent protein kinase expression and signalling in skeletal muscle during exercise. J Physiol. 2006;574:889-903.

12. Green MF, Scott JW, Steel R, Oakhill JS, Kemp BE, Means AR. Ca2+/Calmodulin-dependent protein kinase kinase beta is regulated by multisite phosphorylation. J Biol Chem. 2011;286:28066-79.

13. Rose AJ, Hargreaves M. Exercise increases Ca2+-calmodulin-dependent protein kinase II activity in human skeletal muscle. J Physiol. 2003;553:303-9.

14. Wright DC, Hucker KA, Holloszy JO, Han DH. Ca2+ and AMPK both mediate stimulation of glucose transport by muscle contractions. Diabetes. 2004;53:330-5.

15. Abbott MJ, Bogachus LD, Turcotte LP. AMPKalpha2 deficiency uncovers time dependency in the regulation of contraction-induced palmitate and glucose uptake in mouse muscle. J Appl Physiol. 2011;111:125-34.

16. Abbott MJ, Edelman AM, Turcotte LP. CaMKK is an upstream signal of AMP-activated protein kinase in regulation of substrate metabolism in contracting skeletal muscle. Am J Physiol Regul Integr Comp Physiol. 2009;297:R1724-32.

17. Woods A, Dickerson K, Heath R, Hong SP, Momcilovic M, Johnstone SR, et al. Ca2+/calmodulindependent protein kinase kinase-beta acts upstream of AMP-activated protein kinase in mammalian cells. Cell Metab. 2005;2:21-33.

18. Hawley SA, Pan DA, Mustard KJ, Ross L, Bain J, Edelman AM, et al. Calmodulin-dependent protein kinase kinase-beta is an alternative upstream kinase for AMP-activated protein kinase. Cell Metab. 2005;2:9-19.

19. Jensen TE, Rose AJ, Jorgensen SB, Brandt N, Schjerling P, Wojtaszewski JF, et al. Possible CaMKKdependent regulation of AMPK phosphorylation and glucose uptake at the onset of mild tetanic skeletal muscle contraction. Am J Physiol Endocrinol Metab. 2007;292:E1308-17.

20. Witczak CA, Jessen N, Warro DM, Toyoda T, Fujii N, Anderson ME, et al. CaMKII regulates contraction- but not insulin-induced glucose uptake in mouse skeletal muscle. Am J Physiol Endocrinol Metab. 2010;298:E1150-60.

21. Fischer Y, Rose H, Kammermeier H. Highly insulin-responsive isolated rat heart muscle cells yielded by a modified isolation method. Life Sci. 1991;49:1679-88. 
22. Luiken JJ, van Nieuwenhoven FA, America G, van der Vusse GJ, Glatz JF. Uptake and metabolism of palmitate by isolated cardiac myocytes from adult rats: involvement of sarcolemmal proteins. J Lipid Res. 1997;38:745-58.

23. Heemskerk JW, Willems GM, Rook MB, Sage SO. Ragged spiking of free calcium in ADP-stimulated human platelets: regulation of puff-like calcium signals in vitro and ex vivo. J Physiol. 2001;535:625-35.

24. Auger JM, Kuijpers MJ, Senis YA, Watson SP, Heemskerk JW. Adhesion of human and mouse platelets to collagen under shear: a unifying model. FASEB J. 2005;19:825-7.

25. van Oort MM, van Doorn JM, Bonen A, Glatz JF, van der Horst DJ, Rodenburg KW, et al. Insulininduced translocation of CD36 to the plasma membrane is reversible and shows similarity to that of GLUT4. Biochim Biophys Acta. 2008;1781:61-71.

26. Hagen BM, Boyman L, Kao JP, Lederer WJ. A comparative assessment of fluo Ca2+ indicators in rat ventricular myocytes. Cell Calcium. 2012;52:170-81.

27. Luiken JJ, Vertommen D, Coort SL, Habets DD, El Hasnaoui M, Pelsers MM, et al. Identification of protein kinase D as a novel contraction-activated kinase linked to GLUT4-mediated glucose uptake, independent of AMPK. Cell Signal. 2008;20:543-56.

28. Dirkx E, Schwenk RW, Coumans WA, Hoebers N, Angin Y, Viollet B, et al. Protein kinase D1 is essential for contraction-induced glucose uptake but is not involved in fatty acid uptake into cardiomyocytes. J Biol Chem. 2012;287:5871-81.

29. Coort SL, Hasselbaink DM, Koonen DP, Willems J, Coumans WA, Chabowski A, et al. Enhanced sarcolemmal FAT/CD36 content and triacylglycerol storage in cardiac myocytes from obese zucker rats. Diabetes. 2004;53:1655-63.

30. Lanner JT, Bruton JD, Katz A, Westerblad H. Ca(2+) and insulin-mediated glucose uptake. Curr Opin Pharmacol. 2008;8:339-45.

31. Lanner JT, Katz A, Tavi P, Sandstrom ME, Zhang SJ, Wretman C, et al. The role of Ca2+ influx for insulin-mediated glucose uptake in skeletal muscle. Diabetes. 2006;55:2077-83.

32. Lally JS, Jain SS, Han XX, Snook LA, Glatz JF, Luiken JJ, et al. Caffeine-stimulated fatty acid oxidation is blunted in CD36 null mice. Acta Physiol (Oxf). 2012;205:71-81.

33. Sweeney G, Garg RR, Ceddia RB, Li D, Ishiki M, Somwar R, et al. Intracellular delivery of phosphatidylinositol $(3,4,5)$-trisphosphate causes incorporation of glucose transporter 4 into the plasma membrane of muscle and fat cells without increasing glucose uptake. J Biol Chem. 2004;279:32233-42.

34. Jessen N, An D, Lihn AS, Nygren J, Hirshman MF, Thorell A, et al. Exercise increases TBC1D1 phosphorylation in human skeletal muscle. American journal of physiology Endocrinology and metabolism. 2011;301:E164-71.

35. Fukuda M. TBC proteins: GAPs for mammalian small GTPase Rab? Biosci Rep. 2011;31:159-68.

36. Guthmann F, Maehl P, Preiss J, Kolleck I, Rustow B. Ectoprotein kinase-mediated phosphorylation of FAT/CD36 regulates palmitate uptake by human platelets. Cell Mol Life Sci. 2002;59:1999-2003.

37. Begum N, Draznin B. Effect of streptozotocin-induced diabetes on GLUT-4 phosphorylation in rat adipocytes. J Clin Invest. 1992;90:1254-62.

38. Pohl J, Ring A, Korkmaz U, Ehehalt R, Stremmel W. FAT/CD36-mediated long-chain fatty acid uptake in adipocytes requires plasma membrane rafts. Mol Biol Cell. 2005;16:24-31.

39. Gusarova GA, Trejo HE, Dada LA, Briva A, Welch LC, Hamanaka RB, et al. Hypoxia leads to Na,KATPase downregulation via $\mathrm{Ca}(2+)$ release-activated $\mathrm{Ca}(2+)$ channels and AMPK activation. Mol Cell Biol. 2011;31:3546-56.

40. Mohankumar SK, Taylor CG, Zahradka P. Domain-dependent modulation of insulin-induced AS160 phosphorylation and glucose uptake by $\mathrm{Ca} 2+/$ calmodulin-dependent protein kinase II in L6 myotubes. Cellular signalling. 2012;24:302-8. 


\section{Chapter 5}

\section{Involvement of zinc in fatty acid transport function of CD36: A novel link to type 2 diabetes}

Yeliz Angin ${ }^{1}$, Antoinette van den Dikkenberg², H. Th. Marc Timmers ${ }^{3}$, Dick J. Van der Horst ${ }^{2}$, Will A. Coumans ${ }^{1}$, Dietbert Neumann ${ }^{1}$, Jan F.C. Glatz ${ }^{1}$, Kees W. Rodenburg ${ }^{2}$, and Joost J.F.P. Luiken ${ }^{1 *}$

\footnotetext{
${ }^{1}$ Department of Molecular Genetics, Cardiovascular Research Institute Maastricht (CARIM), Maastricht University, NL-6200 MD Maastricht, the Netherlands, ${ }^{2}$ Division of Endocrinology and Metabolism, Department of Biology and Institute of Biomembranes, Utrecht University, NL-3584 CH Utrecht, the Netherlands, ${ }^{3}$ Department of Physiological Chemistry, University Medical Centre-Utrecht, Universiteitsweg 100, 3584 CG Utrecht, The Netherlands,
}

In preparation for submission 


\begin{abstract}
Diabetic cardiomyopathy is associated with zinc $\left(\mathrm{Zn}^{2+}\right)$ deficiency. However, the mechanistical link between both processes is incompletely understood. One of the main causal factors in diabetic cardiomyopathy is chronically elevated long-chain fatty acid uptake via increased flux through CD36, the predominant cardiac longchain fatty acid (LCFA) transporter. This results in lipid accumulation, insulin resistance and contractile dysfunction. Given that the impact of $\mathrm{Zn}^{2+}$ depletion on cardiac substrate uptake is unknown, our aim was to investigate whether $\mathrm{Zn}^{2+}$ depletion would increase CD36-mediated LCFA uptake, and whether this would lead to lipid accumulation and insulin resistance in cardiomyocytes. Acute (20 min) or long-term (48 h) $\mathrm{Zn}^{2+}$ depletion was induced in isolated cardiomyocytes by exposure to the $\mathrm{Zn}^{2+}$ chelators $\mathrm{N}, \mathrm{N}, \mathrm{N}^{\prime}, \mathrm{N}^{\prime}$-tetrakis-(2pyridylmethyl)ethylenediamine (TPEN) or 1-10-phenanthroline. 20 min-exposure of cardiomyocytes to each $\mathrm{Zn}^{2+}$ chelator increased LCFA uptake (1.4-fold), whereas glucose uptake was unaltered. In the presence of AMPK-activating stimuli or insulin, each known to increase LCFA uptake, the stimulatory effect of $\mathrm{Zn}^{2+}$ chelation on LCFA uptake was retained without altering AMPK or insulin signaling. LCFA uptake stimulation by $\mathrm{Zn}^{2+}$ chelation was abolished in CD36-null cardiomyocytes. $\mathrm{Zn}^{2+}$ chelation did not affect CD36 expression nor its cell surface content, but increased its transport activity. $48 \mathrm{~h}$ exposure of cardiomyocytes to TPEN decreased insulin-stimulated Akt phosphorylation, and increased cellular triacylglycerol contents. Each of the 4 cysteines that are located in the intracellular domains of CD36, were found to be required for $\mathrm{Zn}^{2+}$ binding. CD36 carries a $\mathrm{Zn}^{2+}$ finger motif regulating its transport function. $\mathrm{Zn}^{2+}$ chelation activates CD36, and thereby might cause lipid overload and insulin resistance. Thus, CD36 might play a key role in $\mathrm{Zn}^{2+}$ deficiency related diabetic cardiomyopathy.
\end{abstract}




\section{Introduction}

Zinc $\left(\mathrm{Zn}^{2+}\right)$ is an essential cofactor for many enzymes and transcription factors. Additionally, $\mathrm{Zn}^{2+}$ has potent antioxidant properties [1]. $\mathrm{Zn}^{2+}$ deficiency is associated with human disease, especially with diabetic cardiomyopathy and nephropathy $[1,2]$. Accordingly, $\mathrm{Zn}^{2+}$ depletion in the drinking water or in the diet can induce (and/or worsen) type 2 diabetes both in man and experimental animals $[3,4]$. Another link between diabetes and $\mathrm{Zn}^{2+}$ deficiency which has been shown in many groups is the lower serum $\mathrm{Zn}^{2+}$ concentrations $[1,2,5]$. The exact mechanisms by which $\mathrm{Zn}^{2+}$ deficiency induces the development of diabetic cardiomyopathy are not well addressed [2]. It has been speculated that $\mathrm{Zn}^{2+}$ deficiency can directly result in insulin resistance $[6,7]$. On the one hand the loss of $\mathrm{Zn}^{2+}$ s antioxidant effects might cause oxidative stress and activation of stress signaling leading to Ser-phosphorylation of IRS1. On the other hand $\mathrm{Zn}^{2+}$ is a negative regulator of protein-tyrosine phosphatases, and their resulting activation by $\mathrm{Zn}^{2+}$ depletion would diminish Tyr-phosphorylation of IRS1, and thereby shift to IRS-Ser-phosphorylation [7, 8]. However, $\mathrm{Zn}^{2+}$ deficiency might also be more indirectly involved in the development of myocellular insulin resistance.

With respect to lipid metabolism, $\mathrm{Zn}^{2+}$ is an important regulator of longchain fatty acid (LCFA) utilization in mammalian tissues [9], including the heart [1] via modulation of $\mathrm{Zn}^{2+}$-dependent lipid metabolizing enzymes, but also through mechanisms that are ill-understood. LCFA utilization is disturbed in the diabetic heart [10]. Specifically, the diabetic heart is characterized by exaggerated lipid storage, and there is an increase in LCFA deposition into diacylglycerols, triacylglycerols and ceramides. Especially, the increase in myocellular content of the latter two LCFA metabolites is postulated to result in the development of myocellular insulin resistance. The rise in diacylglycerols would activate PKCs and a consequent Ser/Thr signaling pathway leading to Ser-phosphorylation of IRS1. The rise in ceramides would impair insulin signaling at the level of Akt through direct inhibition of this kinase [11].

The accumulation of LCFA metabolites is likely not due to redirection of LCFA from oxidation to storage, because LCFA oxidation is not impaired in cardiomyocytes from diabetic rodent models [12,13]. Rather, LCFA uptake is chronically increased to such an extent that the mitochondrial capacity is exceeded, and the surplus LCFA are, by default, converted into triacylglycerols, diacylglycerols and ceramides [10]. The mechanism of this maladaptive increase in LCFA uptake in the diabetic rodent heart [10] or in obese human muscle cells [14] is pinpointed to increased surface abundance of the LCFA transporter CD36. CD36 is the main cardiac LCFA transporter and accounts for $\sim 70 \%$ of the total LCFA flux into the heart [15]. CD36 is not only present at the sarcolemma, but also within intracellular/endosomal storage compartments. LCFA uptake is inducible within minutes upon exposure of cardiomyocytes to physiological and pharmacological stimuli that activate insulin signaling or AMPK signaling. These stimuli will induce CD36 translocation from the endosomes to the sarcolemma, and thereby increase myocellular LCFA uptake. Within $30 \mathrm{~min}$ after termination of stimulation, CD36 reversibly returns to endosomal storage [16]. However, in the hearts of diabetic 
rodent models, CD36 permanently relocates from the endosomes to the sarcolemma. Since there is no change in CD36 expression in the diabetic rodent heart, permanent CD36 relocation is responsible for the above described maladaptive increases in contents of insulin resistance-inducing LCFA metabolites.

The aim of the present study was to investigate whether CD36 is involved in $\mathrm{Zn}^{2+}$ deficiency-induced insulin resistance in the heart. We first investigated whether $\mathrm{Zn}^{2+}$ deficiency has the ability to alter CD36 dynamics in the heart. For this, we studied the effects of $\mathrm{Zn}^{2+}$ chelation on cardiomyocytic LCFA uptake, CD36 expression, subcellular localization and intrinsic activity. Subsequently, we investigated whether the same experimental conditions in which $\mathrm{Zn}^{2+}$ chelation successfully upregulated CD36-mediated LCFA uptake, also resulted in myocellular lipid accumulation and insulin resistance. Finally, we assessed the ability of $\mathrm{Zn}^{2+}$ to bind to a peptide mimicking the intracellular structure of CD36. Thereby we focused on the four Cys residues in both intracellular domains of CD36. Each of these four was mutated to Ser, and we compared the binding properties to $\mathrm{Zn}^{2+}$ and other divalent metal ions between the wild-type and the different Cys $\rightarrow$ Ser mutant peptides.

\section{Materials and Methods}

\section{$\underline{\text { Materials }}$}

2-Deoxy-D-[1-3 H]glucose and $\left[1-{ }^{14} \mathrm{C}\right]$ palmitic acid were obtained from GE Healthcare (Piscataway, NJ, USA). Bovine serum albumin (BSA, fraction V, essentially fatty acid free), bovine insulin, laminin, phloretin, DMSO, oligomycin, 5amino-1- $\beta$-D-ribofuranosyl-imidazole-4-carboxamide (AICAR), the intracellular $\mathrm{Zn}^{2+}$ chelator $\mathrm{N}, \mathrm{N}, \mathrm{N}^{\prime}, \mathrm{N}$ '-tetrakis-(2-pyridylmethyl)ethylenediamine (TPEN) and 1,10-o-Phenanthroline were obtained from Sigma Aldrich (St. Louis, MO, USA). Sulfo-NHS-LC-biotin and immobilized streptavidin were from Perbio Science (Etten-Leur, the Netherlands). Cell culture chemicals and media were purchased from Invitrogen (Breda, the Netherlands).

\section{$\underline{\text { Antibodies }}$}

Antibodies were purchased as indicated: phospho-ACC (Ser79) (\# 07-303) from Upstate (Billerica, MA, USA);phospho-AMPKa (Thr172) (\#2531), Akt, phospho-Akt (Ser473), phospho-GSK3 $\beta$ (Ser9) from Cell Signaling Technology (Beverly, MA, USA); caveolin3 (\#610420) from BD Transduction Laboratories (Franklin Lakes, NJ, USA); anti-CD36 antibody (CRF D-2717) used in 2-photon microscopic images from BD Pharmingen (Franklin Lakes, NJ, USA). FITC-labeled rabbit anti-mouse IgA secondary antibody was from from Rockland Immunochemical (Gilbertsville, PA, USA). The anti-CD36 antibody (\# MO25) used in Western Blotting was a gift from dr. N. Tandon (Bethesda, USA). 


\section{Isolation of primary rat cardiomyocytes and culture}

Adult rat cardiomyocytes (Lewis rats 200-250 g, 2-3 months of age) were isolated by using a Langendorff perfusion system according to the procedure described by Fischer et al [17] which has been described previously [18] with the only difference being the sterile conditions that were taken into account for subsequent culturing. A modified Krebs Henseleit bicarbonate (MKR) medium containing 1.17 $\mathrm{M} \mathrm{NaCl}, 26 \mathrm{mM} \mathrm{KCl}, 12 \mathrm{mM} \mathrm{KH} \mathrm{PO}_{4}, 12 \mathrm{mM} \mathrm{MgSO}_{4}, 100 \mathrm{mM} \mathrm{NaHCO}, 100 \mathrm{mM}$ HEPES was adjusted to $\mathrm{pH} 7.55$ and stored at a 10-fold concentration. Upon daily use MKR medium was diluted 10 times and equilibrated with a 95\% $\mathrm{O}_{2} / 5 \% \mathrm{CO}_{2}$ gas phase at $37^{\circ} \mathrm{C}$. For culturing the cells after isolation of cardiomyocytes, 200,000 cells/well were routinely seeded in laminin coated 6-well plates $(9.6 \mathrm{~cm} 2)$. After 90 min of seeding in the adhesion medium (1xMKR buffer supplemented with $0.45 \% \mathrm{BSA}$ and $2 \mathrm{mM}$ D-glucose), the medium was replaced with control medium (based on M199 supplemented with $5 \mathrm{mM}$ creatine monohydrate, $3.2 \mathrm{mM}$ carnitine hydrochloride, $3.1 \mathrm{mM}$ taurine, $100 \mathrm{U} / \mathrm{ml}$ penicillin and streptomycin, $20 \mu \mathrm{M}$ palmitate (palmitate:BSA 0.3:1)). Cells were cultured for $48 \mathrm{~h}$ in the absence (control medium) and in the presence of either high palmitate (control medium with more palmitate; $200 \mu \mathrm{M}$, palmitate:BSA 3:1) or $5 \mu \mathrm{M}$ TPEN containing control medium. At the end of 48 hour culturing cell were washed with $1 \mathrm{x}$ MKR supplemented with $1 \mathrm{mM} \mathrm{CaCl} 2$ and $0,45 \%$ BSA (medium A) two times and left 30 min in the medium A before stimulation with insulin for signaling experiments.

\section{Myocellular triacylglycerol and diacylglycerol levels}

For measurement of intramyocellular lipid content, cardiomyocytes were cultured in $55 \mathrm{~cm}^{2}$ glass petridishes with $1 \times 10^{6}$ cell density. Intramyocellular lipids were determined after 2 days of culturing as described previously [19]. In short, samples containing $200 \mu \mathrm{g}$ of protein were used for intracellular lipid extraction in methanol/chloroform, and an internal standard and water were added. Afterwards thin-layer chromatography was used to separate lipids. Bands were resolved with a hexane/diethylether/propanol (87:10:3) resolving solution. Triacylglycerol and diacylglycerol bands were detected with a Molecular Imager (ChemiDoc XRS, BioRad) and analyzed with Quantity One® (BioRad).

\section{Experiments with freshly isolated cardiomyocytes}

To recover from the isolation procedure, cardiomyocytes were incubated for an additional $90 \mathrm{~min}$ in medium A while rotating at room temperature $\left(24^{\circ} \mathrm{C}\right)$. For substrate uptake measurements, approximately 200,000 cells per condition and for signaling experiments approximately 100,000 cells per condition were used. During these experiments, cell suspensions were incubated for 20 min either with 1,10-o-Phenanthroline (phenanthroline)or TPEN alone or for additional $20 \mathrm{~min}$ together with stimulators of insulin or AMPK signaling in capped 20-ml glass vials. The vials were placed in a $37^{\circ} \mathrm{C}$ water bath under continuous shaking at $160 \mathrm{rpm}$. 
Measurement of 2-Deoxy-D-[1- $\left.{ }^{-} \mathrm{H}\right]$ glucose and $\left[1-{ }^{14} \mathrm{C}\right]$ palmitic acid uptake rates into cardiomyocytes

To chelate and thereby remove intracellular Zn2+, cardiomyocytes were exposed to either $1 \mathrm{mM}$ Phenantroline or $5 \mu \mathrm{M}$ TPEN during $20 \mathrm{~min}$ incubations. For activation of AMPK and insulin signaling pathway, cardiomyocytes were either treated with oligomycin $(5 \mu \mathrm{M})$, AICAR $(1.5 \mathrm{mM})$, or insulin $(100 \mathrm{nM})$ during 20 min incubations. For co-exposure experiments cardiomyocytes were incubated with either chelators for $20 \mathrm{~min}$ thereafter insulin or AMPK activating stimuli were added for an additional $20 \mathrm{~min}$. Subsequently, substrate uptake was measured by addition of a $0.5 \mathrm{ml}$-mixture of 2-deoxy-[1-3 $\mathrm{H}]$ glucose and $\left[1-{ }^{-14} \mathrm{C}\right]$ palmitate/BSA complex. Five min after addition of the radiolabeled substrates, the uptake reaction was stopped by transferring the cell contents to $15-\mathrm{ml}$ Falcon tubes containing icecold stop solution with $0.2 \mathrm{mM}$ phloretin. Cells then were washed two-times for 2 min at $45 \mathrm{~g}$ in ice-cold stop solution, as previously described [18]. The radioactivity of the cell pellets was measured by scintillation counting.

Detection of phosphorylation of enzymes within the insulin and AMPK signaling network

Following a $15 \mathrm{~min}$ treatment with/without insulin (100 nM), cells were lysed in sample buffer (40\% glycerol, 0.25 M Tris, 1 M DTT, bromo-phenol-blue) and used for protein detection by SDS-polyacrylamide gel electrophoresis $(20 \mu \mathrm{g}$ protein per lane), followed by Western blotting. Western blot images were analyzed with a Molecular Imager (ChemiDoc XRS, BioRad) and quantified with Quantity One® (BioRad).

\section{Detection of surface CD36}

Following a 10 min pre-treatment with either Phenanthroline or TPEN cells were labeled during $10 \mathrm{~min}$ with $2 \mu \mathrm{g} / \mathrm{ml}$ (diluted in medium A) anti-CD36 antibody. Subsequently, FITC-labeled rabbit anti-mouse IgA secondary antibody $\left(C_{\text {end }} 1: 500\right)$ was added to the cells. Finally, cardiomyocytes were washed twice with medium A. Viable cardiomyocytes were imaged using Leica SP5 Multiphoton imaging platform (Leica Microsystems). The excitation wavelength of the 140 fs-pulsed laser was $800 \mathrm{~nm}$, while emission filters were optimized for FITC detection $(500-560 \mathrm{~nm})$. Laser power was kept as low as possible to avoid bleaching and photo-damage. Images were processed with ImageJ software (JAVA-based imaging software from the National Institutes of Health). Cardiomyocytes were kept at $37^{\circ} \mathrm{C}$ during incubations and imaging.

\section{Palmitate uptake by giant-vesicles}

Palmitate uptake was measured in giant vesicles isolated from rat skeletal muscles as described previously [20]. Preparation of giant vesicles: Briefly, rat hindlimb muscles from both legs were cut into thin layers (1-3 mm thick) and incubated for $1 \mathrm{~h}$ at $34^{\circ} \mathrm{C}$ in $140 \mathrm{~mm} \mathrm{KCl} / 10 \mathrm{~mm}$ MOPS (pH 7.4), collagenase type VII (150 units $/ \mathrm{ml})$ and aprotinin $(10 \mathrm{mg} / \mathrm{ml})$. At the end of the incubation, the supernatant 96 
was collected and the remaining muscle tissue was washed with $\mathrm{KCl} / \mathrm{MOPS}$ and 10 mm EDTA which resulted in a second supernatant. Both supernatants were pooled, and Percoll and aprotinin were added to final concentrations of $16 \%(\mathrm{v} / \mathrm{v})$ and 10 $\mathrm{mg} / \mathrm{ml}$, respectively. The resulting suspension was placed at the bottom of a density gradient consisting of a $3 \mathrm{ml}$ middle layer of $4 \%$ Nycodenz $(\mathrm{w} / \mathrm{v}$ ) and a $1 \mathrm{ml}$ $\mathrm{KCl} / \mathrm{MOPS}$ upper layer. This sample was centrifuged at $60 \mathrm{~g}$ for $45 \mathrm{~min}$ at room temperature. Subsequently, the vesicles were harvested from the interface of the upper and middle layer, diluted in $\mathrm{KCl} / \mathrm{MOPS}$, and recentrifuged at $900 \mathrm{~g}$ for $4 \mathrm{~min}$. The pellet was resuspended in $\mathrm{KCl} / \mathrm{MOPS}$ to a protein concentration of $1-2 \mathrm{mg} / \mathrm{ml}$. Palmitate uptake measurements in giant vesicles: Vesicles were pre-treated with phenanthroline $(200 \mu \mathrm{M})$ and TPEN $(1 \mu \mathrm{M})$ for 20 min at $37 \mathrm{C}$. After that, unlabeled and radiolabeled $0.3 \mu \mathrm{Ci}[9,10-3 \mathrm{H}]$ palmitate and $0.06 \mu \mathrm{Ci}[14 \mathrm{C}]$ mannitol in a $0.1 \%$ BSA KCI/MOPS solution were added to $40 \mu$ l of vesicles ( $\sim 40 \mu$ g protein). The reaction was carried out at room temperature for $15 \mathrm{sec}$. Palmitate uptake was terminated by addition of $1.4 \mathrm{ml}$ of ice-cold $\mathrm{KCl} / \mathrm{MOPS}(2.5 \mathrm{mM}) \mathrm{HgCl}_{2}$ and $0.1 \%$ BSA. The sample was quickly centrifuged at maximal speed in a microcentrifuge for 1 min. The supernatant was discarded, and radioactivity left in the tip of the vial $(1.5 \mathrm{ml})$ was measured. Non-specific uptake was measured by adding the stop solution prior to addition of the radiolabeled palmitate solution.

\section{Peptide synthesis}

Peptide amides were synthesized using an automatic ABI 433APeptide synthesizer, using the ABI FastMoc $(0.25 \mathrm{mM})$ protocols with coupling times of 45 minutes. Fmoc (9-fluorenylmethoxycarbonyl) amino acid derivatives, activated in situ by using HBTU/HOBt (2 - (1H - benzotriazole - 1 - yl) - 1,1,3,3 tetramethyluronium hexafluorophosphate in $0.5 \mathrm{M}$ 1-hydroxybenzotriazole) and DiPEA (N,N-diisopropylethylamine) in NMP (1-Methyl-2-pyrrolidone), were used in coupling steps. The peptides were deprotected and cleaved from the resin by treatment with $25 \mathrm{ml}$ TFA (trifluoroacetic acid)/H20/TIS (triisopropylsilane) (95:2.5:2.5) for $2 \mathrm{hr}$ at room temperature. Finally, the peptides were precipitated in a MTBE (methyl t-butyl ether)/n-hexane $(1: 1, v / v)$ solution. After this, the pellets were dissolved in tertiar butanol/water $(1: 1, \mathrm{v} / \mathrm{v}$ ) (ca. $60 \mathrm{ml}$ ) and lyophilised to obtain the crude peptides as solids. Peptides were checked for purity using reversed phase (rp) HPLC and integrity using electrospray ionization mass spectrometry (ESI-MS). Final peptide purification was accomplished by preparative rpHPLC using C18-bonded silica column chromatography (Vydac 218TP510) using a GE Pharmacia ÄKTA Purifier. The peptides were eluted with a linear gradient of 5 to $30 \%$ acetonitrile $(\mathrm{CH} 3 \mathrm{CN})$ in $0.1 \%$ aqueous TFA, over 30 minutes with $10 \mathrm{ml} / \mathrm{min}$ flow rate. The purified peptides were once again lyophilised and stored as dried powder at $-20^{\circ} \mathrm{C}$ until further use. The peptide nMGCDRNCGGSGGSGGSGGSYCACRSKNGK-c containing the wild type sequences of the $\mathrm{N}(\mathrm{n})$ - and $\mathrm{C}(\mathrm{c})$-terminal ends (underlined), spaced by ten amino acids (GSGGSGGSGG) is indicated as 'CCCC', where the position of each ' $\mathrm{C}$ ' represents each of the four Cys (C) residues (italic) in N-to C-terminal manner. The two CD36 peptide sequence segments correspond to NCBI protein sequence with accession number Q07969.3. Variant peptides were synthesized in the same manner and varied in each individual or combinations of the position of $C$ by introducing Ser 
(S), His (H) or Asp (D). The variant peptides were indicated by a combination of four of the four letters, where the position of the letter in the four-letter sequence indicates the position of the amino acid in the respective peptide.

\section{Mass spectrometry}

Proteomic analysis was performed by nano-ESI-MS. The instrument used was a Finnigan LCQ-DECA-XP ion-trap spectrometer (Thermo Scientific). The ESI conditions (i.e. cone temperature, electrostatic potentials, ion optical elements, flow rate) were kept constant throughout the measurements to insure constancy. The conditions were chosen using peptide CCCC (wild type sequence).

\section{Binding experiments of divalent metal ions to oligopeptides}

Peptide stock solutions were prepared by dissolving the purified peptides in Milli$\mathrm{Q}$ water in a concentration of $2 \mathrm{mM}$. Metal stock solutions were prepared by dissolving chloride salts in Milli- $Q$ water in different concentrations. These stock solutions were stored at $-20 \mathrm{oC}$. Samples for metal ion binding experiments were performed under the following standard conditions. Samples were prepared by diluting $1 \mu \mathrm{l}$ of the peptide and $1 \mu \mathrm{l}$ of the metal salt (chloride form) solutions in 20 $\mu \mathrm{l}$ of ammonium carbonate (AC) buffer at a final concentration of $10 \mathrm{mM}$, either of $\mathrm{pH} 7.5$ or $\mathrm{pH} 6$, thus obtaining solutions containing $0.1 \mathrm{mM}$ peptide with a threefold molar excess of metal ions. Subsequently, the solution is mixed, incubated at room temperature for the required time, diluted 10 times in $10 \mathrm{mM} \mathrm{AC}$ buffer and continuously infused into the ESI source at a flow rate of $20 \mu \mathrm{l} / \mathrm{min}$. Mass spectra were recorded in the range of 750-2,500 Da, and a window of $100 \mathrm{Da}$ in which the peptide with and without the bound metal are both visible. For each sample a measurement consisted of the average of 30 scans. The Cys containing peptides undergo oxidation once diluted in AC buffer. A varying oxidation degree of 5-20\% was observed in the Cys-containing peptides. This degree of oxidation was determined by comparing the obtained mass spectra with theoretical mass spectra of varying degrees of oxidation. As the addition of a reducing agent interfered too much with the measurement it was chosen to proceed without reducing agent. The oxidized fraction of the peptide did not bind metal ions, thus a $100 \%$ metal binding was not observed.

Peptide CCCC (wild type CD36 sequence) or SSSS was incubated with a three- or nine fold molar excess of the divalent cations of $\mathrm{Zn}, \mathrm{Ca}, \mathrm{Ba}, \mathrm{Mg}$, or $\mathrm{Mn}$ (chloride salts). The theoretical mono-isotopic mass for each peptide with or without bound divalent cation was calculated, and compared with the measured mono-isotopic mass of the free peptide or peptide in complex with the cation. For $\mathrm{Zn}^{2+}$ an increase in mass (64 Da) was measured; this is the mass of the metal atom minus that of two hydrogen $(\mathrm{H})$ atoms. The binding of $\mathrm{Zn}^{2+}$ to different peptides was calculated in a semi-quantitative manner; the quotient of the heights (in \%) of the two peaks representing the lowest isotopic mass of the obtained isotope mass pattern of the peptide in complex with $\mathrm{Zn}^{2+}$ and free peptide, respectively, was determined when the peptide was incubated with $3 \mathrm{mM} \mathrm{ZnCl}$. To determine the $\mathrm{Kd}(\mu \mathrm{M})$ of the $\mathrm{Zn}^{2+}$ binding of peptide CCCC in a semi-quantitative manner, $\mathrm{Zn}^{2+}$ in 98 
the concentration range of $1 \mu \mathrm{M}$ to $9 \mathrm{mM}$ was incubated with the peptide, the MS spectra recorded, from which the ratio of the lowest mono-isotopic peak for the bound and unbound peaks were determined.

\section{$\underline{\text { Statistics }}$}

Differences among the data obtained from five to eight experiments are presented as means \pm SEM. Statistical differences between groups of observations was evaluated by unpaired Student's t-test, one way-ANOVA and/or two-Way ANOVA, depending on the groups compared by using statistical analysis software Prism 5 (GraphPad Software, Inc.). A P-value equal or less than 0.05 was considered statistically significant.

\section{Results}

Effects of $\mathrm{Zn}^{2+}$ chelators on palmitate and deoxyglucose uptake into primary cardiomyocytes.

Before applying $\mathrm{Zn}^{2+}$ chelators to cardiomyocyte cultures for induction of insulin resistance, we tested whether and under which specific conditions $\mathrm{Zn}^{2+}$ chelators would influence LCFA uptake (and for comparison glucose uptake) into cardiomyocytes. For this purpose, suspensions of primary cardiomyocytes were either exposed to each of two $\mathrm{Zn}^{2+}$ chelating agents for $20 \mathrm{~min}$; phenanthroline (1 $\mathrm{mM})$ and TPEN $(5 \mu \mathrm{M})$ or in combination with insulin $(100 \mathrm{nM})$, oligomycin (5 $\mu \mathrm{M}$ ) and AICAR (1.5 mM) for an additional $20 \mathrm{~min}$. We found that both $\mathrm{Zn}^{2+}$ chelating agents increased palmitate uptake by 1.4-fold (Fig. 1). Concentrations of each chelator that were 5 -fold lower than the indicated concentrations had a smaller stimulatory effect on palmitate uptake, whereas concentration that were 5fold higher appeared to affect cell viability (data not shown). At the indicated concentrations, phenanthroline and TPEN both further increased insulinstimulated palmitate uptake from 1.5-fold to 2.0 fold. Additionally, palmitate uptake stimulated by the AMPK activators oligomycin (1.9-fold) or AICAR (1.5fold) was further stimulated to 2.6-fold or 2.4-fold, respectively, or to 1.9-fold or 2.3-fold, respectively by phenanthroline or TPEN (Fig. 1), suggesting separate mechanisms involved in $\mathrm{Zn}^{2+}$ depletion-stimulated LCFA uptake versus insulin/AMPK-stimulated LCFA uptake.

Neither phenanthroline nor TPEN increased basal deoxyglucose uptake (Fig. 1). In contrast, deoxyglucose uptake was increased by insulin (3.9-fold) or oligomycin (2.0-fold) treatment, but not by AICAR (Fig. 1). The inability of AICAR to stimulate glucose uptake has been previously reported by us [21], and relates to the notion that AMPK activation is not sufficient to stimulate glucose uptake, and that additional PKD activation is required for AMPK activators to stimulate glucose uptake. This additional PKD activation is achieved by oligomycin treatment but not by AICAR [21]. In contrast, AMPK-mediated LCFA uptake is not dependent on coactivation of PKD1 [21]. In agreement with their inability to stimulate basal deoxyglucose uptake, both $\mathrm{Zn}^{2+}$ chelators also did not further stimulate insulinstimulated or AMPK-mediated deoxyglucose uptake (Fig. 3). Instead, 
phenanthroline consistently decreased glucose uptake in the absence or presence of insulin or AMPK stimulators by 34-56\%, whereas TPEN did not alter deoxyglucose uptake under any tested condition (Fig. 1).

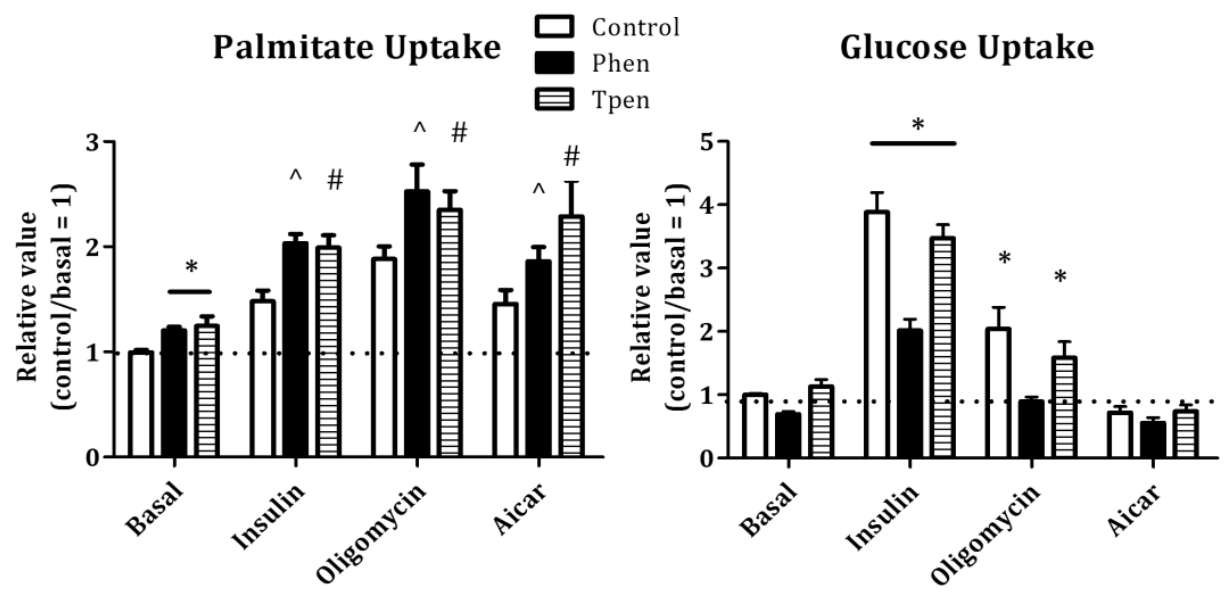

Fig. 1 Effect of $\mathrm{Zn}^{2+}$ chelators on substrate uptake into rat cardiomtocytes. Primary rat cardimyocytes were pre-incubated for 20 minutes in the absence or presence of 1-10-phenantroline (1 $\mathrm{mM})$ or TPEN $(5 \mu \mathrm{M})$, and then further incubated for $20 \mathrm{~min}$ with/without insulin (100 nM), oligomycin $(5 \mu \mathrm{M})$ or AICAR $(1.5 \mathrm{mM})$. Finally, uptake of 2-Deoxy-D-[1-3H]glucose and [1-14C]palmitic acid/BSA complex (5 min) was determined as pelletable radioactivity $(n=4) .{ }^{*} p<0.05$.

In order to study the role of CD36 in $\mathrm{Zn}^{2+}$ chelation-mediated LCFA uptake, we used cardiomyocytes isolated from hearts of CD36-null mice. Phenanthroline treatment stimulated palmitate uptake into cardiomyocytes from WT mice by 1.6fold (Fig. 2), i.e., a similar magnitude as observed in rat cardiomyocytes (Fig. 1). Phenanthroline-stimulated palmitate uptake was complete abrogated in CD36-null cardiomyocytes (Fid. 2). Unexpectedly, TPEN failed to stimulate palmitate uptake in mice cardiomyocytes in contrast to rat cardiomyocytes. This lack of TPEN to enhance palmitate uptake occurred not only at $5 \mu \mathrm{M}$ (Fig. 2), but also at 5-fold higher or lower concentrations (data not shown) which could relate to yet unknown species differences in the effectiveness of this $\mathrm{Zn}^{2+}$ chelator. In agreement with the rat cardiomyocyte data, TPEN did not alter basal deoxyglucose uptake into cardiomyocytes from WT and CD36 mull mice, whereas phenantroline had a marked inhibitory effect ( $-18 \%$ to $-43 \%$; Fig. 2$)$. These findings suggest that $\mathrm{Zn}^{2+}$ chelation increases basal LCFA uptake via involvement of CD36 but independently of insulin or AMPK-stimulated LCFA uptake. This stimulatory effect of $\mathrm{Zn}^{2+}$ chelation on LCFA uptake is specific because glucose uptake was not stimulated under these same conditions. Given that GLUT1 is the main cardiac glucose transporter involved in basal glucose uptake, perhaps the inhibitory action of phenanthroline on glucose uptake is due to direct inhibition of GLUT1, because this effect is already apparent under basal conditions. 
Fig. 2 Effect of $\mathrm{Zn}^{2+}$ chelators on substrate uptake into cardiomtocytes from CD36 null mice. Primary cardiomyocytes from wild-type and CD36-null mice were incubated for 20 minutes in the absence or presence of 1 10-phenantroline $(1 \mathrm{mM})$ or TPEN $(5 \mu \mathrm{M})$, and subsequently used for uptake of 2deoxy-[1-3 $\mathrm{H}]$ glucose and $\quad[1-$ $\left.{ }^{14} \mathrm{C}\right]$ palmitate/BSA complex (5 $\left.\mathrm{min}\right)(\mathrm{n}=4)$. $* \mathrm{p}<0.05$.

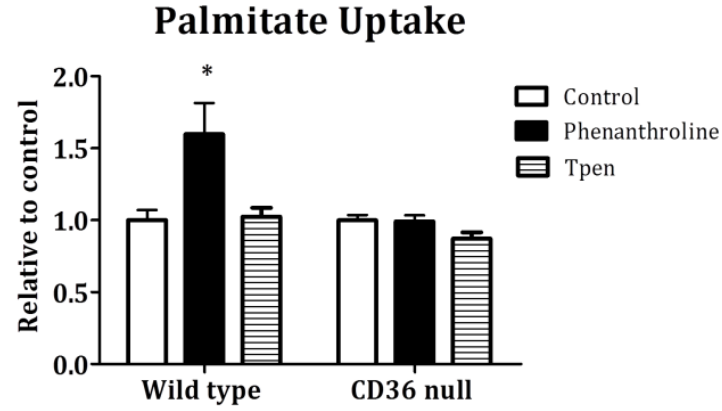

Glucose Uptake

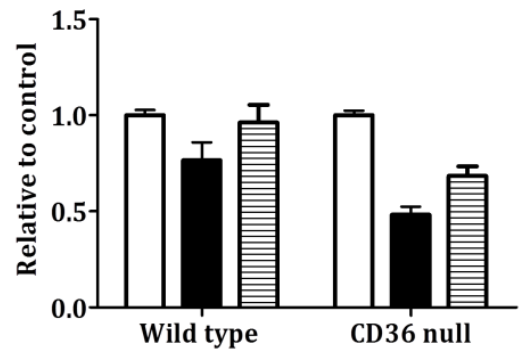

\section{Effects of $\mathrm{Zn}^{2+}$ chelators on insulin and AMPK signaling}

The non-additive effect of $\mathrm{Zn}^{2+}$ chelation with that of insulin or AMPK activators on LCFA uptake suggests that insulin or AMPK signaling is not involved in $\mathrm{Zn}^{2+}$ chelation-mediated LCFA uptake. To further study this, we tested whether phenanthroline or TPEN treatment stimulated Akt-Ser463 phosphorylation (as readout of insulin signaling), as well as AMPK-Thr172 and ACC-Ser97 phosphorylation (as readout of AMPK signaling). Insulin treatment stimulated AktSer463 phosphorylation by $>5$-fold, and oligomycin or AICAR treatment stimulated ACC-Ser97 phosphorylation by $>5$-fold and AMPK-Thr172 phosphorylation by $>2$ fold (in case of oligomycin) (Fig. 3), in agreement with previous results [22]. In contrast, phenanthroline or TPEN were without any effect on phosphorylation of any of these proteins, neither under basal conditions, nor in the presence of insulin or AMPK activators (Fig. 3). Hence, the stimulatory action of $\mathrm{Zn}^{2+}$ chelators on LCFA uptake is independent of insulin or AMPK signaling.

\section{Effects of $\mathrm{Zn}^{2+}$ chelators on surface CD36 content and activity}

Translocation of CD36 from endosomal stores to the sarcolemma is the main cellular mechanism via which cardiomyocytes can increase cellular LCFA uptake on a short-term scale. Insulin and AMPK activators stimulate LCFA uptake via this mechanism. In order to assess whether $\mathrm{Zn}^{2+}$ depletion induces CD36translocation, cardiomyocytes were exposed for $15 \mathrm{~min}$ to phenanthroline or TPEN, and cell surface CD36 presence was detected by immunofluorescence microscopy, using a two-photon microscope. Using this method, we previously showed that $15 \mathrm{~min}$ insulin treatment markedly enhanced cell surface CD36 staining without altering 


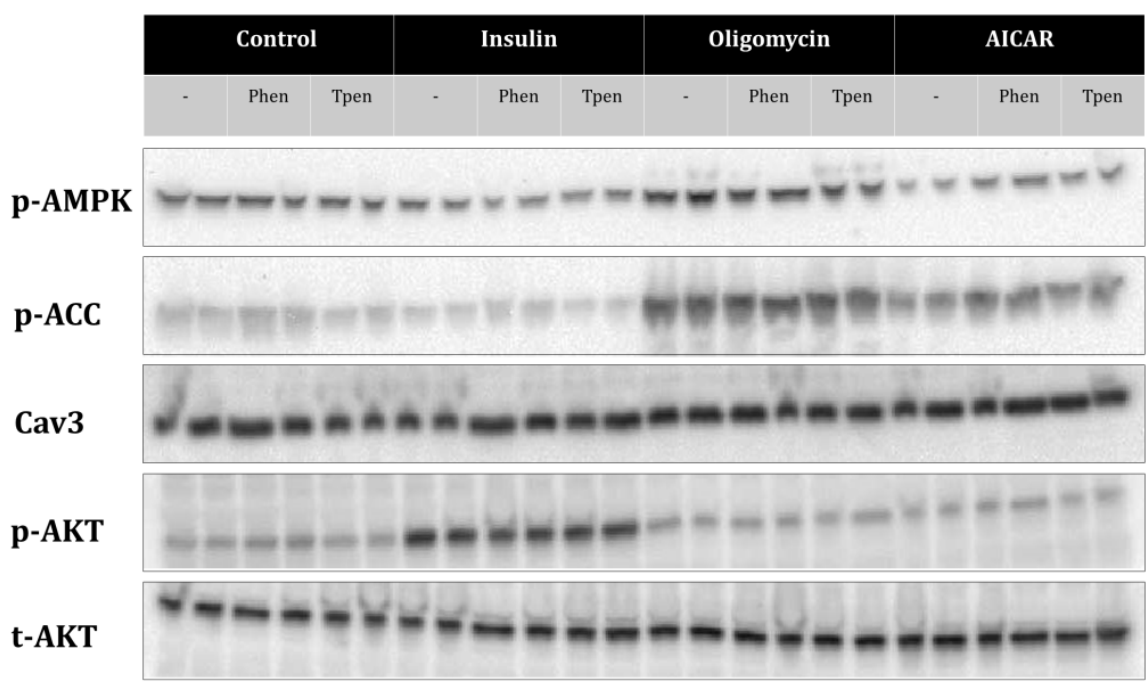

Fig. 3 Effect of $\mathrm{Zn}^{2+}$ chelators on insulin and AMPK signaling in rat cardiomtocytes. Primary rat cardimyocytes were pre-incubated for 20 minutes in the absence or presence of 1-10-phenantroline (1 $\mathrm{mM})$ or TPEN $(5 \mu \mathrm{M})$, and then further incubated for $20 \mathrm{~min}$ with/without insulin (100 nM), oligomycin $(5 \mu \mathrm{M})$ or AICAR $(1.5 \mathrm{mM})$. Subsequently, cells were lysed, and phosphorylation of Akt, AMPK and ACC, as well as total protein levels of caveolin-3 (Cav3) and Akt were assessed by Western blotting Representative images from $n=4$.

total CD36 expression, indicative of CD36 translocation to the cell surface [23]. In contrast, both $\mathrm{Zn}^{2+}$ chelators failed to enhance CD36 translocation to the cell surface (Fig. 4). Hence, other mechanisms must be responsible for the stimulatory action of $\mathrm{Zn}^{2+}$ chelators on CD36-mediated LCFA uptake.

A

C

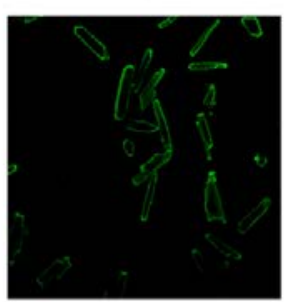

Total cellular CD36

Cav-3 (loading control)
Tpen

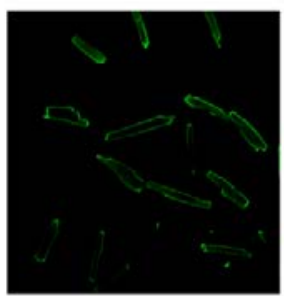

C

Tpen
Phen

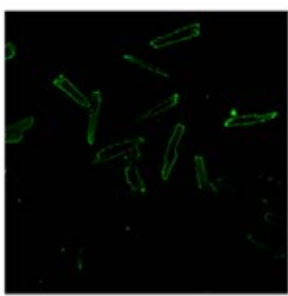

Phen

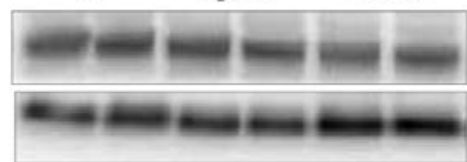


B

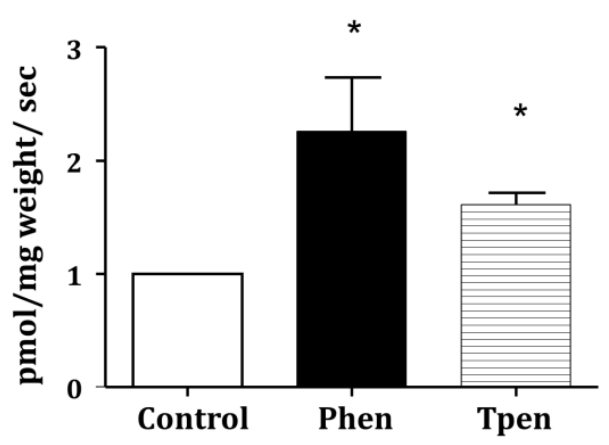

Fig. 4 Effect of $\mathrm{Zn}^{2+}$ chelators on CD36 translocation and on CD36 transport function. (A) Primary rat cardiomyocytes incubated for 20 minutes in the absence or presence of 1-10-phenantroline (1 mM), or TPEN (5 $\mu \mathrm{M}$ ), and subsequently used for immunofluorescence microscopy using a two-photon microscope to detect cell surface localization of CD36. (B) Giant sarcolemmal vesicles were incubated for 20 minutes in the absence or presence of 1-10phenantroline $(1 \mathrm{mM})$ or TPEN (5 $\mu \mathrm{M})$. Thereafter, uptake of $\left[{ }^{3} \mathrm{H}\right]$ palmitate/BSA complex (5 min) was determined as pelletable radioactivity $(\mathrm{n}=5){ }^{*} \mathrm{p}<0.05$.

To test the possibility that $\mathrm{Zn}^{2+}$ chelators increase the intrinsic LCFA transport activity of CD36, giant vesicles from rat muscle were used. This sarcolemmal preparation is enriched in CD36 and excellently suited to measure unidirectional LCFA uptake in the absence of translocation or other trafficking processes, because intracellular membrane compartments are absent [24]. Exposure of giant sarcolemmal vesicles for $15 \mathrm{~min}$ to phenantroline or TPEN increased palmitate uptake by 2.2 and 1.6-fold, respectively (Fig. 4), indicating that $\mathrm{Zn}^{2+}$ chelators directly increase the fatty acid transport facilitating property of CD36.

\section{Effects of $\mathrm{Zn}^{2+}$ depletion on insulin sensitivity and lipid content of cultured cardiomyocytes}

We tested whether 5 TPEN or $1 \mathrm{mM}$ phenanthroline, successfully stimulating CD36-mediated LCFA uptake, would induce insulin resistance and lipid accumulation in cardiomyocyte cultures. For comparison, we also induced insulin resistance in these cells by exposing them to a high concentration of palmitic acid $(\mathrm{HP}, 200 \mu \mathrm{M})$ during $48 \mathrm{~h}$ of culturing [23]. Unfortunately, exposing cardiomyocytes for $48 \mathrm{~h}$ to phenanthroline greatly impaired the cell viability. Perhaps this could be related to phenanthroline's inhibitory effect on glucose uptake. When cells were cultered in HP medium, and thereafter tested for shortterm insulin-induced Akt phosphorylation and GSK3 $\beta$ phosphorylation, as well as for myocellular lipid content, it appeared that insulin signaling was largely impaired in HP-exposed cells compared to basally cultured cells (Fig. 5A). Measurement of myocellular lipids in HP medium-cultured cardiomyocytes revealed that the contents of triacylglycerol and diacylglycerol were increased by 2.1-fold (Fig. 5B) and unchanged (data not shown), respectively. This is in agreement with our previous observations [23], and confirms the suitability of cardiomyocyte cultures as a cellular model system to assess the development of lipid-induced insulin resistance. Similarly, TPEN-exposed cells showed markedly decreased Akt and GSK3 $\beta$ phosphorylation upon short-term insulin treatment, and also exhibited elevated myocellular triacylglycerol content (1.6-fold), whereas the 
diacylglycerol content was unchanged (data not shown). In conclusion, cardiomyocytes cultured both in HP medium and in $\mathrm{Zn}^{2+}$ depletion medium exhibit characteristics of lipid-induced insulin resistance.

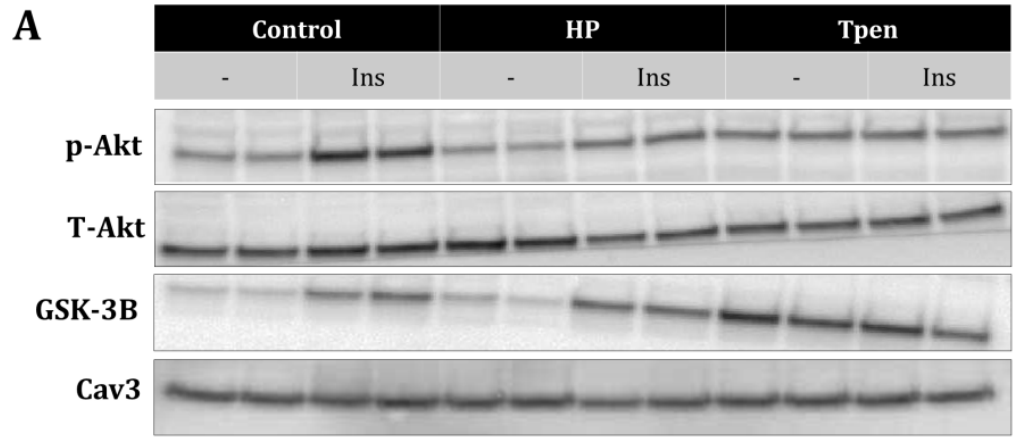

B

Triacylglycerol content

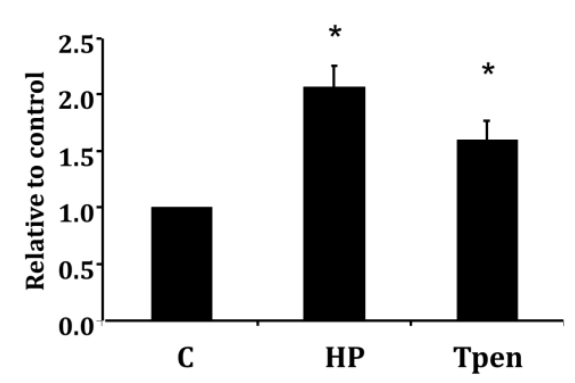

Fig. 5 Effect of $\mathrm{Zn}^{2+}$ depletion on development of insulin resistance and lipid accumulation in cultures of primary rat cardiomyocytes. Primary rat cardiomyocytes were cultured for 48 hours in the absence (C) or presence of high palmitate $(200 \mu \mathrm{M})$ or TPEN $(5 \mu \mathrm{M})$-containing medium (A) For assessment of insulin signaling, cells were incubated for another $30 \mathrm{~min}$ under basal conditions (recovery period). Thereafter, cells were incubated with/without $100 \mathrm{nM}$ insulin for a final 25 minutes. Harvested cells were lysed and used for Western detection of p-Akt, p-GSK3 $\beta$, total Akt (t-Akt) and caveolin-3 (Cav3). Representative images from n=4. (B) For assessment of lipid accumulation, cells were lysed, and used for measurement of triacylglycerol and diacylglycerol content via HPTLC $(n=4)$. * $\mathrm{p}<0.05$.

\section{Metal ion binding of protein terminal ends of CD36}

To explain the ability of $\mathrm{Zn}^{2+}$ chelators to directly "activate" CD36, we speculated that CD36 binds to $\mathrm{Zn}^{2+}$, and that this binding decreases CD36 activity. We further speculated that the four intracellular cysteines, two in each of the short intracellular $\mathrm{N}$ - and C-terminal ends of CD36, might provide a $\mathrm{Zn}^{2+}$-binding motif. To test the metal binding potential of the putative intracellular $\mathrm{N}$ - and $\mathrm{C}$-terminal ends of CD36 and the involvement of the Cys residues in this binding, a peptide, termed CCCC, was synthesized that contains the N-terminal eight amino acid sequence of the protein (MGCDRNCG), C-terminally linked to the eleven C-terminal amino acids (SYCACRSKNGK) by a spacer of ten amino acids (GSGGSGGSGG) (Fig. 
6A). In addition variants of this peptide were synthesized in which each of the four Cys residues is replaced by Ser (peptides termed SCCC, CSCC, CCSC, or CCCS), two Cys residues (SSCC or CCSS), or all four (SSSS). The GS-rich linker allows the spanning of a distance of $13-20 \AA$ (22) that is potentially present between the two protein terminal ends on the presumptive basis of two transmembrane $\alpha$-helical segments of CD36 that succeed and preceded the two terminal ends, respectively. The capacity of the peptides to bind the divalent cations $\mathrm{Mg}^{2+}, \mathrm{Ca}^{2+}, \mathrm{Ba}^{2+}, \mathrm{Zn}^{2+}$, or $\mathrm{Mn}^{2+}$ was assayed in the range of 0.001 to $9 \mathrm{mM}$ (chloride as counter ion), using electrospray ionization mass spectrometry (ESI-MS) analysis. For detection of complex formation of oligopeptide and metal cation, the occurrence and the combination of monoisotopic peaks in the position of the mass spectrum that corresponds to a mass of the peptide and cation is taken as measurement. Peptide CCCC formed a single molecular complex with one $\mathrm{Zn}^{2+}$ ion, as indicated by the appearance of a combination of monoisotopic peaks in the mass spectrum beginning at 1387.47 $\mathrm{Da}$ and upwards (1387.47 $\mathrm{Da}$ is the molecular mass of the first double charged monoisotopic peak representing the mass of the complex of peptide and $\mathrm{Zn}^{2+}$ ) (Fig. 6A). In the absence of $\mathrm{Zn}^{2+}$, the peptide exhibited a mass spectrum with the first monoisotopic peak at $1356.57 \mathrm{Da}$. Since the lowest monoisotopic form of $\mathrm{Zn}^{2+}$ is $64 \mathrm{Da}$, and the difference in mass between the free and $\mathrm{Zn}^{2+}$ bound form is 31 but not $32 \mathrm{Da}$ (i.e double charged form of the $\mathrm{Zn}^{2+}$ complex), this confirms that two $\mathrm{H}$ atoms were displaced to bind the $\mathrm{Zn}^{2+}$ cation. This result is in excellent agreement with the results obtained by Maret for other $\mathrm{Zn}^{2+}$ binding proteins (18). At approximately $0.1 \mathrm{mM} \mathrm{Zn}^{2+}$, the combination of monoisotopic peaks representing the complex, reached its maximum; the peaks representing the free oligopeptide reached a minimum level. At higher $\mathrm{Zn}^{2+}$ concentrations up to $9 \mathrm{mM}$, no further decrease of peaks was observed. In contrast, the peptide did not form a complex with any of the other above mentioned cations in the indicated concentration range, as judged by the absence of peaks in the spectrum at positions specific for the mass of the peptide increased with that of the metal cations.

In a semi-quantitative manner a $\mathrm{Kd}$ for the $\mathrm{Zn}^{2+}$-binding to CCCC could be determined at approximately $20 \mu \mathrm{M}$, by performing a similar binding experiment as described above, using titrating concentrations of $\mathrm{Zn}^{2+}$ in the range of $1 \mu \mathrm{M}$ to 9 mM. At approximately $20 \mu \mathrm{M}$ the monoisotopic peak representing the $\mathrm{Zn}^{2+}$ complex was half maximal of that at $300 \mu \mathrm{M}$ or $3 \mathrm{mM} \mathrm{Zn}^{2+}$ (data not shown). The stability of the $\mathrm{Zn}^{2+}$-complex (peptide CCCC and $\mathrm{Zn2+}$ ) was determined in the presence of titrating concentrations of the other divalent cations, in particular $\mathrm{Ca}^{2+}$, that functions directly or indirectly in signal transduction by binding to proteins. The occurrence of complex formed when peptide CCCC was incubated with $20 \mu \mathrm{M}$ $\mathrm{Zn}^{2+}$, was tested in the presence of the other metal cations in a concentration range of $10 \mu \mathrm{M}$ to $3 \mathrm{mM}$. Results showed that $\mathrm{Ca}^{2+}$ or the other cations do not affect complex formation of peptide CCCC and $\mathrm{Zn}^{2+}$ (data not shown), indicating that peptide CCCC specifically and uniquely binds $\mathrm{Zn}^{2+}$. Binding experiments performed at $\mathrm{pH} 6$, incubation in the presence of acetate as counter ion, or a prolonged preincubation time of peptide and metal-ion up to two hours before analysis of complex formation by ESI-MS, showed identical results as indicated above. This 
indicates that the complex of CCCC and $\mathrm{Zn}^{2+}$ is $\mathrm{pH}$ independent, specific for $\mathrm{Zn}^{2+}$, and is stable during prolonged incubation times.

To study the involvement of the Cys residues in metal ion binding of oligopeptide CCCC, oligopeptide SSSS was tested for its $\mathrm{Zn}^{2+}$ binding potential or that of the other above mentioned cations, tested in a concentration range of up to $3 \mathrm{mM}$. Peptide SSSS bound $\mathrm{Zn}^{2+}$ only poorly (Fig. 6B), however, like peptide CCCC did not bind any of other metal cations (data not shown). Single and double Cys to Ser-variant peptides (SCCC, CSCC, CCSC and CCCS, and SSCC and CCSS, respectively) showed a similar binding pattern for the metal ions indicated above as for peptide CCCC; the variant peptides bound $\mathrm{Zn}^{2+}$, but did not bind to the other cations. The single Cys to Ser-variants (SCCC, CSCC, CCSC, and CCCS) bound $\mathrm{Zn}^{2+}$ to a similar extent as peptide CCCC, whereas both the double Cys-residue variants (SSCC and CCSS) bound $\mathrm{Zn}^{2+}$ to a substantial lesser extent than the single site variant peptides or CCCC (Fig. 6B). These results indicate the specific involvement of the four Cys residues of the CD36 terminal ends in complex formation with $\mathrm{Zn}^{2+}$. In addition, when His or Asp replaces the Cys residues in the peptide, a similar $\mathrm{Zn}^{2+}$ binding and cation specificity as the Cys to Ser-variant peptides was observed (data not shown). These results indicate that the $\mathrm{Zn}^{2+}$ binding properties of the different peptides used in this study, obey biochemical binding properties that apply to zinc coordination in proteins (for review see [25]).

Conclusively, these results indicate that the protein terminal ends of CD36 are able to form a $\mathrm{Zn}^{2+}$ binding motif that specifically involves all four Cys residues in both $\mathrm{N}$ - and C-terminal ends. Suggested $\mathrm{Zn}^{2+}$ binding of cysteine residues on one or two CD36 molecules is illustrated in Fig. 6C. 
A

$$
\text { n-MGCDRNCGGSGGSGGSGGSYCACRSKNGK-c }
$$

B
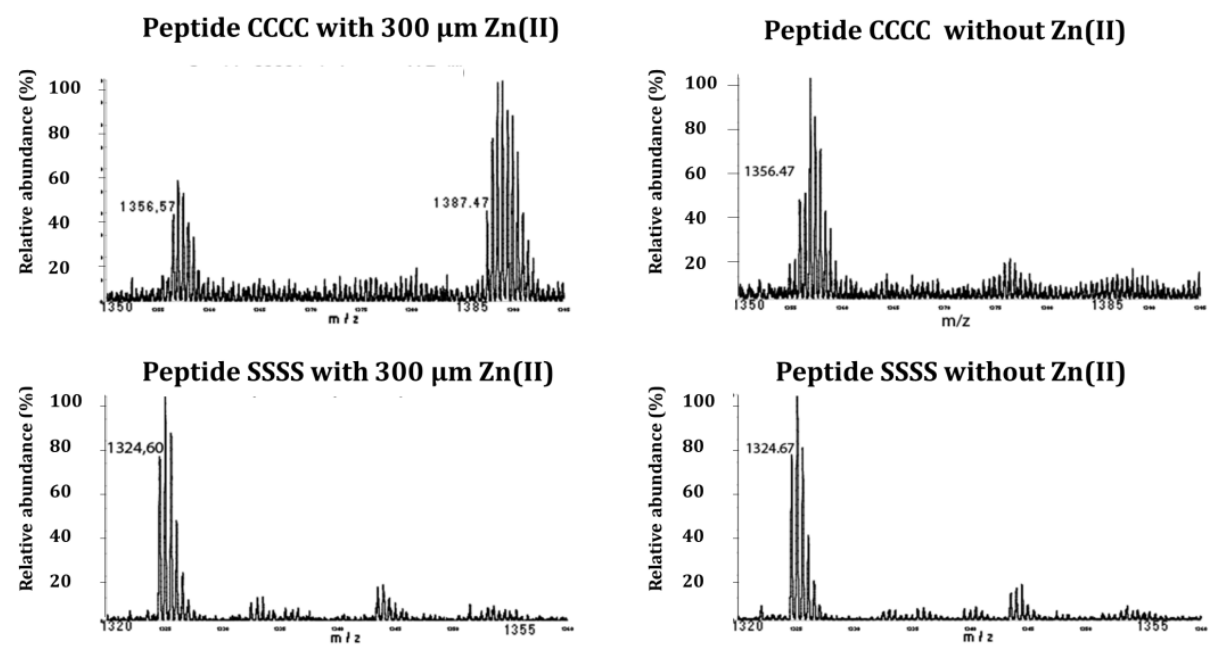

SSSS can not be oxidised

C

Serine mutants at pH 7.5: 1st mono-isotope normalised

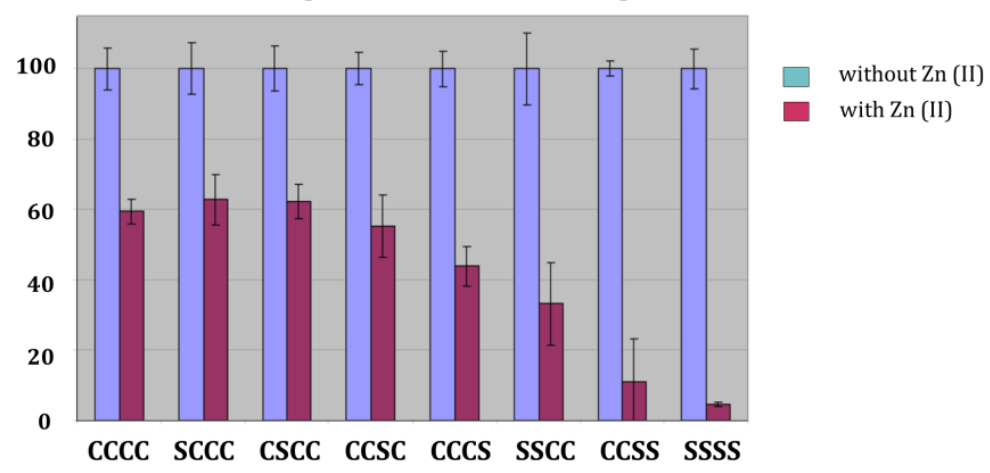

D

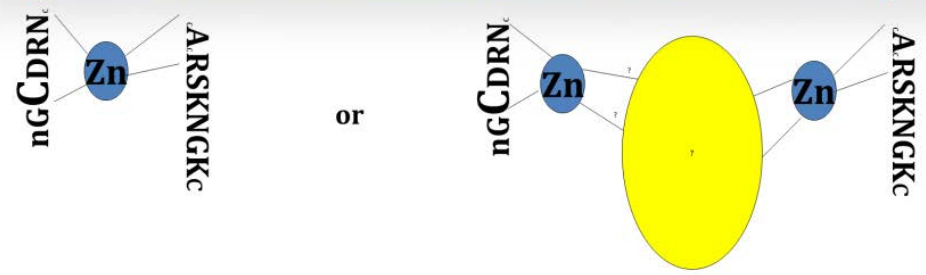

$\mathrm{Zn}^{2+}$ binding within a single CD36

$\mathrm{Zn}^{2+}$ binding between two CD36 molecules linked molecule by other protein 
Fig. $6 \mathrm{Zn}^{2+}$ binding of the protein terminal ends of CD36. (A) Primary structure of synthetic petide. (B) Upper two panels represent a relevant part of the ESI-MS mass spectrum of oligopeptide CCCC in the presence (left) or absence (right) of $\mathrm{Zn}^{2+}$. The lower two panels represent a relevant mass spectrum of the oligopeptide SSSS in the presence (left) or absence (right) of $\mathrm{Zn}^{2+}$. The relative abundance indicates the abundance of a component after evaporation and detection by ESI-MS. m/z indicates the mass of a detected ionized component, measured per charge (the mass spectrum indicates the $\mathrm{m} / \mathrm{z}$ part of the spectrum in which components are ionized with two charges). The numbers in the spectrum indicate molecular masses (in Da) of the monoisotopic peaks directly below the numbers. (C) The normalized binding of $\mathrm{Zn}^{2+}$ at $0.3 \mathrm{mM}$ to variant oligopeptides. The first monoisotopic peak of the free peptide was set at $100 \%$ and the monoisotopic peak of the peptide in complex with $\mathrm{Zn}^{2+}$ was determined as a fraction of that. The result shows the average of three independent binding experiments for each of the different peptides. The bar labels indicate the standard deviation. (D) Illustration of suggested $\mathrm{Zn}^{2+}$-bindings to Cysteine residues either from one or two CD36 proteins.

\section{Discussion}

Western diet-induced lipid oversupply causes diabetic cardiomyopathy, one of the main mortality causes in diabetic patients. Previously we showed that diabetic cardiomyopathy induced by lipid oversupply to rodents is due to CD36 relocation from intracellular stores to the sarcolemma, resulting in myocellular lipid accumulation, insulin resistance and contractile dysfunction of cardiomyocytes [13]. Another factor known to be associated with the development of myocellular insulin resistance and diabetic cardiomyopathy is $\mathrm{Zn}^{2+}$ deficiency. In the present study we investigated whether insulin resistance associated with $\mathrm{Zn}^{2+}$ deficiency shared subcellular molecular events with lipid-induced insulin resistance, thereby focusing on CD36. The main conclusions are that (i) $\mathrm{Zn}^{2+}$ depletion in cardiomyocytes results in increased CD36-mediated LCFA uptake, lipid accumulation and insulin resistance. Finally, (ii) CD36 possesses a $\mathrm{Zn}^{2+}$-binding domain that requires all of the four cysteines in the short intracellular terminal segments of the protein.

\section{(i) $\mathrm{Zn}^{2+}$ depletion in cardiomyocytes results in increased CD36-mediated LCFA uptake and lipid-induced insulin resistance.}

Using two structurally unrelated $\mathrm{Zn}^{2+}$ chelators, we showed that $\mathrm{Zn}^{2+}$ depletion results in increased LCFA uptake into cardiomyocytes. Uptake of glucose, the other major cardiac energy substrate, was not influenced by $\mathrm{Zn}^{2+}$ depletion. This indicates that $\mathrm{Zn}^{2+}$ depletion does not act as a general stimulator of cardiac substrate uptake, and at a specific mechanism may underlay $\mathrm{Zn}^{2+}$ depletionstimulated LCFA uptake. This specific mechanism includes CD36, as $\mathrm{Zn}^{2+}$ depletionstimulated LCFA uptake is abolished in CD36-null cardiomyocytes. Other conditions known to increase CD36-mediated LCFA uptake are insulin exposure or AMPK activation. This occurs via CD36 translocation from intracellular membrane compartments to the sarcolemma. However, the observation that $\mathrm{Zn}^{2+}$ depletioninduced LCFA uptake is non-additive to insulin/AMPK-stimulated LCFA uptake suggests that $\mathrm{Zn}^{2+}$ depletion uses a different mechanism via which flux through CD36 is increased. Further evidence that $\mathrm{Zn}^{2+}$ depletion-stimulated LCFA uptake is independent from insulin/AMPK-stimulated LCFA uptake is provided by the lack of ability of $\mathrm{Zn}^{2+}$ depletion to stimulate insulin or AMPK signaling. Indeed, as shown with immunofluorescence microscopy, $\mathrm{Zn}^{2+}$ depletion does not lead to 
enhanced surface CD36 content, thereby excluding CD36 translocation. Instead $\mathrm{Zn}^{2+}$ chelators enhanced LCFA uptake into giant sarcolemmal vesicles containing a fixed content of CD36 within the sarcolemma. Therefore, the effect of $\mathrm{Zn}^{2+}$ depletion on stimulation of LCFA uptake must be due to an increase in the intrinsic transport activity of CD36. Given that we earlier showed that the phosphodiesterase inhibitor 3-isobutyl-1-methylxanthine stimulates LCFA uptake into giant sarcolemmal vesicles [26], this makes $\mathrm{Zn}^{2+}$ depletion the second condition to increase LCFA uptake via CD36 activation.

During prolonged exposure to $\mathrm{Zn}^{2+}$ depleting conditions, i.e., when CD36 activation is sustained, cardiomyocytes exhibit a marked increase in triacylglycerol content and also to insulin resistance. This is very similar to the accumulation in triacylglycerol and the development of insulin resistance seen in cardiomyocytes in HP medium. However, cardiomyocytes cultured in HP medium displayed an elevated sarcolemmal CD36 content in the absence of increases in total CD36 expression, indicating that during lipid overload a permanent relocation of CD36 to the sarcolemma is responsible for lipid-induced insulin resistance [23]. Hence, irrespective of the mechanism by which flux through CD36 is increased, an increase in CD36-mediated LCFA uptake leads to lipid-induced insulin resistance. It is commonly accepted that triacylglycerols are not directly responsible for the induction of insulin resistance, but rather an indicator of cellular lipid overload [27]. However, myocellular diacylglycerol levels were not altered by HP medium or $\mathrm{Zn}^{2+}$ depletion, indicating that diacylglycerol-mediated impairment of IRS1 does not provide the mechanism for HP or $\mathrm{Zn}^{2+}$ depletion-mediated-induced insulin resistance. In conclusion, we present CD36 activation as a novel mechanism by which $\mathrm{Zn}^{2+}$ depletion induces insulin resistance. This might be in concordance with the other mechanisms by which $\mathrm{Zn}^{2+}$ depletion is suggested to cause insulin resistance, including loss of antioxidant capacity and loss of downregulation of protein-tyrosine phosphatases.

\section{(ii) CD36 possesses a $\mathrm{Zn}^{2+-}$ binding domain}

The importance of the intracellular domains of CD36 in CD36 localization and/or function is supported by multiple investigations in various different cell systems. For example, in a rat hepatoma cell line, deletion of the ten C-terminal amino acids resulted in decreased glycosylation and intracellular retention of CD36, corresponding to a decreased LCFA uptake, while deletion of only the last five amino acids - thus still containing both C-terminal Cys - had no effect on CD36 localization and LCFA uptake [28]. Replacement of the $11 \mathrm{C}$-terminal amino acids of CD36 by alanines does not change the plasma membrane localization in HEK293 cells, but does diminish its role in toll-like receptor signaling, as does mutation of C464 alone [29]. The two cytosolic lysine residues at position 469 and 472 of CD36 are ubiquitinated. CD36 ubiquitination is decreased by insulin treatment and increased by LCFA incubation of $\mathrm{C} 2 \mathrm{C} 12$ muscle cells, leading to an enhancement and decrease in the amount of total CD36 (and LCFA uptake levels), respectively [30]. Thus, the four cysteines within the intracellular domains of CD36 might play a potentially essential role in CD36 localization and/or function. 
By using a synthetic oligopeptide peptide composed of both protein terminal ends of CD36 in metal binding experiments, we found strong suggestive evidence for the potential of the four Cys residues in the CD36 terminal ends to specifically bind divalent $\mathrm{Zn}^{2+}$, in a $\mathrm{Zn}^{2+}$-binding motif dependent manner. All four Cys residues are necessary for optimally coordinating $\mathrm{Zn}^{2+}$, since the $\mathrm{Zn}^{2+}$-binding potential of the oligopeptide was substantially compromised when at least two of the four Cys residues was replaced by Ser in the oligopeptide (Ser can not easily replace Cys in $\mathrm{Zn}^{2+}$-binding motifs [25, 31-35]). This result is in line with those of a similar studies by Bergman et al. [36] or Brandt et al. [37], who showed that $\mathrm{Zn}^{2+}$ binding of oligopeptide analogs of the $\mathrm{Zn}^{2+}$-binding site of alcohol dehydrogenase, a typical $\mathrm{Zn}^{2+}$-binding protein, also showed clearly compromised $\mathrm{Zn}^{2+}$-binding upon replacement of two Cys residues that function in the $\mathrm{Zn}^{2+}$-binding motif of the enzyme. Additional evidence for the involvement of the four Cys residues of the two terminal ends in a $\mathrm{Zn}^{2+}$-binding motif is provided by the data that shows that His or Asp can replace each of the Cys residues in the binding experiments, which is also observed in many other $\mathrm{Zn}^{2+}$-binding motif containing proteins [25, 31-35]. The relatively high affinity of the oligopeptide composed of the wild type sequences of the two terminal ends ( $\mathrm{Kd}$ of $20 \mu \mathrm{M}$ ), considering $\mathrm{Zn}^{2+}$ concentrations in (cardiac) cells can be as high as $200 \mu \mathrm{M}$ [32], suggests that the existence of a complex of the two protein ends and $\mathrm{Zn}^{2+}$ in CD36 is physiologically not unrealistic. Taken together, the present study is the first to show that CD36 has a specific $\mathrm{Zn}^{2+}$ binding domain. Hence, $\mathrm{Zn}^{2+}$ regulation of $\mathrm{CD} 36$ extends the role of $\mathrm{Zn}^{2+}$ in regulation of lipid metabolism, as investigated earlier [9].

Studies with the $\mathrm{Zn}^{2+}$ indicator FluoZin-3, demonstrate that $\mathrm{Zn}^{2+}$ is present in the cytoplasm of cardiomyocytes in sufficient abundance to act as a regulator of metabolism or gene expression [38]. Likely, under normal/basal, conditions, the intracellular $\mathrm{Zn}^{2+}$ concentration in cardiomyocytes is sufficiently high to bind to a large portion of the total CD36 population via its $\mathrm{Zn}^{2+}$-binding domain. This will keep CD36 in a suboptimal activation state. Then, exposure of cardiomyocytes to $\mathrm{Zn}^{2+}$ chelators will lead to disassociation of $\mathrm{Zn}^{2+}$ from $\mathrm{CD} 36$ and subsequent activation of CD36. We do not know yet the molecular mechanisms by which $\mathrm{Zn}^{2+}$ displacement from CD36's intracellular arms might activate CD36, but this might trigger a conformational change within the extracellular loop of CD36, thereby improving the exposure of the LCFA binding pocket (within this extracellular loop) to LCFA in the extracellular medium.

\section{(iii) Concluding remarks}

Insulin resistance associated with $\mathrm{Zn}^{2+}$ deficiency and lipid-induced insulin resistance share the key involvement of CD36. However, differently from CD36 being relocated from intracellular stores to the sarcolemma as primary cause for lipid-induced insulin resistance, $\mathrm{Zn}^{2+}$ deficiency-associated insulin resistance is caused by an activation of CD36 that is already present at the sarcolemma. The present findings also propose that, besides $\mathrm{Zn}^{2+}$ supplementation to $\mathrm{Zn}^{2+}$-deficient diabetic patients as a strategy to combat diabetic cardiomyopathy, an alternative strategy might include specific drugs aimed at inhibition of CD36. Finally, polymorphisms within CD36 might be discovered in the future in which the 
intracellular cysteines might be replaced by other amino acid residues, resulting in CD36 forms with increased transport activity. These mutant CD36 forms might then be predictive of an increased risk for the development of type- 2 diabetes and diabetic cardiomyopathy.

\section{Acknowledgments}

We thank Arnoud de Ru and Peter van Veelen (Department of Immunohematology and Blood Transfusion, Leiden University Medical Centre, Leiden, The Netherlands) for useful discussions and technical help. D.N. and J.L. are the recipients of a VIDI-Innovational Research Grant from the Netherlands Organization of Scientific Research (NWO-ALW Grant 864.10.007 and NWOZonMW Grant 016.036.305, respectively). 


\section{References}

1. $\quad$ Song Y, Wang J, Li XK, Cai L. Zinc and the diabetic heart. Biometals. 2005;18:325-32.

2. Li B, Tan Y, Sun W, Fu Y, Miao L, Cai L. The role of zinc in the prevention of diabetic cardiomyopathy and nephropathy. Toxicol Mech Methods. 2013;23:27-33.

3. Goldberg ED, Eshchenko VA, Bovt VD. The diabetogenic and acidotropic effects of chelators. Exp Pathol. 1991;42:59-64.

4. Goldberg ED, Eshchenko VA, Bovt VD. Diabetogenic activity of chelators in some mammalian species. Endocrinologie. 1990;28:51-5.

5. Kinlaw WB, Levine AS, Morley JE, Silvis SE, McClain CJ. Abnormal zinc metabolism in type II diabetes mellitus. Am J Med. 1983;75:273-7.

6. Oteiza PI, Clegg MS, Zago MP, Keen CL. Zinc deficiency induces oxidative stress and AP-1 activation in 3T3 cells. Free Radic Biol Med. 2000;28:1091-9.

7. Haase $\mathrm{H}$, Maret W. Protein tyrosine phosphatases as targets of the combined insulinomimetic effects of zinc and oxidants. Biometals. 2005;18:333-8.

8. Le Marchand-Brustel Y, Gual P, Gremeaux T, Gonzalez T, Barres R, Tanti JF. Fatty acid-induced insulin resistance: role of insulin receptor substrate 1 serine phosphorylation in the retroregulation of insulin signalling. Biochem Soc Trans. 2003;31:1152-6.

9. Cunnane SC. Role of zinc in lipid and fatty acid metabolism and in membranes. Prog Food Nutr Sci. 1988;12:151-88.

10. Glatz JF, Luiken JJ, Bonen A. Membrane fatty acid transporters as regulators of lipid metabolism: implications for metabolic disease. Physiol Rev. 2010;90:367-417.

11. Savage DB, Petersen KF, Shulman GI. Disordered lipid metabolism and the pathogenesis of insulin resistance. Physiol Rev. 2007;87:507-20.

12. Coort SL, Hasselbaink DM, Koonen DP, Willems J, Coumans WA, Chabowski A, et al. Enhanced sarcolemmal FAT/CD36 content and triacylglycerol storage in cardiac myocytes from obese zucker rats. Diabetes. 2004;53:1655-63.

13. Ouwens DM, Diamant M, Fodor M, Habets DD, Pelsers MM, El Hasnaoui M, et al. Cardiac contractile dysfunction in insulin-resistant rats fed a high-fat diet is associated with elevated CD36-mediated fatty acid uptake and esterification. Diabetologia. 2007;50:1938-48.

14. Aguer C, Mercier J, Man CY, Metz L, Bordenave S, Lambert K, et al. Intramyocellular lipid accumulation is associated with permanent relocation ex vivo and in vitro of fatty acid translocase (FAT)/CD36 in obese patients. Diabetologia. 2010;53:1151-63.

15. Habets DD, Coumans WA, Voshol PJ, den Boer MA, Febbraio M, Bonen A, et al. AMPK-mediated increase in myocardial long-chain fatty acid uptake critically depends on sarcolemmal CD36. Biochem phys Res Commun. 2007;355:204-10.

16. van Oort MM, van Doorn JM, Bonen A, Glatz JF, van der Horst DJ, Rodenburg KW, et al. Insulininduced translocation of CD36 to the plasma membrane is reversible and shows similarity to that of GLUT4. Biochim Biophys Acta. 2008;1781:61-71.

17. Fischer Y, Rose H, Kammermeier H. Highly insulin-responsive isolated rat heart muscle cells yielded by a modified isolation method. Life Sci. 1991;49:1679-88.

18. Luiken JJ, van Nieuwenhoven FA, America G, van der Vusse GJ, Glatz JF. Uptake and metabolism of palmitate by isolated cardiac myocytes from adult rats: involvement of sarcolemmal proteins. J Lipid Res. 1997;38:745-58.

19. Alkhateeb H, Chabowski A, Glatz JF, Luiken JF, Bonen A. Two phases of palmitate-induced insulin resistance in skeletal muscle: impaired GLUT4 translocation is followed by a reduced GLUT4 intrinsic activity. Am J Physiol Endocrinol Metab. 2007;293:E783-93.

20. Luiken JJ, Turcotte LP, Bonen A. Protein-mediated palmitate uptake and expression of fatty acid transport proteins in heart giant vesicles. J Lipid Res. 1999;40:1007-16.

21. Dirkx E, Schwenk RW, Coumans WA, Hoebers N, Angin Y, Viollet B, et al. Protein kinase D1 is essential for contraction-induced glucose uptake but is not involved in fatty acid uptake into cardiomyocytes. J Biol Chem. 2012;287:5871-81.

22. Steinbusch LK, Wijnen W, Schwenk RW, Coumans WA, Hoebers NT, Ouwens DM, et al. Differential regulation of cardiac glucose and fatty acid uptake by endosomal $\mathrm{pH}$ and actin filaments. Am J Physiol Cell Physiol. 2010;298:C1549-59.

23. Angin Y, Steinbusch LK, Simons PJ, Greulich S, Hoebers NT, Douma K, et al. CD36 inhibition prevents lipid accumulation and contractile dysfunction in rat cardiomyocytes. The Biochemical journal. 2012;448:43-53.

24. Koonen DP, Coumans WA, Arumugam Y, Bonen A, Glatz JF, Luiken JJ. Giant membrane vesicles as a model to study cellular substrate uptake dissected from metabolism. Mol Cell Biochem. 2002;239:121-30. 
25. Auld DS. Zinc coordination sphere in biochemical zinc sites. Biometals. 2001;14:271-313.

26. Luiken JJ, Willems J, Coort SL, Coumans WA, Bonen A, Van Der Vusse GJ, et al. Effects of cAMP modulators on long-chain fatty-acid uptake and utilization by electrically stimulated rat cardiac myocytes. Biochem J. 2002;367:881-7.

27. Shulman GI. Cellular mechanisms of insulin resistance. J Clin Invest. 2000;106:171-6.

28. Eyre NS, Cleland LG, Tandon NN, Mayrhofer G. Importance of the carboxyl terminus of FAT/CD36 for plasma membrane localization and function in long-chain fatty acid uptake. J Lipid Res. 2007;48:528-42.

29. Stuart LM, Deng J, Silver JM, Takahashi K, Tseng AA, Hennessy EJ, et al. Response to Staphylococcus aureus requires CD36-mediated phagocytosis triggered by the COOH-terminal cytoplasmic domain. J Cell Biol. 2005;170:477-85.

30. Smith J, Su X, El-Maghrabi R, Stahl PD, Abumrad NA. Opposite regulation of CD36 ubiquitination by fatty acids and insulin: effects on fatty acid uptake. J Biol Chem. 2008;283:13578-85.

31. Gamsjaeger R, Liew CK, Loughlin FE, Crossley M, Mackay JP. Sticky fingers: zinc-fingers as proteinrecognition motifs. Trends Biochem Sci. 2007;32:63-70.

32. Korichneva I. Zinc dynamics in the myocardial redox signaling network. Antioxid Redox Signal. 2006;8:1707-21.

33. Maret W. Zinc coordination environments in proteins as redox sensors and signal transducers. Antioxid Redox Signal. 2006;8:1419-41.

34. Maret W. Molecular aspects of human cellular zinc homeostasis: redox control of zinc potentials and zinc signals. Biometals. 2009;22:149-57.

35. Maret W, Li Y. Coordination dynamics of zinc in proteins. Chem Rev. 2009;109:4682-707.

36. Bergman T, Zhang K, Palmberg C, Jornvall H, Auld DS. Zinc binding to peptide analogs of the structural zinc site in alcohol dehydrogenase: implications for an entatic state. Cell Mol Life Sci. 2008;65:4019-27.

37. Brandt EG, Hellgren M, Brinck T, Bergman T, Edholm O. Molecular dynamics study of zinc binding to cysteines in a peptide mimic of the alcohol dehydrogenase structural zinc site. Phys Chem Chem Phys. 2009; 11:975-83.

38. Palmer BM, Vogt S, Chen Z, Lachapelle RR, Lewinter MM. Intracellular distributions of essential elements in cardiomyocytes. J Struct Biol. 2006;155:12-21. 
Chapter 6

General Discussion 
Membrane-associated transporter proteins play an important role in the facilitation of substrate entry across the plasma membrane in response to changes in high energy demands of heart and contracting skeletal muscle [1]. Upon a physiological (insulin) or mechanical stimulus (enhanced contraction) the glucose transporter GLUT4 and the long-chain fatty acid (LCFA) transporter CD36, each located in intracellular compartments, translocate to the plasma membrane to facilitate glucose and LCFA entry into cell, respectively [2]. Mediators of the vesicular transport play a major role in the regulation of the translocation process of the vesicles containing GLUT4 and CD36 to the plasma membrane [3-5].

With respect to GLUT4-mediated glucose uptake some reported findings suggest that glucose uptake is not only regulated by GLUT4 translocation to the plasma membrane but also by changes in the activity of GLUT4 once at the side of the plasma membrane [6-8]. Knowledge in the literature regarding the possible requirement of an additional activation step after translocation to the membrane was not fully appreciated. In addition, for CD36 there are no such examples. In this thesis we provide novel mechanisms for the regulation of transporters and the transporter mediated substrate uptake process in health and disease.

Permanent relocation of endosomal CD36 to the sarcolemma is one of the hallmarks of insulin resistance and associated cardiac lipotoxicity $[9,10]$. It is known that CD36-mediated LCFA influx is responsible for increased TAG content in the diabetic heart and skeletal muscle. In this thesis we showed that inhibition of CD36-mediated LCFA influx by targeting CD36 via an antibody resulted in diminished TAG levels and attenuated insulin signaling in primary rat cardiomyocytes cultured under insulin resistance-inducing conditions (chapter 2). We also showed beneficial effects of n-3 PUFAs (EPA and DHA) on insulin signaling in primary rat cardiomyocytes cultured under insulin resistance-inducing conditions (chapter 3 ).

Another novel finding in this thesis is that translocation of substrate transporters to the plasma membrane and their activation at the membrane (i.e., increasing their substrate transport facilitating function) are separate events for both substrate transporters GLUT4 and CD36. It was found that both transporters can be activated upon arrival at the plasma membrane with a common mechanism (chapter 4). Finally, we obtained strong evidence for the regulation of CD36 intrinsic activity at the site of the membrane by $\mathrm{Zn}^{2+}$-binding which thereby modulates the fatty acid transport function of CD36 (chapter 5). This latter finding may have clinical implications as it may explain why $\mathrm{Zn}^{2+}$ deficiency is associated with diabetes.

In this discussion chapter selected aspects of these studies will be discussed in more detail. This discussion is structured under four titles. Perspectives for future research also will be stated under each title. First, we will discuss the transporter-mediated substrate uptake process with special attention to transporter translocation and subsequent transporter activation at the site of the plasma membrane. Second, based on our findings in chapters 2, 3 and 5, the importance of fatty acid translocase/CD36 in the treatment of fatty acid-induced 
insulin resistance and related diseases will be discussed. Under the third title, the importance of calcium signaling in the regulation of cardiac substrate metabolism will be discussed with special reference to our findings reported in chapter 4 . In the fourth and final title the reverse effect, i.e, of CD36 on calcium signaling, will be discussed using recently obtained and unpublished findings from our group.

\section{(i) GLUT4 and CD36 translocation to the plasma membrane and their membrane activation are separate events}

The general knowledge on the mechanism of transporter-mediated substrate uptake comes mainly from the findings reported for glucose transporters. It is well accepted that mainly GLUT4 translocation is responsible for the increases in glucose uptake in heart and muscle [11]. There is a number of findings for GLUT4 which show unchanged glucose uptake levels after translocation of GLUT4/1 to plasma membrane [12] or alternatively increased glucose uptake levels upon a stimuli without any change in membrane GLUT content [13]. For instance, PI3K activation is needed for insulin mediated GLUT4 translocation and glucose uptake. However, addition of a cell permeable phosphoinoside-binding peptide (PBP-10) into 3T3-L1 cells induced GLUT4 translocation to the plasma membrane without leading to increases in glucose uptake [6]. Furthermore, inhibition of PI3K with wortmannin did not prevent the phosphoinoside-binding peptide-induced GLUT4 translocation but prevented insulin to increas glucose uptake [6, 7]. These findings suggest that translocation to the plasma membrane and membrane activation of GLUT4 are separate events and insulin induced GLUT4 activation requires PI3K activity.

In addition, for GLUT4 there is evidence for the requirement of an additional regulation step at the plasma membrane to increase substrate uptake [6-8]. L6 rat skeletal muscle cells incubated with recombinant resistin or stably transfected with myc-tagged mouse resistin showed diminished levels of 2-deoxyglucose uptake without any changes neither in components of the insulin signaling pathway nor in the amount of GLUT4 moved to plasma membrane [14]. The authors concluded that resistin-triggered insulin resistance is the result of changes in GLUT4 intrinsic activity at the membrane. Subsequently, these authors showed that the activity of GLUT4 is regulated by phosphorylation of GLUT4 from at the serine-488 residue [14]. All together these findings suggest that translocation itself is not always sufficient to account for increases in substrate uptake and that an additional increase in activity of GLUTs is needed for elevation of glucose uptake through the membrane. Mechanisms which might regulate activity of GLUT4 on the membrane will be discussed in detail below.

All the findings listed so far provide evidence for the additional activation steps for GLUT-mediated substrate uptake. There is to our knowledge no reported evidence for CD36 intrinsic activity as a mechanism to control its fatty acid transport function at the site of the plasma membrane. Our findings in chapters 4 and $\mathbf{5}$ show for the first time that CD36 intrinsic activity is regulated via AMPK activation and/or via zinc ions. This finding in chapter 4 is the first evidence suggesting two distinct regulatory mechanisms in CD36 mediated substrate 
uptake, i.e., translocation to the membrane and regulation of activity of CD36 at the membrane.

We showed that a rise in $\left[\mathrm{Ca}^{2+}\right]_{\mathrm{i}}$ upon exposure of cardiomyocytes to the $\mathrm{Ca}^{2+-i o n o p h o r e ~ A 23187 ~ o r ~ t h e ~ S E R C A / A T P a s e ~ i n h i b i t o r ~ t h a p s i g a r g i n ~ r e s u l t e d ~ i n ~ a n ~}$ increases of membrane GLUT4 and CD36 content without any increases in cellular substrate uptake. We showed that both plasma membrane recruited GLUT4 and CD36 upon activation of $\mathrm{Ca}^{2+}$ signaling needed additional AMPK activation to upregulate glucose and palmitate uptake, respectively (chapter 4, figure 5) The findings in chapter 4 suggest that AMPK is responsible for the activation of $\mathrm{Ca}^{2+}$ recruited transporters at the plasma membrane to increase substrate uptake (chapter 4). There are also other examples in the literature showing the involvement of protein kinases to activate transporters on the plasma membrane. For instance, p38-MAPK was suggested to enhance GLUT4 activity on the plasma membrane [15-17]. Inhibition of p38-MAPK with SB203580 in 3T3-L1 adipoycytes and in L6 myotubes prevented insulin stimulated glucose uptake but did not affect basal glucose uptake. The observed effect was without inhibition of GLUT4 and GLUT1 translocations [18]. Taken together, our findings and that of others suggest that the activation of substrate transporters on the plasma membrane involves protein kinases. However, it is not exactly known under which circumstances AMPK or (an)other protein kinase(s) could phosphorylate the transporters or regulatory proteins in vesicular transport like TBC1D4 $[19,20]$ to effectuate/prevent proper fusion of the transporter with the plasma membrane. It is conceivable that protein kinases phosphorylate and activate or inhibit substrate transporters or proteins involved in the fusion process of substrate transporters to plasma membrane [21]. Possible activation mechanisms of transporters including their phosphorylation will be discussed in more detail under the "posttranslational modifications" subtitle.

Another novel finding is the modulation of CD36 activity via $\mathrm{Zn}^{2+}$-binding. We showed for the first time that CD36 has a zinc finger motif (chapter 5). Binding of $\mathrm{Zn}^{2+}$ ions to cysteine residues on both the intracellular $\mathrm{N}$ - and $\mathrm{C}$ - terminals of CD36 regulates its fatty acid transport function. We showed that removal of $\mathrm{Zn}^{2+}$ ions by chelating effectuated CD36 function on the membrane and increased CD36 mediated fatty acid uptake into cardiomyocytes (chapter 5). These novel findings provide evidence for different regulatory mechanisms to control the activity and functioning of substrate transporters upon constantly changing cell needs and environment in health and disease. As we have shown, a rise in $\left[\mathrm{Ca}^{2+}\right]_{\mathrm{i}}$ leads to CD36 and GLUT4 translocation to the plasma membrane whereas depletion of $\mathrm{Zn}^{2+}$ ions selectively effectuates the fatty acid transport function of CD36.

In the following sections an overview of potential activation mechanisms of substrate transporters on the plasma membrane, which might affect the substrate transport function of GLUT4 and of CD36, will be discussed. 
Proper fusion of vesicles carrying substrate transporters with the physiologically active membrane domains at the cell surface is one of the parameters affecting the substrate uptake process. Upon appropriate stimuli GLUT4 storing vesicles (GSV) translocate to the plasma membrane, and then are tethered, docked and fused to the membrane [3, 20, 22]. Heyward et al. [23] discovered a phosphatidic acid (PtdOH) binding motif on the extracellular loop of GLUT4 which is unique for GLUT4 and not found on other carbohydrate transporter proteins. PtdOH, which is generated by action of phospholipase D on membrane phospholipids, is a lipid secondary messenger and plays a role in different signaling pathways. PtdOH has been suggested to be involved in insulin-induced glucose uptake through achieving an effective fusion process of GLUT4 containing vesicles to the plasma membrane [23]. Alanine mutation of the PtdOH binding peptide of GLUT4 attenuated insulin stimulated fusion of GLUT4 containing vesicles with the plasma membrane which resulted in unchanged glucose uptake [23]. This finding indicates that proper fusion of GLUT4 containing vesicles to the plasma membrane by PtdOH binding effect GLUT4 activity to transport glucose upon insulin stimulation.

In addition to proper vesicle fusion, the membrane (lipid) composition has been reported to affect the incorporation and functioning of the substrate transporters at the plasma membrane. For instance, cholesterol and sphingolipidrich membrane microdomains which are called lipid rafts play a role in the cellular uptake processes of both glucose and LCFA mainly via affecting the membrane localization and thereby presumably also the functioning of the substrate transporters (GLUT4, CD36, FABPc1-4) [24, 25]. Caveolae are intracellular invaginations of lipid raft membranes and contain caveolin (caveolin 1,-2,-3) proteins. In 3T3-L1 adipocytes caveolin-enriched membrane lawns were found to contain GLUT4 $[26,27]$. Later it has been suggested that caveolins play a role in GLUT4 internalization into the plasma membrane after insulin stimulation during exocytosis or during endocytosis $[27,28]$. Similar to GLUT4, CD36 has been shown to be present in lipid rafts in 3T3-L1 adipocytes where it is involved in LCFA uptake $[29,30]$. Specifically, lipid rafts are suggested to play a role in fatty acid uptake by modulating the surface availability of CD36 [29]. Accordingly, caveolin-1 deficient mice have been shown to be resistant to diet-induced obesity [31]. Furthermore, caveolin-1 deficient mouse embryonic fibroblasts (MEFs) showed diminished FAT/CD36 content in plasma membrane fractions and a decreased fatty acid uptake rate compared to wild-type MEFs [32]. As discussed above, the functional activity of GLUT4 and of CD36 to increase cellular substrate uptake is dependent on their membrane availability which, in turn, is dependent on the lipid composition of the membrane and the effective fusion of GLUT4 and CD36 vesicles with the membrane.

\section{Post-translational modifications}

GLUT4 is subject to many post-translational modifications (PTM) following physiological responses to external stimuli. These PTM affect its subcellular localization and functioning. Several PTM have been identified on GLUT4, including 
phosphorylation of serine-274 and serine-478 residues, $\mathrm{N}$-glycosylation sites, and interchangeable ubiquitination sites [33]. ATP binding of GLUT4 has been proposed to have an inhibitory effect on GLUT4-mediated glucose uptake. Lawrence et al. [34] were the first to identify a phosphorylation site on GLUT4 which at that time was designated as "insulin regulatable glucose transporter" (IRGT). These investigators showed in rat adipocytes that treatment with cAMPdependent protein kinase leads to phosphorylation of the serine-488 residue which is located at the C-terminal side of GLUT4. The effect of GLUT4 phosphorylation on its functioning was investigated by others. Reusch et al. [35] showed decreased intrinsic activity of GLUT4 upon insulin stimulation in adipocytes treated with parathyroid hormone (PTH) compared to non-treated control cells despite no difference between the plasma membrane GLUT4 distribution in control and PTH treated cells neither before nor after insulin stimulation. These findings suggest that GLUT4 phosphorylation decreases glucose uptake without changing GLUT4 recruitment to the plasma membrane. Begum et al. [36] also showed reduced insulin stimulated glucose uptake in adipocytes which were exposed to ATP or thapsigargin to increase $\left[\mathrm{Ca}^{2+}\right]_{\mathrm{i}}$. Although there was not a change on the GLUT4 content or its translocation to the plasma membrane, they showed increased phosphorylation of GLUT4 upon a rise in $\left[\mathrm{Ca}^{2+}\right]_{\text {i }}$. They suggested that a rise in $\left[\mathrm{Ca}^{2+}\right]_{\mathrm{i}}$ interferes with the ability of insulin to dephosphorylate GLUT4 thereby leading to a decrease in GLUT4 intrinsic activity [36]. Taken together, insulin was suggested to prevent GLUT4 phosphorylation and thereby allowing its activation.

Similarly to GLUT4, CD36 has also several PTM sites, i.e. palmitoylation, phosphorylation, and ubiquitination, as illustrated in Fig. 1. Palmitoylation and ubiquitinaton have been shown to affect its fatty acid transport function; however, under which circumstances these processes are executed is a research area which still needs further investigations. CD36 has two transmembrane spanning domains, one large extracellular loop which has a small hydrophobic pocket and two short cytoplasmic tails. The hydrophobic domain is predicted to be flexible and in some cases it might fall back into the lipid bilayer [37]. However, there are few reports on the physiological relevance of PTMs on the functioning of CD36. We showed that four cysteine residues, each two located on the both the N- and Cintracellular domains of $\mathrm{CD} 36$, can bind to $\mathrm{Zn}^{2+}$ ions (chapter 5). These cysteines are located in the 3rd, 7th, 464th and 466th positions in the amino-acid sequence of CD36 peptide. Based on our findings, $\mathrm{Zn}^{2+}$ - binding to CD36 modulates its fatty acid transport function. We showed that removal of $\mathrm{Zn}^{2+}$ ions by chelation resulted in increases in palmitate taken up into cells.

Likewise, ubiquitination of CD36 has been shown to control its levels and stability in different tissues upon different stimuli [38]. Insulin decreased CD36 ubiquitination (on lysine 48 and lysine 63) in Chinese hamster ovary (CHO) cells and thereby increased CD36 protein levels while the long-chain fatty acids palmitate and oleate increased CD36 ubiquitination [37, 38] and decreased CD36 protein levels. Parkin is an E3-ubiquitin ligase and involved in either polyubiquitination with subsequent degradation of targets proteins or mono- and multi-mono-ubiquitination to modify protein function and stability $[39,40]$. 
Parkin plays an important role in lipid metabolism. It has been shown that parkin levels were increased in wild type mice fed with high fat diet in parallel to increases in fatty acid transport proteins (CD36, FABP, SR-B1). In the same study it was shown that parkin-dependent CD36 ubiquitination enhanced its stability and elicited its translocation to the plasma membrane to subsequently increase the rate of fatty acid uptake [40].

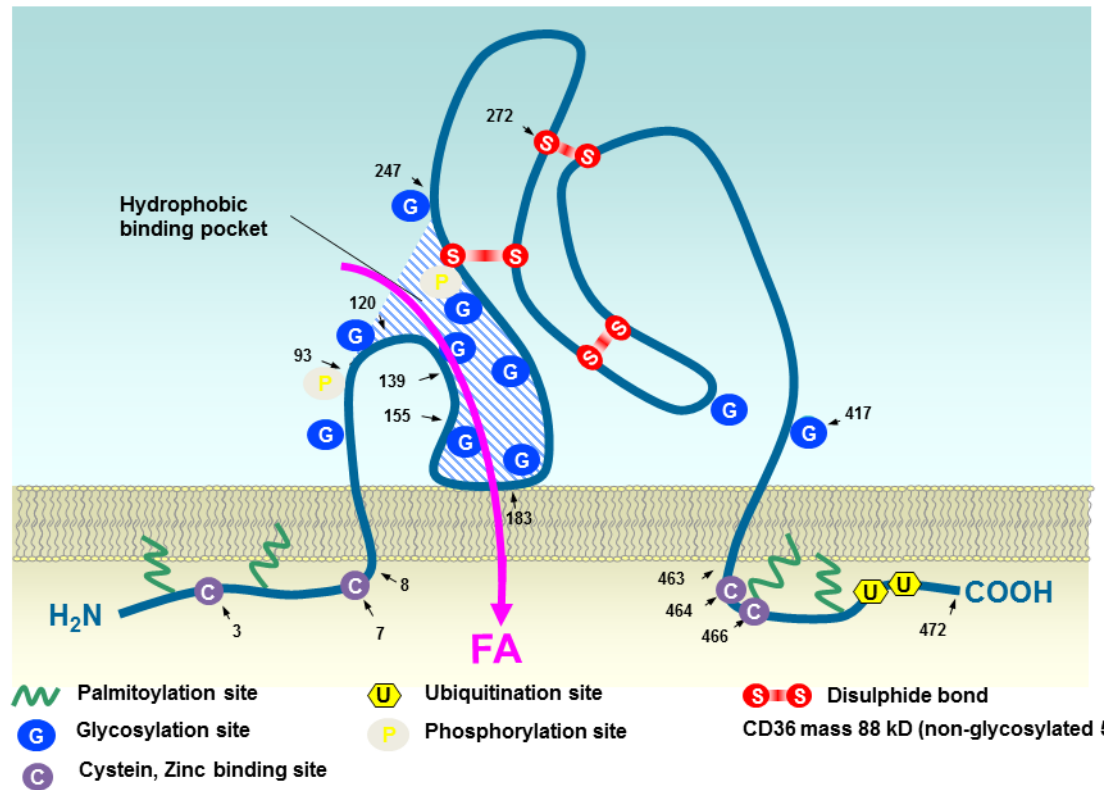

Fig. 1 Putative membrane topology of CD36 together with known disulfide bonds and posttranslational modifications. (Adapted from Glatz et al., Physiol Rev, 2010) The pink arrow illustrates the putative binding site and transmembrane transport route of long-chain fatty acids.

Two phosphorylation sites (Thr-92 and Ser-237) have been identified on CD36 [41] but the significance of these sites for the fatty acid transport activity of CD36 has not been reported. It is possible that sarcolemmal CD36 (and also GLUT4) that is recruited by a rise in $\left[\mathrm{Ca}^{2+}\right]_{i}$ and activated by AMPK (chapter 4), is additionally phosphorylated. To check potential phosphorylation of CD36/GLUT4 via AMPK activation one could use mass spectrometric analysis of the samples which were pre-treated with A23187 or thapsigargin before AMPK activation. On the other hand, it is possible that AMPK phosphorylates one of the vesicular membrane proteins so as to complete CD36 (and also GLUT4) internalization into a proper plasma membrane site after recruitment of CD36 to the plasma membrane with cytosolic $\mathrm{Ca}^{2+}$ rise. The latter option is more difficult to study as it is known that a number ( $>40$ ) of distinct proteins are involved in subcellular trafficking processes [42]. 


\section{Protein-protein interaction}

The intrinsic transporter activation of GLUT4 is also regulated by protein-protein interaction. Not only proteins involved in the regulation of vesicular traffic of GLUT4 but also some glycolytic proteins, such as GAPDH (glyceraldehyde-3phosphate dehydrogenase) and hexokinase-II (HK-II), were shown to coprecipitate with myc-tagged GLUT4 in L6 myotubes [43]. In a follow-up study it was shown that insulin stimulation resulted in increased GAPDH and decreased HK-II amounts in the co-precipitates of GLUT4. These findings suggest that binding of either GAPDH or HK-II to GLUT4 is part of a mechanism controlling GLUT4 activity either at plasma membrane or in endomembranes [44]. CD36 was also found to co-precipitate with $\mathrm{FABP}_{\mathrm{pm}}$, however it is not entirely known whether CD36 functions alone or as a hetoromeric complex with $\mathrm{FABP}_{\mathrm{pm}}$ to facilitate fatty acid transport. [45].

Our present results together with findings from the literature clearly indicate that translocation of the substrate transporters to the plasma membrane and activation on the membrane to facilitate substrate uptake are separate events. There are many mechanisms controlling both processes in response to changes in intra- and extra-cellular environment. However, there is little known about these regulatory mechanisms controlling the transporter functions of GLUT4 and CD36, especially their membrane activation. Identification of potential effects of PTMs on both GLUT4 and CD36 activity and functioning is an incomplete research field. Given the impact of these regulatory mechanisms on whole body lipid metabolism it would be of much interest to investigate how these potential activation mechanisms of both transporter are regulated in different physiological as well as pathophysiological conditions.

\section{(ii) Fatty acid translocase/CD36 as a target to ameliorate insulin resistance}

Diabetic cardiomyopathy is associated with a disturbed regulation of substrate uptake and utilization including impaired GLUT4 and CD36 trafficking and membrane signaling [46, 47]. Rats fed a high fat diet during 8 weeks showed cardiac contractile dysfunction, impaired insulin signaling, increased membrane CD36 levels, and increased LCFA uptake rates and intracellular triacylglycerol (TAG) stores [9]. A study in which intramyocellular lipid contents of muscle biopsies were compared between obese humans with or without type 2 diabetes reported increased lipid contents and CD36 plasma membrane levels in all pathological conditions compared to healthy controls [48]. Palmitate exposure of rat soleus muscle during 6, 12 and 18 hours resulted in a decrease in glucose uptake and a concomitant decrease in GLUT4 translocation [49]. Although there were no changes in GLUT4 translocation after 6 hour incubation, glucose uptake into the soleus muscle diminished (\% 50) at 12 and 18 hours [49] which suggests that changes occurred in GLUT4 intrinsic activity.

Several approaches have been considered so far to ameliorate glucose utilization in the treatment of insulin resistance and related disease. For instance, selective overexpression of GLUTs in a diabetic animal model has been used to 
repair impaired insulin signaling and insulin dependent glucose uptake. However, this approach led to increases in plasma membrane GLUT levels which then resulted in increases in basal glucose uptake even without any insulin stimulation [50]. Another approach was to directly target insulin signaling and/or downstream players. Phosphoinosides (PIP3 and PIP2) are lipid second messengers and decreased levels of PIP3 are associated with the development of impaired insulin signaling [51]. It was shown that addition of PIP3 but not PIP2 resulted in increases in GLUT4 expression, GLUT4 membrane distribution and glucose utilization in 3T3L1 adipocytes cultured in high glucose $(25 \mathrm{mM})$ containing medium [12]. Similarly we have shown that transiently over-expression of VAMP3 (vesicle-associated membrane protein 3) in HL-1 atrial cardiomyocytes, which were treated with elevated levels of insulin and palmitate during 16 hours of culturing, prevented lipid induced inhibition of GLUT4 translocation [52]. VAMPs are a type of vesicle-associated SNAREs (Soluable N-ethylmaleimide-sensitive factor (NSF) attachment protein receptors) which are involved in membrane fusion and subcellular distribution of GLUT4 and CD36. VAMP2 is involved in insulin while VAMP3 is involved in contraction mediated GLUT4 and CD36 translocation to the plasma membrane [53]. Interestingly overexpression of VAMP3 but not VAMP 2 attenuated insulin mediated GLUT4 translocation in HL-1 cells via a mechanism involving PKD activation [52]. Other therapeutic approaches in the treatment of type 2 diabetes include compounds targeting the rebalancing of impaired substrate uptake and utilizations. Thiazolidinediones (TZDs) are agonists of the transcription factor peroxisome proliferator-activated receptor-gamma (PPAR $\gamma$ ). Rosiglitazone is a thiazolidinedione subspecies used for the treatment of type 2 diabetes. Rosiglitazone increases glucose uptake by increasing endosomal recycling of GLUT4 upon insulin treatment [54].

In light of the above approaches we hypothesize that rebalancing impaired substrate utilization by directly interfering with fatty acid transport would be beneficial for the amelioration of insulin resistance and associated disease. Therefore, first we aimed to inhibit the fatty acid transport function of CD36 via exposing primary rat cardiomyocyte cultures to a monoclonal antibody of CD36 (chapter 2). Secondly, we aimed to rebalance fatty acid utilization and impaired insulin signaling by exposing primary cardiomyocytes (same culture model) to polyunsaturated fatty acids (EPA and DHA) (chapter 3). $\omega$-3 LC-PUFAs have many beneficial effects like anti-inflammatory [55], anti-athoregenic [56], insulin sensitizing effects [57] and improvement of cardiac functions. However, not much is known about the underlying mechanism(s).

We showed improved insulin mediated glucose uptake and insulin signaling upon blocking of CD36-mediated fatty acid flux into cardiomyocytes (chapter 2). This effect could be explained by the diminished levels of fatty acid influx and cellular TAG levels. Thus, inhibition of the fatty acid transport function of CD36 would be a therapeutic approach for the treatment of insulin resistance and associated disease. However, CD36 has many functions besides fatty acid transport and has broad diversity of ligands (e.g., ox-LDL, thrombospondin). Fatty acids are suggested to bind in the hydrophobic pocket between the residues 139-183 of multiligand binding site [41]. Generating peptides which would only bind to this 
fatty acid binding pocket without interfering with other ligand bindings and functions of CD36 would be a strong therapeutic approach for the treatment of lipid-induced insulin resistance. Inhibition of fatty acid uptake by Sulfo- $N$ succinimidyloleate is also successful for short term application. Because of the short-life time of SSO, it is not suitable for in vivo applications. A similar approach has been recently considered for the inhibition of other LCFA transporters. Thus, recently the identification and characterization of a small molecule which would inhibit FABP5 has been reported [58].

We also showed beneficial effects of $\omega$-3 LC-PUFA (EPA and DHA) on insulin signaling in cardiomyocytes cultured for $48 \mathrm{~h}$ with HI containing medium (chapter 3). EPA exposure rescued diminished glucose uptake upon insulin stimulation. Both EPA and DHA improved phosphorylation of insulin downstream target proteins GSK-3 $\beta$ and AS160. Both LC-PUFAs increased basal palmitate uptake into cardiomyocytes, however only EPA improved increases in palmitate uptake upon insulin stimulation which would suggest the involvement of CD36 in the EPA transport. However, we did not see any increase in membrane abundance of CD36 (chapter 3, Fig. 2C) and total CD36 protein levels (chapter 3, Fig. 3B) upon EPA treatment compare to control. This might suggest that EPA increased either activity of CD36 which is at the plasma membrane or fatty acid flip-flop through membrane. It has been evidenced that PUFAs increase membrane fluidity by changing membrane lipid composition [59]. Although EPA and DHA exposure increased palmitate uptake via a yet unknown mechanism into cardiomyocytes, insulin sensitivity of cardiomyocytes were still improved independent of increases in palmitate uptake. These findings are quite paradoxical as the reported antiatherogenic effect of PUFAs in macrophages where EPA increased CD36 mRNA and protein expressions via increased activity of PPAR $\gamma$, which suggest that these antiatherogenic effects of PUFAs were not through diminished CD36 levels [56]. These observed effects of LC-PUFAs are similar to findings from others [60] but it is difficult to address their action mechanisms. Contrary findings about PUFAs effect might be sourced from different tissue specifity of PUFAs. Although we did not measure intracellular TAG stores and lipid metabolities, it is possible that EPA and DHA could also increase the rate of fatty acid utilization as PUFAs were shown to activate cellular lipid utilization [61]. Interestingly, inhibition of CD36-mediated fatty acid flux with anti-CD36 antibody during EPA treatment, led to a diminished palmitate uptake rate suggesting that EPA was transported via CD36.

It is also suggested that LC-PUFAs exert their beneficial effect through activation of the transcription factors PPARs. EPA and DHA supplementation was shown to diminish plasma TAG levels and increase HDL cholesterol [57]. These effects indeed could be exerted through activation of PPARs. PPAR $\alpha$ modulates LCFA metabolism and glucose homeostasis in skeletal muscle and liver whereas PPAR $\gamma$ is responsible for the modulation of adipocyte fatty acid metabolism. PPAR $\gamma$ activation results in improvement of whole body insulin sensitivity in type 2 diabetic patients [62] and a decrease in cell size and intracellular TAG content in 3T3-L1 adipocytes [63]. Both fatty acid and eicosanoids activate PPARs. The exact molecular mechanism of how fatty acids activate PPARs is not known. Recently one study described an example of direct interaction between FABPc and PPAR $\alpha$ in the 
liver [64]. The investigators showed that FABPc forms a complex with the PPAR ligand binding domain. They suggested that this binding could led to direct channeling of ligands to activate PPAR transcriptional activity [64]. It is not known whether cytosolic FABP in the heart would be involved in a similar activation mechanism of PPARs.

\section{(iii) Regulation of cardiac substrate uptake upon contraction and hypoxia (possible role for $\mathrm{Ca}^{2+}$ signaling)}

The contraction-dependent substrate uptake process in heart and skeletal muscle involves activation of AMPK. However, the involvement of other signaling pathways has been proposed, such as $\mathrm{Ca}^{2+}$ signaling because contractions in both of heart and contracting skeletal muscle induce regularly occurring $\mathrm{Ca}^{2+}$ oscillations. In our studies we showed that inhibition of calcium-dependent protein kinases (CaMKs/CaMKK- $\beta$ ) via ST0-609 and KN93 did not diminish glucose nor palmitate uptake into primary rat cardiomyocytes which were subjected to electric field stimulation (chapter 4). These findings suggest that calcium-activated protein kinases (CaMKs/CaMKKs) are not involved in the substrate uptake process. On the other hand, by increasing $\left[\mathrm{Ca}^{2+}\right]_{\mathrm{i}}$ with $\mathrm{A} 23187$ or thapsigargin, we were able to show increased CD36 and GLUT4 levels at the sarcolemma.(see section "i"). Interestingly, membrane recruitment of CD36 and GLUT4 upon A23187 or thapsigargin were sensitive to inhibition of CaMKs/CaMKKs which suggests that the translocation process of GLUT4 and CD36 upon a rise in $\left[\mathrm{Ca}^{2+}\right]_{\mathrm{i}}$ involves activation of CaMKs/CaMKK- $\beta$ (chapter 4).

The importance of these findings for the heart is difficult to address. In the healthy heart under physiological conditions $\left[\mathrm{Ca}^{2+}\right]_{\mathrm{i}}$ and the activity of CaMKs (especially CaMKII) are finely regulated during each beat of the heart. We can only speculate about their role in the myocellular substrate uptake process. It was stated that autonomous activity of CaMKII is not changed in cardiomyocytes upon electric field stimulation [65]. We also found that phosphorylation of CaMKII in rat cardiomyocytes was not changed upon electric field stimulation $(4 \mathrm{~Hz}, 7 \mathrm{~min}$ ) (chapter 4, Fig. 1C). This might relate to a difference between heart and skeletal muscle physiology. Namely, in skeletal muscle of exercising humans increased CaMKII activity and phosphorylation of Thr287 was shown [66, 67]. CaMKII activity was measured in skeletal muscle of humans during the $40 \mathrm{~min}$ of exercise. The investigators showed increased autonomous activity of CaMKII at 40 min but not at 5 min of exercising human muscle while the total CaMKII activity remained the same [67].

Regulation of CaMKII activity in the heart is an important issue since CaMKII is involved in the modulation of other protein functions like ryanodine receptors, phospholamban, and troponin $\mathrm{C}$ which each are involved in $\mathrm{Ca}^{2+}$ homeostasis and contraction. In summary, our present findings suggest an important involvement of $\mathrm{Ca}^{2+}$ in the regulation of cardiac substrate transporters perhaps in each beat of the heart. Our findings in heart muscle are however different from those in skeletal muscle in terms of the role of $\mathrm{Ca}^{2+}$ in the substrate uptake process. 
Yet, is not clear under which physiological/supraphysiological circumstances $\mathrm{Ca}^{2+}$-signaling might regulate the contraction-mediated substrate uptake process. Nevertheless, a regulatory role of $\mathrm{Ca}^{2+}$ in contraction-mediated substrate uptake can be elaborated with different findings from the literature. Elevated $\left[\mathrm{Ca}^{2+}\right]_{\mathrm{i}}$ in muscle cells has been proposed to act as a secondary messenger to initiate con-traction dependent glucose transport and GLUT4 translocation in earlier days [68]. Many studies using caffeine or ionophores to increase $\left[\mathrm{Ca}^{2+}\right]_{\mathrm{i}}$ without inducing contraction or changing the levels of high energy phosphates have shown increased glucose uptake [69, 70]. Studies investigating the modulators of contraction-mediated substrate uptake in skeletal muscle suggested the contribution of both CaMKII and AMPK signaling. Increases in glucose transport into skeletal muscle induced by caffeine and AICAR was shown to be additive [70]. In another study caffeine-induced fatty acid uptake into rat hindquarters was completely abolished while contraction induced fatty acid uptake was decreased upon inhibition of CaMKII with KN93 [71]. Similarly, inhibition of CaMKII by the specific inhibitor KN62 or KN93 was shown to prevent caffeine-induced increases in 2-deoxyglucose uptake [70]. These findings suggest that both CaMKII and AMPK are involved in contraction-induced substrate uptake in skeletal muscle. On the other hand, another study performed in skeletal muscle showed a contribution of CaMKKo in the regulation of skeletal muscle glucose uptake independent of AMPK [72]. Expression of a dominant inhibitory mutant of AMPK in transgenic mouse muscle was shown to reduce contraction-induced glucose uptake (by 30-40\%) [73]. This latter study also supports the notion that contraction-dependent signaling pathways regulating substrate uptake include the involvement of other protein kinases, besides AMPK.

We suggest that $\mathrm{Ca}^{2+}$-induced GLUT4 and CD36 translocation (chapter 4) is important for the regulation of cardiac substrate uptake under hypoxic conditions or in arrhythmia where a rise in $\left[\mathrm{Ca}^{2+}\right]_{i}$ is seen. It has already been known that during hypoxic conditions AMPK is activated and is responsible for the regulation of cardiac and skeletal muscle substrate uptake [74]. We suggest that $\mathrm{Ca}^{2+}$ and CaMKs/CaMKKs might also have a role under hypoxic conditions in the regulation of cardiac substrate uptake in the heart. In this context it is of note that hypoxia induces ROS production and leads to increases in $\left[\mathrm{Ca}^{2+}\right]_{\mathrm{i}}$ which activates AMPK in alveolar epithelial cells $[74,75]$.

Similarly, $\left[\mathrm{Ca}^{2+}\right]_{\mathrm{i}}$ are shown to increase in cardiomyocytes during hypoxia [76] and also activation of CaMKII [77]. During ischemia-reperfusion (IR) injury activation of CAMKII has been observed indirectly via increased phosphorylation of its downstream target phospholamban [78]. Inhibition of CaMKII by KN93 showed increased contractile activity and decreased infarction size [78]. These findings clearly show that under hypoxic conditions there is an increased activation of CaMKII. This could strengthen our hypothesis that CaMKII might play a role in the regulation of substrate uptake under conditions in which there is a rise in $\left[\mathrm{Ca}^{2+}\right]_{i}$ such as hypoxic conditions. Substrate uptake has been investigated in the isolated cardiomyocytes and whole heart perfused under hypoxic conditions [79], but a role for $\mathrm{Ca}^{2+}$ signaling or CaMKs/CaMKK- $\beta$ has not been investigated in this study. Specifically, in the perfused heart, CD36 was shown to translocate to the 
sarcolemma upon 15 min of hypoxia, leading to increased LCFA uptake. Because, LCFA oxidation will come to a halt under hypoxic condi-tions, the default metabolic fate of the excess LCFA taken up will be increased storage in lipid droplets, as is indeed observed [79]. In another study in which cardioprotective effect of an anaesthetic sevoflurane on ischaemia-reperfusion injury was investigated showed that hearts perfused with sevoflurane recovered from $\mathrm{Ca}^{2+}$ overload after ischemia-reperfusion injury. It was reported that sevoflurane increased GLUT4 presence in lipid rafts and thereby caused increases in glucose uptake. There was no increase in phosphorylation of AMPK upon sevoflurane perfusion compared to untreated control hearts [80]. The authors explained these increases in presence of GLUT4 in lipid rafts as a result of increased contractility and they did not check activation of other protein kinases than AMPK. However, these findings might be the result of CaMKII activation.

In summary, both hypoxia and contraction activate AMPK because of increases in the cellular AMP/ATP ratio. Activation of CaMKII has been shown to occur under both conditions because of increases in $\left[\mathrm{Ca}^{2+}\right]_{\mathrm{i}}$ it is still unknown whether both kinases work alone or together to accomplish substrate uptake under hypoxic conditions in the heart. It is possible to address this question by using hypoxic chambers. Although it is difficult to perform $\mathrm{Ca}^{2+}$ measurements under hypoxic conditions, it would be still possible to measure surface CD36 and GLUT4 by the biotinylation method in cardiomyocytes which are plated and kept in hypoxic conditions during different time points $(15,30$ and $45 \mathrm{~min})$. Preincubation of cardiomyocytes with the inhibitors of CaMKs/CaMKKs would allow evaluating the involvement of CaMKs/CaMKKs in the translocation process of CD36 and GLUT4. It is also possible to measure 2-deoxyglucose and palmitate levels taken up by cardiomyocytes under hypoxic conditions.

\section{(iv) Effects of CD36 on $\mathrm{Ca}^{2+}$ dynamics in cardiomyocytes}

CD36 is a multifunctional protein. Besides being a membrane transporter for LCFA, it serves also as a signaling molecule. Lingual CD36 has been shown to be involved in fat perception through a signaling mechanisms involving activation of Src kinases and neurotransmitter release [81]. Src kinase activation was a result of elevated $\left[\mathrm{Ca}^{2+}\right]_{i}$ through activated SOCC (store-operated calcium channels) channels. We wanted to investigate whether CD36 can act as a signaling molecule via lipid binding and whether lipid binding triggers cytosolic $\mathrm{Ca}^{2+}$ rise in cardiomyocytes. For this, we first measured intracellular $\mathrm{Ca}^{2+}$ transients upon addition of palmitate, and for comparison, addition of the calcium ionophore A23178 to cardiomyocytes from WT and CD36 null mice which were loaded with the fluorescent $\mathrm{Ca}^{2+}$-indicator fluo-4AM. We found that CD36 null mice showed larger initial $\mathrm{Ca}^{2+}$ sparks upon palmitate or A23187 addition in comparison to cardiomyocytes from WT mice (Fig. 2). Interestingly, cardiomyocytes in control conditions from CD36 null mice showed more frequent spontaneous and more irregular $\mathrm{Ca}^{2+}$ oscillations compared to cardiomyocytes from WT mice. It seems that absence of CD36 was associated with impaired $\mathrm{Ca}^{2+}$ homeostasis. Shortly after our preliminary findings Pietka et al. [82] was the first group showing that CD36 is important in the regulation of myocardial $\mathrm{Ca}^{2+}$ metabolism. They showed that 
CD36 null mice during a fasting period have conduction anomalies and altered expression of $\mathrm{Ca}^{2+}$ handing proteins [82]. They hypothesized that these conduction anomalies during fasting were due to increased SERCA levels and increased ATP utilization to recruit intracellular $\mathrm{Ca}^{2+}$. However, the absence of CD36 caused compromisation in LCFA uptake and energy production during fasting. Contrary to the above findings it was shown in another study that CD36 deficiency did not compromise the function and energy use in hearts before and after ischemia [83]. Findings from Pietka et al. might illuminate the molecular mechanism behind pathophysiology of hypertrophic cardiomyopathy in patients with CD36 deficiency [84] although the pathophysiology of CD36 deficiency in both man and mice vary.
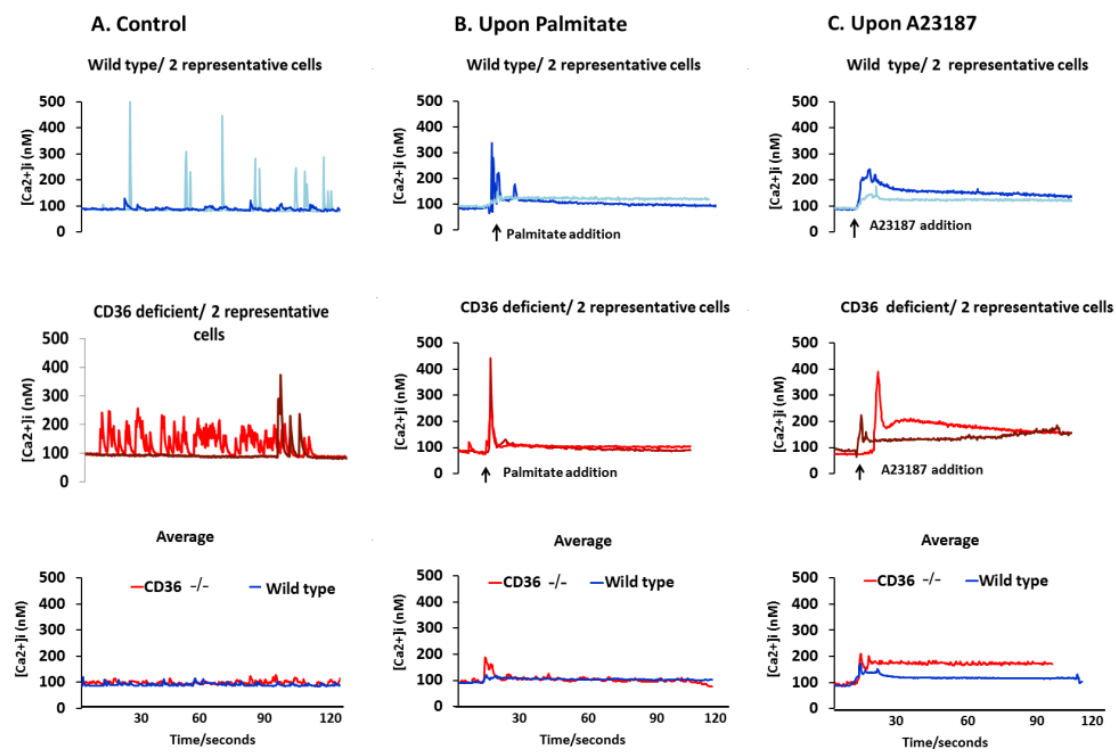

Fig. 2 Spontaneous $\mathrm{Ca}^{2+}$ sparks and transients in cardiomyocytes from wild type and CD36 null mice. Freshly isolated cardiomyocytes from wild type and CD36 null mice were adhered in 12-well plates and loaded with the $\mathrm{Ca}^{2+}$ probe Fluo- 4 to $(2.5 \mu \mathrm{M}$ during $30 \mathrm{~min}$ in combination with $1 \mathrm{mg} / \mathrm{ml}$ pluronic acid) measure single-cell $\left[\mathrm{Ca}^{2+}\right]_{\mathrm{i}}$ by fluorescence microscopic imaging. Fluorescence changes in individual cells were recorded during $2 \mathrm{~min}$ in the absence (control conditions) and presence of palmitate $(100 \mathrm{uM})$ and $\mathrm{A} 23187(5 \mathrm{uM})$. (Arrows indicate the pipetting time of the compounds). Averaged traces are from 30-40 cells.

\section{Future perspectives}

In this thesis we have disclosed a novel regulatory mechanism of the fatty acid transport function of the membrane-associated protein CD36. We showed for the first time that CD36 has a $\mathrm{Zn}^{2+}$ finger motif and that $\mathrm{Zn}^{2+}$ binding by CD36 is important for the regulation of CD36 activity towards its transmembrane fatty acid transport facilitating function. However, it is still unknown whether $\mathrm{Zn}^{2+}$-binding would affect the fatty acid binding function or other functions of CD36 in different tissues. For instance, it is known that CD36 is associated with foam cell formation and atherosclerosis [85] and that the absence of CD36 is associated with 
diminished size of adipose tissue, diminished macrophage infiltration and inflammation [86]. A recent finding has shown the involvement of $\mathrm{Zn}^{2+}$ deficiency in the recruitment of macrophages into adipose tissue [87]. A $\mathrm{Zn}^{2+}$-deficient diet (3 weeks) following a high fat diet (6 weeks) in C57BL/6 caused increased levels of leptin and infiltration of activated macrophages into adipose tissue [87]. These findings clearly point a role for $\mathrm{Zn}^{2+}$ dependent modulation of CD36 fatty acid transport function in other tissues which will be a link between $\mathrm{Zn}^{2+}$ deficiency and associated disease. Therefore, further study of the role of $\mathrm{Zn}^{2+}$-binding to CD36 and its effect on the distinct functions of CD36 in both physiological and pathophysiological processes is likely to be a significant future area of investigation.

Furthermore, the role of $\mathrm{Ca}^{2+}$ and CaMKs/CaMKKs on cardiac substrate transporters and metabolism in various physiological and pathophysiological conditions needs further investigation. It is still not known whether substrate transporters undergo post-translational modifications such as phosphorylation by either $\mathrm{Ca}^{2+}$-activated protein kinases or AMPK in response to a rise in $\left[\mathrm{Ca}^{2+}\right]_{\mathrm{i}}$ or arrival at the membrane, respectively. Molecular mechanisms of how LC-PUFAs ameliorate insulin resistance also need further investigation. Finally it is worth to invest in development of small peptides which inhibit fatty acid transport function of CD36 for use in clinical studies in the treatment of diabetic humans. 


\section{References}

1. Luiken JJ, Coort SL, Koonen DP, Van der Horst DJ, Bonen A, Zorzano A, et al. Regulation of cardiac long-chain fatty acid and glucose uptake by translocation of substrate transporters. Pflügers Arch. 2004;448:1-15.

2. van Oort MM, Van Doorn JM, Bonen A, Glatz JF, Van der Horst DJ, Rodenburg KW, et al. Insulininduced translocation of CD36 to the plasma membrane is reversible and shows similarity to that of GLUT4. Biochim Biophys Acta. 2008;1781:61-71.

3. Steinbusch LK, Schwenk RW, Ouwens DM, Diamant M, Glatz JF, Luiken JJ. Subcellular trafficking of the substrate transporters GLUT4 and CD36 in cardiomyocytes. Cellular and molecular life sciences : CMLS. 2011;68:2525-38.

4. Samovski D, Su X, Xu Y, Abumrad NA, Stahl PD. Insulin and AMPK regulate FA translocase/CD36 plasma membrane recruitment in cardiomyocytes via Rab GAP AS160 and Rab8a Rab GTPase. J Lipid Res. 2012;53:709-17.

5. Schwenk RW, Holloway GP, Luiken JJ, Bonen A, Glatz JF. Fatty acid transport across the cell membrane: regulation by fatty acid transporters. Prostaglandins Leukot Essent Fatty Acids. 2010;82:149-54.

6. Funaki M, Randhawa P, Janmey PA. Separation of insulin signaling into distinct GLUT4 translocation and activation steps. Molecular and cellular biology. 2004;24:7567-77.

7. Hausdorff SF, Fingar DC, Morioka K, Garza LA, Whiteman EL, Summers SA, et al. Identification of wortmannin-sensitive targets in 3T3-L1 adipocytes. Dissociation of insulin-stimulated glucose uptake and glut4 translocation. The Journal of biological chemistry. 1999;274:24677-84.

8. Sweeney G, Keen J, Somwar R, Konrad D, Garg R, Klip A. High leptin levels acutely inhibit insulinstimulated glucose uptake without affecting glucose transporter 4 translocation in 16 rat skeletal muscle cells. Endocrinology. 2001;142:4806-12.

9. Ouwens DM, Diamant M, Fodor M, Habets DD, Pelsers MM, El Hasnaoui M, et al. Cardiac contractile dysfunction in insulin-resistant rats fed a high-fat diet is associated with elevated CD36-mediated fatty acid uptake and esterification. Diabetologia. 2007;50:1938-48.

10. Luiken JJ, Arumugam Y, Dyck DJ, Bell RC, Pelsers MM, Turcotte LP, et al. Increased rates of fatty acid uptake and plasmalemmal fatty acid transporters in obese Zucker rats. J Biol Chem. 2001;276:40567-73.

11. Abel ED. Glucose transport in the heart. Front Biosci. 2004;9:201-15.

12. Sweeney G, Garg RR, Ceddia RB, Li D, Ishiki M, Somwar R, et al. Intracellular delivery of phosphatidylinositol $(3,4,5)$-trisphosphate causes incorporation of glucose transporter 4 into the plasma membrane of muscle and fat cells without increasing glucose uptake. J Biol Chem. 2004; 279:32233-42.

13. Huang C, Somwar R, Patel N, Niu W, Torok D, Klip A. Sustained exposure of L6 myotubes to high glucose and insulin decreases insulin-stimulated GLUT4 translocation but upregulates GLUT4 activity. Diabetes. 2002;51:2090-8.

14. Moon B, Kwan JJ, Duddy N, Sweeney G, Begum N. Resistin inhibits glucose uptake in L6 cells independently of changes in insulin signaling and GLUT4 translocation. American journal of physiology Endocrinology and metabolism. 2003;285:E106-15.

15. Somwar R, Perreault M, Kapur S, Taha C, Sweeney G, Ramlal T, et al. Activation of p38 mitogenactivated protein kinase alpha and beta by insulin and contraction in rat skeletal muscle: potential role in the stimulation of glucose transport. Diabetes. 2000;49:1794-800.

16. Niu W, Huang C, Nawaz Z, Levy M, Somwar R, Li D, et al. Maturation of the regulation of GLUT4 activity by p38 MAPK during L6 cell myogenesis. The Journal of biological chemistry. 2003;278:17953-62.

17. Somwar R, Koterski S, Sweeney G, Sciotti R, Djuric S, Berg C, et al. A dominant-negative p38 MAPK mutant and novel selective inhibitors of p38 MAPK reduce insulin-stimulated glucose uptake in 3T3-L1 adipocytes without affecting GLUT4 translocation. The Journal of biological chemistry. 2002;277:50386-95.

18. Sweeney G, Somwar R, Ramlal T, Volchuk A, Ueyama A, Klip A. An inhibitor of p38 mitogenactivated protein kinase prevents insulin-stimulated glucose transport but not glucose transporter translocation in 3T3-L1 adipocytes and L6 myotubes. The Journal of biological chemistry. 1999;274:10071-8.

19. Gaidhu MP, Perry RL, Noor F, Ceddia RB. Disruption of AMPKalpha1 signaling prevents AICARinduced inhibition of AS160/TBC1D4 phosphorylation and glucose uptake in primary rat adipocytes. Mol Endocrinol. 2010;24:1434-40. 
20. Stockli J, Fazakerley DJ, James DE. GLUT4 exocytosis. Journal of cell science. 2011;124:4147-59.

21. Treebak JT, Taylor EB, Witczak CA, An D, Toyoda T, Koh HJ, et al. Identification of a novel phosphorylation site on TBC1D4 regulated by AMP-activated protein kinase in skeletal muscle. American journal of physiology Cell physiology. 2010;298:C377-85.

22. Watson RT, Pessin JE. GLUT4 translocation: the last 200 nanometers. Cell Signal. 2007;19:2209-17.

23. Heyward CA, Pettitt TR, Leney SE, Welsh GI, Tavare JM, Wakelam MJ. An intracellular motif of GLUT4 regulates fusion of GLUT4-containing vesicles. BMC Cell Biol. 2008; 9:25.

24. Pohl J, Ring A, Korkmaz U, Ehehalt R, Stremmel W. FAT/CD36-mediated Long-Chain Fatty Acid Uptake in Adipocytes Requires Plasma Membrane Rafts. Mol Biol Cell. 2005;16:24-31.

25. Pohl J, Ring A, Ehehalt R, Schulze-Bergkamen H, Schad A, Verkade P, et al. Long-chain fatty acid uptake into adipocytes depends on lipid raft function. Biochemistry. 2004;43:4179-87.

26. Scherer PE, Lisanti MP, Baldini G, Sargiacomo M, Mastick CC, Lodish HF. Induction of caveolin during adipogenesis and association of GLUT4 with caveolin-rich vesicles. J Cell Biol. 1994;127:1233-43.

27. Shigematsu S, Watson RT, Khan AH, Pessin JE. The adipocyte plasma membrane caveolin functional/structural organization is necessary for the efficient endocytosis of GLUT4. J Biol Chem. 2003;278:10683-90.

28. Ros-Baro A, Lopez-Iglesias C, Peiro S, Bellido D, Palacin M, Zorzano A, et al. Lipid rafts are required for GLUT4 internalization in adipose cells. Proc Natl Acad Sci U S A. 2001;98:12050-5.

29. Pohl J, Ring A, Korkmaz U, Ehehalt R, Stremmel W. FAT/CD36-mediated long-chain fatty acid uptake in adipocytes requires plasma membrane rafts. Molecular biology of the cell. 2005;16:2431.

30. Ehehalt R, Sparla R, Kulaksiz H, Herrmann T, Fullekrug J, Stremmel W. Uptake of long chain fatty acids is regulated by dynamic interaction of FAT/CD36 with cholesterol/sphingolipid enriched microdomains (lipid rafts). BMC cell biology. 2008;9:45.

31. Razani B, Combs TP, Wang XB, Frank PG, Park DS, Russell RG, et al. Caveolin-1-deficient mice are lean, resistant to diet-induced obesity, and show hypertriglyceridemia with adipocyte abnormalities. J Biol Chem. 2002;277:8635-47.

32. Ring A, Le Lay S, Pohl J, Verkade P, Stremmel W. Caveolin-1 is required for fatty acid translocase (FAT/CD36) localization and function at the plasma membrane of mouse embryonic fibroblasts. Biochimica et biophysica acta. 2006;1761:416-23.

33. Sadler JB, Bryant NJ, Gould GW, Welburn CR. Posttranslational Modifications of GLUT4 Affect Its Subcellular Localization and Translocation. Int J Mol Sci. 2013;14:9963-78.

34. Lawrence JC, Jr., Hiken JF, James DE. Phosphorylation of the glucose transporter in rat adipocytes. Identification of the intracellular domain at the carboxyl terminus as a target for phosphorylation in intact-cells and in vitro. The Journal of biological chemistry. 1990;265:2324-32.

35. Reusch JE, Sussman KE, Draznin B. Inverse relationship between GLUT-4 phosphorylation and its intrinsic activity. J Biol Chem. 1993;268:3348-51.

36. Begum N, Leitner W, Reusch JE, Sussman KE, Draznin B. GLUT-4 phosphorylation and its intrinsic activity. Mechanism of $\mathrm{Ca}(2+)$-induced inhibition of insulin-stimulated glucose transport. J Biol Chem. 1993;268:3352-6.

37. Su X, Abumrad NA. Cellular fatty acid uptake: a pathway under construction. Trends Endocrinol Metab. 2009;20:72-7.

38. Smith J, Su X, El-Maghrabi R, Stahl PD, Abumrad NA. Opposite regulation of CD36 ubiquitination by fatty acids and insulin: effects on fatty acid uptake. J Biol Chem. 2008;283:13578-85.

39. Kim KY, Sack MN. Parkin in the regulation of fat uptake and mitochondrial biology: emerging links in the pathophysiology of Parkinson's disease. Curr Opin Lipidol. 2012;23:201-5.

40. Kim KY, Stevens MV, Akter MH, Rusk SE, Huang RJ, Cohen A, et al. Parkin is a lipid-responsive regulator of fat uptake in mice and mutant human cells. The Journal of clinical investigation. 2011;121:3701-12.

41. Glatz JF, Luiken JJ, Bonen A. Membrane fatty acid transporters as regulators of lipid metabolism: implications for metabolic disease. Physiol Rev. 2010;90:367-417.

42. Larance M, Ramm G, Stockli J, van Dam EM, Winata S, Wasinger V, et al. Characterization of the role of the Rab GTPase-activating protein AS160 in insulin-regulated GLUT4 trafficking. The Journal of biological chemistry. 2005;280:37803-13.

43. Foster LJ, Rudich A, Talior I, Patel N, Huang X, Furtado LM, et al. Insulin-dependent interactions of proteins with GLUT4 revealed through stable isotope labeling by amino acids in cell culture (SILAC). J Proteome Res. 2006;5:64-75.

44. Zaid H, Talior-Volodarsky I, Antonescu C, Liu Z, Klip A. GAPDH binds GLUT4 reciprocally to hexokinase-II and regulates glucose transport activity. The Biochemical journal. 2009;419:475-84. 
45. Chabowski A, Gorski J, Luiken JJ, Glatz JF, Bonen A. Evidence for concerted action of FAT/CD36 and FABPpm to increase fatty acid transport across the plasma membrane. Prostaglandins, leukotrienes, and essential fatty acids. 2007;77:345-53.

46. Glatz JF, Bonen A, Ouwens DM, Luiken JJ. Regulation of sarcolemmal transport of substrates in the healthy and diseased heart. Cardiovasc Drugs Ther. 2006;20:471-6.

47. Dirkx E, Schwenk RW, Glatz JF, Luiken JJ, van Eys GJ. High fat diet induced diabetic cardiomyopathy. Prostaglandins, leukotrienes, and essential fatty acids. 2011;85:219-25.

48. Aguer C, Mercier J, Man CY, Metz L, Bordenave S, Lambert K, et al. Intramyocellular lipid accumulation is associated with permanent relocation ex vivo and in vitro of fatty acid translocase (FAT)/CD36 in obese patients. Diabetologia. 2010;53:1151-63.

49. Alkhateeb H, Chabowski A, Glatz JF, Luiken JF, Bonen A. Two phases of palmitate-induced insulin resistance in skeletal muscle: impaired GLUT4 translocation is followed by a reduced GLUT4 intrinsic activity. Am J Physiol Endocrinol Metab. 2007;293:E783-93.

50. Tozzo E, Gnudi L, Kahn BB. Amelioration of insulin resistance in streptozotocin diabetic mice by transgenic overexpression of GLUT4 driven by an adipose-specific promoter. Endocrinology. 1997;138:1604-11.

51. Manna P, Jain SK. PIP3 but not PIP2 increases GLUT4 surface expression and glucose metabolism mediated by AKT/PKCzeta/lambda phosphorylation in 3T3L1 adipocytes. Molecular and cellular biochemistry. 2013.

52. Schwenk RW, Angin Y, Steinbusch LK, Dirkx E, Hoebers N, Coumans WA, et al. Overexpression of vesicle-associated membrane protein (VAMP) 3, but not VAMP2, protects glucose transporter (GLUT) 4 protein translocation in an in vitro model of cardiac insulin resistance. The Journal of biological chemistry. 2012;287:37530-9.

53. Schwenk RW, Dirkx E, Coumans WA, Bonen A, Klip A, Glatz JF, et al. Requirement for distinct vesicle-associated membrane proteins in insulin- and AMP-activated protein kinase (AMPK)induced translocation of GLUT4 and CD36 in cultured cardiomyocytes. Diabetologia. 2010;53:2209-19.

54. Martinez L, Berenguer M, Bruce MC, Le Marchand-Brustel Y, Govers R. Rosiglitazone increases cell surface GLUT4 levels in 3T3-L1 adipocytes through an enhancement of endosomal recycling. Biochemical pharmacology. 2010;79:1300-9.

55. Magee P, Pearson S, Whittingham-Dowd J, Allen J. PPARgamma as a molecular target of EPA antiinflammatory activity during TNF-alpha-impaired skeletal muscle cell differentiation. J Nutr Biochem. 2012;23:1440-8.

56. Babaahmadi Rezaei H, Doosti M, Aminian M, Shabani P. Compare the effect of eicosapentaenoic acid and oxidized low-density lipoprotein on the expression of CD36 and peroxisome proliferatoractivated receptor gamma. Iran Biomed J. 2013;17:84-92.

57. Lorente-Cebrian S, Costa AG, Navas-Carretero S, Zabala M, Martinez JA, Moreno-Aliaga MJ. Role of omega-3 fatty acids in obesity, metabolic syndrome, and cardiovascular diseases: a review of the evidence. Journal of physiology and biochemistry. 2013.

58. Berger WT, Ralph BP, Kaczocha M, Sun J, Balius TE, Rizzo RC, et al. Targeting fatty acid binding protein (FABP) anandamide transporters - a novel strategy for development of anti-inflammatory and anti-nociceptive drugs. PLoS One. 2012;7:e50968.

59. Stulnig TM, Huber J, Leitinger N, Imre EM, Angelisova P, Nowotny P, et al. Polyunsaturated eicosapentaenoic acid displaces proteins from membrane rafts by altering raft lipid composition. The Journal of biological chemistry. 2001;276:37335-40.

60. Aas V, Rokling-Andersen MH, Kase ET, Thoresen GH, Rustan AC. Eicosapentaenoic acid (20:5 n-3) increases fatty acid and glucose uptake in cultured human skeletal muscle cells. Journal of lipid research. 2006;47:366-74.

61. Khan RS, Chokshi A, Drosatos K, Jiang H, Yu S, Harris CR, et al. Fish oil selectively improves heart function in a mouse model of lipid-induced cardiomyopathy. J Cardiovasc Pharmacol. 2013;61:345-54.

62. Olefsky JM, Saltiel AR. PPAR gamma and the treatment of insulin resistance. Trends Endocrinol Metab. 2000;11:362-8.

63. Tamori Y, Masugi J, Nishino N, Kasuga M. Role of peroxisome proliferator-activated receptorgamma in maintenance of the characteristics of mature 3T3-L1 adipocytes. Diabetes. 2002;51:2045-55.

64. Velkov T. Interactions between Human Liver Fatty Acid Binding Protein and Peroxisome Proliferator Activated Receptor Selective Drugs. PPAR Res. 2013;2013:938401. 
65. Wu X, Patki A, Lara-Castro C, Cui X, Zhang K, Walton RG, et al. Genes and biochemical pathways in human skeletal muscle affecting resting energy expenditure and fuel partitioning. Journal of applied physiology. 2011;110:746-55.

66. Rose AJ, Kiens B, Richter EA. Ca2+-calmodulin-dependent protein kinase expression and signalling in skeletal muscle during exercise. J Physiol. 2006;574:889-903.

67. Rose AJ, Hargreaves M. Exercise increases Ca2+-calmodulin-dependent protein kinase II activity in human skeletal muscle. J Physiol. 2003;553:303-9.

68. Holloszy JO, Constable SH, Young DA. Activation of glucose transport in muscle by exercise. Diabetes Metab Rev. 1986;1:409-23.

69. Youn JH, Gulve EA, Holloszy JO. Calcium stimulates glucose transport in skeletal muscle by a pathway independent of contraction. Am J Physiol. 1991;260:C555-61.

70. Wright DC, Hucker KA, Holloszy JO, Han DH. Ca2+ and AMPK both mediate stimulation of glucose transport by muscle contractions. Diabetes. 2004;53:330-5.

71. Raney MA, Turcotte LP. Evidence for the involvement of CaMKII and AMPK in Ca2+-dependent signaling pathways regulating FA uptake and oxidation in contracting rodent muscle. Journal of applied physiology. 2008;104:1366-73.

72. Witczak CA, Fujii N, Hirshman MF, Goodyear LJ. Ca2+/calmodulin-dependent protein kinase kinase-alpha regulates skeletal muscle glucose uptake independent of AMP-activated protein kinase and Akt activation. Diabetes. 2007;56:1403-9.

73. Furtado LM, Somwar R, Sweeney G, Niu W, Klip A. Activation of the glucose transporter GLUT4 by insulin. Biochem Cell Biol. 2002;80:569-78.

74. Mu J, Brozinick JT, Jr., Valladares O, Bucan M, Birnbaum MJ. A role for AMP-activated protein kinase in contraction- and hypoxia-regulated glucose transport in skeletal muscle. Mol Cell. 2001;7:1085-94.

75. Gusarova GA, Trejo HE, Dada LA, Briva A, Welch LC, Hamanaka RB, et al. Hypoxia leads to Na,KATPase downregulation via $\mathrm{Ca}(2+)$ release-activated $\mathrm{Ca}(2+)$ channels and AMPK activation. Mol Cell Biol. 2011;31:3546-56.

76. Piper HM, Abdallah Y, Schafer C. The first minutes of reperfusion: a window of opportunity for cardioprotection. Cardiovascular research. 2004;61:365-71.

77. Vittone L, Mundina-Weilenmann C, Said M, Ferrero P, Mattiazzi A. Time course and mechanisms of phosphorylation of phospholamban residues in ischemia-reperfused rat hearts. Dissociation of phospholamban phosphorylation pathways. Journal of molecular and cellular cardiology. 2002;34:39-50.

78. Vila-Petroff M, Salas MA, Said M, Valverde CA, Sapia L, Portiansky E, et al. CaMKII inhibition protects against necrosis and apoptosis in irreversible ischemia-reperfusion injury. Cardiovascular research. 2007;73:689-98.

79. Chabowski A, Gorski J, Calles-Escandon J, Tandon NN, Bonen A. Hypoxia-induced fatty acid transporter translocation increases fatty acid transport and contributes to lipid accumulation in the heart. FEBS Lett. 2006;580:3617-23.

80. Lucchinetti E, Wang L, Ko KW, Troxler H, Hersberger M, Zhang L, et al. Enhanced glucose uptake via GLUT4 fuels recovery from calcium overload after ischaemia-reperfusion injury in sevofluranebut not propofol-treated hearts. Br J Anaesth. 2011;106:792-800.

81. El-Yassimi A, Hichami A, Besnard P, Khan NA. Linoleic acid induces calcium signaling, Src kinase phosphorylation, and neurotransmitter release in mouse CD36-positive gustatory cells. The Journal of biological chemistry. 2008;283:12949-59.

82. Pietka TA, Sulkin MS, Kuda O, Wang W, Zhou D, Yamada KA, et al. CD36 influences myocardial Ca2+ homeostasis and phospholipid metabolism: Conduction anomalies in CD36 deficient mice during fasting. J Biol Chem. 2012.

83. Kuang M, Febbraio M, Wagg C, Lopaschuk GD, Dyck JR. Fatty acid translocase/CD36 deficiency does not energetically or functionally compromise hearts before or after ischemia. Circulation. 2004;109:1550-7.

84. Nakamura T, Sugihara H, Inaba T, Kinoshita N, Adachi Y, Hirasaki S, et al. CD36 deficiency has little influence on the pathophysiology of hypertrophic cardiomyopathy. Journal of molecular and cellular cardiology. 1999;31:1253-9.

85. Kennedy DJ, Kuchibhotla S, Westfall KM, Silverstein RL, Morton RE, Febbraio M. A CD36dependent pathway enhances macrophage and adipose tissue inflammation and impairs insulin signalling. Cardiovasc Res. 2011;89:604-13.

86. Cai L, Wang Z, Ji A, Meyer JM, van der Westhuyzen DR. Scavenger receptor CD36 expression contributes to adipose tissue inflammation and cell death in diet-induced obesity. PLoS One. 2012;7:e36785. 
87. Liu MJ, Bao S, Bolin ER, Burris DL, Xu X, Sun Q, et al. Zinc deficiency augments leptin production and exacerbates macrophage infiltration into adipose tissue in mice fed a high-fat diet. J Nutr. 2013;143:1036-45. 
Summary 


\section{Summary}

Heart function is a result of alternating contractions that require continuous energy supply through cellular uptake of energy rich-compounds. Glucose and longchain fatty acids are the major substrates, oxidation of which meets the daily energy needs of the heart. Glucose transporter 4 (GLUT4) and fatty acid transporter CD36, present in the plasma membrane, facilitate the entry of glucose and fatty acids into the cardiac muscle cell, respectively. Both these transporters are stored in subcellular organelles (endosomes) from which they can translocate to the plasma membrane to increase the rate of substrate uptake. In case cardiac energy requirements decrease, these transporters are internalized and stored in endosomes (recycling).

Under physiological conditions the heart can switch between available substrates to ensure a continuous ATP production. However, in diabetic cardiomyopathy the heart switches to the use of mainly fatty acids. This change is accompanied by impaired CD36 recycling between endosomal compartments and the plasma membrane thus leading to a permanent CD36 relocation to the plasma membrane while GLUT4 remains intracellularly (insulin resistance) In this thesis we describe studies that have revealed novel factors and mechanisms controlling CD36mediated fatty acid uptake into cardiac muscle. This knowledge is important for a better understanding of the perturbations in cardiac energy metabolism occurring in diabetes and also offers new targets for its treatment.

Chapter 1 introduces the molecular mechanism of the protein transporter mediated substrate uptake process, involving GLUT4 and CD36. Several stimuli, including insulin and contraction, initiate signaling events to increase substrate uptake into cardiac muscle cells. Impairment of signaling events that control the recycling of GLUT4 and CD36 containing vesicles from endosomal compartments to the plasma membrane contributes to the progression of diabetes or related chronic diseases, such as diabetic cardiomyopathy.

Chapter 2 is a report on studies in which we aimed at inhibiting CD36 so as to reduce fatty acid influx into the heart to ameliorate lipid induced insulin resistance. It has been shown in both skeletal and cardiac muscle that upon exposure to a high fat diet CD36 permanently translocates to the plasma membrane thereby causing an elevated fatty acid influx and storage in intracellular lipid pools, which eventually leads to insulin resistance. Hence, we hypothesized that interfering with CD36 fatty acid binding would prevent excessive fatty acid uptake and further impairment of insulin signaling via accumulation of intracellular lipids and their metabolites. For these studies, a cell model was established comprising of primary rat cardiomyocytes cultured in the absence (control) or presence of either a high con- 
centration of insulin (HI-medium) or a high concentration of palmitic acid (HP medium) to provoke insulin resistance. We showed that exposure to either HI or HP media during 48 hours leads to impaired insulin signaling (including Akt phosphorylation), a diminished response to insulin stimulated glucose uptake, increased TAG levels and cellular contractile dysfunction. Exposure to HI or HP media also caused an increased plasma membrane occurrence of CD36. Blocking CD36 fatty acid transport via co-incubation of the primary cardiomyocytes with CD36 monoclonal antibodies resulted in a reduction of TAG stores, amelioration of insulin sensitivity and the prevention of contractile dysfunction. These findings suggest CD36 to be a suitable target to prevent lipid-induced insulin resistance and related disease.

In chapter 3 we studied the beneficial effect of polyunsaturated fatty acids (PUFA) of marine origin, namely eicosapentaenoic acid (EPA, C20:5 n-3) and docosahexaenoic acid (DHA, C22:6 n-3), on primary rat cardiomyocytes subjected to insulin-resistance-evoking conditions (treatment with HI medium). Our data indicate that the simultaneous presence of either EPA or DHA in the HI medium prevented the induction of insulin resistance in cardiomyocytes by preserving the insulin responsiveness of key proteins in the insulin signaling cascade and by preventing the net relocation of the fatty acid transporter CD36 to the sarcolemma. Cardiomyocytes incubated in the presence of EPA, not DHA, also showed maintained insulin-stimulated glucose and fatty acid uptake rates and maintained contractile function. Hence, EPA protects all metabolic and functional properties of cardiomyocytes subjected to insulin resistance-evoking conditions, whereas DHA only preserves insulin sensitivity. These findings indicate that preservation of insulin sensitivity is not sufficient to preserve contractile function and that EPA and DHA use different action mechanisms.

In chapter 4 we investigated the role of calcium $\left(\mathrm{Ca}^{2+}\right)$ and $\mathrm{Ca}^{2+}$-activated protein kinases (CaMKK $\beta / \mathrm{CaMKII}$ ) in the regulation of substrate transporters and contraction mediated substrate uptake. In heart a direct involvement of $\mathrm{Ca}^{2+}$ and CaMKK $\beta /$ CaMKII signaling in the substrate uptake process has remained undefined. We found that a rise in intracellular $\mathrm{Ca}^{2+}$ concentrations $\left(\left[\mathrm{Ca}^{2+}\right]_{\mathrm{i}}\right)$ leads to translocation of both GLUT4 and CD36 from endosomal compartments to the plasma membrane via a process involving activation of CaMKK $\beta /$ CaMKII without a change in substrate uptake. We also show that AMP-activated protein kinase (AMPK) activation switches on the transporter function after initial recruitment to the plasma membrane via activated $\mathrm{Ca}^{2+}$ signaling. This study provides evidence that translocation and membrane activation are two separate steps in transporter mediated substrate uptake into the heart. 
Zinc $\left(\mathrm{Zn}^{2+}\right)$ deficiency often occurs in diabetic patients. However the molecular link between $\mathrm{Zn}^{2+}$ deficiency and substrate uptake in the context of type 2 diabetes is unknown. Therefore, in chapter $\mathbf{5}$ we investigated a possible connection between $\mathrm{Zn}^{2+}$ deficiency and CD36 transporter function in cultured and freshly isolated cardiomyocytes. We measured insulin signaling and substrate uptake into cardiomyocytes from which $\mathrm{Zn}^{2+}$ had been removed by exposure of the cells to the $\mathrm{Zn}^{2+}$-chelators 1-10 phenantroline or TPEN. Cardiomyocytes cultured with TPEN for 48 hours showed impaired Akt phosphorylation in response to insulin stimulation, and increased triacylglycerol levels. Exposing freshly isolated adult rat cardiomyocytes to either phenanthroline or TPEN for 15 min resulted in further increases in fatty acid uptake mediated by each of stimuli activating insulin or AMPK signaling. Further studies indicated a direct physical interaction between $\mathrm{Zn}^{2+}$ and cysteine residues located on the intracellular arms of CD36, two of which are located on the $\mathrm{N}$ - and two others on the $\mathrm{C}$ - terminals. These cysteine residues bind $\mathrm{Zn}^{2+}$ ions but not bind other divalent cations such as $\mathrm{Ba}^{2+}, \mathrm{Mg}^{2+}, \mathrm{Ca}^{2+}$. The combined results suggest that $\mathrm{Zn}^{2+}$ binding to CD36 compromises its fatty acid transport function. These findings represent a first molecular explanation how $\mathrm{Zn}^{2+}$ deficiency through elevated CD36 mediated fatty acid import could contribute to lipid induced diabetes development.

In chapter 6, we discuss the major findings of this thesis and place them in the context of the current state-of-the-art literature. The three main findings are:

1. The GLUT4 and CD36 mediated myocardial substrate uptake processes involve the separate translocation of these proteins to the plasma membrane and the subsequent activation of their transport function, pointing to novel regulatory mechanisms in cardiac substrate uptake regulation that require further elucidation.

2. Inhibition of CD36 mediated fatty acid uptake prevents lipid induced insulin resistance and contractile dysfunction in cardiomyocytes indicating CD36 as a possible drug target.

3. Zinc binding to CD36 controls its fatty acid transport function putatively explaining the link between zinc deficiency and diabetes.

Collectively, the work described in this thesis provides a deepened knowledge about the molecular mechanisms of membrane transporter mediated substrate uptake in the healthy and diabetic heart. These novel insights will facilitate the development of future strategies aimed at preventing and/or treating diabetic cardiomyopathy. 
Samenvatting 


\section{Samenvatting}

De functie van het hart is het voortdurend rondpompen van bloed door het lichaam. Hiertoe trekt de hartspier regelmatig samen. Voor deze spiercontractie is veel energie nodig, die het hart verkrijgt door verbranding van energierijke stoffen die vanuit de bloedbaan in de hartspiercellen worden opgenomen. Glucose en langketenige vetzuren zijn de belangrijkste brandstoffen voor de energievoorziening van het hart. De opname van deze brandstoffen door de hartspiercellen vindt plaats door middel van speciale transporteiwitten aanwezig in de plasmamembraan (dit is het celomhulsel) van de hartspiercellen. Het transporteiwit voor glucose is glucose transporter 4 (GLUT4) en dat voor vetzuren is CD36. Beide eiwitten zijn opgeslagen in subcellulaire organellen, de endosomen, vanwaar deze eiwitten naar de plasmamembraan migreren om de brandstofopname te vergroten. Indien de behoefte aam brandstoffen afneemt, keren deze transporteiwitten weer terug naar hun endosomale opslagplaats.

Onder normale fysiologische omstandigheden kan het hart het gebruik van glucose en vetzuren afwisselen, afhankelijk van de beschikbaarheid ervan, om zodoende de energieproductie (ATP) veilig te stellen. Het diabete hart kan dit echter niet of nauwelijks en is voor de energievoorziening vrijwel uitsluitend aangewezen op vetzuren. Deze aanpassing gaat samen met een permanente aanwezigheid van CD36 op de plasmamembraan, terwijl GLUT4 juist in de cel (endosomen) blijft (insuline resistentie). In dit proefschrift worden een viertal experimentale studies beschreven die onze kennis over de regulatie van de CD36gemedieerde vetzuuropname door de hartspiercellen aanzienlijk hebben vergroot. Deze kennis is van belang voor een beter begrip van de verstoorde energiehuishoudng van het diabete hart en biedt nieuwe aangrijpingspunten voor behandeling ervan.

In hoofdstuk 1 wordt een overzicht gegeven van onze huidige kennis van het moleculaire mechanisme van eiwitgemedieerde brandstofopname door de hartspiercel, met name de rol van de glucosetransporter GLUT4 en die van de vetzuurtransporter CD36. Zowel de aanwezigheid van het hormoon insuline in de bloedbaan als veranderingen in contractiesnelheid van de hartspier worden door middel van ketens van intracellulaire signalen (signaaltransductiecascade) doorgegeven en leiden tot migratie van GLUT4 en CD36 naar de plasmamembraan om de opname van glucose en vetzuren te vergroten. Verstoringen in deze signaalketens dragen bij aan het ontstaan en de verergering van (type II) diabetes mellitus en verwante chronische ziekten, zoals diabete cardiomyopathie (verminderde hartfunctie ten gevolge van diabetes).

Hoofdstuk 2 beschrijft een studie die tot doel had om het eiwit CD36 op de plasmamembraan te blokkeren om zodoende de instroom van vetzuren in de hartspiercellen te verminderen en daarmee bovenmatige vetopslag in het hart (hartvervetting) tegen te gaan. Hartvervetting is een belangrijke oorzaak van insulineresistentie van het hart. In zowel hart- als skeletspier is eerder aangetoond dat een vetrijke voeding leidt tot een permanente relocatie van CD36 naar de plasmamembraan en een toegenomen vetzuuropname en -opslag in de hartspiercel. Onze hypothese was dat bij een vetrijke voeding een blokkering van 
CD36 de excessieve vetzuuropname zou tegengaan en dit zou leiden tot minder vetopslag en daarbij het ontstaan van insuline resistentie kan voorkomen.

Voor deze studie hebben we eerst een celmodel ontwikkeld voor het ontstaan van insuline resistentie door vetrijke voeding. Dit model bestaat uit primaire hartspiercellen (cardiomyocyten) die uit het rattehart worden geïsoleerd en vervolgens gedurende 48 uur in kweek gebracht in een medium met een hoge concentratie insuline (HI medium) of een medium met een hoge concentratie palmitinezuur (langketenig vetzuur; HP medium). In beide gevallen leidt dit tot insulineresistentie van de hartspiercellen, blijkend uit een verminderde insuline signaaltransductie (Akt fosforylatie), een verminderde insuline-gestimuleerde glucose opname, meer vetopslag en een verslechtering van contractiele eigenschappen van de cellen. $\mathrm{Na}$ het kweken van de cellen in een $\mathrm{HI}$ of HP kweekmedium was ook de hoeveelheid CD36 op de plasmamembraan sterk toegenomen. Door tegelijkertijd monoclonale antilichamen gericht tegen CD36 aan het medium toe te voegen, kon dit CD36 worden geblokkeerd. Onder deze omstandigheden nam de vetopslag in de hartspiercellen gedurende de 48 uur niet toe, was er geen sprake van insuline resistentie en bleef de contractiele functie van de cellen geheel behouden. Deze resultaten geven aan dat CD36 een geschikt aangrijpingspunt kan zijn om insulineresistentie van de hartspier door vetrijke voeding te voorkomen.

In hoofdstuk 3 bestudeerden we de gunstige invloed van meervoudig onverzadigde visvetzuren, namelijk eicosapentaeenzuur (eicosapentaenoic acid, EPA; C20:5 n-3) en docosahexaeenzuur (docosahexaenoic acid, DHA; C22:6 n-3) op primaire hartspiercellen die aan insulineresistentie bevorderende omstandigheden worden blootgesteld (HI en HP kweekmedium gedurende 48 uur; zie hoofdstuk 2). De gelijktijdige aanwezigheid van EPA of DHA in het HI kweekmedium voorkwam de inductie van insulineresistentie in de hartspiercellen. Dit bleek uit het feit dat sleuteleiwitten uit de insuline signaalketen hun gevoeligheid voor insuline behielden en dat er geen sprake was van een toegenomen hoeveelheid CD36 op de plasmamembraan. In aanwezigheid van EPA - niet DHA - bleken de hartspiercellen bovendien onveranderd in hun gevoeligheid voor insuline-gestimuleerde glucose en vetzuuropname en waren de contractiele eigenschappen van de cellen ook niet gewijzigd. We mogen dus concluderen dat EPA alle metabole en functionele eigenschappen beschemt van hartspiercellen die worden blootgesteld aan insulineresistentie bevorderende omstandigheden (HI medium) terwijl DHA alleen de insulinegevoeligheid van de cellen beschermt. Deze bevindingen suggereren voorts dat behoud van insulinegevoeligheid niet voldoende is voor behoud van cellulaire contractiele eigenschappen en dat EPA en DHA volgens verschillende mechanismen werkzaam zijn.

De rol van calcium $\left(\mathrm{Ca}^{2+}\right)$ en $\mathrm{Ca}^{2+}$-geactiveerde eiwitkinases (CaMKII/ CaMKK $\beta$ ) in de regulatie van GLUT4 en CD36 en contractie-gemedieerde glucose en vetzuuropname is in hoofdstuk 4 beschreven. In de hartspier is de eventuele betrokkenheid van $\mathrm{Ca}^{2+}$ en de CaMKII/ CaMKK $\beta$ signaaltransductie bij de opname van glucose en vetzuren voor de energiehuishoudng niet eerder onderzocht. Wij vonden dat een toename in de intracellulaire $\mathrm{Ca}^{2+}$ concentratie $\left.\left(\left[\mathrm{Ca}^{2+}\right]\right]_{\mathrm{i}}\right)$ via de activatie van CaMKII/ CaMKK $\beta$ de translocatie van zowel GLUT4 als CD36 van 
endosomen naar de plasmamembraan stimuleert, maar dat dit niet leidt tot een hogere opnamesnelheid van glucose of vetzuren. Activatie van de AMP-geactiveerd eiwitkinase (AMPK), een belangrijke cellulaire energiesensor, was nodig om de transportfunctie van de door $\mathrm{Ca}^{2+}$ signalering naar de plasmamembraan gebrachte GLUT4 en CD36 aan te schakelen. Op grond van deze studie concluderen we dan ook, dat bij de regulatie van de opname van glucose en vetzuren door de hartspier de translocatie van de transporters GLUT4 en CD36 naar de plasmamembraan enerzijds en activatie van hun transportfunctie anderszijds gescheiden processen zijn.

Bij patiënten met diabetes is er vaak sprake van een tekort aan zink $\left(\mathrm{Zn}^{2+}\right)$. Het moleculaire mechanisme dat ten grondslag ligt aan dit verband is onopgehelderd. In hoofdstuk 5 bestudeerden we een mogelijke samenhang tussen $\mathrm{Zn}^{2+}$ deficëntie en de transportfunctie van CD36. Daartoe onderzochten we de insulinegevoeligheid en de opname van vetzuren in geïsoleerde hartspiercellen waarin $\mathrm{Zn}^{2+}$ was verwijderd door behandeling met zogenaamde $\mathrm{Zn}^{2+}$ chelators (zoals 1-10 fenantroline of TPEN). Wanneer de hartspiercellen gedurende 48 uur aan TPEN werden blootgesteld nam hun insulinegevoeligheid af (verminderde Akt fosforylatie) en namen de opnamesnelheid van vetzuren en de intracellulaire vetopslag toe. In vervolgstudies konden we vaststellen dat er een directe fysische interactie is tussen $\mathrm{Zn}^{2+}$ en vier cysteïne-residuen in het intracellulaire gedeelte van het CD36 molecuul. Twee van deze cysteïne-residuen bevinden zich in het $\mathrm{N}$ terminale segment en twee in het $\mathrm{C}$-terminale segment van het eiwit. De cysteïneresiduen binden specifiek $\mathrm{Zn}^{2+}$; andere divalente kationen, zoals $\mathrm{Ba}^{2+}, \mathrm{Mg}^{2+}$ of $\mathrm{Ca}^{2+}$, binden niet. Tesamengenomen duiden deze nieuwe onderzoeksgegevens erop dat de binding van $\mathrm{Zn}^{2+}$ aan CD36 de vetzuurtransportfunctie van CD36 remt. Bij afwezigheid van $\mathrm{Zn}^{2+}$ toont CD36 een grotere vetzuurtransportactiviteit hetgeen kan leiden tot een toegenomen vetopslag en uiteindelijk tot insuline resistentie en (type II) diabetes mellitus. Dit is een eerste moleculaire verklaring voor het verband tussen $\mathrm{Zn}^{2+}$ deficiëntie en het voorkomen van type II diabetes.

Tenslotte worden de belangrijkste in dit proefschrift beschreven resultaten in hoofdstuk 6 samengenomen en bediscussieerd in relatie tot de huidige kennis omtrent de oorzaken van een afgenomen hartfunctie bij diabetes. De drie belangrijkste bevindingen zijn:

1. In de regulatie van de GLUT4-gemedieerde glucose opname en de CD36gemedieerde vetzuuropname door de hartspier moeten we onderscheid maken tussen de translocatie van deze transporteiwitten van endosomen naar de plasmamembraan en activatie van deze eiwitten aan de plasmamembraan. Dit is een nieuw element in het regelmechanisme van de opname van brandstoffen voor de energievoorziening van de hartspier dat vervolgonderzoek verdient.

2. Blokkering van de vetzuurtransportfunctie van CD36 aan de plasmamembraan voorkomt het ontstaan van vetzuur-gemedieerde insuline resistentie en een verminderde contractiele functie van hartspiercellen. CD36 lijkt daarmee een geschikt aangrijpingspunt voor de preventie en de behandeling van diabete cardiomyopathie. 
3. De binding van zink aan CD36 reguleert de transportfunctie van CD36. Dit fenomeen zou verantwoordelijk kunnen zijn van het gevonden verband tussen een zinktekort en diabetes.

De in dit proefschrift beschreven nieuwe inzichten in de moleculaire mechanismen die ten grondslag liggen aan de regulatie van de opname van glucose en vetzuren door de gezonde en de diabete hartspier zullen bijdragen aan de ontwikkeling van nieuwe strategiën ter voorkoming en genezing van diabete cardiomyopathie. 
